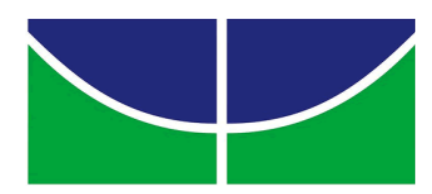

UNIVERSIDADE DE BRASÍLIA

INSTITUTO DE QUÍMICA

PROGRAMA DE PÓS-GRADUAÇÃO EM TECNOLOGIAS QUíMICA E BIOLÓGICA

LABORATÓRIO DE MATERIAIS E COMBUSTÍVEIS

REAÇÕES DE HIDRODESOXIGENAÇÃO APLICADAS À PRODUÇÃO DE BIOCOMBUSTÍVEIS PARAFÍNICOS DE CADEIA LONGA A PARTIR DE ÓLEOS E GORDURAS

\author{
DISSERTAÇÃO DE MESTRADO
}

ANTÔNIO MARTINS DE FREITAS JÚNIOR

Orientador: Prof. Dr. Marcos Juliano Prauchner

Coorientador: Prof. Dr. Paulo Anselmo Ziani Suarez

Brasília-DF 
UNIVERSIDADE DE BRASÍLIA

INSTITUTO DE QUIIMICA

PROGRAMA DE PÓS-GRADUAÇÃO EM TECNOLOGIAS QUÍMICA E BIOLÓGICA

LABORATÓRIO DE MATERIAIS E COMBUSTÍVEIS

\section{REAÇÕES DE HIDRODESOXIGENAÇÃO APLICADAS À PRODUÇÃO DE BIOCOMBUSTÍVEIS PARAFÍNICOS DE CADEIA LONGA A PARTIR DE ÓLEOS E GORDURAS}

Dissertação apresentada como requisito parcial para obtenção do título de Mestre pelo programa de Pós-Graduação em Tecnologias Química e Biológica

ANTÔNIO MARTINS DE FREITAS JÚNIOR

Orientador: Prof. Dr. Marcos Juliano Prauchner

Coorientador: Prof. Dr. Paulo Anselmo Ziani Suarez

Brasília-DF 


\section{COMUNICADO}

Comunicamos a aprovação da Defesa de Dissertação de Mestrado do (a) aluno (a) Antônio Martins de Freitas Junior, matrícula no 13/0092258, intitulada "Reações de hidrodesoxigenação aplicadas à produção de biocombustiveis parafínicos de cadeia longa a partir de óleos e gorduras", apresentada no (a) Auditório Verde do Instituto de Química (IQ) da Universidade de Brasília (UnB) em 17 de julho de 2015.

Prof. Dr. Marcos Juliano Prauchner Presidente de Banca (IQ/UnB)

Profa. Dra. Vânya Márcia Duarte Pasa Membro Titular (UFMG/MG)

Profa. Dra. Juliana Petrocchi Rodrigues Membro Titular (FGA / UnB)

Prof. Dr. Ângelo Henrique de Lira Machado Membro Suplente (IQ/UnB)

Em 17 de julho de 2015.

ه Caixa Postal 4478 - CEP: 70904-970 - Brasília - DF - BRASIL

므w.unb.br/iq/pg posgiq@unb.br 


\section{Dedicatória}

"A verdadeira riqueza de um homem é o bem que ele faz ao seu semelhante."

Mahatma Gandhi

Aos meus pais, Antônio e Neomésia,

Com profunda admiração, respeito e amor, dedico este trabalho a vocês. Pelo incondicional e inesgotável apoio e afeto que me tem brindado ao longo de minha vida, e que tem me permitido desenvolver como pessoa, não apenas para meu benefício, mas também para o próximo. Este trabalho é uma forma de ser digno de vocês. 


\section{Agradecimentos}

A todas as pessoas que tem se constituído em uma parte fundamental de minha vida, sendo inspiradores que contribuem para o sucesso e culminância de minhas metas.

Aos meus pais Antônio e Neomésia, pelo amor, educação e incentivo que possibilitaram desenvolver-me como pessoa.

Aos meus irmãos, Ney, Fernando e José, que incondicionalmente sempre estão me incentivando.

A Carla, minha amada esposa, que nestes últimos anos, tem sido a força e fonte inspiradora que instiga a me esforçar e seguir sempre adiante.

Aos meus filhos, Antônio Neto e Mariana, que tem mostrado como é simples amar, tornando-me uma pessoa melhor.

Aos meus tios e primos, que em algum momento compartilharam suas vidas comigo, constituindo-se em segundos pais e irmãos, contribuindo para a formação de meu caráter e personalidade.

Aos meus sogros Carlão e Leninha, e meus cunhados Petrônio e Carlos Júnior, pela sincera amizade e apoio em momentos cruciais da vida de minha família.

À família de Seu Jackson e Dona Eva, obrigado por cuidarem e participarem da educação de meus filhos enquanto estive distante.

Aos meus amigos Manoel (da Sidersa), Bernadete, Leandro e Letícia, vocês têm meus amigos, pais e irmãos durante todo o tempo. $\mathrm{O}$ acolhimento e a amizade de vocês estarão sempre no coração de toda a minha família. 
Aos amigos e colegas do LMC (Laboratório de Materiais e Combustíveis): Ruana Brandão, Sílvia Oliveira, Letícia Borges, Daniel Andrade, Anderson Mendonça, Marcelo Rodrigues, Osvaldo Kojiro Iha, Arilson Onésio, David Mark, Vinícius Mello, Isabela, Beatriz Mangas, Maria Bethânia, Elton Carlos, Hélvia Lira, Guilherme Bandeira, Karoline Villela, Renato, Maria Clara, Vianney Santos, Ana Caroline, Yuri Falcão, meu muito obrigado pelos ensinamentos, participações em reações e análises experimentais, e pelos momentos de descontração no dia-a-dia do laboratório. Estendo meus agradecimentos aos demais amigos e colegas do Instituto de Química que porventura não tenha citado.

Aos amigos e colegas do IFNMG (Instituto Federal do Norte de Minas Gerais) Elton Carlos, Allisson Lopes, Diego Porto, Wilson Lopes, Marcos de Oliveira, Roberto Freitas, Gabriel Muller, Inácio Barbosa, Charles Rocha pela companhia e bate-papo em nossas constantes viagens Arinos-DF-Arinos. Vocês as tornaram menos cansativas e mais divertidas.

Ao Artur e ao Xavier, da Engenharia Mecânica, pela resolução de problemas mecânicos com o reator, sempre de forma rápida e eficiente.

Ao Prof. Marcos Juliano Prauchner pela generosidade, paciência, amizade, orientação constante, apoio incondicional e incessante na realização deste trabalho.

Ao Prof. Paulo Anselmo Ziani Suarez pela coorientação e disponibilização de toda a infraestrutura laboratorial sem a qual a realização do presente trabalho não teria sido possível.

Ao Instituto Federal do Norte de Minas Gerais por contribuir em minha formação profissional e desenvolvimento acadêmico, possibilitando o comparecimento às aulas e trabalhos de bancada na UnB (Universidade de Brasília).

À Petrobras que, na pessoa do engenheiro Jefferson Roberto Gomes, gentilmente nos cedeu o catalisador que possibilitou a realização do presente trabalho.

À UnB por todo apoio proporcionado durante a realização deste trabalho. 


\section{RESUMO}

Um dos grandes desafios da atualidade é a substituição dos combustíveis derivados do petróleo por combustíveis de fontes renováveis e menos poluentes. Entretanto, os biocombustíveis hoje mais utilizados, o bioetanol e o biodiesel, apresentam significativas diferenças de composição em relação aos combustíveis fósseis. Como exemplo, pode-se citar a presença de grupos oxigenados, o que resulta, por exemplo, em um menor poder calorífico, incompatibilidades com motores projetados para operar com os combustíveis fósseis e maiores acidez e susceptibilidade à deterioração microbiana. Nesse contexto, o objetivo geral do presente trabalho é o desenvolvimento de um procedimento que possibilite obter, a partir de óleos vegetais, biocombustíveis líquidos parafínicos para substituição ao bioquerosene para aviação e/ou óleo diesel. Para isso, foi realizado um estudo acerca da hidrodesoxigenação (HDO), em presença do catalisador $\mathrm{NiMoS}_{2} / \mathrm{Al}_{2} \mathrm{O}_{3}$, dos óleos de coco e de soja e de compostos modelo (ácidos láurico e oleico). Em primeiro lugar, esse estudo propiciou importantes constatações acerca das reações e mecanismos envolvidos nos processos de hidropirólise não catalítica e de HDO de triacilglicerídeos e ácidos carboxílicos. Verificou-se, também, que a temperatura de $340{ }^{\circ} \mathrm{C}$ e uma pressão inicial de $\mathrm{H}_{2}$ de 30 bar propiciam uma eficiente e adequada desoxigenação das moléculas. Em temperaturas mais elevadas, acentua-se o indesejado craqueamento térmico das cadeias; em temperaturas mais baixas, além das reações tornarem-se mais lentas, ocorre pronunciada polimerização térmica do material. Análises cromatográficas mostram que os produtos obtidos a partir da HDO dos óleos de coco e de soja apresentam distribuições de tamanho de cadeias carbônicas na mesma faixa do bioquerosene de aviação e do óleo diesel, respectivamente, mas com menor teor de alcanos ramificados. Entretanto, foi possível aumentar consideravelmente o teor de isômeros nas misturas por meio de um tratamento posterior de hidroisomerização catalisada por Pt/SAPO-11. Assim, o trabalho realizado demonstrou a viabilidade técnica de se preparar bioquerosene e biodiesel parafínicos a partir de óleos vegetais.

Palavras-chave: Hidrotratamento; Hidrodesoxigenação; Óleos Vegetais; Biocombustíveis. 


\begin{abstract}
The development of renewable and environmentally friendly fuels aimed to substitute petroleum derivatives is one of the biggest current challenges. However, the main biofuels employed nowadays, biodiesel and bioethanol, present significant differences in composition as compared to fossil fuels. For example, they have a high oxygen content, which results in a lower calorific power and in a limited compatibility with engines projected to operate with fossil fuels. Besides, it increases the fuel acidity and susceptibility to the microbial deterioration. In this context, the aim of the present work is to develop a protocol to prepare paraffinic liquid biofuels intendd to substitute jet fuel and diesel oil. For that, it was carried out a study about the hydrodeoxygenation (HDO), in the presence of the $\mathrm{NiMoS}_{2} / \mathrm{Al}_{2} \mathrm{O}_{3}$ catalyst, with of coconut and soybean oils, besides model compounds. Foremost, the study lead to important findings about the reactions and mechanisms involved in non-catalytic hydropyrolysis and HDO of triacylglycerol and carboxylic acids. It was observed that, at $340{ }^{\circ} \mathrm{C}$ and an initial pressure of 30 bar of $\mathrm{H}_{2}$, an efficient and appropriate deoxygenation of the molecules occurs. At higher temperatures, the undesired thermic cracking of the chains is favored. In turn, at lowest temperature, the reaction rate is too low and thermic polymerization takes place. Chromatography analysis showed that the products obtained from the HDO of coconut and soybean oils present molar mass distributions in the same range of jet fuel and and diesel, respectively, but with a lower content of branched alkane. Nonetheless, It was possible to increase the isomer content through hydroisomerization catalyzed by Pt/SAPO-11. This way, the work shows the feasibility of producing biokerosene and paraffinic biodiesel from vegetable oils.
\end{abstract}

Keywords: Hydrotreatment; Hydroeoxygenation; Vegetable oils; Biofuels. 


\section{LISTA DE ABREVIATURAS E ACRÔNIMOS}

ANP - Agência Nacional de Petróleo, Gás Natural e Biocombustíveis AOCS - American Oil Chemists' Society

ATR - Attenuated Total Reflectance

BET - Brunauer, Emmett e Teller.

DRX - Difração de raios $X$

EAG - Ésteres de ácidos graxos

EEAG - Ésteres etílicos de ácidos graxos

EMAG - Ésteres metílicos de ácidos graxos

FT - Fisher-Tropsch

FTIR - Fourier Transformed Infrared

GC/MS - Gas Chromatography Mass Spectrometry

HDM - Hidrodesmetalização

HDN - Hidrodesnitrogenação

HDO - Hidrodesoxigenação

HDS - Hidrodessulfurização

HDT - Hidrotratamento

IUPAC - International Union of Pure and Applied Chemistry

TG - Termogravimetria

TPD - Temperature Programmed Desorption 


\section{LISTA DE FIGURAS}

CAPÍTULO 2 - REVISÃO BIBLIOGRÁFICA - BIOCOMBUSTÍVEIS ........................

Figura 2.1 Produção mundial de etanol...........................................................

Figura 2.2 Fontes e processos de conversão de biomassa...................................4

Figura 2.3 Arranjo típico da parede celular de uma planta......................................5

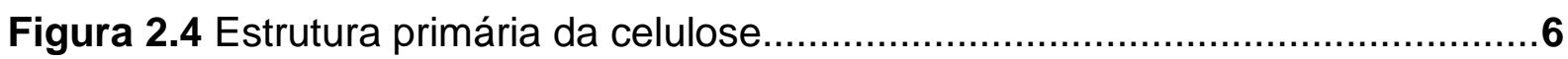

Figura 2.5 Componentes da fração hemicelulose.............................................

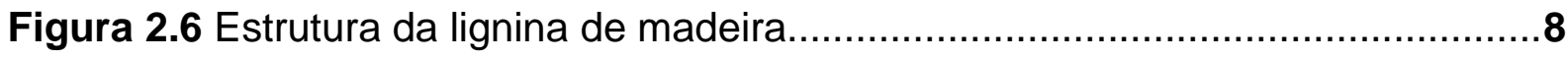

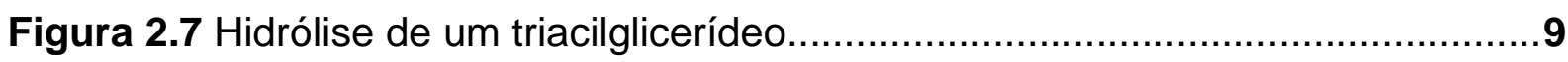

Figura 2.8 Temperaturas de fusão dos principais ácidos graxos conhecidos na

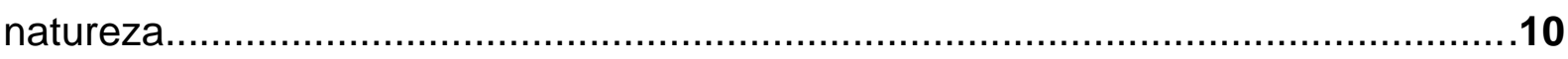

Figura 2.9 Produção de óleos vegetais no mundo em 2011 - 2012.....................11

Figura 2.10 Representação genérica de uma reação de transesterificação..............14

Figura 2.11 Resumo de aplicações de bio-óleos..................................................16

Figura 2.12 Distribuição de produtos do HDT do hexanoato de metila em reator de leito fixo, com catalisadores de sulfetos de NiMo e de CoMo (250 ํㅜ $; 1,5$ $\mathrm{MPa}$ )

Figura 2.13 Distribuição de produtos do HDT do ácido heptanoico, em reator de leito fixo, com catalisadores de sulfetos de NiMo e de CoMo (250 우 1,5 $\mathrm{MPa})$. .20

Figura 2.14 Concentração de produtos em função do tempo de reação para o hidrotratamento do hexanoato de metila, em sistema de batelada, com catalisador de sulfeto de NiMo (250 ํㅜ; 7,5 MPa)

Figura 2.15 Concentração de produtos em função do tempo de reação para o hidrotratamento do ácido heptanoico, em sistema de batelada, com catalisador de sulfeto de NiMo (250 $\left.{ }^{\circ} \mathrm{C} ; 7,5 \mathrm{MPa}\right)$.

Figura 2.16 Estrutura dos catalisadores de $\mathrm{MoS}_{2}$

Figura 2.17 Imagens por microscopia de tunelamento com varredura (STM) dos catalisadores (a) $\mathrm{MoS}_{2}$ e do (b) sulfeto de CoMo...

Figura 2.18 Modelo de bolas do sulfeto de CoMo.

Figura 2.19 Representação das estruturas das bordas contendo os dopantes nos catalisadores de sulfeto de NiMo (a) e CoMo (b). 
Figura 2.20 Proposta de mecanismo para a reação de hidrodessulfurização de tioálcoois em catalisadores a base de $\mathrm{MoS}_{2}$

Figura 2.21 Mecanismo de HDO do 2-etilfenol em um catalisador de $\mathrm{CoMoS}_{2}$

Figura 2.22 Efeitos do catalisador na conversão e seletividade do processo de HDT do óleo de soja.

Figura 3.1 Esquema do sistema de adsorção gasosa simultânea.

Figura 3.2 Imagens do reator empregado.

Figura 3.3 Sistematização do comportamento da temperatura e da pressão durante o período inicial das reações de HDO com pi igual a (a) 30 bar e (b) 15 bar..

\section{CAPÍTULO 4 - RESULTADOS E DISCUSSÕES}

Figura 4.1 Difratogramas de Raios-X do catalisador $\mathrm{NiMoS}_{2} / \mathrm{Al}_{2} \mathrm{O}_{3}$ (a) utilizado no presente trabalho e de (b) obtido da literatura.

Figura 4.2 Isotermas de adsorção/dessorção de $\mathrm{N}_{2}$ do catalisador $\mathrm{NiMoS}_{2} / \mathrm{Al}_{2} \mathrm{O}_{3} \ldots 37$

Figura 4.3 Cromatograma (GC/MS) do produto da reação do dodecano em ausência de catalisador, a $400 \stackrel{\circ}{\circ}$, por $3 \mathrm{~h}$. 39

Figura 4.4 Região relativa aos compostos $\leq \mathrm{C} 11$ do cromatograma (GC/MS) do produto da reação do dodecano em ausência de catalisador a $400 \stackrel{\circ}{\circ}$ por $3 \mathrm{~h}$.

Figura 4.5 Cromatograma (GC/MS) do produto da reação do ácido dodecanoico (láurico) em ausência de catalisador, a $400 \stackrel{\circ}{\circ}$, por $3 \mathrm{~h}$.

Figura 4.6 Região relativa aos alcanos $\geq \mathrm{C} 14$ do cromatograma (GC/MS) do produto da reação do ácido dodecanoico (ácido láurico) em ausência de catalisador a $400{ }^{\circ} \mathrm{C}$ por $3 \mathrm{~h}$. Os picos relativos aos $\mathrm{n}$-alcanos com $\mathrm{X}$ átomos de carbono são identificados por CX; as cetonas, pelo número correspondente à Tabela 4.2.

Figura 4.7 Região relativa aos compostos $<\mathrm{C} 11$ do cromatograma (GC/MS) do produto da reação do ácido dodecanoico (láurico) em ausência de catalisador a 400 ${ }^{\circ} \mathrm{C}$ por $3 \mathrm{~h}$

Figura 4.8 Espectros de FTIR do ácido oleico e do ácido láurico (este último, obtido em pastilha de $\mathrm{KBr}$ ) .52

Figura 4.9 Espectros de FTIR dos produtos da HDO do ácido láurico utilizando o catalisador $\mathrm{NiMoS}_{2} / \mathrm{Al}_{2} \mathrm{O}_{3}$, a diferentes temperaturas, por diferentes períodos de 
tempo: (a) $400^{\circ} \mathrm{C}, 1 \mathrm{~h}$; (b) $340^{\circ} \mathrm{C}, 1 \mathrm{~h}$; (c) $340^{\circ} \mathrm{C}, 3 \mathrm{~h}$; (d) $280^{\circ} \mathrm{C}, 3 \mathrm{~h}$; (e) $280^{\circ} \mathrm{C}, 6$ h......

Figura 4.10 Cromatogramas (GC/MS) dos produtos da reação de HDO do ácido láurico utilizando o catalisador $\mathrm{NiMoS}_{2} / \mathrm{Al}_{2} \mathrm{O}_{3}$, a diferentes temperaturas, por diferentes períodos de tempo: (a) $400^{\circ} \mathrm{C}, 1 \mathrm{~h}$; (b) $340^{\circ} \mathrm{C}, 3 \mathrm{~h}$; (c) $280^{\circ} \mathrm{C}, 6 \mathrm{~h}$. CX e i$\mathrm{CX}$ correspondem, respectivamente, aos $\mathrm{n}$-alcanos com $\mathrm{X}$ átomos de carbono e a seus isômeros ramificados.

Figura 4.11 Região correspondente à eluição dos hidrocarbonetos $\mathrm{C} 11$ e $\mathrm{C} 12$ do cromatograma (GC/MS) do produto da reação de HDO do ácido láurico utilizando o catalisador $\mathrm{NiMoS}_{2} / \mathrm{Al}_{2} \mathrm{O}_{3}$ a $400^{\circ} \mathrm{C}$ por $1 \mathrm{~h}$. O número identificando cada pico corresponde à posição do radical metil na cadeia carbônica. .58

Figura 4.12 - Espectros de FTIR dos produtos da HDO do ácido láurico utilizando o catalisador $\mathrm{NiMoS}_{2} / \mathrm{Al}_{2} \mathrm{O}_{3}$, a $340^{\circ} \mathrm{C}$, com uma pressão inicial de $\mathrm{H}_{2}$ de 15 bar, por (a) $3 \mathrm{~h}$ e (b) $5 \mathrm{~h}$

Figura 4.13 Cromatogramas (GC/MS) dos produtos das reações de HDO do ácido láurico utilizando o catalisador $\mathrm{NiMoS}_{2} / \mathrm{Al}_{2} \mathrm{O}_{3}$ a $280 \stackrel{\circ}{\mathrm{C}}$ por $6 \mathrm{~h}$ e, $340 \stackrel{\circ}{\mathrm{C}}$ por $1 \mathrm{~h}$. CX: $\mathrm{n}$-alcanos com $\mathrm{X}$ átomos de carbono; \#: alquenos terminais; * $\mathrm{e}+$ : isômeros cis $\mathrm{e}$ trans dos 2-alquenos, respectivamente.

Figura 4.14 Espectro FTIR do produto da HDO do ácido oleico utilizando o catalisador $\mathrm{NiMoS}_{2} / \mathrm{Al}_{2} \mathrm{O}_{3}$ a $340^{\circ} \mathrm{C}$ por $3 \mathrm{~h}$.

Figura 4.15 Cromatograma (GC/MS) do produto da reação de HDO do ácido oleico utilizando o catalisador $\mathrm{NiMoS}_{2} / \mathrm{Al}_{2} \mathrm{O}_{3}$, a $340^{\circ} \mathrm{C}, 3 \mathrm{~h}$; CX corresponde aos $\mathrm{n}$-alcanos com $\mathrm{X}$ átomos de carbono 68

Figura 4.16 Espectros de FTIR dos óleos de coco e de soja. 71

Figura 4.17 Espectros de FTIR dos produtos da HDO do óleo de coco utilizando o catalisador $\mathrm{NiMoS}_{2} / \mathrm{Al}_{2} \mathrm{O}_{3}$ a $340 \stackrel{\circ}{\mathrm{C}}$ por 3 e $6 \mathrm{~h}$ .72

Figura 4.18 Cromatogramas (GC/MS) dos produtos da HDO do óleo de coco utilizando o catalisador $\mathrm{NiMoS}_{2} / \mathrm{Al}_{2} \mathrm{O}_{3}$, a $340^{\circ} \mathrm{C}$ por (a) e $3 \mathrm{~h}$ (b) $6 \mathrm{~h}$. $\mathrm{CX}$ corresponde aos $n$-alcanos com $X$ átomos de carbono

Figura 4.19 Espectro de FTIR do produto da HDO do óleo de soja utilizando o catalisador $\mathrm{NiMoS}_{2} / \mathrm{Al}_{2} \mathrm{O}_{3}$ a $340 \stackrel{\circ}{\circ} \mathrm{C}$ por $6 \mathrm{~h}$

Figura 4.20 Cromatogramas (GC/MS) do produtos da HDO do óleo de soja utilizando o catalisador $\mathrm{NiMoS}_{2} / \mathrm{Al}_{2} \mathrm{O}_{3}$, a $340^{\circ} \mathrm{C}$ por $6 \mathrm{~h}$. CX corresponde aos $\mathrm{n}$ alcanos com $\mathrm{X}$ átomos de carbono. 
Figura 4.21 Esquema proposto para as principais reações que ocorrem durante a hidrodesoxigenação de óleos vegetais catalisada por

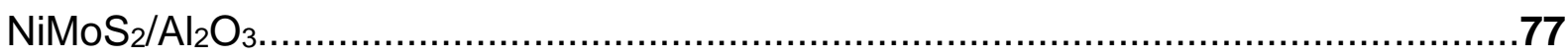

Figura 4.22 Cromatogramas (GC/MS) dos produtos da HDO do (a) óleo de coco e do (b) óleo de soja utilizando o catalisador $\mathrm{NiMoS}_{2} / \mathrm{Al}_{2} \mathrm{O}_{3}$, a $340^{\circ} \mathrm{C}$ por $6 \mathrm{~h}$, e (c) de uma amostra comercial de querosene para aviação. $C X$ corresponde aos $n$-alcanos com $X$ átomos de carbono

Figura 4.23 Cromatogramas GC-FID do: (a) produto da HDO do óleo de coco, catalisada por $\mathrm{NiMoS}_{2} / \mathrm{Al}_{2} \mathrm{O}_{3}\left(340^{\circ} \mathrm{C}, 6 \mathrm{~h}\right)$; (b) produto da reação de isomerização do óleo de coco desoxigenado catalisada por Pt/SAPO- $11\left(350^{\circ} \mathrm{C}, 8 \mathrm{~h}\right)$. 80

Figura 4.24 Espectros de massas correspondente (a) ao pico em 2,20 min no cromatograma das Figuras 4.5 e 4.7 e (b) ao hexano na biblioteca digital. 82

Figura 4.25 Espectros de massas correspondentes aos picos em (a)12,12 min (decano) e (b)12,30 min (trans-2-deceno) no cromatograma das Figuras 4.5 e 4.7.82 Figura 4.26 Espectros de massas correspondentes aos picos em (a) 37,41 min (eicosano) e (b) 39,26 min (eneicosano) no cromatograma das Figuras 4.5 e 4.6....84 Figura 4.27 Espectro de massas correspondente ao pico entre 28,3 e 29,0 min (ácido láurico) no cromatograma das Figuras 4.5 e 4.6. .85

Figura 4.28 Espectros de massas correspondente (a) ao pico em 24,43 min no cromatograma das Figuras 4.5 e 4.6 e (b) ao dodecanal na biblioteca digital. .87

Figura 4.29 Espectros de massas correspondentes aos picos em (a) 33,01 min (5hexadecanona), (b) 35,04 min (6-heptadecanona), (c) 37,00 min (7-octadecanona) e (d) 38,89 min (8-nonadecanona) no cromatograma das Figuras 4.5 e 4.6 88 Figura 4.30 Espectros de massas correspondente (a) ao pico em 47,07 min no cromatograma das Figuras 4.5 e 4.6 .89

Figura 4.31 Espectros de massas da literatura para o dodecanoato de dodecila.....89 Figura 4.32 Espectros de massas correspondente (a) ao pico em 26,05 min no cromatograma das Figuras 4.5 e 4.6 e (b) ao dodecanol na biblioteca digital. .90 


\section{LISTA DE TABELAS}

CAPÍTULO 2 - REVISÃO BIBLIOGRÁFICA - BIOCOMBUSTÍVEIS

Tabela 2.1 Composição percentual de ácidos graxos em distintos óleos e gorduras vegetais

Tabela 2.2 Comparação de características de bio-óleo de madeira pirolisada e de petróleo bruto .15

Tabela 2.3 Composição do produto da HDO do óleo de colza, a $340{ }^{\circ} \mathrm{C}$ e 35 bar, catalisada por $\mathrm{NiMoS}_{2} / \mathrm{Al}_{2} \mathrm{O}_{3}$.

Tabela 2.4 Resultados da análise elementar e do teor de $n$-alcanos dos produtos da HDT do óleo de soja empregando diferentes catalisadores

\section{CAPÍTULO 4 - RESULTADOS E DISCUSSÕES}

Tabela 4.1 Propriedades texturais do suporte utilizado. 37

Tabela 4.2 Relação de alquilundecilcetonas identificadas no cromatograma (GC/MS) do produto da reação do ácido láurico em ausência de catalisador a $400^{\circ} \mathrm{C}$ por 3 h.

Tabela 4.3 Índices de acidez para as misturas obtidas a partir da HDO do ácido do ácido láurico utilizando o catalisador $\mathrm{NiMoS}_{2} / \mathrm{Al}_{2} \mathrm{O}_{3}$, a diferentes temperaturas, por diferentes períodos de tempo.

Tabela 4.4 Composição, a partir dos cromatogramas GC/FID, dos produtos obtidos a partir da hidroisomerização, catalisada por Pt/SAPO-11, dos óleos de coco e de soja desoxigenados por meio do processo de $\mathrm{HDO}\left(\mathrm{NiMoS}_{2} / \mathrm{Al}_{2} \mathrm{O}_{3}, 340^{\circ} \mathrm{C}, 6 \mathrm{~h}\right)$. 


\section{ÍNDICE}

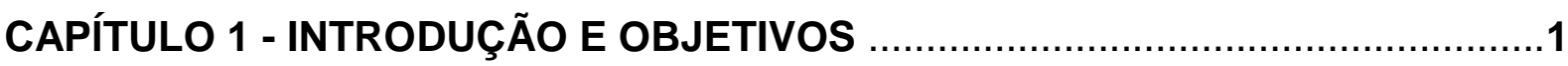

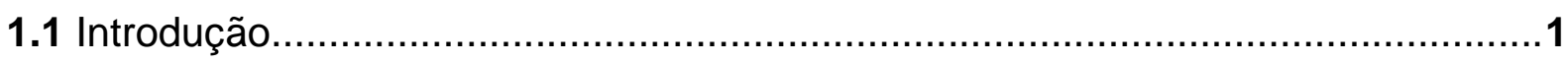

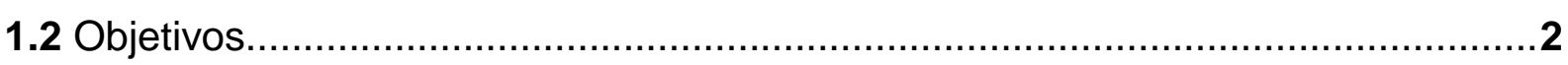

CAPÍTULO 2 - REVISÃO BIBLIOGRÁFICA - BIOCOMBUSTÍVEIS..........................

2.1 Tipos de biomassa empregados na produção de biocombustíveis........................4

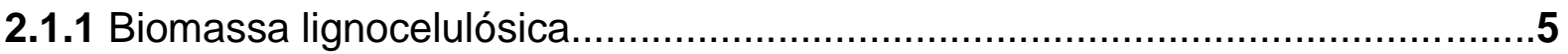

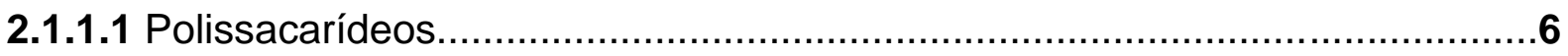

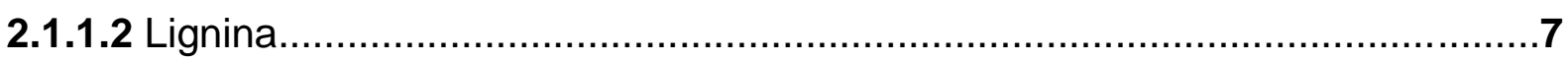

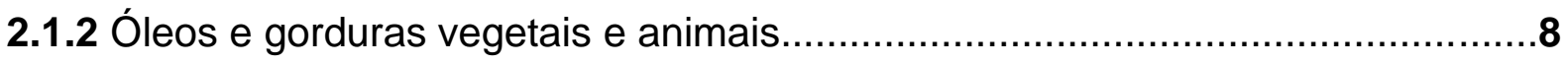

2.2 O emprego de óleos e gorduras vegetais e animais como combustível..............12

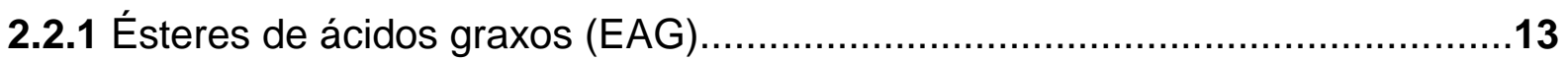

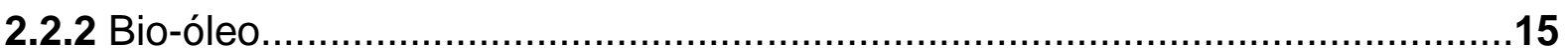

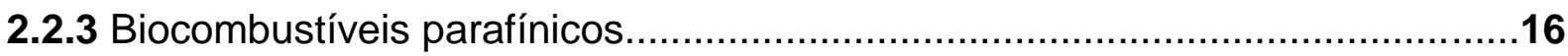

2.3 HDO de óleos e gorduras animais e vegetais...............................................17

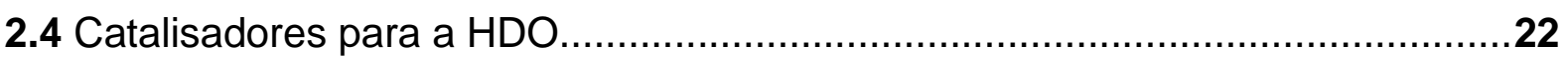

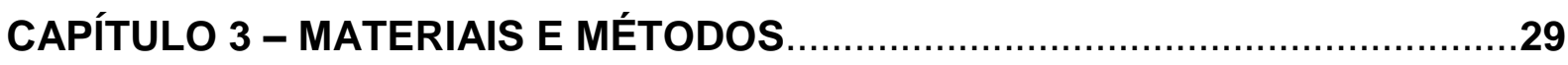

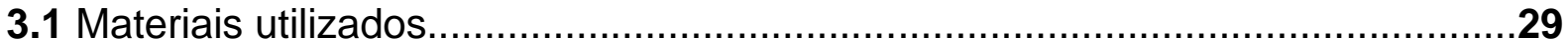

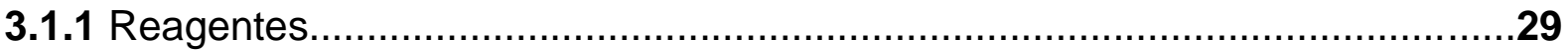

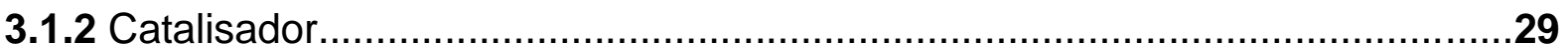

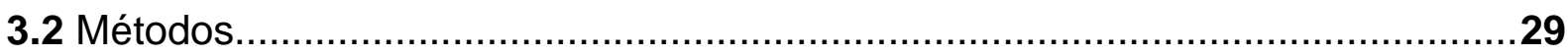

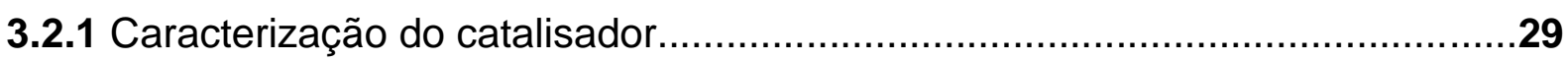

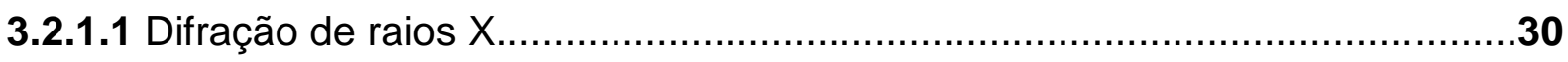

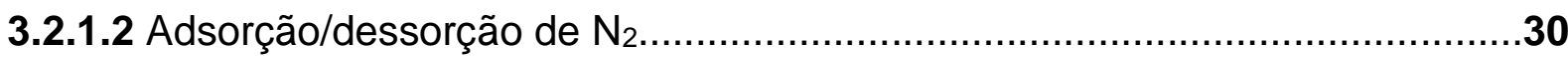

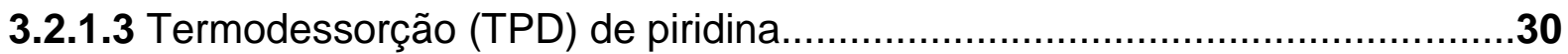

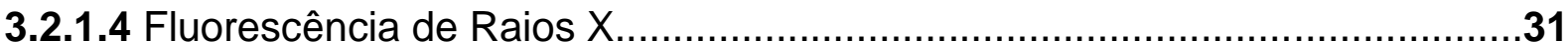

3.2.2 Reações de pirólise e hidrodesoxigenação (HDO) ........................................32

3.2.3 Caracterização dos produtos de desoxigenação............................................35

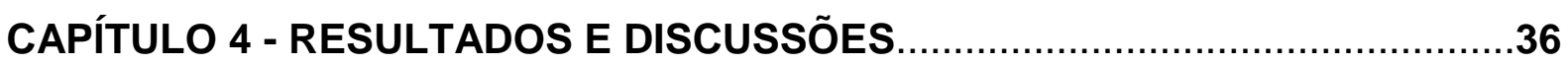

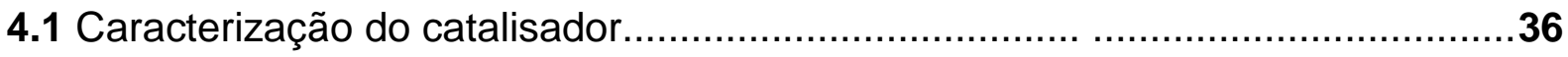


4.2 Reações envolvendo compostos modelo

4.2.1 Reações de compostos modelo sem o emprego de catalisador.......................38

4.2.1.1 Hidropirólise não catalítica do dodecano...............................................38

4.2.1.2 Hidropirólise não catalítica do ácido láurico................................................44

4.2.2 $\mathrm{HDO}$ de compostos modelo catalisada por $\mathrm{NiMoS}_{2} / \mathrm{Al}_{2} \mathrm{O}_{3} \ldots \ldots \ldots \ldots \ldots \ldots \ldots \ldots \ldots . . .51$

4.2.2.1 Caracterização dos ácidos láurico e oleico por FTIR....................................52

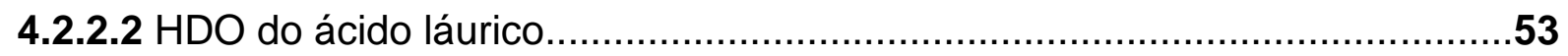

4.2.2.2.1 Efeito da temperatura sobre a reação de HDO do ácido láurico..................55

4.2.2.2.2 Efeito da pressão de $\mathrm{H}_{2}$ sobre a $\mathrm{HDO}$ do ácido láurico............................59

4.2.2.2.3 Mecanismos das reações de desoxigenação envolvidas na HDO do ácido láurico

4.2.2.2.4 Mecanismos das reações de isomerização durante a HDO do ácido láurico. .66

4.2.2.2.5 Considerações finais acerca da HDO do ácido láurico. .67

4.2.2.3 HDO do ácido oleico. .67

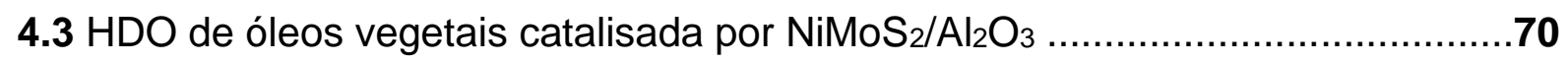

4.3.1 Caracterização dos óleos de coco e de soja por FTIR....................................70

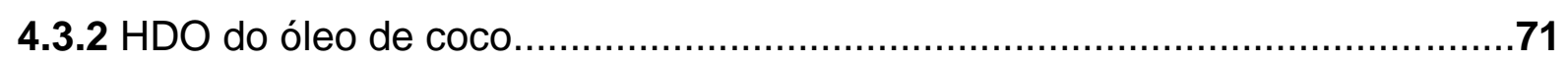

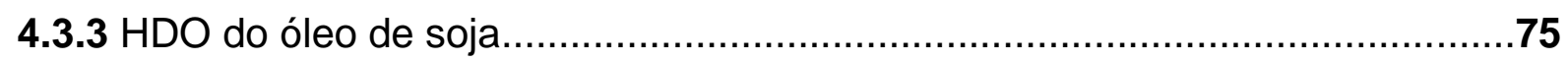

4.4 Considerações finais acerca das reações de HDO de óleos vegetais.................77

4.5 Avaliação da composição e das propriedades dos óleos de coco e de soja

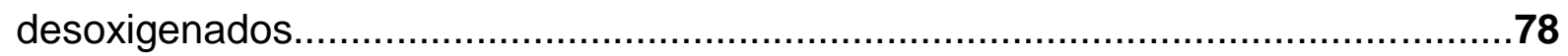

4.6 Hidroisomerização dos óleos de coco e de soja desoxigenados.........................79

4.7 Identificação dos componentes dos produtos de reação por GC/MS...................81

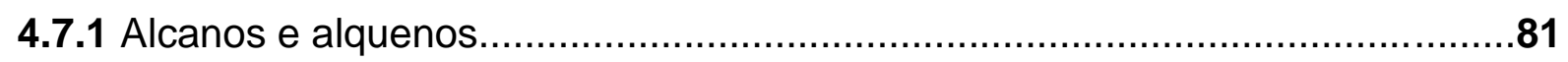

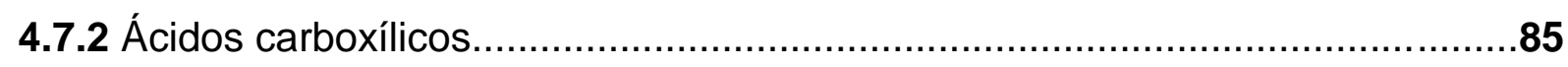

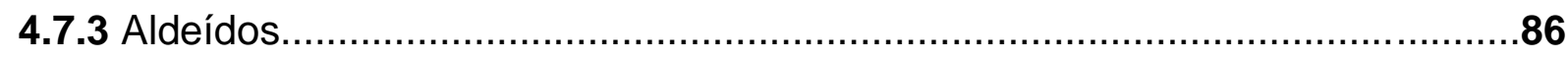

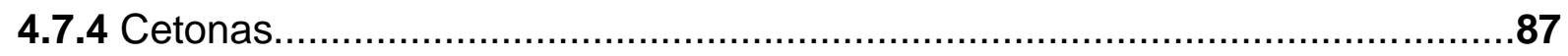

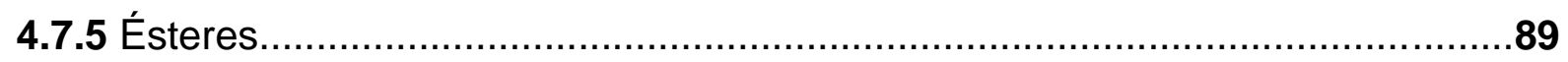

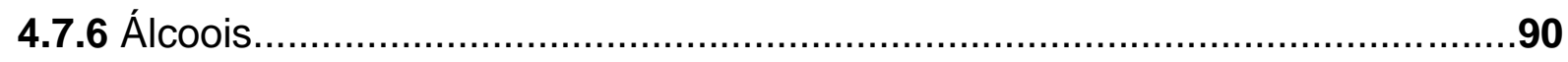

CAPÍTULO 5 - CONCLUSÕES E PERSPECTIVAS.............................................

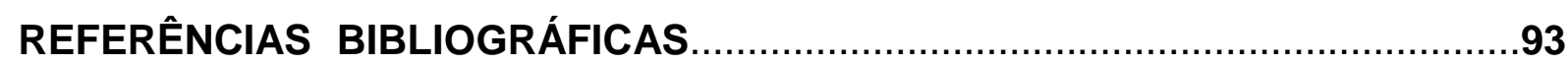




\section{CAPÍTULO 1 - INTRODUÇÃO E OBJETIVOS}

\subsection{Introdução}

Atualmente, a principal fonte de energia utilizada no mundo é o petróleo. Entretanto, a especulação acerca dos preços deste insumo, a possibilidade de esgotamento de suas reservas e os efeitos ambientais advindos de sua utilização têm conduzido a um interesse crescente no desenvolvimento de fontes alternativas de energia. Nesse contexto, o emprego de derivados de biomassa na produção de biocombustíveis assume especial interesse, pois se trata de uma matéria-prima renovável, cujo emprego minimiza os impactos sobre o ciclo de carbono. Além disso, os combustíveis derivados de biomassa apresentam reduzidos teores de nitrogênio e enxofre formadores dos gases responsáveis pelo fenômeno da chuva ácida, e de compostos aromáticos, que estão associados à elevada incidência de diversos tipos de cânceres no ser humano, conforme reportado por Pereira Netto et al. ${ }^{1}$

Os biocombustíveis mais empregados atualmente são o etanol e os ésteres de ácidos graxos (EAG), que podem ser usados isoladamente ou em blendas com combustíveis derivados do petróleo. Entretanto, esses biocombustíveis são constituídos por moléculas oxigenadas e, no caso dos EAG, usualmente insaturadas. Por esse motivo, algumas de suas propriedades químicas e físico-químicas diferem substancialmente daquelas verificadas para os derivados de petróleo, o que gera desafios no que diz respeito ao armazenamento, distribuição e uso. O menor poder calorífico, a polimerização, a oxidação e a degradação microbiana durante o armazenamento, a elevada viscosidade, as propriedades a frio inadequadas e a combustão incompleta, são possíveis problemas relacionados à utilização de biocombustíveis no setor de transportes. ${ }^{2,3,4,5}$

Um biocombustível ideal deveria apresentar composição química e, dessa forma, propriedades químicas e físico-químicas muito similares às dos derivados de petróleo. Visto que o elevado teor de oxigênio é uma característica intrínseca da biomassa, torna-se evidente a conveniência da remoção do oxigênio durante o processo de conversão dessa matéria-prima em biocombustível. Assim, o produto obtido poderia ser utilizado sem perda de eficiência e incompatibilidade de infraestrutura, atendendo ao conceito denominado drop-in. ${ }^{4}$ É válido destacar a 
especial importância deste conceito quando se trata do bioquerosene de aviação, visto os riscos intrínsecos a esse setor de transporte.

\subsection{Objetivos}

Dentro do contexto acima exposto, o objetivo geral do presente trabalho é o desenvolvimento de um procedimento que possibilite obter, a partir de óleos vegetais, combustíveis líquidos constituídos basicamente por hidrocarbonetos, com teor de oxigênio muito próximo de zero.

Para atingir esse objetivo principal, foram delineados alguns objetivos secundários, conforme abaixo descrito.

a) Desenvolver um sistema reacional que permita realizar o hidrotratamento (catalítico ou não catalítico) de óleos vegetais e de compostos modelo.

b) Utilizando compostos modelo, testar diferentes condições reacionais visando aperfeiçoar o processo de desoxigenação, de forma a se obter misturas com composições adequadas.

c) Caracterizar quimicamente os produtos obtidos a partir de reações com compostos modelo, visando compreender as reações ocorridas.

d) Ajustar as condições definidas nos estudos com compostos modelo para as reações com diferentes espécies de óleos vegetais.

e) Caracterizar quimicamente os produtos obtidos a partir das reações dos óleos vegetais, visando identificar modificações necessárias para a obtenção de combustíveis líquidos com propriedades físico-químicas semelhantes às dos derivados de petróleo.

f) Realizar essas modificações e caracterizar as propriedades físico-químicas dos biocombustíveis obtidos. 


\section{CAPÍTULO 2 - REVISÃO BIBLIOGRÁFICA - BIOCOMBUSTÍVEIS}

Conforme já citado na seção 1.1, os dois principais tipos de biocombustíveis empregados atualmente são o etanol e os ésteres de ácidos graxos (EAG). O etanol é obtido por meio da fermentação de açúcares presentes em espécies tais como cana-de-açúcar, milho, beterraba, mandioca e batata. Em 2012, a produção mundial de etanol foi de 85,2 bilhões de litros (Figura 2.1). Ele pode ser empregado isoladamente, na forma de álcool hidratado, ou na forma anidra, em blendas com a gasolina. ${ }^{6}$

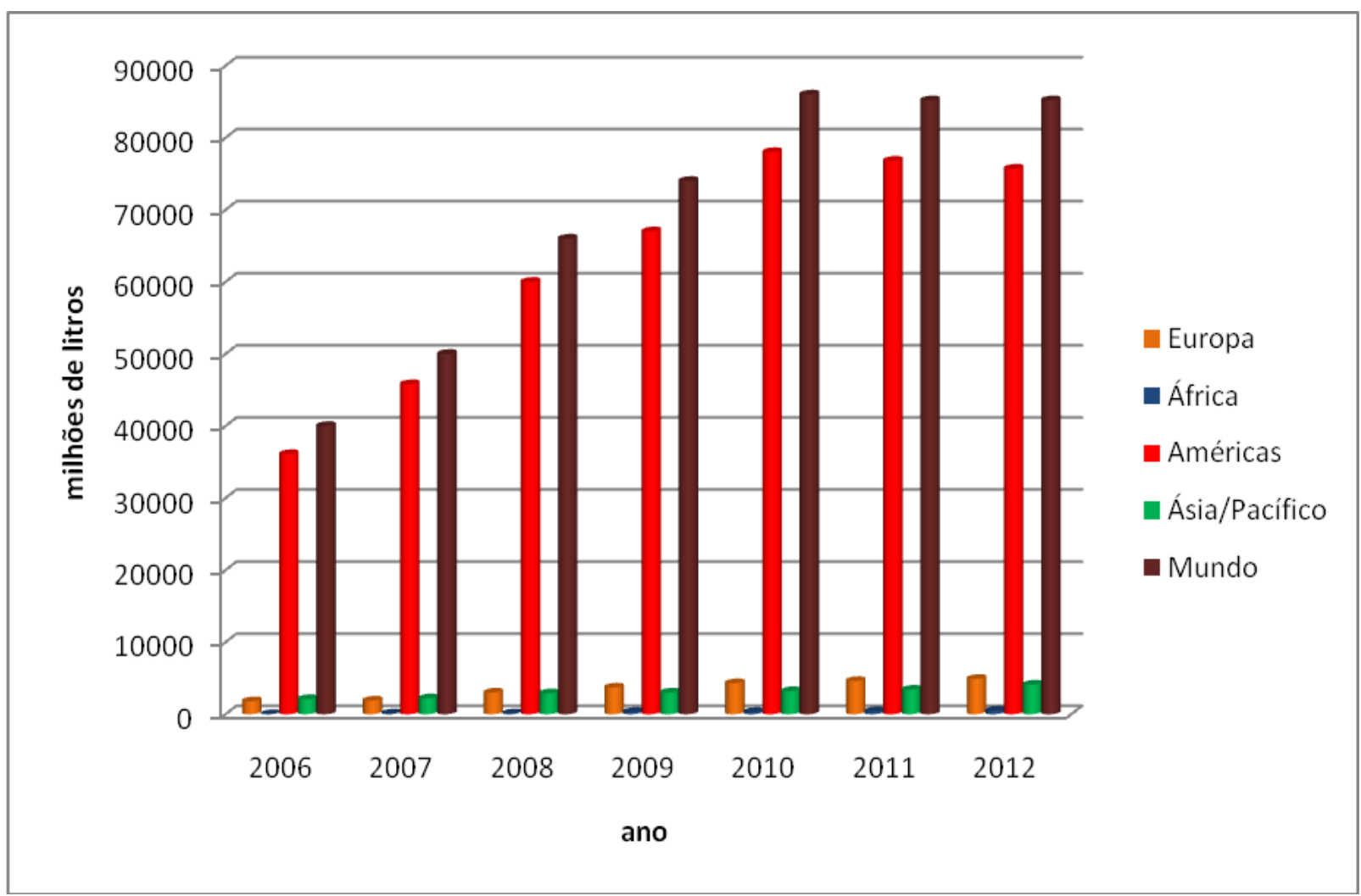

Figura 2.1 - Produção mundial de etanol. Adaptada da ref. ${ }^{6}$.

Não obstante a importânica do etanol no cenário energético mundial, particularmente no Brasil, atenção maior será dada aqui aos biocombustíveis - EAG, obtidos a partir de óleos vegetais, as mesmas matérias-primas empregadas na produção dos biocombustíveis líquidos parafínicos que são alvo do presente estudo. 


\subsection{Tipos de biomassa empregados na produção de biocombustíveis}

Segundo a Resolução no 23 da ANP (Agência Nacional de Petróleo, Gás Natural e Biocombustíveis) de 13 de agosto de 2012, biomassa é todo recurso renovável oriundo de matéria orgânica (de origem animal ou vegetal) que pode ser utilizado na geração de biocombustíveis. ${ }^{7}$ Portanto, é um termo que engloba a matéria vegetal gerada por meio da fotossíntese, incluindo seus diversos produtos e subprodutos derivados, tais como dejetos animais, culturas e resíduos agrícolas, florestas, e matéria orgânica presente em rejeitos industriais e urbanos. A utilização de biomassa para fins energéticos consiste na conversão da energia química acumulada a partir da radiação solar, por meio de processos distintos, em diferentes produtos energéticos, tais como carvão vegetal, etanol, gases e óleos combustíveis. ${ }^{8}$, ${ }^{9}$ A Figura 2.2 exemplifica fontes e processos de conversão energética de biomassa.

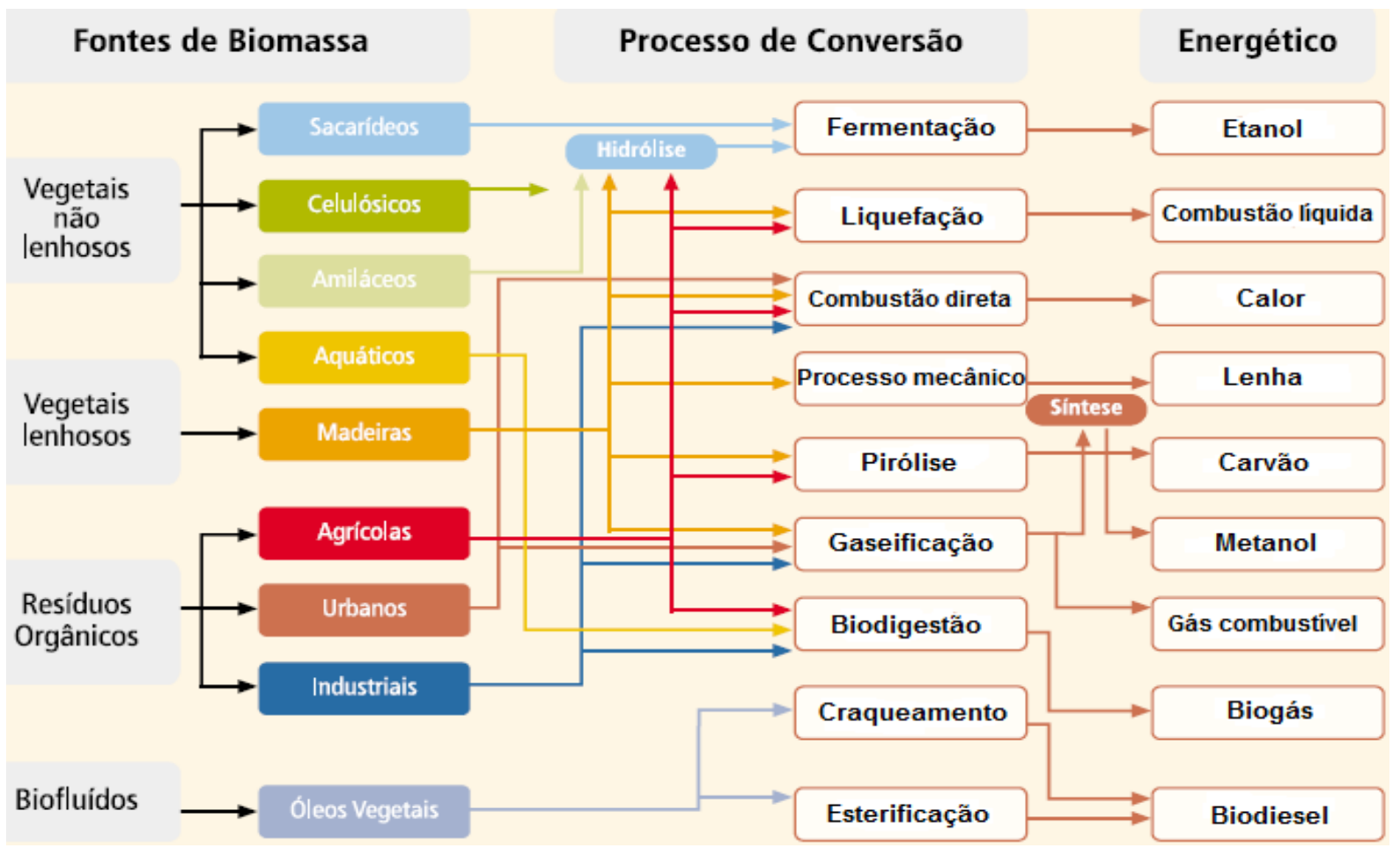

Figura 2.2 - Fontes e processos de conversão de biomassa. ${ }^{8}$

A utilização de biomassa como fonte de matéria-prima para a produção de novos produtos tem acentuado o interesse de pesquisadores e da indústria, sobretudo por sua abundância e caráter renovável.

A seguir, o presente estudo revisa, brevemente, fundamentos relacionados à composição de derivados de biomassa. 


\subsubsection{Biomassa lignocelulósica}

Os derivados lignocelulósicos são formados por estruturas cristalinas e fibrosas, constituídas principalmente pelos polissacarídeos celulose e hemicelulose, e pela lignina, estrutura formada por álcoois aromáticos. Ambas as estruturas encontram-se unidas por ligações covalentes e de hidrogênio. Ácidos graxos, resinas, fenóis, taninos, compostos nitrogenados e sais minerais podem estar presentes em menores proporções nos vegetais e seus derivados. ${ }^{10}$ A Figura 2.3 representa uma estrutura simplificada das principais fibras de derivados lignocelulósicos.

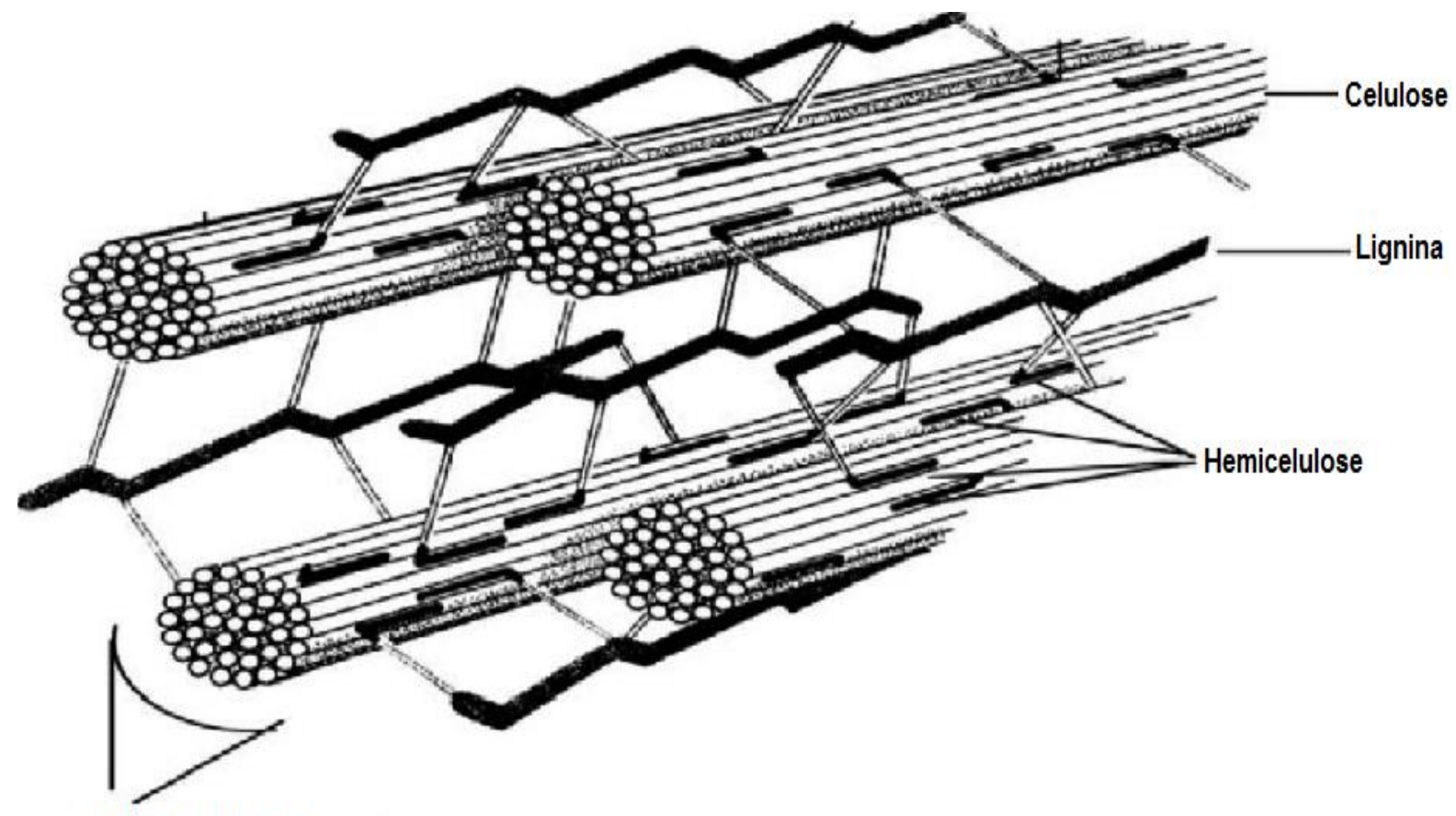

Feixes de celulose

Figura 2.3 - Arranjo típico da parede celular de uma planta. Adaptada da ref. ${ }^{10}$.

Estes três componentes essenciais da matéria lignocelulósica, de estrutura complexa, formam uma rede tridimensional e, necessitam ser hidrolisados mediante processos ácidos ou enzimáticos com a finalidade de obtenção de açúcares fermentescíveis. 


\subsubsection{Polissacarídeos}

Os polissacarídeos compreendem os carboidratos de elevada massa molecular (celulose e hemicelulose), representando cerca de $70 \%$ do total dos derivados lignocelulósicos. ${ }^{11}$

A celulose é o polissacarídeo mais abundante, correspondendo a cerca de $50 \%$ da massa seca total nos materiais lignocelulósicos. Trata-se de um polímero linear que apresenta porções amorfas e cristalinas, constituídas, exclusivamente, por moléculas de anidro-glicose unidas por ligações $\beta$-(1,4)-glicosídicas ${ }^{2,}{ }^{12}$, conforme representado na Figura 2.4.

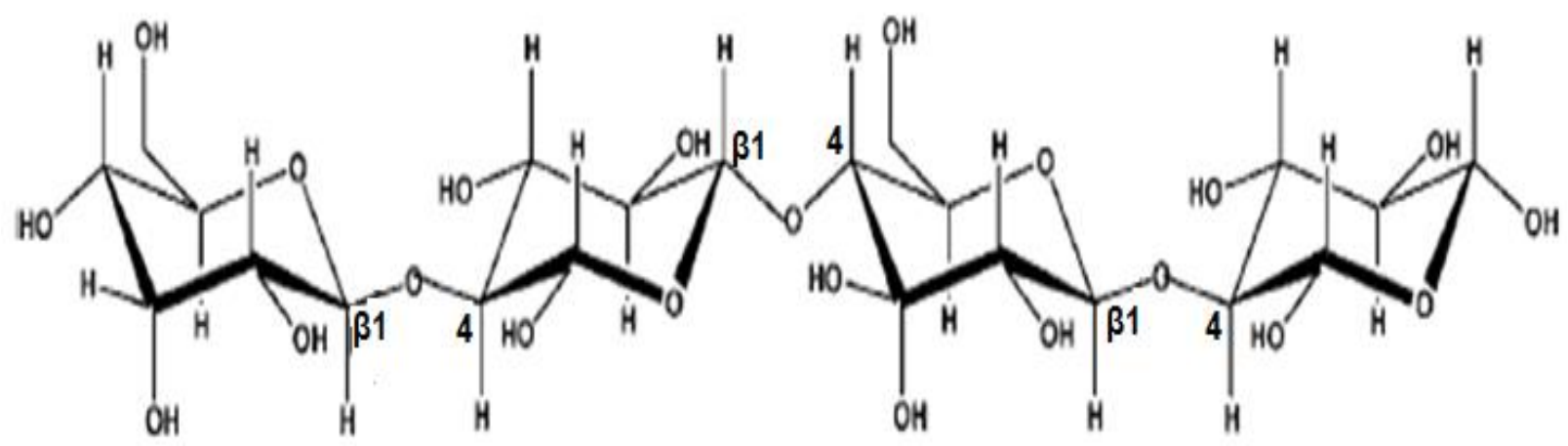

Figura 2.4 - Estrutura primária da celulose. Adaptada da ref. ${ }^{9}$.

A hemicelulose, cujo teor na matéria lignocelulósica varia entre 20 a $25 \%$, é um polissacarídeo ramificado e de massa molecular menor que a da celulose. É composta, principalmente por xilose (ligações $\beta-1,4)$, e várias ramificações de manose, arabinose, galactose e ácidos urônicos. ${ }^{12,13}$ A proporção dos diversos componentes da hemicelulose varia de acordo com a espécie vegetal, e mesmo no tocante a uma mesma espécie. ${ }^{14}$

Comparativamente à celulose, a hemicelulose, devido à sua estrutura ramificada, sem regiões cristalinas, é mais facilmente hidrolisável aos seus açúcares monoméricos. ${ }^{15} \mathrm{~A}$ Figura 2.5 apresenta componentes da fração de hemicelulose. 


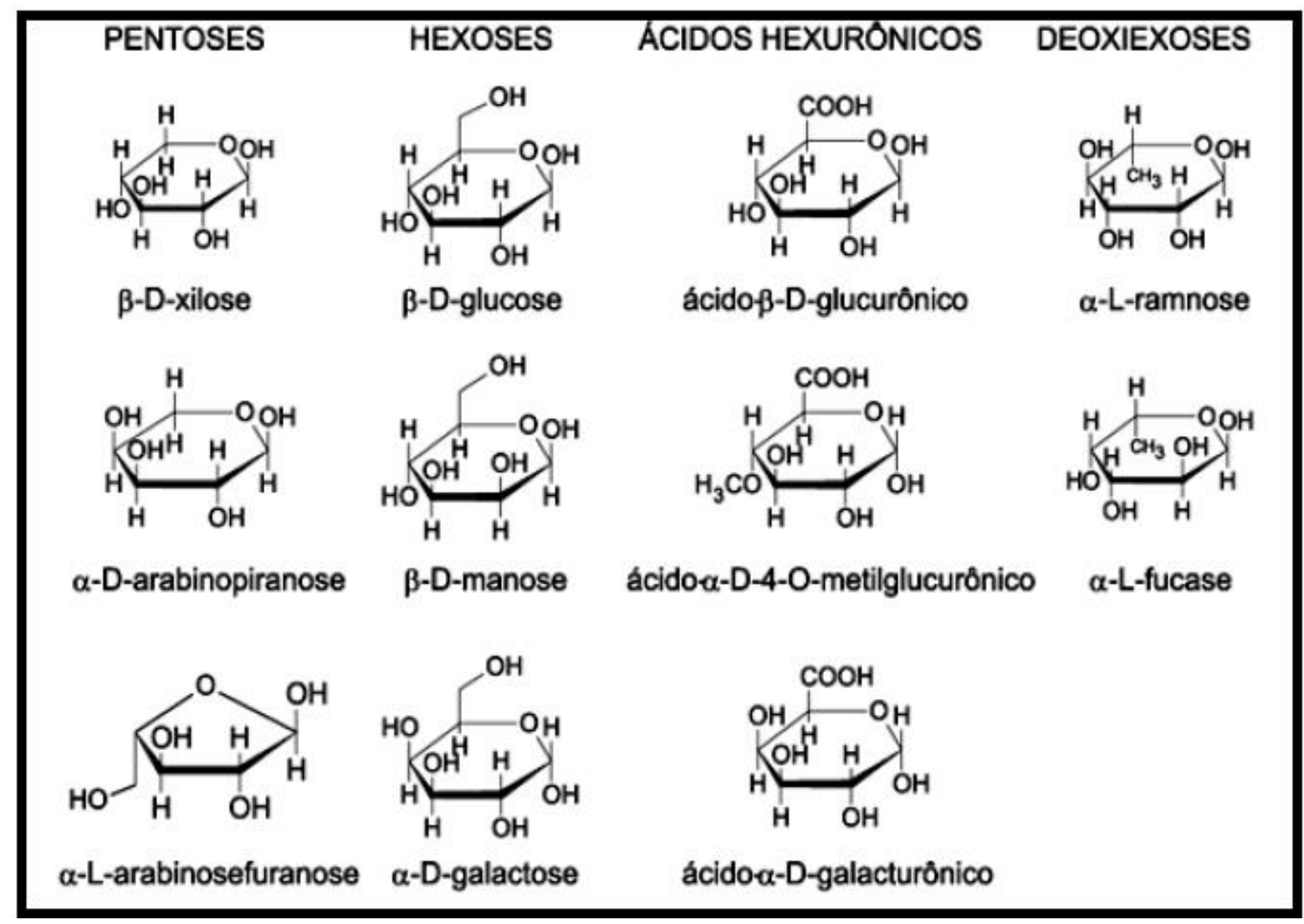

Figura 2.5 - Componentes da fração hemicelulose. ${ }^{14}$

\subsubsection{Lignina}

A lignina representa de 20 a $30 \%$ do componente seco do material lignocelulósico. É constituída por um polímero tridimensional, com estrutura altamente ramificada, com vários grupos polifenólicos. Esta estrutura está embutida e vinculada à hemicelulose, proporcionando rigidez ao material lignocelulósico. ${ }^{15} \mathrm{~A}$ Figura 2.6 representa a estrutura da lignina. 


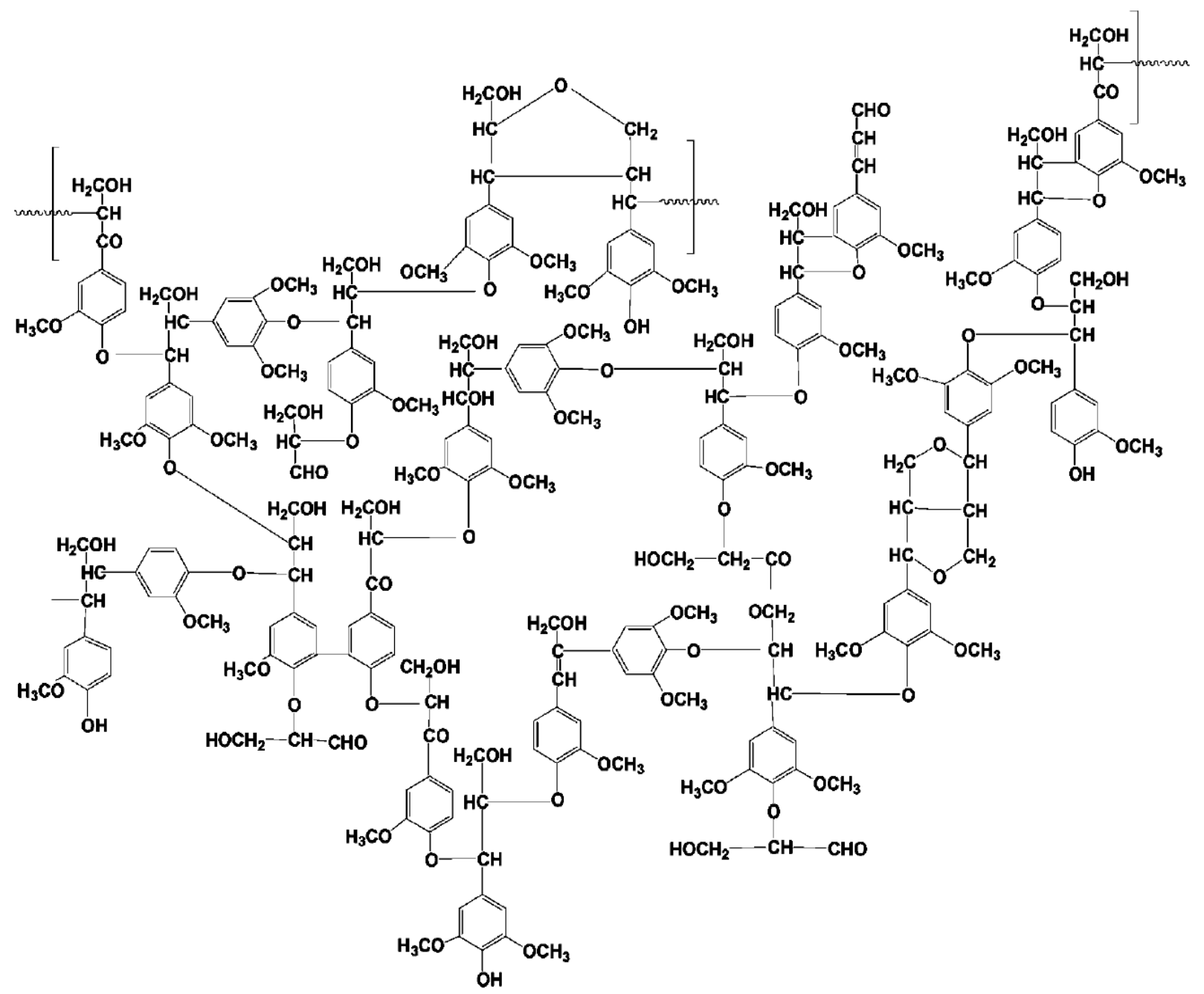

Figura 2.6 - Estrutura da lignina de madeira. ${ }^{11}$

A produção de biocombustíveis eficientes, tanto dos pontos de vista ambiental, como econômico, tem demandado estudos para o desenvolvimento de rotas e processos biotecnológicos que permitam a utilização dos derivados lignocelulósicos no mercado de combustíveis destinados ao setor de transportes, com o objetivo de reduzir a dependência dos derivados energéticos fósseis.

\subsection{2 Óleos e gorduras vegetais e animais}

Os óleos e gorduras animais e vegetais são substâncias hidrofóbicas, insolúveis em água, que quando modificadas, podem ser utilizadas como complementares ou substitutas aos derivados de petróleo. ${ }^{16}$ Os primeiros estudos sobre a constituição de óleos e gorduras foram realizados no início do século XIX, pelo químico francês, Michel-Eugène Chevreul, em sua obra publicada em 1823 e 
intitulada: Recherches chimiques sur les corps gras d'origine animal (Pesquisa química sobre a origem das gorduras animais). Ele observou que a hidrólise de óleos e gorduras originava ácidos graxos e glicerol, conforme detalhado na Figura 2.7.<smiles>[R]C(=O)OCC(COC([R])=O)OC(=O)[PH2]O[C@@H](O)C(CO)CO</smiles><smiles>[R]C(=O)O</smiles>

\section{Triacilglicerideo}

Glicerol

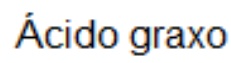

Figura 2.7 - Hidrólise de um triacilglicerídeo. ${ }^{17}$

A partir das observações de Chevreul, os óleos e gorduras passaram a ser denominados glicerídeos, acilglicerídeos ou triacilglicerídeos, que são ésteres formados a partir de glicerol e de ácidos carboxílicos de cadeia longa (ácidos graxos). Esses ácidos apresentam, geralmente, de 12 a 18 átomos de carbono, com ou sem a presença de uma ou mais ligações duplas. A composição exata das cadeias graxas depende da origem do óleo ou gordura. A Tabela 2.1 apresenta a composição, em porcentagem de ácidos graxos, dos principais óleos produzidos no Brasil e no mundo, e também, do óleo de coco, empregado como matéria-prima, junto com o óleo de soja, no presente trabalho.

Tabela 2.1 - Composição percentual de ácidos graxos em distintos óleos e gorduras vegetais. Adaptada das referências ${ }^{16,17,18,19,20,21}$.

\begin{tabular}{lccccccc}
\hline $\begin{array}{l}\text { Ácido graxo } \\
\text { (X:Y)(insaturação) }\end{array}$ & Soja $^{\mathbf{1 8}}$ & Coco $^{\mathbf{1 6}}$ & Tucumã $^{\mathbf{1 8}}$ & Girassol $^{\mathbf{1 7}}$ & $\begin{array}{l}\text { Pinhão } \\
\text { manso }\end{array}$ & Colza $^{\mathbf{2 0}}$ & Palma $^{\mathbf{2 1}}$ \\
\hline Caprílico (8:0) & - & $5-9$ & - & - & - & - & - \\
Cáprico (10:0) & - & $4-10$ & - & - & - & - & - \\
Láurico (12:0) & - & $44-51$ & - & - & - & - & $0-0,4$ \\
Mirístico (14:0) & - & $13-18$ & - & - & - & 0,1 & $0,6-1,6$ \\
Palmítico (16:0) & 14 & $7-10$ & 32,9 & $3,6-6,5$ & 13,62 & 4,8 & $41-47$ \\
Palmitoleico (16:1)(n9) & - & - & - & - & 0,93 & 0,3 & $0-0,6$ \\
Esteárico (18:0) & 4,0 & $1-4$ & 5,3 & $1,3-3,0$ & 5,85 & 1,9 & $3,7-5,6$ \\
Oleico (18:1)(n9) & 24 & $5-8$ & 57,6 & $14-43$ & 43,39 & 61,9 & $38,2-43,5$ \\
Linoleico (18:2)(n9,12) & 52 & $1-3$ & 4,2 & $44-68$ & 36,21 & 19,8 & $6,6-11,9$ \\
Linolênico (18:3)(n9,12,15) & 5,0 & - & - & - & - & 9,2 & $0-0,5$ \\
Araquídico (20:0) & 0,4 & - & - & - & - & 0,6 & $0-0,8$ \\
Gadoleico (20:1)(n11) & - & - & - & - & - & 1,4 & - \\
Behêmico (22:0) & 0,6 & - & - & - & - & - & - \\
\hline X:Y = número de carbonos:número de insaturações & & & & &
\end{tabular}


O tamanho das cadeias carbônicas, o grau de insaturação e a orientação geométrica das insaturações promovem diferenças nas propriedades fisico-químicas dos óleos e gorduras vegetais e animais. Enquanto, à temperatura ambiente, os óleos se apresentam no estado líquido, devido ao elevado conteúdo de ácidos graxos insaturados, as gorduras são sólidas ou pastosas, apresentando predominância de ácidos graxos saturados. A temperatura de fusão decresce com a presença de insaturações, pois estas dificultam o empacotamento das cadeias. Esse efeito é acentuado para as duplas ligações na configuração cis, e pequeno para a configuração trans. Além disso, a temperatura de fusão também decresce com a diminuição do tamanho da cadeia em razão do enfraquecimento das interações intermoleculares. ${ }^{16,22} \mathrm{Na}$ Figura 2.8 são apresentadas as estruturas de alguns ácidos graxos, com as respectivas temperaturas de fusão, os quais ilustram muito bem os efeitos acima discutidos.

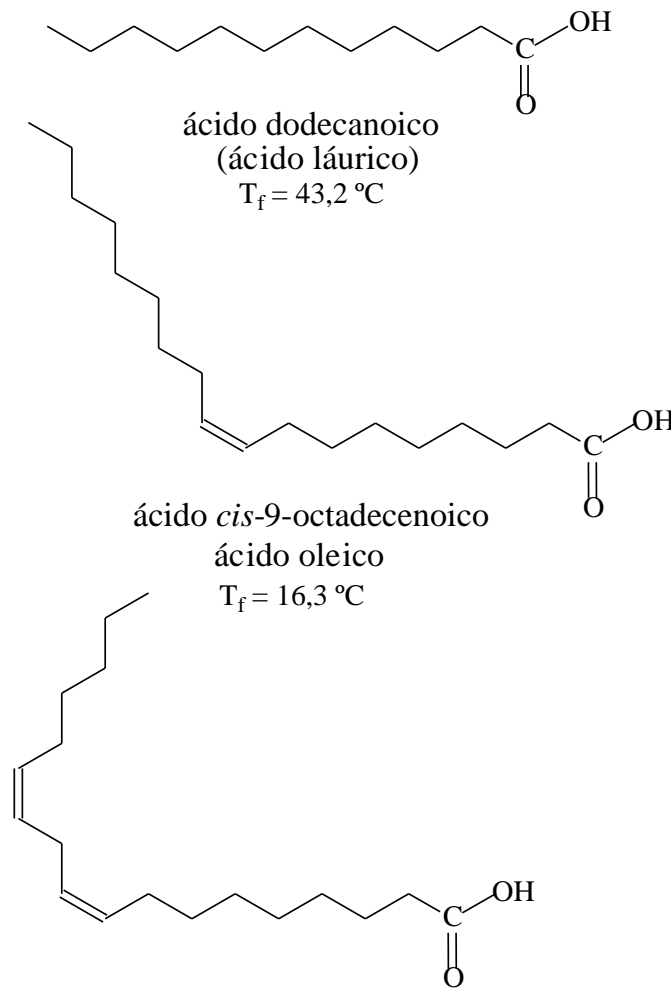

ácido cis,cis-9,12-octadecadienoico

(ácido linoleico) $\mathrm{T}_{\mathrm{f}}=-5,0^{\circ} \mathrm{C}$

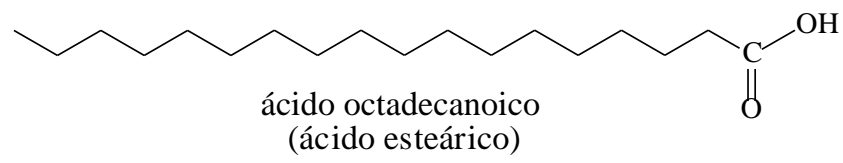

$\mathrm{T}_{\mathrm{f}}=69,6^{\circ} \mathrm{C}$

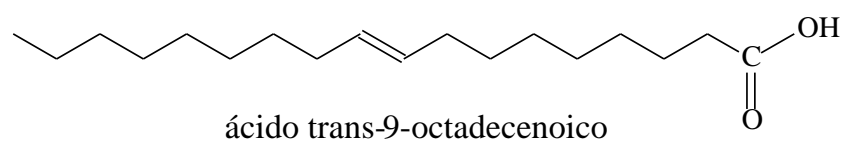

(ácido elaídico) $\mathrm{T}_{\mathrm{f}}=43,7^{\circ} \mathrm{C}$

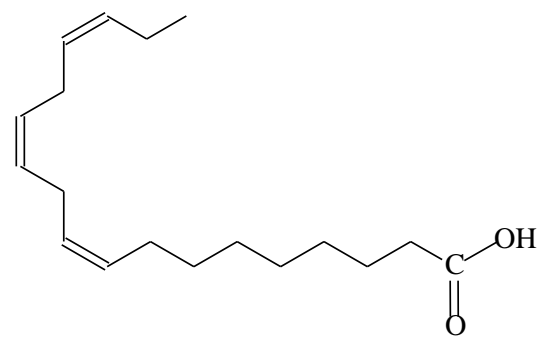

ácido cis,cis,cis-9,12,15-octadecatrienoico (ácido linoleico) $\mathrm{T}_{\mathrm{f}}=-17,0^{\circ} \mathrm{C}$

Figura 2.8 - Temperaturas de fusão dos principais ácidos graxos conhecidos na natureza.

Como a viscosidade também se encontra atrelada à propensão de as moléculas estabelecerem interações intermoleculares, ela é outra propriedade físico- 
química que aumenta com a elevação do número de carbonos das cadeias e decresce com a presença de insaturações, sobretudo do tipo cis.

Além de triacilglicerídeos, os óleos e gorduras podem conter pequenas quantidades de fosfatídeos, esteróis, antioxidantes, ceras, vitaminas e ácidos graxos livres, o que torna os óleos e gorduras uma mistura bastante complexa. Os ácidos graxos livres, assim como fosfatídeos, interferem na acidez de um óleo ou gordura, relacionando-se à sua respectiva qualidade, sobretudo no que se refere ao uso alimentar ou como biocombustível. $O$ índice de acidez de um óleo ou gordura é medido pela quantidade em miligramas de hidróxido de potássio $(\mathrm{KOH})$ necessários para neutralizar um grama do material analisado. ${ }^{22}$

Nas últimos décadas, têm havido intensos investimentos e pesquisas em todo o mundo, com a finalidade de promover culturas que elevem a produção de óleos e gorduras. No Brasil, o óleo de soja é o mais abundante como fonte de triacilglicerídeos. O mesmo ocorre nos Estados Unidos, com destaque também para os óleos de canola e girassol. Na Europa, o óleo de colza é mais comumente utilizado, enquanto na Ásia, sobretudo na Índia, Indonésia e Malásia, o óleo de palma é o mais comum. ${ }^{23}$ A Figura 2.9 apresenta os principais tipos de óleos produzidos no mundo para uma produção de 143,15 milhões de toneladas.

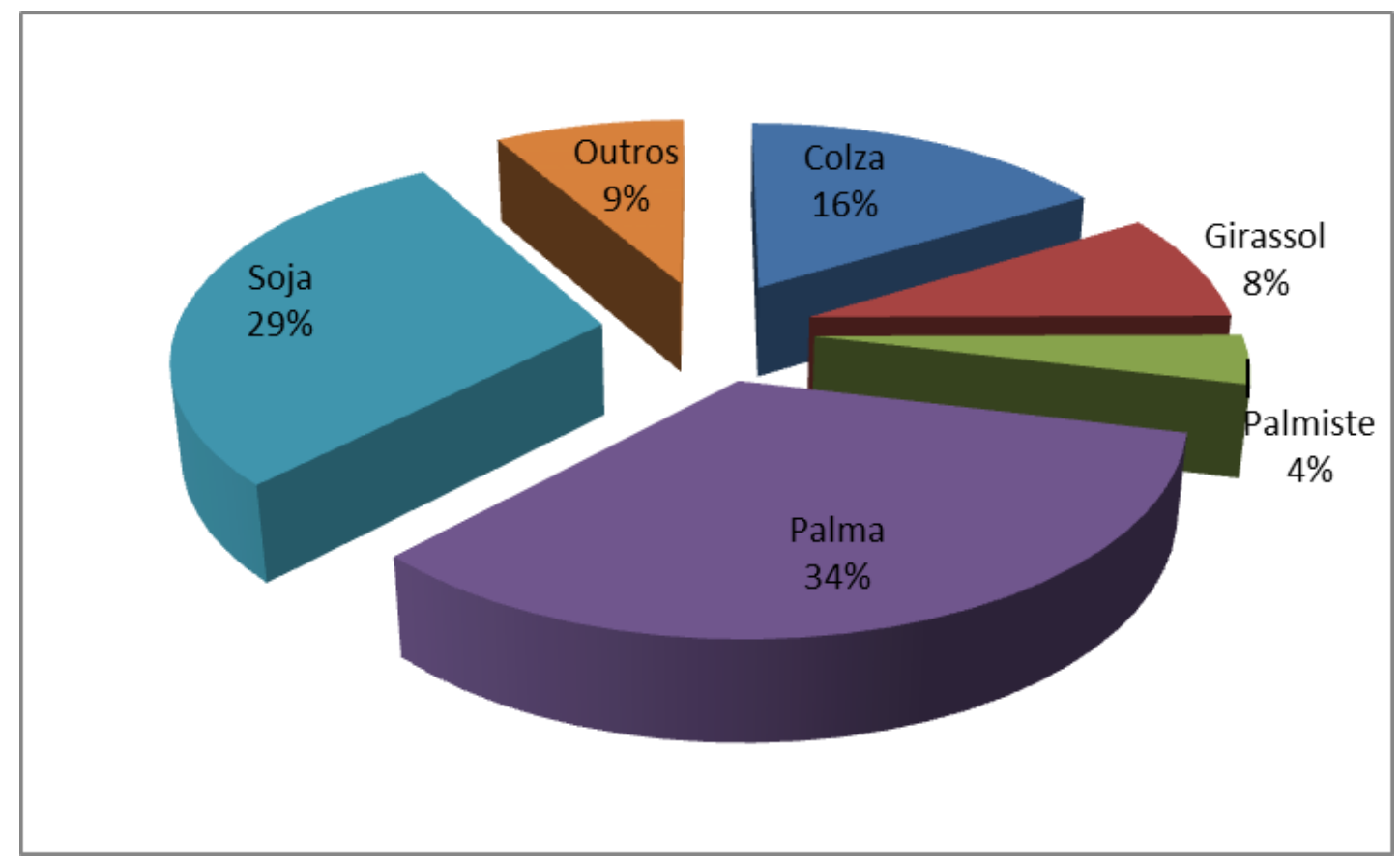

Figura 2.9 - Produção de óleos vegetais no mundo em 2011 - 2012. Adaptada da Ref. ${ }^{4}$. 


\subsection{O emprego de óleos e gorduras vegetais e animais como combustível}

No século XIX, Rudolf Diesel inventou o motor a óleo diesel. De suas pesquisas sobre motores de combustão interna, foi escrito, em 1893, o livro Teoria e construção de um motor térmico racional. O objetivo de Diesel era comprimir o ar rapidamente em um motor e promover a injeção de combustível, provocando a autoignição. Em 1900, Rudolf Diesel utilizou em seus ensaios, petróleo cru e óleo de amendoim. Ele acreditava que se um motor pudesse ser alimentado com óleos e gorduras vegetais, também poderia contribuir para o desenvolvimento da agricultura em países que os utilizassem. No entanto, a elevada disponibilidade de petróleo à época, aliada ao seu baixo custo, tornou este insumo preferencial para o uso em motores. ${ }^{3,24}$

Com o petróleo barato, frações adequadas foram refinadas para servirem como combustível, promovendo a evolução conjunta dos motores diesel em busca de menor custo e maior eficiência. Entre 1930 e 1940, devido a guerras, óleos vegetais e seus derivados foram utilizados em situações emergenciais. ${ }^{3,} 25$ Recentemente, 0 foco sobre a utilização de fontes alternativas derivadas de biomassa para obtenção de combustíveis similares ao petróleo e seus derivados tem-se acentuado. Países como o Brasil e os Estados Unidos tem incentivado a produção de biocombustíveis em larga escala, defendendo a tese de que estes poderiam ser uma alternativa economicamente viável para a substituição de combustíveis fósseis, e, também, de minimização de problemas ambientais. Em contrapartida, outros países e organismos internacionais afirmam que isso estimularia o uso de áreas agricultáveis para a produção de combustíveis, comprometendo a produção de alimentos e gerando um aumento de problemas sociais relacionados à fome em diversas regiões pobres do planeta.

Uma das opções para minimizar os efeitos sobre a disponibilidade de alimentos seria o emprego, na produção de biocombustíveis, de culturas não comestíveis (pinhão-manso, rícino, entre outras) que, supostamente, poderiam fazer uso de terras de baixa fertilidade. Entretanto, essas culturas alternativas demandam água e fertilizantes, de forma que também afetam a atividade de produção de alimentos. Outra opção mais conveniente do ponto de vista da segurança alimentar seria o emprego de óleo de cozinha usado. Entretanto, para que fosse possível suprir 
parcela representativa da demanda por biocombustíveis, seria necessário criar sistemas logísticos eficientes para coleta e reutilização do óleo usado. ${ }^{25}$

Embora os óleos vegetais possam ser usados diretamente como combustíveis, suas características tornam esse emprego inadequado. Um dos principais problemas é a elevada viscosidade que apresentam. Além disso, o elevado teor de oxigênio ocasiona uma diminuição da entalpia de combustão e da miscibilidade com combustíveis fósseis e eleva a tendência à decomposição térmica e à polimerização. As consequências nos motores diesel ao operarem continuamente com óleos vegetais seriam: deposição excessiva de carbono no motor, obstrução de filtros de óleo e do sistema de bicos injetores, diminuição da vida útil do motor, e elevação dos custos operacionais relacionados à necessidade constante de manutenção. ${ }^{26}$ No entanto, diversos processos de conversão de óleos vegetais em produtos mais compatíveis ao emprego como combustível líquido foram desenvolvidos, como a transesterificação ou a hidrólise/esterificação para produção de EAG, e a pirólise para produção de bio-óleo. Estes processos serão abordados na sequência.

\subsection{1 Ésteres de ácidos graxos (EAG)}

Os óleos e gorduras podem ser convertidos em ésteres de ácidos graxos (EAG) por meio de reações de transesterificação de seus triacilglicerídos com álcoois. São empregados, usualmente, o metanol ou etanol, sendo denominados respectivamente, ésteres metílicos de ácidos graxos (EMAG) e ésteres etílicos de ácidos graxos (EEAG). As reações de transesterificação são, geralmente, catalisadas por ácidos ou bases de Brönsted, destacando-se o uso de soda cáustica $(\mathrm{NaOH})$ ou outras bases fortes, sobretudo em razão de seus baixos custos e da rapidez do processo. ${ }^{27,} 28$ Além dos EAG, essas reações geram o glicerol, subproduto utilizado em indústrias de cosméticos, farmacêuticas, químicas e alimentícias. No entanto, seu eventual excesso não pode ser descartado como efluente ou lixo, necessitando de uma destinação adequada para tal. A Figura 2.10 mostra a representação esquemática de uma reação de transesterificação para formação de biodiesel, cuja composição dependerá da estrutura das cadeias de ácidos graxos presentes em cada triacilglicerídeo. 
<smiles></smiles>

Triacilglicerídeo<smiles>[R]OC([R3])=O</smiles><smiles>OCC(O)CO</smiles>

Ésteres alquílicos (Biodiesel)

Figura 2.10 - Representação genérica de uma reação de transesterificação.

De acordo com as normas da ANP, os EAG também são conhecidos como biodiesel. Entretanto, em sentido literal, qualquer combustível obtido a partir de biomassa e empregado em motores a diesel também poderia ser denominado como biodiesel. No presente trabalho, com a finalidade de evitar interpretações ambíguas, os biocombustíveis obtidos a partir de reações de transesterificação de triacilglicerídeos, serão denominados EAG, ou ainda, EMAG ou EEAG.

Os EAG podem ser utilizados como substitutos do óleo diesel fóssil ou em blendas com este, em motores do ciclo diesel. ${ }^{28}$ Entretanto, eles apresentam diversas desvantagens. Em primeiro lugar, a presença de oxigênios no grupo funcional éster resulta em um menor poder calorífico quando comparado aos combustíveis hidrocarbônicos de origem fóssil, além de elevar a densidade e a viscosidade. Além disso, a presença de cadeias insaturadas reduz a estabilidade oxidativa, devido à facilidade de formação de radicais alílicos e bis-alílicos (especialmente os últimos); por outro lado, cadeias insaturadas resultam em temperaturas de fusão mais baixas, o que compromete as propriedades a frio do combustível. Finalmente, são verificados ainda problemas relacionados à sensiblilidade à hidrólise das ligações éster, a qual gera ácidos graxos livres que aumentam a corrosividade do combustível. ${ }^{29}, 30$ Esses inconvenientes relacionados ao emprego dos EAG como biocombustível tem conduzido pesquisadores à proposição de diferentes processos de produção de biocombustíveis a partir dos triacilglicerídeos, conforme discutido na sequência. 


\subsubsection{Bio-óleo}

O método mais econômico e direto para a conversão de derivados da biomassa em combustível líquido é a pirólise rápida, que consiste na conversão de uma substância por meio de aquecimento, com ou sem catalisador, em atmosfera não oxidante. ${ }^{3}$ No entanto, produtos obtidos a partir da pirólise de biomassa (chamados bio-óleos) não são adequados para ser utilizados diretamente como combustível de transporte, principalmente devido ao elevado teor de oxigênio que apresentam (que pode ser tão elevado quanto $40 \%$ ). ${ }^{31}$ Conforme já discutido, um alto grau de oxigenação ocasiona elevada viscosidade e ação corrosiva, baixas densidade energética, estabilidade química e miscibilidade com derivados de combustíveis fósseis. ${ }^{31}, 32,33,34$ A Tabela 2.2 traz dados comparativos entre propriedades típicas de bio-óleos e petróleo bruto.

Tabela 2.2 - Comparação de características de bio-óleo de madeira pirolisada e de petróleo bruto. Adaptada da ref. ${ }^{35}$.

\begin{tabular}{|c|c|c|}
\hline Propriedades físicas & Bio-óleo & Petróleo Bruto \\
\hline Água $(\% \mathrm{~m} / \mathrm{m})$ & $15-30$ & 0,1 \\
\hline $\mathrm{Ph}$ & $2,8-3,8$ & - \\
\hline Densidade $\left(\mathrm{kg} / \mathrm{dm}^{3}\right)$ & $1,05-1,25$ & 0,86 \\
\hline \multicolumn{3}{|c|}{ Composição elementar (\% m/m) } \\
\hline C & $55-65$ & $83-86$ \\
\hline $\mathrm{H}$ & $5-7$ & $11-14$ \\
\hline $\mathrm{O}$ & $28-40$ & $<1$ \\
\hline $\mathrm{N}$ & $<0,4$ & $<1$ \\
\hline Cinzas & $<0,2$ & 0,1 \\
\hline Poder Calorífico, MJ/kg & $16-19$ & 44 \\
\hline Viscosidade $\left(50^{\circ} \mathrm{C}\right), \mathrm{cP}$ & $40-100$ & 180 \\
\hline $\mathrm{H} / \mathrm{C}$ & $0,9-1,5$ & $1,5-2,0$ \\
\hline $\mathrm{O} / \mathrm{C}$ & $0,3-0,5$ & $\approx 0$ \\
\hline
\end{tabular}

Bio-óleos têm sido eficientes quando utilizados como combustível em caldeiras, e tem mostrado potencial para serem usados em motores ciclo diesel, turbinas, e na geração de eletricidade, mediante 0 melhoramento de suas propriedades físicas e físico-químicas, significativamente diferentes dos derivados de petróleo. ${ }^{31,34,36}$ Aplicações de bio-óleos são mostradas na Figura 2.11. 


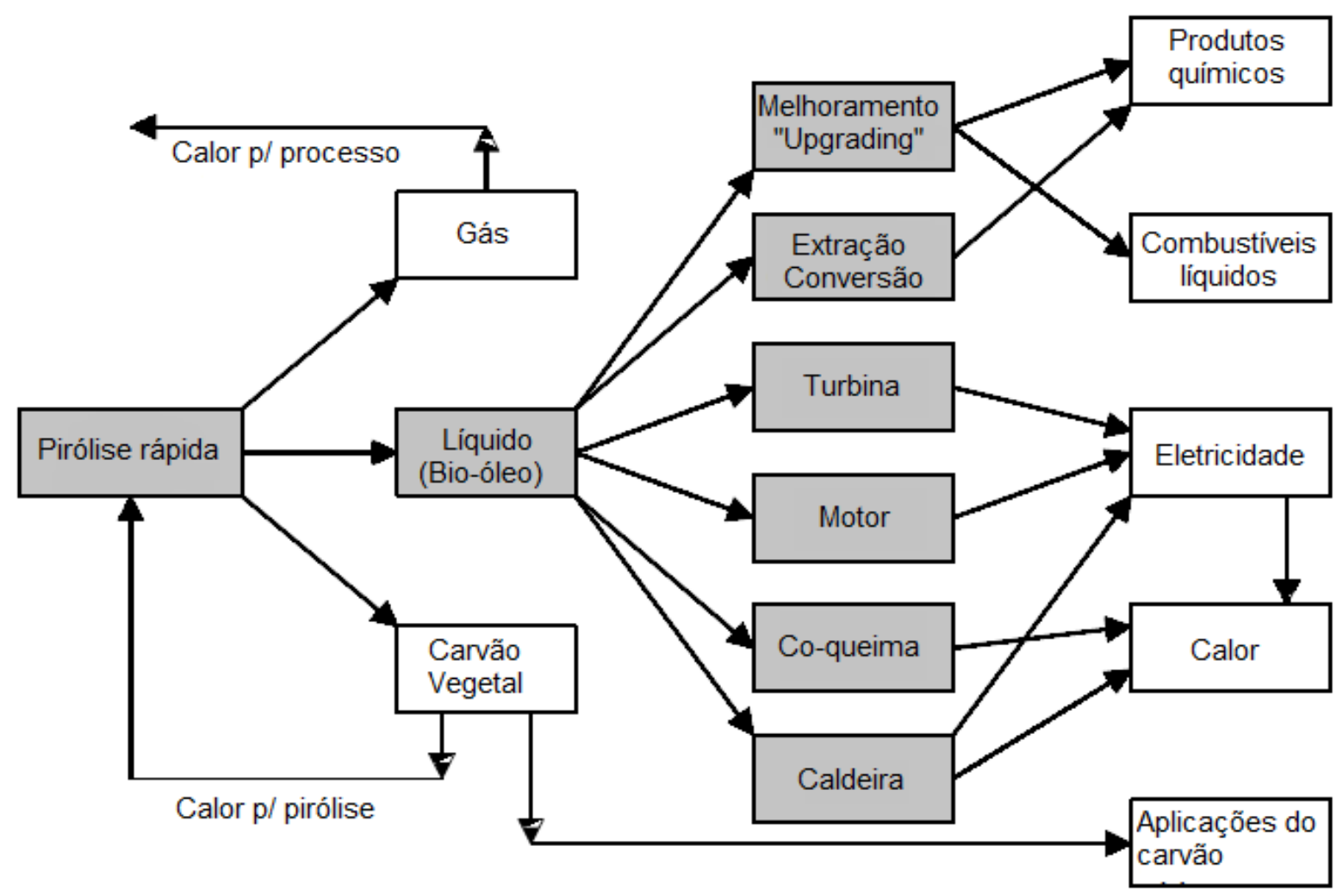

Figura 2.11 - Resumo de aplicações de bio-óleos. Adaptada da ref. ${ }^{37}$.

\subsubsection{Biocombustíveis parafínicos}

Visto que o elevado teor de oxigênio é uma característica intrínseca da biomassa, torna-se evidente a conveniência da remoção desse oxigênio durante o processo de conversão dessa matéria-prima em biocombustível. A hidrodesoxigenação (HDO) tem-se mostrado o método mais efetivo para a remoção de oxigênio em derivados de biomassa. Nele, a desoxigenação é realizada por meio de tratamento térmico, sob pressão de $\mathrm{H}_{2(\mathrm{~g})}$, em presença de um catalisador, apresentando como vantagem a possibilidade de obtenção de hidrocarbonetos parafínicos líquidos compatíveis com os derivados fósseis. ${ }^{4,32}$

A HDO é um tipo específico de reação envolvida nos processos denominados hidrotratamento (HDT), que é muito empregado no refino do petróleo visando à remoção não só de oxigênio, mas de outros heteroátomos ( $S, N, P$ e metais). $O$ objetivo é melhorar as propriedades dos combustíveis produzidos e minimizar a emissão de gases tóxicos ao meio ambiente, de forma a atender às crescentes restrições das legislações ambientais. ${ }^{38}$ Durante $0 \mathrm{HDT}$, há a ocorrência de várias 
reações simultâneas, entre as quais se destacam a hidrodessulfurização (HDS), a hidrodesnitrogenação (HDN), a hidrodesoxigenação (HDO) e a hidrodesmetalização (HDM), para remover, respectivamente, enxofre, nitrogênio, oxigênio e metais (níquel, vanádio, arsênio, entre outros). ${ }^{39}$ Há ainda, outras reações que ocorrem no processo de refino, como a hidrodesaromatização (HDA) e a hidroisomerização (HID). Além disso, a hidrogenação de olefinas e estruturas aromáticas conduzem à remoção de suas respectivas insaturações.

A literatura traz um estudo bastante vasto sobre o HDT e os catalisadores mais usados no processo de refino do petróleo. No entanto, este trabalho enfocará a aplicação do hidrotratamento e a utilização do catalisador de NiMo sulfetado, depositado em alumina, visando a desoxigenação de óleos vegetais para aplicação como combustíveis.

\subsection{HDO de óleos e gorduras animais e vegetais}

Existe atualmente, na literatura, número considerável de trabalhos acerca da hidroconversão de óleos e gorduras vegetais e animais em combustíveis parafínicos. Nos trabalhos são empregadas condições diversas de temperatura, pressão e catalisador, além de matérias-primas variadas, tais como óleo de colza ${ }^{20}$, de pinhão manso ${ }^{19}$, de soja ${ }^{40}$, de canola ${ }^{41}$ e de palma ${ }^{42}$. Nesses trabalhos, é amplamente difundido que a HDO de óleos e gorduras vegetais envolve, primeiramente, a conversão dos triglicerídeos aos respectivos ácidos graxos que, na sequência, podem ser desoxigenados por meio de três rotas distintas: ${ }^{4,}$ 19, 43

I. Descarboxilação: $\quad \mathrm{RCOOH} \rightarrow \mathrm{RH}+\mathrm{CO}_{2}$

II. Descarbonilação: $\quad \mathrm{RCOOH}+\mathrm{H}_{2} \rightarrow \mathrm{RH}+\mathrm{CO}+\mathrm{H}_{2} \mathrm{O}$

III. Hidrogenação/Desidratação: $\mathrm{RCOOH}+3 \mathrm{H}_{2} \rightarrow \mathrm{RCH}_{3}+2 \mathrm{H}_{2} \mathrm{O}$

Na rota de hidrogenação/desidratação, a remoção de oxigênio leva à formação de água e de parafinas normais com número de carbonos igual ao ácido graxo correspondente. $\mathrm{Na}$ descarbonilação, o oxigênio é removido, levando à produção de 
hidrocarbonetos com inferioridade de um átomo de carbono em relação ao ácido graxo de origem, além de $\mathrm{CO}$ e água. A remoção de oxigênio na descarboxilação conduz à formação de hidrocarbonetos com o déficit de um átomo de carbono em relação ao ácido graxo original, além de produzir $\mathrm{CO}_{2}{ }^{4,19,44,45}$

Nesse ponto, é válido destacar que alguns autores ${ }^{43}$ utilizam o termo hidrodesoxigenação para referir-se especificamente à rota III, enquanto outros ${ }^{4} \mathrm{o}$ utilizam para fazer referência ao método como um todo, de promover a desoxigenação via tratamento térmico sob pressão de $\mathrm{H}_{2}(\mathrm{~g})$ e que envolve as três rotas acima elencadas. Para evitar essa confusão, no presente trabalho a rota III será denominada hidrogenação/desidratação, ao passo que o termo hidrodesoxigenação, HDO, será empregado apenas para designar o método global.

Dessa forma, os produtos obtidos a partir da HDO de óleos e gorduras vegetais e animais são os alcanos lineares derivados das reações de descarboxilação, descarbonilação e hidrogenação/desidratação dos ácidos constituintes da matéria-prima. Além disso, são formados produtos de reações de craqueamento das cadeias, de isomerização (alcanos ramificados) e uma pequena proporção de produtos de reações de acoplamento. A título de exemplificação, a Tabela 2.3 apresenta as principais classes de compostos identificados por Mikulec et al..$^{45}$ no produto da reação de HDO do óleo de colza, a $340{ }^{\circ} \mathrm{C}$ e 35 bar, catalisada por $\mathrm{NiMoS} 2 / \mathrm{Al}_{2} \mathrm{O}_{3}$.

Tabela 2.3 - Composição do produto da HDO do óleo de colza, a $340{ }^{\circ} \mathrm{C}$ e 35 bar, catalisada por $\mathrm{NiMoS} 2 / \mathrm{Al}_{2} \mathrm{O}_{3}$. Adaptada da ref. ${ }^{45}$.

\begin{tabular}{cc}
\hline Produto & Composição, \%m/m \\
\hline$<\mathbf{n}-\mathbf{C}_{14}$ & 0,40 \\
$\mathbf{n}-\mathbf{C}_{15}$ & 3,81 \\
$\mathbf{n}-\mathbf{C}_{16}$ & 3,39 \\
$\mathbf{n}-\mathbf{C}_{17}$ & 49,12 \\
$\mathbf{n}-\mathbf{C}_{18}$ & 34,06 \\
$>\mathbf{n}_{\mathbf{1}} \mathbf{C}_{18}$ & 0,84 \\
Isoalcanos, cicloalcanos e olefinas & 7,02 \\
Aromáticos & 1,15 \\
Produto líquido, \%m/m & 90,9 \\
\hline
\end{tabular}


Embora os trabalhos envolvendo óleos e gorduras vegetais e animais não tragam informações detalhadas acerca dos mecanismos de desoxigenação das moléculas, muitas informações podem ser obtidas a partir do trabalho desenvolvido por Senol e colaboradores ${ }^{46}$ que investigaram as reações de desoxigenação de ésteres alifáticos empregando sulfetos de NiMo e CoMo. Conforme demonstra a Figura 2.12, os principais produtos obtidos a partir do hexanoato de metila, nas reações realizadas em leito fixo, foram hidrocarbonetos $\mathrm{C} 7$ (heptano e hepteno) e C6 (hexano e hexeno). Entretanto, nas reações realizadas em batelada, constatouse que, inicialmente, foi formado ácido heptanoico e, em seguida, heptanol (Figura 2.13). Os autores realizaram então reações, em condições idênticas, partindo do ácido, sendo constatada a formação dos mesmos produtos (Figura 2.14); além disso, verificou-se, inicialmente, pronunciada formação de heptanol, o qual foi consumido com o passar do tempo (Figura 2.15). Com essas observações, é possível inferir que o éster é inicialmente hidrolisado ao ácido que, por sua vez, se converte no álcool correspondente. Os autores sugerem que a conversão do ácido a álcool se dê por meio da formação de um aldeído, embora apenas traços de heptanal tenham sido detectados, o que os autores atribuem a instabilidade do composto. O 1-heptanol formado sofre então desidratação para formar o 1-hepteno que, por sua vez, pode sofrer hidrogenação a heptano.

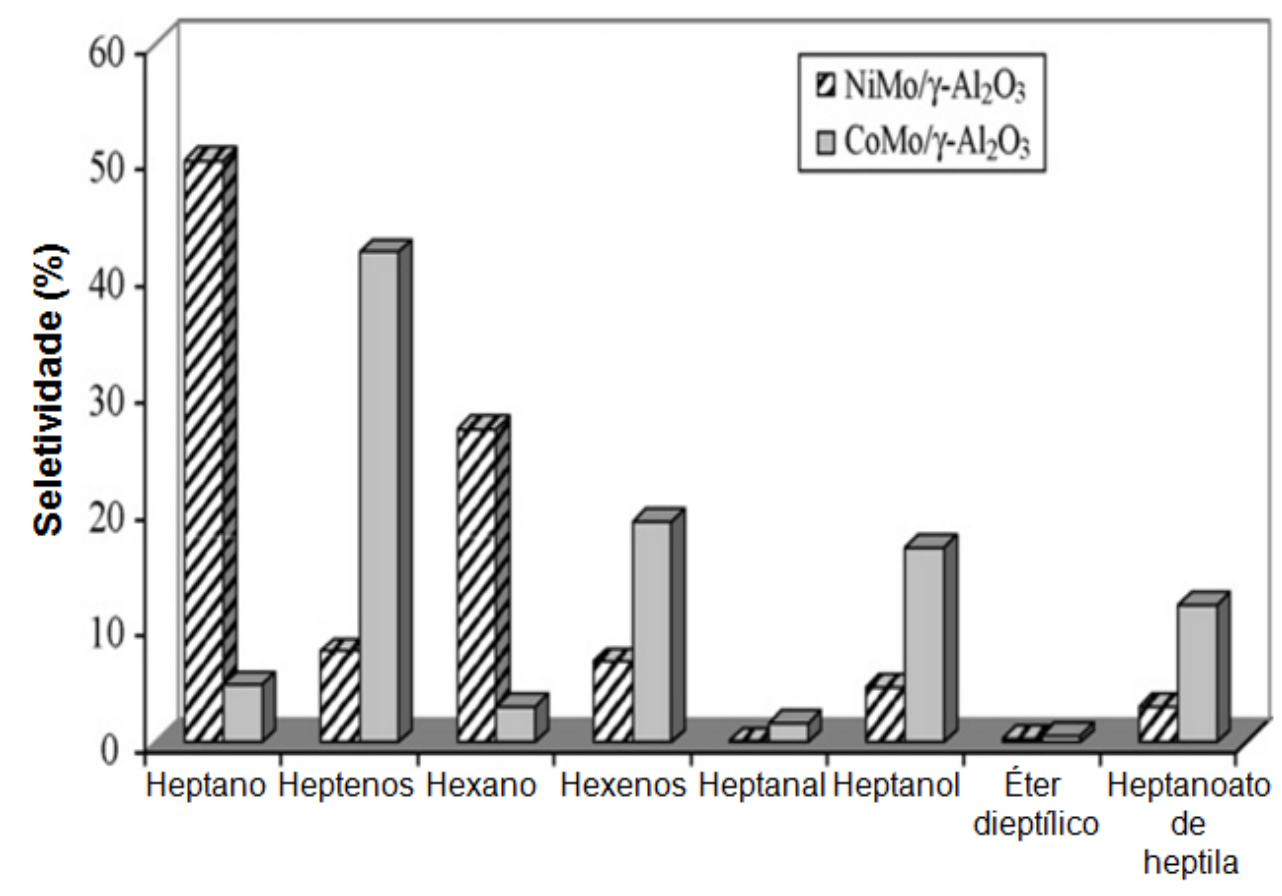

Figura 2.12 - Distribuição de produtos do HDT do hexanoato de metila em reator de leito fixo, com catalisadores de sulfetos de NiMo e de CoMo (250 ํ; $1,5 \mathrm{MPa})$. Adaptada da ref. ${ }^{46}$. 


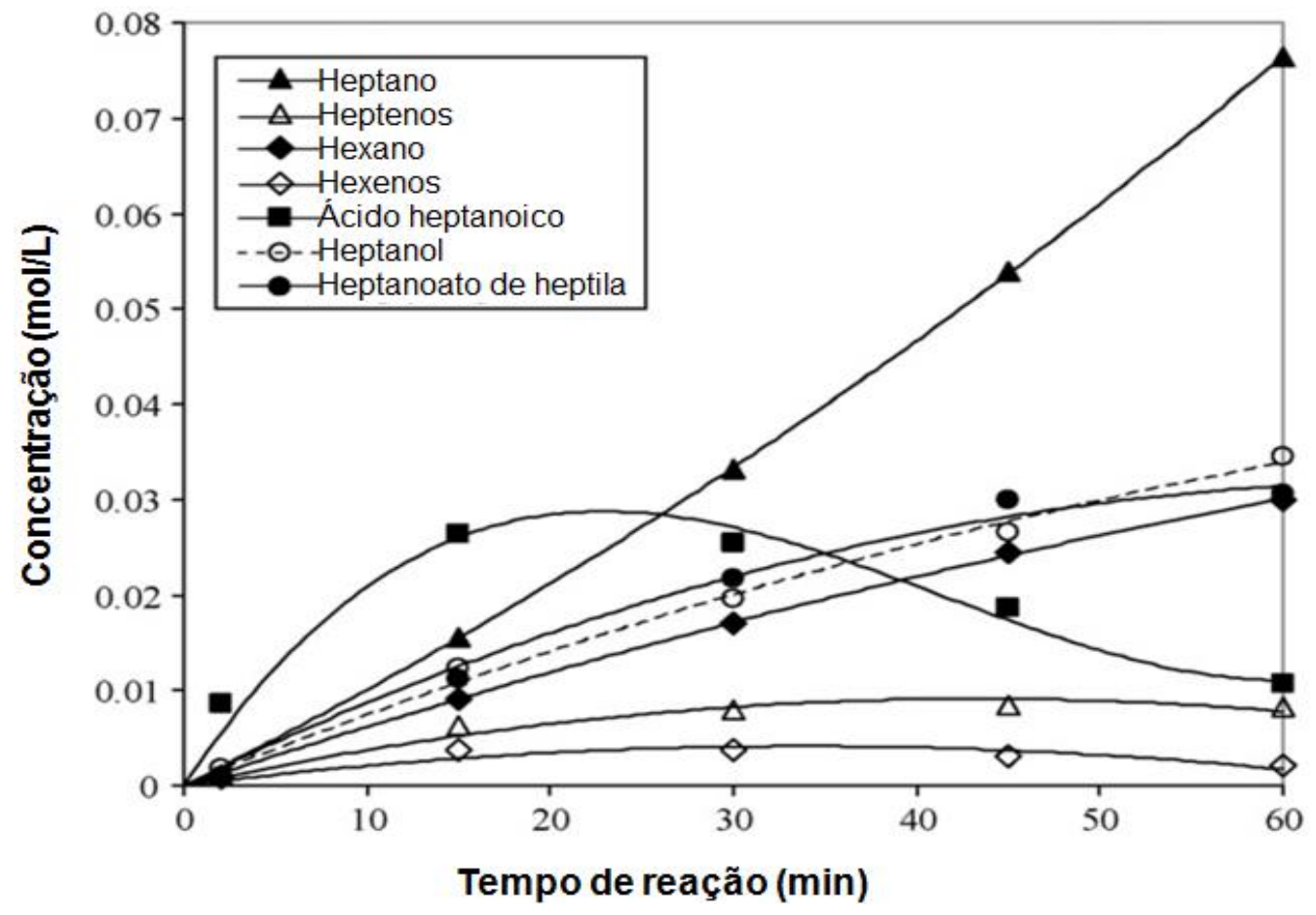

Figura 2.13 - Distribuição de produtos do HDT do ácido heptanoico, em reator de leito fixo, com catalisadores de sulfetos de NiMo e de CoMo (250 ํ; $1,5 \mathrm{MPa})$. Adaptada da ref. ${ }^{46}$.

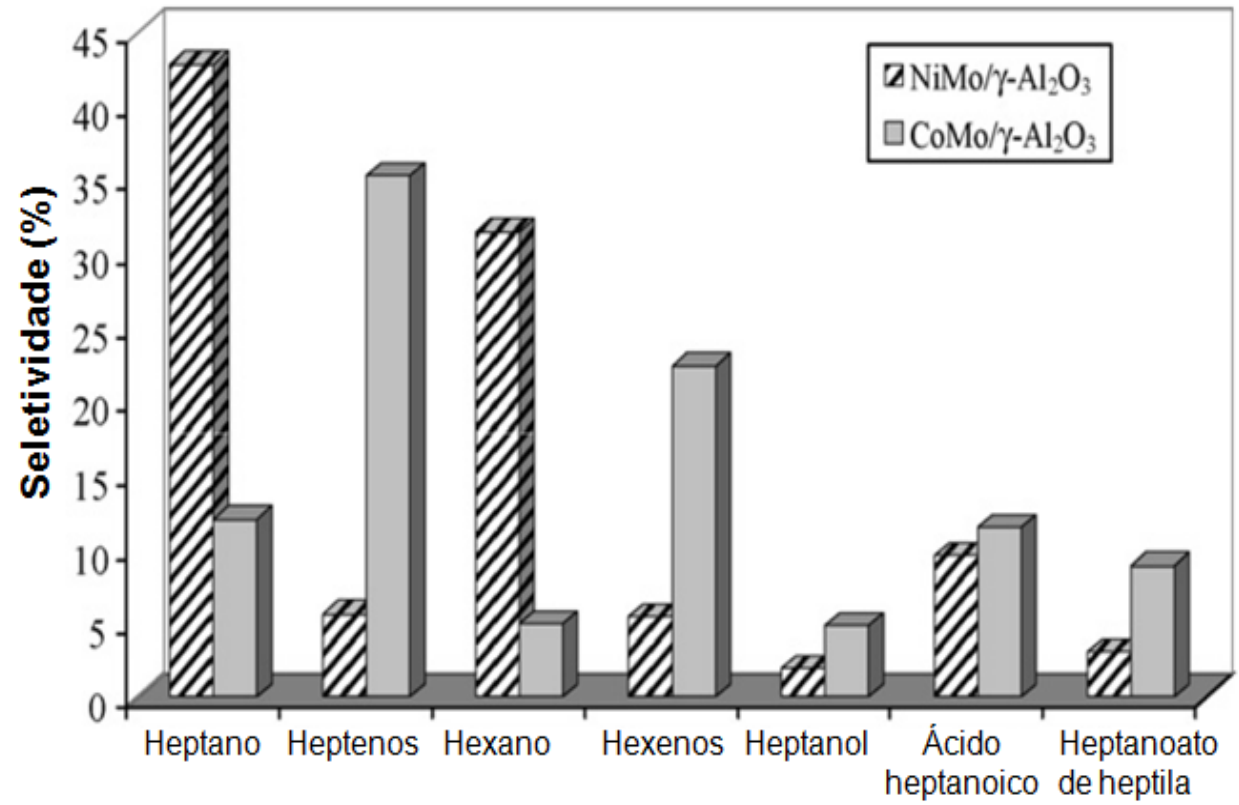

Figura 2.14 - Concentração de produtos em função do tempo de reação para o hidrotratamento do hexanoato de metila, em sistema de batelada, com catalisador de sulfeto de NiMo (250 $\left.{ }^{\circ} \mathrm{C} ; 7,5 \mathrm{MPa}\right)$. Adaptada da ref. ${ }^{46}$. 


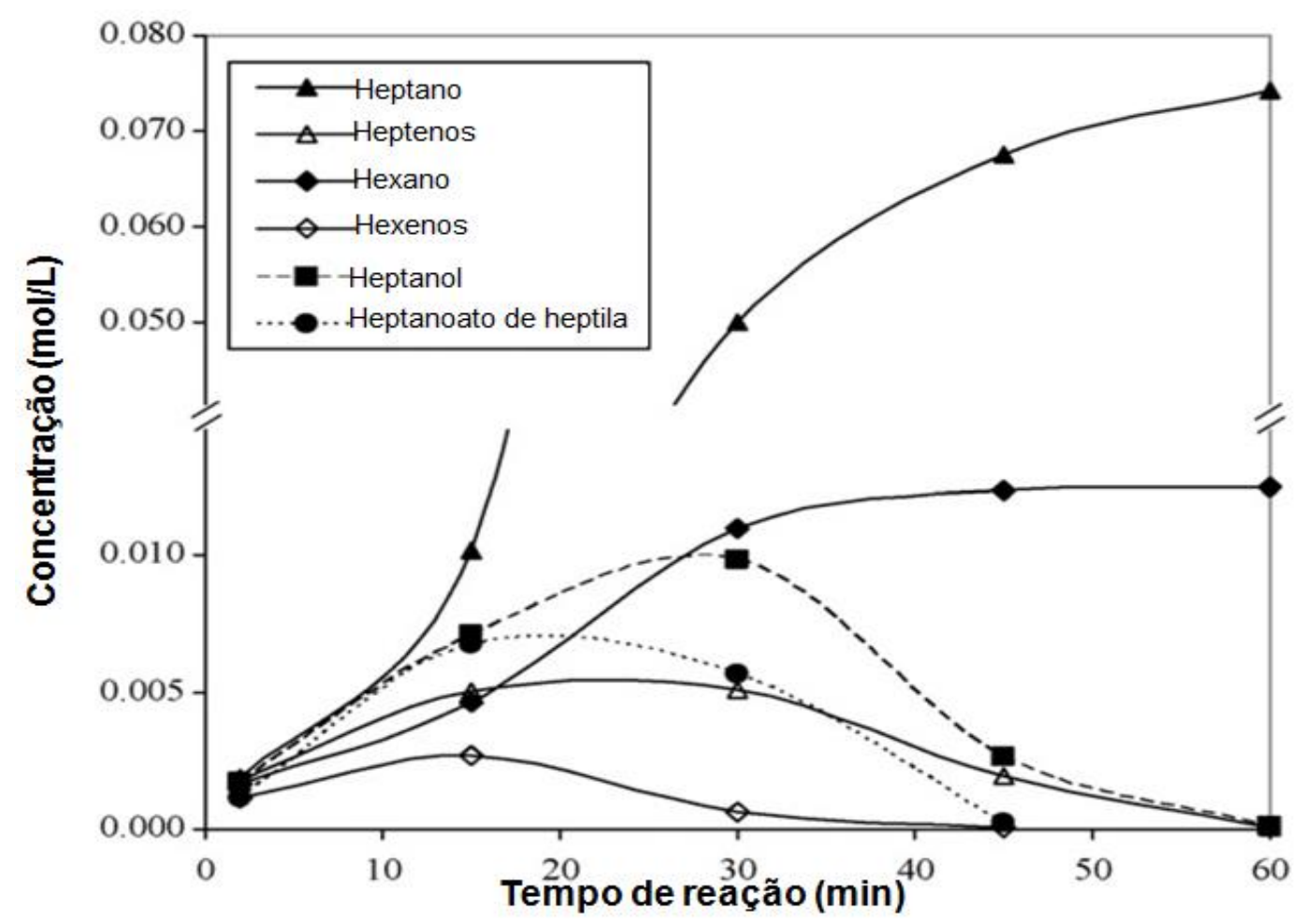

Figura 2.15 - Concentração de produtos em função do tempo de reação para o hidrotratamento do ácido heptanoico, em sistema de batelada, com catalisador de sulfeto de NiMo (250 ${ }^{\circ} \mathrm{C} ; 7,5 \mathrm{MPa}$ ). Adaptada da ref. ${ }^{46}$.

A HDO assume especial importância, não somente pelo fato de possibilitar a desoxigenação de derivados de biomassa, mas também por apresentar o propano como principal subproduto do processo, visto que na transesterificação para produção do biodiesel, este subproduto é o glicerol. ${ }^{47}$ Os combustíveis hidrocarbônicos provenientes do processo de hidrodesoxigenação de óleos vegetais e animais têm baixo teor de oxigênio (próximo de zero), ausência de insaturações e estabilidade oxidativa acentuada, propriedades satisfatórias quando utilizados em ${ }^{47}$ blendas ou como substitutos de derivados fósseis quando comparados aos ésteres de ácidos graxos (EAG), além de apresentarem teores de enxofre e aromáticos menores do que os EAG. ${ }^{30}$

É válido mencionar o processo $\mathrm{H}-\mathrm{BIO}$, que foi desenvolvido e patenteado pela Petrobras. ${ }^{48}$ No processo, de 10 a $30 \%$ de óleo vegetal (foram testados os óleos de soja e mamona) são misturados ao diesel e a mistura é submetida ao HDT. Dessa forma, ao mesmo tempo em que o diesel fóssil é dessulfurizado, o óleo vegetal é convertido em hidrocarbonetos parafínicos. Os testes realizados, tanto em escala piloto quanto industrial, permitiram a obtenção de produtos totalmente especificados segundo os padrões da ANP (Agência Nacional de Petróleo, Gás Natural e 
Biocombustíveis) e com propriedades inclusive superiores às do diesel convencional (maior número de cetano e menores densidade e teor de enxofre). Há de se destacar também, no processo, a possibilidade de utilização das mesmas instalações e equipamentos já existentes para o processamento do diesel de petróleo. ${ }^{39}$

Finalmente, é válido mencionar que a produção de combustíveis hidrocarbônicos pode ser efetivada por meio de outras tecnologias, como a síntese de Fisher-Tropsch (FT), processo químico para produção de hidrocarbonetos líquidos a partir de gás de síntese $\left(\mathrm{CO}\right.$ e $\left.\mathrm{H}_{2}\right)$. No entanto, esta técnica apresenta desvantagens relacionadas ao alto custo em comparação ao hidrotratamento, além de promover uma emissão acentuada de dióxido de carbono. ${ }^{49}$

\subsection{Catalisadores para a HDO}

Os catalisadores mais usados na desoxigenação de derivados de biomassa são os mesmos empregados no HDT do petróleo. Esses catalisadores são sulfetos de metais de transição do grupo 6 (Mo ou W), promovidos por metais de transição com maior número de elétrons $\mathrm{d}$, como $\mathrm{Ni}$ ou $\mathrm{Co}$, depositados sobre suportes de óxidos ou óxidos mistos. O mais empregado é o sulfeto de NiMo depositado em $\mathrm{Al}_{2} \mathrm{O}_{3}$ (com teores de metal na faixa de $8-24 \%$ de Mo e $2-5 \%$ de Ni). ${ }^{50}$ Observa-se que o catalisador, asssim como o suporte catalítico exercem influência sobre o mecanismo e a cinética do HDT. Portanto, sua escolha é vital para a eficiência do processo de desoxigenação.

Os catalisadores são preparados, via de regra, pelos métodos da impregnação a seco ou impregnação úmida. ${ }^{51}$ Após a impregnação, o material é calcinado, com o que se obtém o catalisador na forma de óxido. Usualmente, a sulfetação é realizada in situ por meio do tratamento térmico com $\mathrm{H}_{2} \mathrm{~S}$. No catalisador de $\mathrm{MoS}_{2}$, os átomos de S se coordenam em torno do Mo de acordo com a geometria prismática piramidal e os prismas se unem pelas arestas para formar estruturas lamemelares (Figura 2.16). 


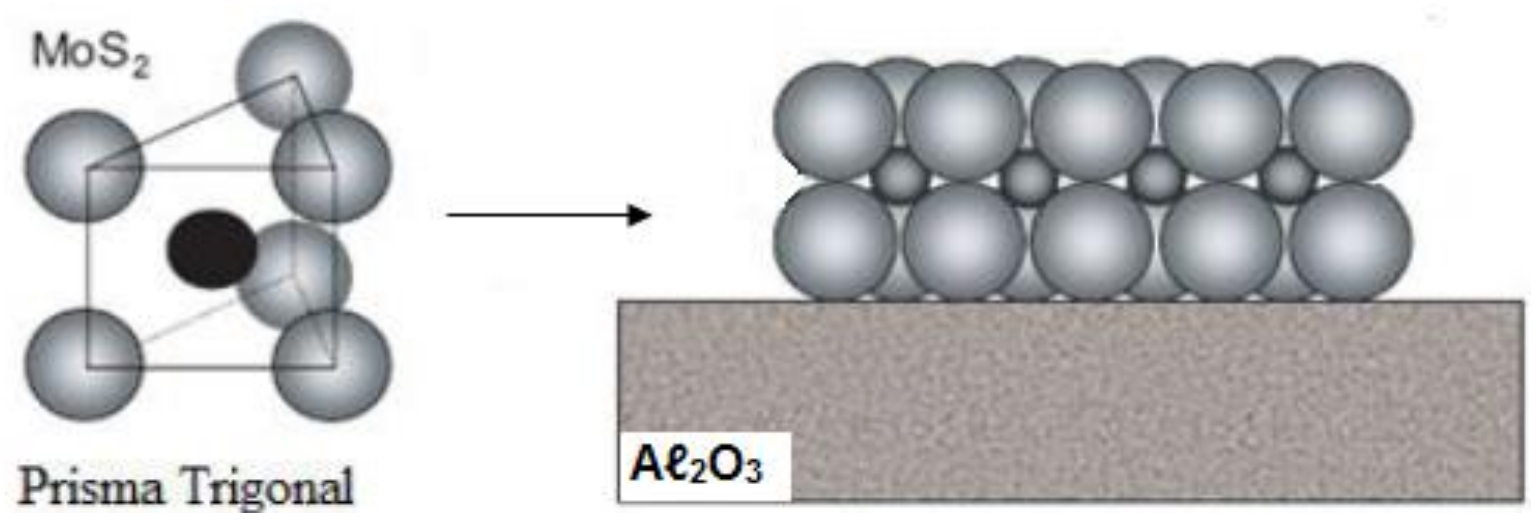

Figura 2.16 - Estrutura dos catalisadores de $\mathrm{MoS}_{2}$. Adaptada da ref..$^{50}$.

Considera-se que a ação catalítica do $\mathrm{MoS}_{2}$ se dê pela adsorção do substrato em "vacâncias de S" nas bordas dos cristais do catalisador (não nos planos basais). Com relação à dopagem com $\mathrm{Ni}$ ou $\mathrm{Co}$, acredita-se que estes atuem simplesmente como agentes promotores da atividade do catalisadores e, desde a década de 70, dezenas de modelos têm sido propostos para explicar a estrutura da fase ativa dos catalisadores. O mais aceito é o que propõe que sejam formados nanoclusters de $\mathrm{MoS}_{2}$, com o Co ou Ni situados nas bordas substituindo átomos de Mo. Os átomos do dopante enfraqueceriam a ligação Mo-S e, assim, facilitariam o desenvolvimento das "vacâncias". ${ }^{52,} 53$ A concentração de $\mathrm{H}_{2}$ e $\mathrm{H}_{2} \mathrm{~S}$ poderiam, também influenciar no desenvolvimento dessas "vacâncias", de modo que a ausência de doadores de enxofre, a presença de água e compostos oxigenados poderiam afetar a estrutura do catalisador. ${ }^{39}$

A Figura 2.17 demonstra que, no caso do $\mathrm{MoS}_{2}$ não dopado, os nanocluesters apresentam forma triangular, conforme demonstrado por miscroscopia de tunelamento com varredura (STM).

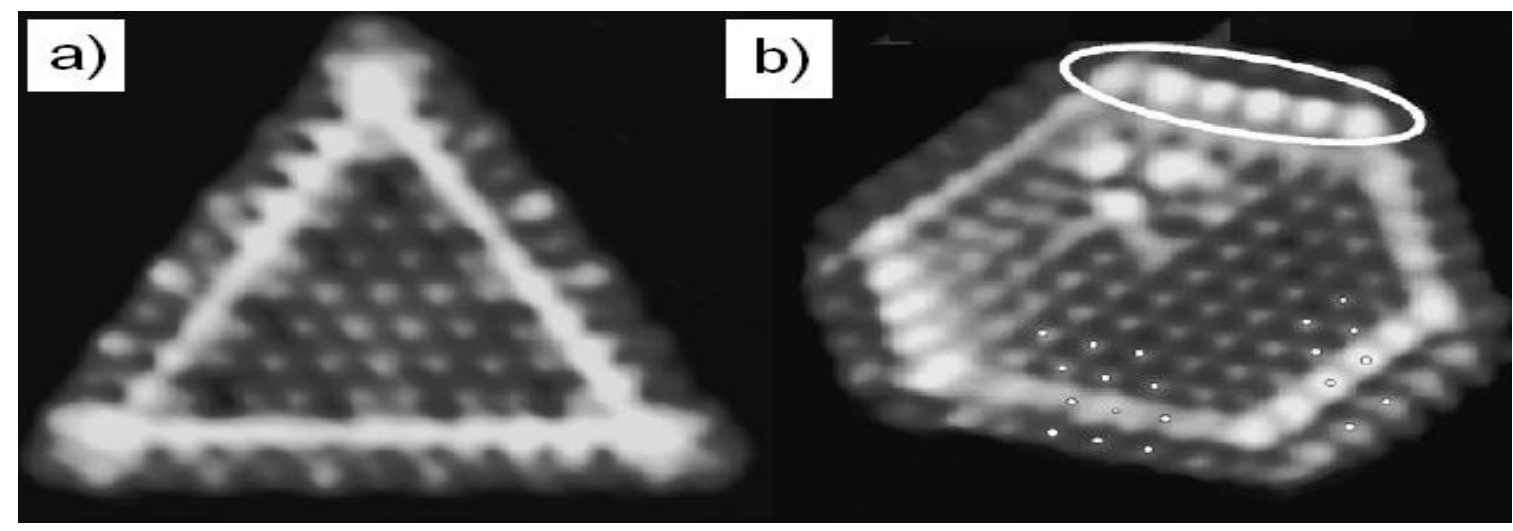

Figura 2.17 - Imagens por microscopia de tunelamento com varredura (STM) dos catalisadores (a) $\mathrm{MoS}_{2}$ e do (b) sulfeto de CoMo. Adaptada da ref. ${ }^{52}$ 
Por outro lado, a presença dos dopantes gera uma morfologia hexagonal truncada. Nesta morfologia, os dopantes se localizam nas bordas do hexágono: no caso do Co, ele ocupa as posições do que é chamado, na literatura, de sulfur edge (bordas do hexágono que correspondem a lados dos prismas trigonais) e apresenta geometria tetraédrica (Figuras 2.18 e 2.19 b); já o Ni ocupa posições do que é chamado, na literatura, de metal edge (bordas do hexágono que correspondem a arestas dos prismas) e apresenta geometria quadrado planar (Figura 2.19 a).

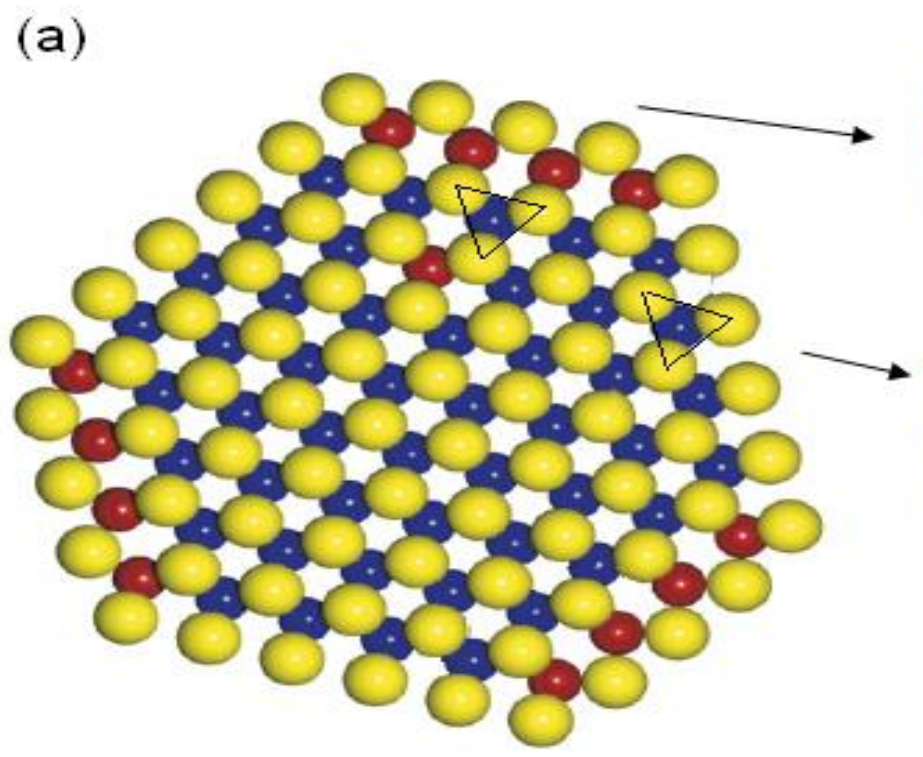

(b)

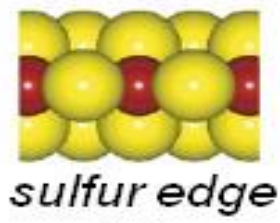

(c)

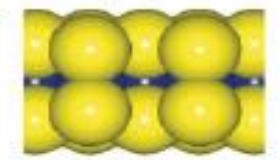

metal edge

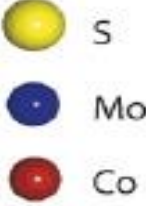

Figura 2.18 - Modelo de bolas do sulfeto de CoMo. Vista do plano basal (a) e vistas laterais (a) e (b). S: amarelo; Mo: azul; Co: vermelho. Adaptada da ref. ${ }^{54}$.

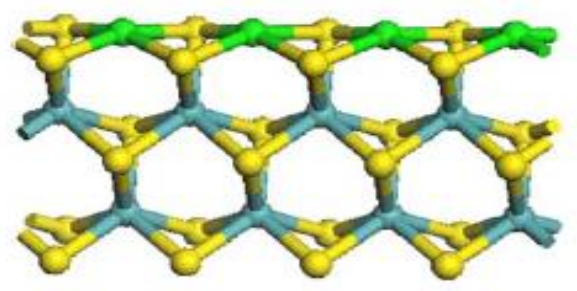

$\mathrm{NiMoS}_{2}$

(a)

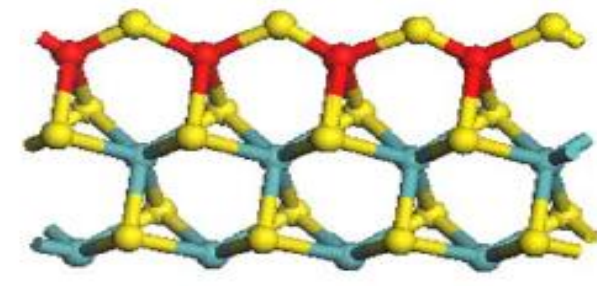

$\mathrm{CoMoS}_{2}$

(b)

Figura 2.19 - Representação das estruturas das bordas contendo os dopantes nos catalisadores de sulfeto de NiMo (a) e CoMo (b). Adaptada da ref. ${ }^{55}$. 
Na Figura 2.20 é apresentada a representação proposta por Chorkendorff e Niemantsverdriet para o mecanismo de hidrodessulfurização de tioálcoois catalisada por MoS2, no qual o passo inicial é a adsorção do enxofre ao Mo em uma "vacância de enxofre" ${ }^{50}$
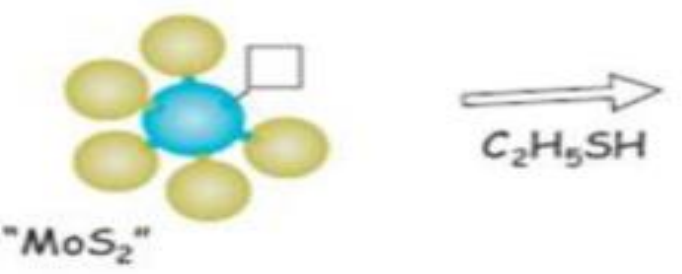

"MoS"

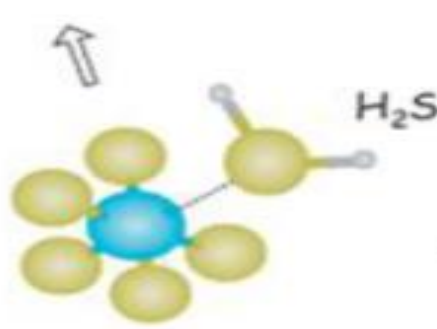

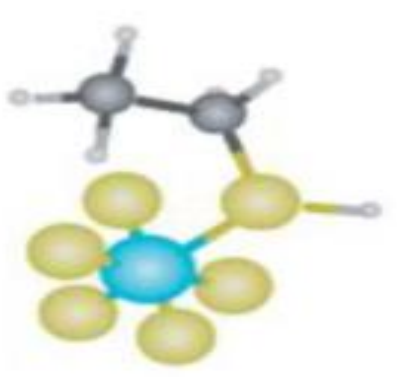

$\mathrm{C}_{2} \mathrm{H}_{4}$
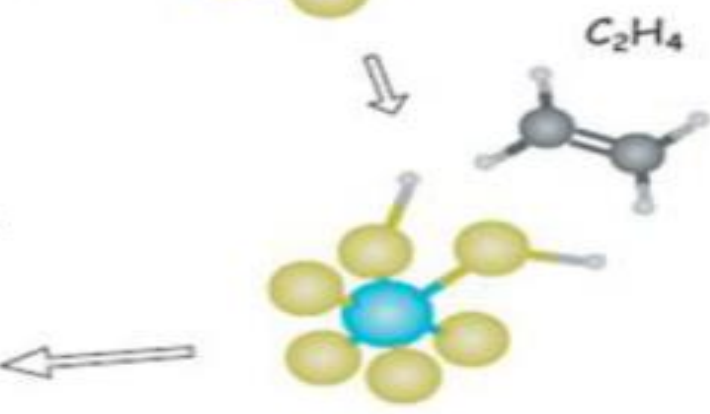

Figura 2.20 - Proposta de mecanismo para a reação de hidrodessulfurização de tioálcoois em catalisadores a base de $\mathrm{MoS}_{2}$. Adaptada da ref. ${ }^{50}$.

Acredita-se que a hidrodesoxigenação de álcoois ocorra de maneira muito similar à acima proposta para a hidrodessulfurização, com a única diferença que a primeira envolve a adsorção de um átomo de oxigênio em vez de enxofre.

Com relação aos compostos aromáticos oxigenados, os estudos reportados na literatura são sempre realizados com compostos modelo, como fenóis ${ }^{32,}{ }^{56} \mathrm{e}$ furanos $^{5}$. De maneira geral, assume-se que dois caminhos distintos podem ser seguidos. O primeiro seria a pré-hidrogenação dos anéis aromáticos, levando à formação dos compostos oxigenados alifáticos que, então, reagem conforme acima discutido. A segunda, envolve a quebra, nos compostos fenólicos, da ligação do oxigênio com o carbono $\mathrm{sp}^{2}$, para formar hidrocarbonetos aromáticos que são posteriormente hidrogenados. A Figura 2.21 apresenta um mecanismo proposto por Romero e colaboradores ${ }^{56}$ para a rota de HDO do 2-etilfenol. 


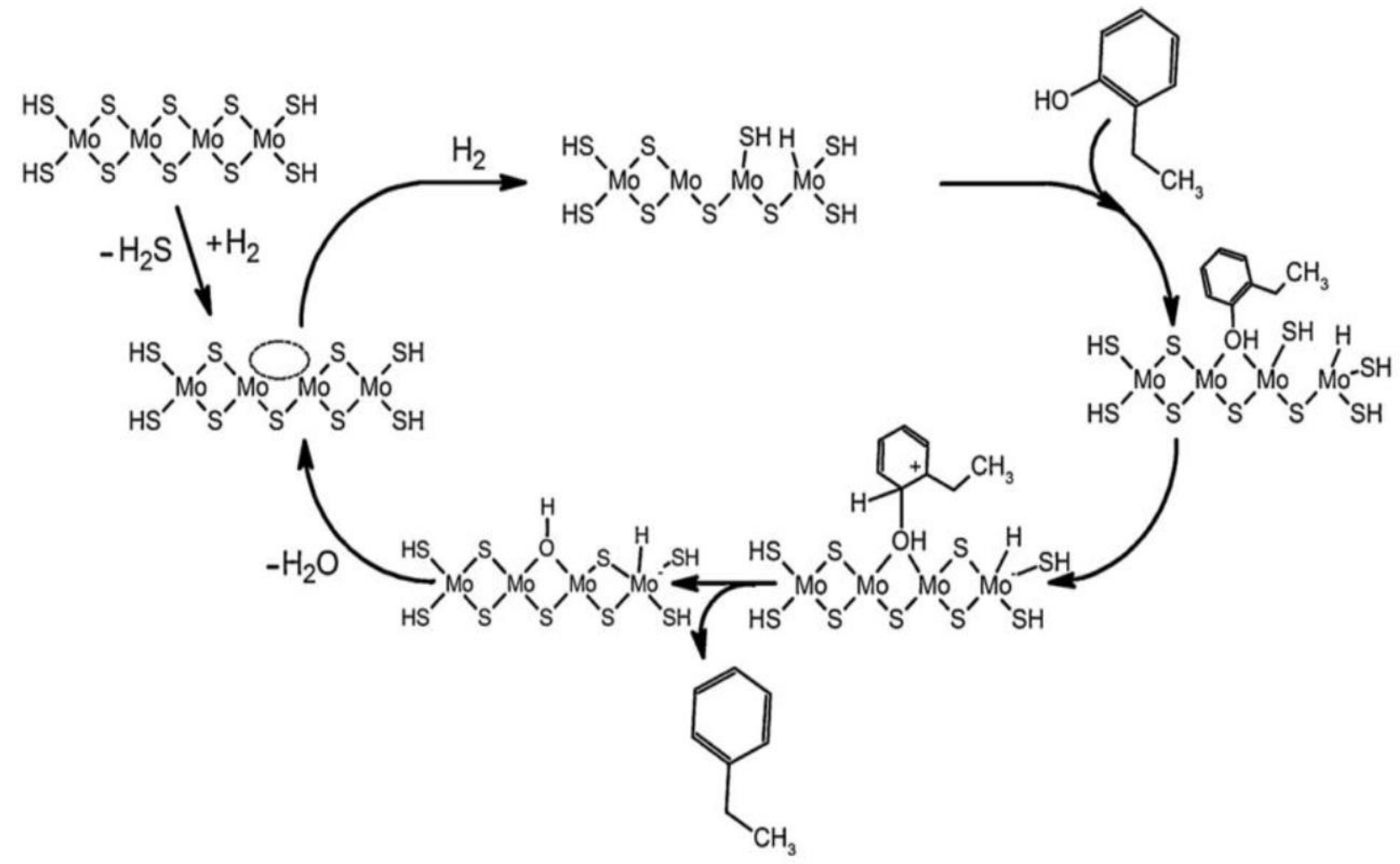

Figura 2.21 - Mecanismo de HDO do 2-etilfenol em um catalisador de Co-MoS2. Adaptada das referências ${ }^{35,} 56$.

A durabilidade e a recuperação do catalisador usado é um fator imprescindível para diminuir os custos do processo. A desativação do catalisador na HDO pode ocorrer quando o oxigênio não é removido com eficiência na formação de água, o que geraria a necessidade de inserção de $\mathrm{H}_{2} \mathrm{~S}$ no meio reacional para regenerar o catalisador. No entanto, tal procedimento poderia acarretar a presença de enxofre no produto, interferindo na qualidade do biocombustível, por se tratar de um elemento poluente. ${ }^{57}$

Finalizando esta revisão, é citado aqui o trabalho de Veriansyah et al. ${ }^{40}$, que compararam a atividade, na HDO de óleos e gorduras vegetais e animais, dos tradicionais catalisadores de sulfetos de NiMo e CoMo suportados em $\mathrm{Al}_{2} \mathrm{O}_{3} \mathrm{com}$ a de outros catalisadores: $\mathrm{Pd}$, Pt e $\mathrm{Ru}$ suportados em $\mathrm{Al}_{2} \mathrm{O}_{3}$; $\mathrm{Ni}$ suportado em $\mathrm{Al}_{2} \mathrm{O}_{3}$ $\mathrm{SiO}_{2}$. Os catalisadores de NiMo, $\mathrm{Pd}$ e Ni propiciaram conversões superiores a $90 \%$ (Figura 2.22). 


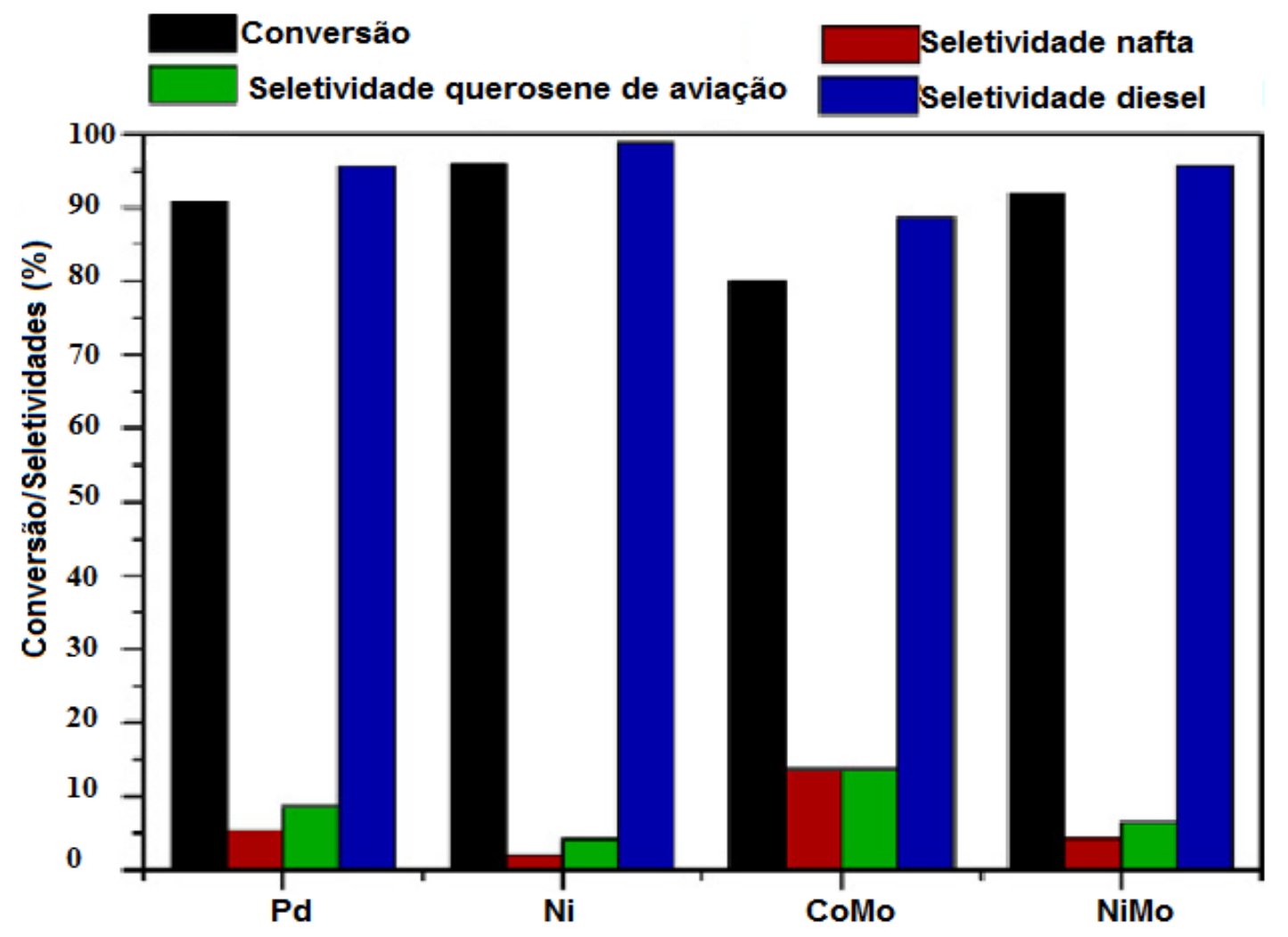

Figura 2.22 - Efeitos do catalisador na conversão e seletividade do processo de HDT do óleo de soja. Adaptada da ref. ${ }^{40}$.

No entanto, apenas os catalisadores na forma de sulfeto propiciaram satisfatória desoxigenação do material, conforme demonstra a tabela 2.4 Os resultados também demonstram que, para os catalisadores de $\mathrm{NiMo}, \mathrm{Pd}$ e $\mathrm{Ni}$, as seletividades para hidrocarbonetos na faixa do diesel foram superiores a $95 \%$ e (Figura 2.22), para n-alcanos, superiores a $80 \%$ (Tabela 2.4).

Tabela 2.4 - Resultados da análise elementar e do teor de n-alcanos dos produtos da HDO do óleo de soja empregando diferentes catalisadores. Adaptada da ref. ${ }^{40}$.

\begin{tabular}{ccccc}
\hline Teor em peso (\%) & Ni & Pd & CoMo & NiMo \\
\hline C & 84,4 & 84,4 & 84,8 & 84,6 \\
$\mathbf{O}$ & 0,5 & 1,0 & $<0,3$ & $<0,3$ \\
H & 15,7 & 14,8 & 15,4 & 15,5 \\
$\mathbf{S}$ & $<0,3$ & $<0,3$ & $<0,3$ & $<0,3$ \\
n-alcano & 82,9 & 87,9 & 52,3 & 82,1 \\
\hline
\end{tabular}


Já para o catalisador de CoMo, houve considerável formação de compostos nas faixas de nafta e querosene (em torno de 13\% cada); além disso, o conteúdo de n-alcanos foi pouco superior a $50 \%$. Assim, conclui-se que os sulfetos de NiMo e CoMo propiciam uma desoxigenação mais efetiva e, enquanto o NiMo leva essencialmente à formação de hidrocarbonetos lineares na faixa do óleo diesel, o segundo propicia considerável ocorrência de produtos de craqueamento e, principalmente, de isomerização. 


\section{CAPÍTULO 3 - MATERIAIS E MÉTODOS}

\subsection{Materiais utilizados}

\subsubsection{Reagentes}

Os materiais empregados durante a realização deste trabalho foram:

- Dodecano - (Sigma-Aldrich, 98\% de pureza);

- Ácido láurico - (Sigma-Aldrich, 98\% de pureza);

- Ácido oleico P.A - Reagente analítico - (Synth);

- Sulfato de magnésio anidro - (Vetec, 98 - 102\% de pureza);

- Dissulfeto de carbono - $\mathrm{CS}_{2}$;

- Hidrogênio - (White Martins, 99,99\% de pureza);

- Nitrogênio - (White Martins, 99,99\% de pureza);

- Óleo de coco virgem orgânico - (Dr. Orgânico);

- Óleo de soja comercial - (Soya).

É válido destacar que os óleos de coco e de soja foram utilizados como adquiridos, sem qualquer purificação ou secagem prévia.

\subsubsection{Catalisador}

$\mathrm{O}$ catalisador $\mathrm{NiMoS}_{2} / \mathrm{Al}_{2} \mathrm{O}_{3}$, na forma de pellets, empregado nas reações de hidrodesoxigenação (HDO), foi gentilmente fornecido pela Petrobras.

\subsection{Métodos}

\subsubsection{Caracterização do catalisador}

A caracterização do catalisador foi realizada utilizando as análises de difração de raios $X(D R X)$; adsorção/dessorção de $\mathrm{N}_{2}$; termodessorção (TPD) de piridina e fluorescência de raios $X$. Nos tópicos seguintes, será feita uma descrição sucinta de cada método de análise. 


\subsubsection{Difração de raios $X$}

A análise de difração de raios $X$ foi realizada em um difratômetro Rigaku, modelo Miniflex 300. No método adotado, o ângulo $\theta$ foi varrido de 0 a $50^{\circ} \mathrm{com}$ incrementos de $0,05^{\circ}$ e uma velocidade de $1 \% \mathrm{~min}$.

\subsubsection{Adsorção/dessorção de $\mathrm{N}_{2}$}

As isotermas de adsorção/dessorção de $\mathrm{N}_{2}(77.3 \mathrm{~K})$ foram obtidas em um equipamento Quantachrome NovaWin 2200e. A área superficial foi determinada pelo método BET (Brunauer, Emmet e Teller). O volume de microporos e a área superficial de microporos foram obtidas pelo método $t$-plot. $O$ volume de mesoporos foi determinado subtraindo-se, do volume de $\mathrm{N}_{2}$ líquido adsorvido a uma pressão relativa de $0,98\left(\mathrm{~V}_{0,98}\right)$, o volume de microporos. Portanto, nessa abordagem, $\mathrm{V}_{0,98}$ é considerado como a soma dos volumes de micro e mesoporos.

\subsubsection{Termodessorção (TPD) de piridina}

A análise de Dessorção a Temperatura Programada de Piridina foi realizada para verificar a acidez do suporte utilizado nos catalisador bifuncional. Para isso, realizou-se a adsorção de piridina gasosa no catalisador e a posterior análise por termogravimetria (TG). Para a adsorção da piridina, a amostra (entre 40 e $50 \mathrm{mg}$ ) foi acondicionada em cadinho de platina, que foi colocado em uma cápsula de porcelana de baixa profundidade. A cápsula foi colocada em um forno tubular da Thermolyne (Modelo F21135) com seu tubo conectado a um fluxo de $\mathrm{N}_{2}$. Foram feitas conexões que permitiam que $\circ \mathrm{N}_{2}$ fosse injetado diretamente para dentro do tubo ou então passasse primeiramente sobre piridina líquida. À saída do tubo, conectou-se um recipiente contendo solução $0,1 \mathrm{~mol} \mathrm{~L}^{-1}$ de $\mathrm{HCl}$ para neutralizar o excesso de base (Figura 3.1).

A amostra foi primeiramente tratada a $300^{\circ} \mathrm{C}$, sob fluxo de $\mathrm{N}_{2}\left(100 \mathrm{~mL} \mathrm{~min}^{-1}\right)$, por $1 \mathrm{~h}$. Depois, o sistema foi resfriado para $100^{\circ} \mathrm{C}$ e permitiu-se a passagem do $\mathrm{N}_{2}$ pela piridina por $1 \mathrm{~h}$, de forma que esta fosse arrastada para dentro do tubo. Por 
fim, a amostra foi exposta a um fluxo de $\mathrm{N}_{2}$, a $100^{\circ} \mathrm{C}$, por $2 \mathrm{~h}$, para remoção da piridina fisicamente adsorvida.

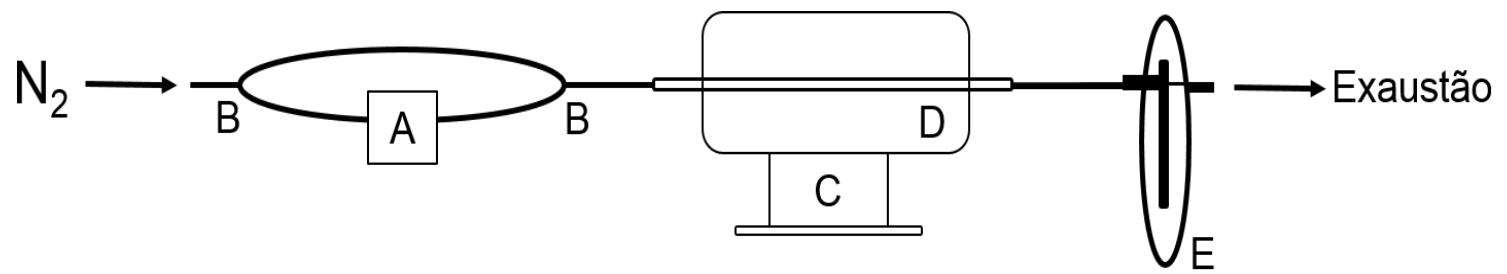

Figura 3.1 - Esquema do sistema de adsorção gasosa simultânea. Onde A - reservatório com piridina (I), B - conexões, $\mathrm{C}$ - forno tubular, $\mathrm{D}$ - tubo de vidro com amostras e $\mathrm{E}$ - recipiente com $\mathrm{HCl}$ $0,1 \mathrm{~mol} \mathrm{~L}^{-1}$.

A amostra contendo a piridina quimicamente adsorvida foi analisada por TG em um equipamento da Shimadzu, modelo DTG-60. A temperatura foi variada de 25 a $600^{\circ} \mathrm{C}$, com uma razão de aquecimento de $10 \% \mathrm{~min}$, sob atmosfera de $\mathrm{N}_{2}$. Com a finalidade de determinar apenas a perda de massa relativa à dessorção da piridina, excluindo-se eventuais perdas devido à decomposição do suporte, foi obtida também a curva TG da amostra do catalisador sem piridina adsorvida.

A determinação da quantidade total de sítios ácidos se deu da seguinte forma: em primeiro lugar, foi desconsiderada a perda de massa entre a temperatura ambiente e $130^{\circ} \mathrm{C}$, pois se trata de perda de água e de possível piridina fisissorvida. A perda de massa (em porcentagem) entre 130 e $600^{\circ} \mathrm{C}$ foi determinada, e foi feita a subtração do valor obtido para a amostra antes e após o tratamento com piridina $\left(m_{(\%)}\right)$. O resultado dessa subtração foi então considerado para o cálculo da quantidade total de sítios ácidos (SA, em $\mu \mathrm{mol} \mathrm{g}^{-1}$ ), a partir da massa molar da piridina $\left(79,1 \mathrm{~g} \mathrm{~mol}^{-1}\right)$, segundo a equação I.

$$
\mathrm{SA}\left(\mu \mathrm{mol} . \mathrm{g}^{-1}\right)=\frac{\left(\frac{\mathrm{m}(\%)}{79,1 \mathrm{~g} \cdot \mathrm{mol}^{-1}}\right) \cdot 10^{6} \quad \text { (equação I) }}{100}
$$

\subsubsection{Fluorescência de Raios X}

Os teores de $\mathrm{Ni}$ e Mo presentes no catalisador foram determinados por meio da técnica de fluorescência de raios $X$ utilizando um espectrômetro Shimadzu 
modelo EDX-720p, sendo a radiação responsável pela excitação dos elementos na amostra proveniente de um tubo de ródio ( $\lambda \mathrm{Rh} \mathrm{K} \alpha=0,6147 \AA$ ).

\subsubsection{Reações de hidropirólise e hidrodesoxigenação (HDO)}

As reações de hidropirólise não catalítica e de hidrodesoxigenação (HDO) com o catalisador $\mathrm{NiMoS}_{2} / \mathrm{Al}_{2} \mathrm{O}_{3}$ foram realizadas em um reator cilíndrico de aço inox com volume interno de $100 \mathrm{~cm}^{3}$. Na execução de cada reação, este é vedado por meio de um anel de bronze e cola adesiva utilizada para vedação de motores a diesel, e fechado com seis parafusos. Acoplado ao cilindro, há uma válvula para inserção de gases e um manômetro para controle da pressão. Há, ainda, uma entrada para o termopar, que permite o monitoramento da temperatura interna. Em torno dos tubos de conexão do manômetro e da válvula para inserção de gases, há um sistema de resfriamento. Como fonte de calor foi utilizada uma resistência confeccionada de acordo com as medidas exatas do reator.

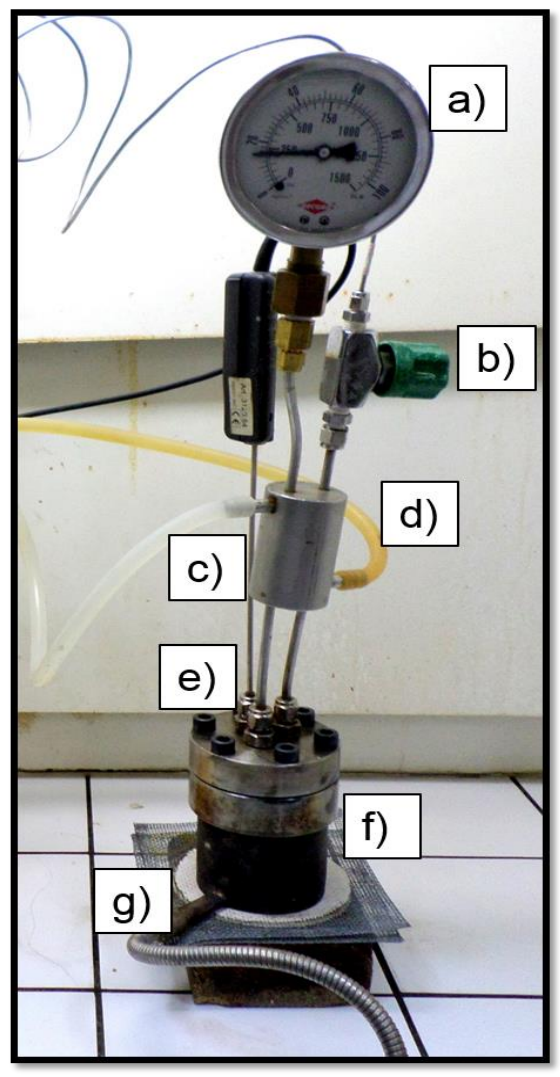

Figura 3.2 - Imagens do reator empregado. a) manômetro, b) válvula de entrada e saída de gás, c) sistema de resfriamento, d) sistema de circulação de água, e) entrada do termopar, f) corpo do reator e g) resistência. 
Embora o catalisador já tenha sido fornecido pela Petrobras na forma sulfetada, antes de cada reação em que ele foi empregado foi realizada sua ressulfetação in situ, com a finalidade de assegurar que todo o metal de fato estivesse na forma de sulfeto, visando a maximizar a atividade catalítica. De forma simplificada, $0,80 \mathrm{~g}$ do catalisador (equivalente a $10 \%$ da massa do reagente principal) foram colocadas no reator e o sistema purgado com $\mathrm{N}_{2(\mathrm{~g})}$ por cerca de 15 minutos. A seguir, $0,50 \mathrm{~mL}$ de $\mathrm{CS}_{2}$ foram rapidamente injetados no reator (para ele não volatilizar), que foi selado e pressurizado com 30 bar de $\mathrm{H}_{2}$. $\mathrm{O}$ sistema foi aquecido a $400^{\circ} \mathrm{C}$ e assim mantido por 1 hora. Na sequência, o sistema foi resfriado até a temperatura ambiente, os gases formados liberados e o reator novamente purgado com $\mathrm{N}_{2}(\mathrm{~g})$ por cerca de 15 minutos.

Para a realização das reações, 10,0 g do substrato (composto modelo ou óleo vegetal) foram adicionados ao reator purgado com $\circ \mathrm{N}_{2(g)}$ e, quando o caso, contendo o catalisador ressulfetado. O sistema foi então purgado e pressurizado com $\mathrm{H}_{2(\mathrm{~g})}$ a 30 ou 15 bar. Após selado, o reator foi aquecido até a temperatura desejada $\left(280,340\right.$ ou $\left.400^{\circ} \mathrm{C}\right)$.

Via de regra, as reações foram realizadas empregando-se uma pressão inicial de $\mathrm{H}_{2}\left(\mathrm{p}_{\mathrm{i}}\right)$ de 30 bar. Apenas para as reações com ácido láurico a $340{ }^{\circ} \mathrm{C}$ empregouse também uma $p_{i}$ de 15 bar. Ao longo do texto, onde a $p_{i}$ não for especificada, deve-se considerar 30 bar.

Durante o período de aquecimento do reator, houve variação da pressão em função: (i) principalmente do aumento da energia cinética do $\mathrm{H}_{2(\mathrm{~g})}$ inicialmente adicionado; (ii) da formação de novos gases a partir da liberação de voláteis (presentes nas amostras ou formados como produtos de decomposição); (iii) consumo de $\mathrm{H}_{2}$ devido às reações ocorridas.

De maneira geral, o comportamento da pressão e da temperatura, durante o período inicial das reações de $\mathrm{HDO}$ catalisadas pelo $\mathrm{NiMoS}_{2} / \mathrm{Al}_{2} \mathrm{O}_{3}$ pode ser sistematizado conforme os gráficos da Figura 3.3. Percebe-se que a pressão aumentou durante o aquecimento e estabilizou após atingido o patamar de temperatura. É válido destacar, também, que o tempo de reação foi contado sempre a partir do momento em que esse patamar foi atingido. 

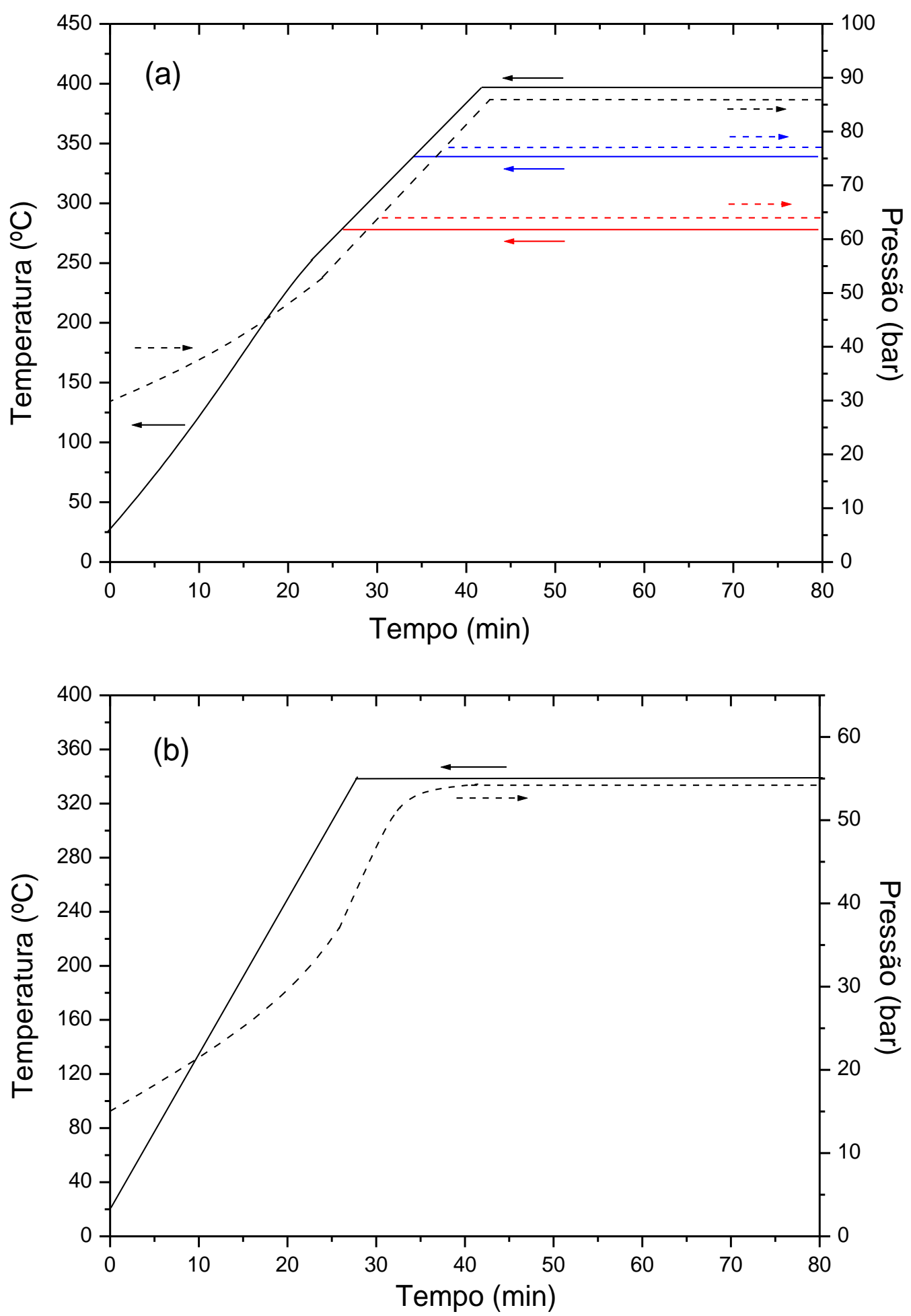

Figura 3.3 - Sistematização do comportamento da temperatura e da pressão durante o período inicial das reações de HDO com pi igual a (a) 30 bar e (b) 15 bar.

Após o término da reação, o sistema foi resfriado e o produto líquido recolhido e secado com sulfato de magnésio anidro. Então, a mistura foi centrifugada para separação do sulfato e também de partículas sólidas (coque) eventualmente formadas durante a reação. 


\subsubsection{Caracterização dos produtos de desoxigenação}

Os produtos líquidos das reações foram analisados por Cromatografia Gasosa em um equipamento GC-17a da Shimadzu equipado com uma coluna de polidimetilsiloxano Rtx - 5MS (30 m; 0,25mm). Como detector, usou-se um Espectrômetro de Massa Shimadzu modelo GCMS-QP5050A. No método utilizado, a temperatura inicial foi $60{ }^{\circ} \mathrm{C}$ (5 min) e, a final, de $250{ }^{\circ} \mathrm{C}(10 \stackrel{\circ}{\circ} \mathrm{C} / \mathrm{min} ; 15 \mathrm{~min})$. A identificação dos compostos foi realizada (i) por meio da interpretação dos espectros de massa gerados e sua comparação aos da biblioteca digital Wiley Library CLASS5000 , também da Shimadzu, e (ii) do cálculo dos índices de Kovats ${ }^{58}$, com posterior comparação a dados disponíveis na literatura.

Além disso, os produtos foram também caracterizados por meio da determinação do índice de acidez (método AOCS Cd-3d-63-O) e de análises de espectroscopia na região do infravermelho com Transformada de Fourier (FTIR), empregando-se o método de Reflectância Total Atenuada (ATR - Attenuated Total Reflectance), em um equipamento Shimadzu IR Prestige-21 usando um detector DLATGS. 


\section{CAPÍTULO 4 - RESULTADOS E DISCUSSÕES}

\subsection{Caracterização do catalisador}

A Figura 4.1.a apresenta o difratograma de Raios-X do catalisador $\mathrm{NiMoS} 2 / \mathrm{Al}_{2} \mathrm{O}_{3}$. Seu aspecto é similar ao verificado na literatura para esse tipo de material, conforme exemplificado na Figura 4.1.b, com destaque para os picos relativos à $\gamma-\mathrm{Al}_{2} \mathrm{O}_{3}$ centrados em 46,0 e 66,5 .

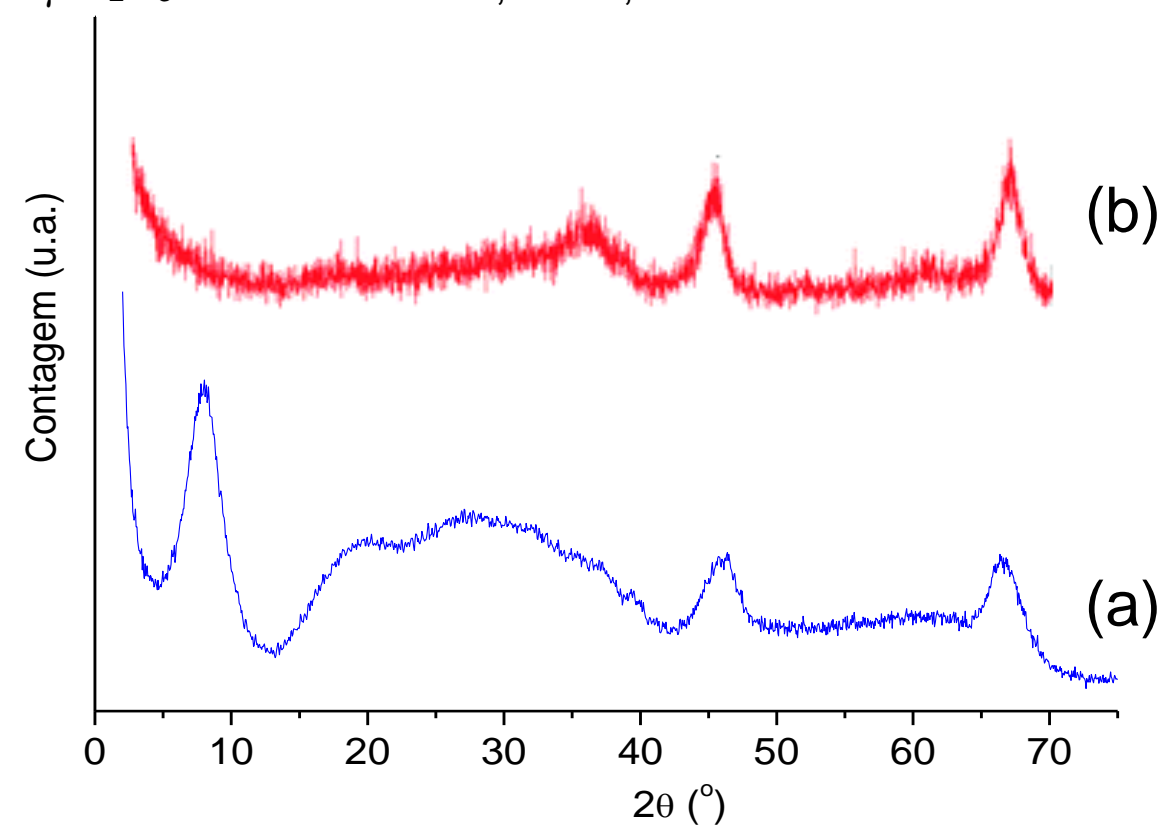

Figura 4.1 - Difratogramas de Raios-X do catalisador $\mathrm{NiMoS}_{2} / \mathrm{Al}_{2} \mathrm{O}_{3}$ (a) utilizado no presente trabalho e de (b) obtido da literatura. ${ }^{59}$

Na Figura 4.2 é apresentada a isoterma de adsorção de $\mathrm{N}_{2}$ para o catalisador $\mathrm{NiMoS}_{2} / \mathrm{Al}_{2} \mathrm{O}_{3}$, que se assemelha às isotermas do tipo IV na classificação da IUPAC (International Union of Pure and Applied Chemistry), característica de sólidos mesoporosos. $\mathrm{Na}$ isoterma, a quantidade adsorvida aumenta acentuadamente em pressões relativas mais elevadas, o que demonstra a existência de mesoporos de tamanho mais avantajado que são preenchidos por capilaridade. A presença dos mesoporos é confirmada pela ocorrência de uma histerese do tipo H3. O volume de microporo foi próximo de zero e, o de mesoporos, $0,21 \mathrm{~cm} / \mathrm{g}$, respectivamente, com áreas superficiais de micro e mesoporos de 15 e 114 m²/g, respectivamente. 


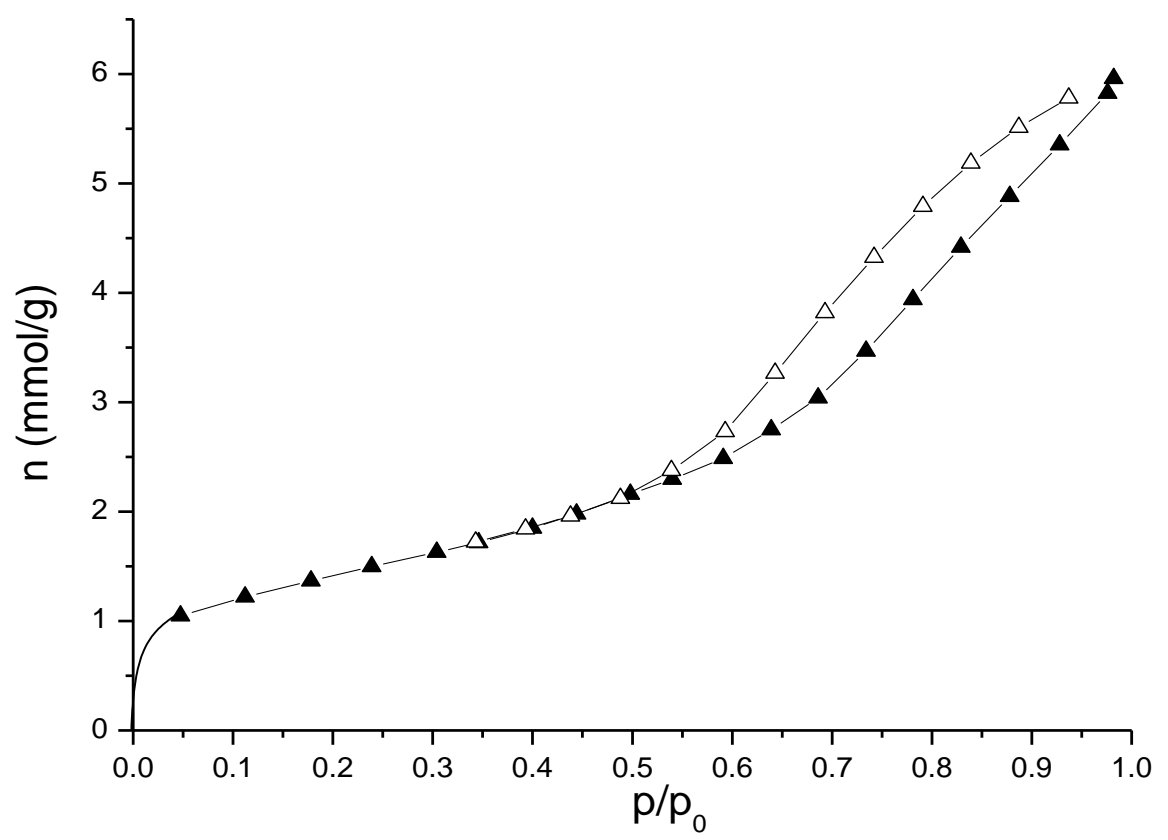

Figura 4.2 - Isotermas de adsorção/dessorção de $\mathrm{N}_{2}$ do catalisador $\mathrm{NiMoS}_{2} / \mathrm{Al}_{2} \mathrm{O}_{3}$. $\boldsymbol{\Delta}$ = adsorção; $\Delta=$ dessorção.

Tabela 4.1 - Propriedades texturais do suporte utilizado.

\begin{tabular}{cccccc}
\hline \multirow{2}{*}{ Amostra } & \multicolumn{2}{c}{ Área Superficial $\left(\mathbf{m}^{2} \cdot \mathbf{g}^{-1}\right)$} & \multicolumn{3}{c}{ Volume de Poros $/\left(\mathbf{c m}^{3} \cdot \mathbf{g}^{-1}\right)$} \\
\cline { 2 - 6 } & $\mathrm{BET}^{\mathrm{a}}$ & Microporos & $\mathrm{V}_{0,98^{\mathrm{c}}}$ & Microporos $^{\mathrm{b}}$ & Mesoporos \\
\hline $\mathrm{NiMoS}_{2} / \mathrm{Al}_{2} \mathrm{O}_{3}$ & 114 & 15 & 0,21 & 0 & 0,21 \\
\hline
\end{tabular}

amétodo BET (Brunauer, Emmet e Teller), ${ }^{b}$ método $t-p l o t,{ }^{c}$ volume de $\mathrm{N}_{2}$ líquido adsorvido em $\mathrm{p} / \mathrm{p}_{0}=$ 0,98 .

Por fim, é válido destacar que as análises de Fluorescência de Raios $X$ demonstraram que os teores de $\mathrm{Ni}$ e Mo no catalisador $\mathrm{NiMoS}_{2} / \mathrm{Al}_{2} \mathrm{O}_{3}$ foram de 4,5 e $19,3 \%$, respectivamente, enquanto as análises de termodessorção programada de piridina apontam para uma acidez de $1.153 \mu \mathrm{mol} / \mathrm{g}$ de amostra, sendo o valor encontrado para os sítios ácidos fortes de $956 \mu \mathrm{mol} / \mathrm{g}$, evidenciando uma característica de elevada acidez para a alumina. 


\subsection{Reações envolvendo compostos modelo}

Conforme reportado na seção 2.1.2, os óleos e gorduras vegetais e animais consistem em complexas misturas de moléculas. Assim, com o intuito de facilitar o entendimento das reações ocorridas durante o processo de hidrodesoxigenação e a caracterização dos produtos obtidos, inicialmente foram realizados testes empregando-se como material de partida compostos modelo. Além disso, com o emprego de compostos modelo, evita-se a interferência de impurezas, tornando possível avaliar mais claramente a resposta dos compostos às condições reacionais. Os compostos modelo escolhidos foram o ácido láurico (ácido dodecanoico) e o ácido oleico (ácido octadecanoico), os quais presumidamente geram, por meio de hidrodesoxigenação, moléculas representativas da composição do querosene e do óleo diesel, respectivamente, além do dodecano.

\subsubsection{Reações de compostos modelo sem o emprego de catalisador}

Inicialmente, foram realizadas reações sem a adição de catalisador, com o objetivo de identificar os efeitos simplesmente térmicos, separando-os daqueles decorrentes da presença do catalisador $\mathrm{NiMoS}_{2} / \mathrm{Al}_{2} \mathrm{O}_{3}$. Para essas reações não catalisadas, empregou-se o ácido láurico e, também, o dodecano. O objetivo do emprego do dodecano foi permitir elucidar o efeito do grupo carboxila dos ácidos sobre o caminho seguido pela reação.

\subsubsection{Hidropirólise não catalítica do dodecano}

A Figura 4.3 apresenta o cromatograma do produto da reação do dodecano, sem a adição de catalisador, a $400^{\circ} \mathrm{C}$, por $3 \mathrm{~h}$. Em primeiro lugar, constata-se que a conversão do dodecano foi pequena, o que resultou na presença de um pico muito intenso em torno de $19 \mathrm{~min}$, relativo a ele. 


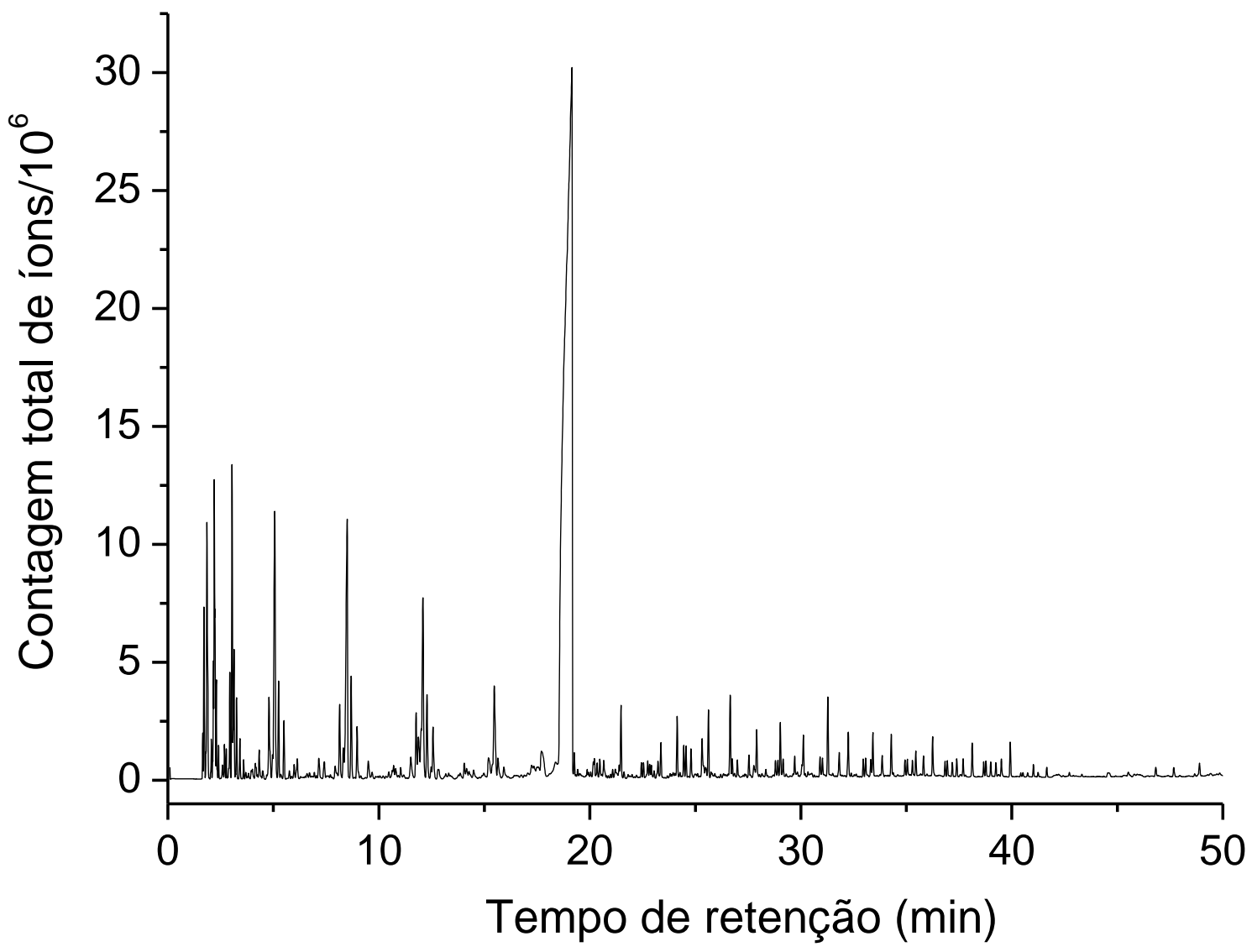

Figura 4.3 - Cromatograma (GC/MS) do produto da reação do dodecano em ausência de catalisador, a $400 \stackrel{\circ}{\circ}$, por $3 \mathrm{~h}$.

Todavia, foram identificados, em pequena proporção, produtos de craqueamento (compostos com número de átomos de carbono abaixo de $12 ;<\mathrm{C}_{12}$ ), os quais aparecem em tempos de retenção inferiores ao do dodecano devido ao fato de que, quanto menor a massa molar de um alcano, menos intensas as interações que ele é capaz de estabelecer com a fase estacionária. É verificada também a ocorrência, em proporção ainda menor, de produtos com massa molar superior à do dodecano (>C $\mathrm{C}_{12}$ ), que aparecem em tempos de retenção mais elevados.

$\mathrm{Na}$ Figura 4.4, é apresentada a região do cromatograma correspondente aos alcanos $\leq \mathrm{C} 11$, o que facilita a observação dos picos de baixa intensidade. Entre os produtos de craqueamento, de maneira geral foram identificados os alcanos lineares (butano, pentano, hexano...) e os alquenos correspondentes, principalmente os alquenos terminais (1-buteno, 1-penteno...) e os isômeros cis e trans dos 2alquenos, sendo que as intensidades dos picos relativos aos alquenos apresentam menor intensidade do que o do alcano correspondente. 


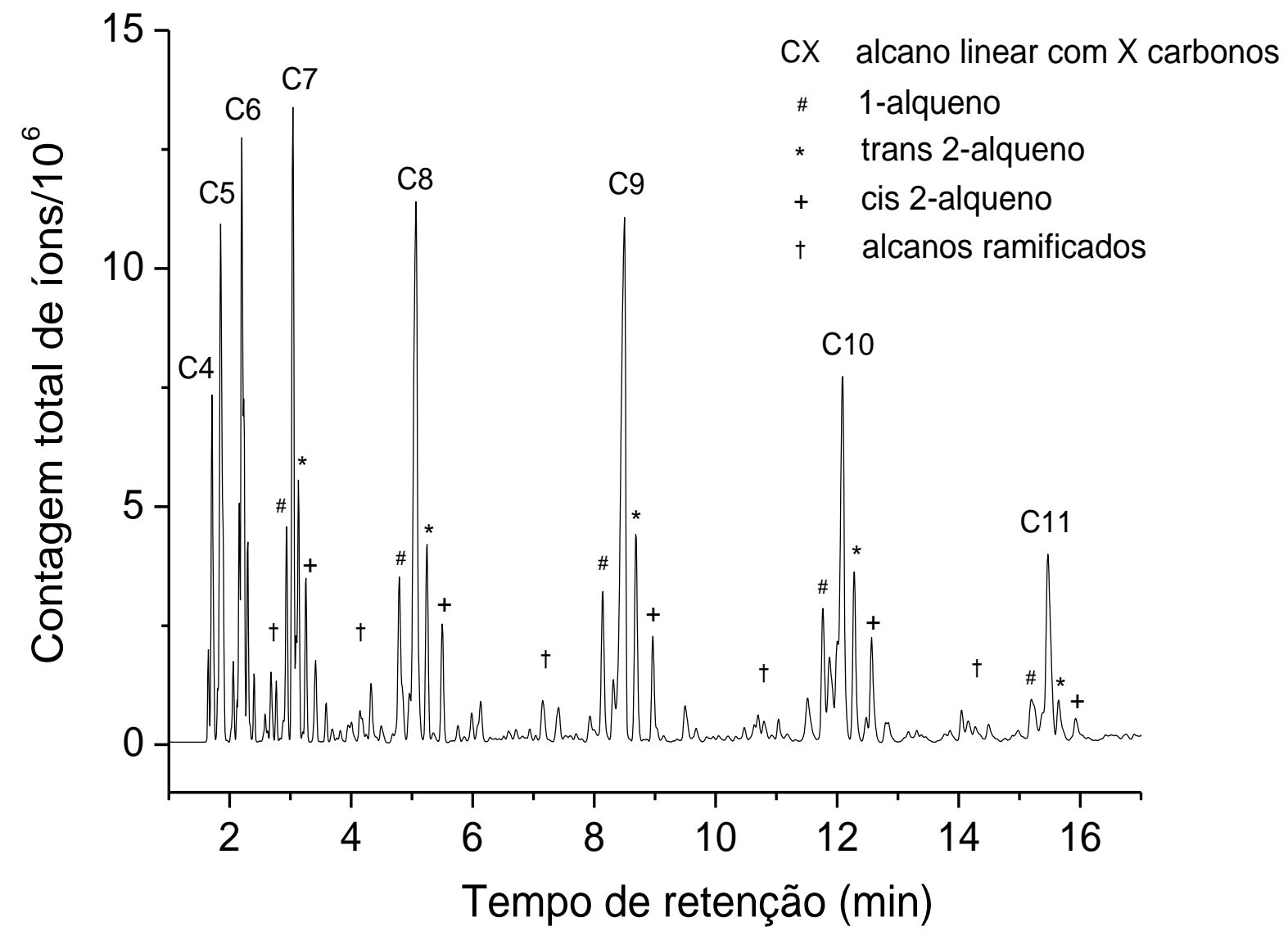

Figura 4.4 - Região relativa aos compostos $\leq \mathrm{C} 11$ do cromatograma (GC/MS) do produto da reação do dodecano em ausência de catalisador a $400 \stackrel{\circ}{\circ}$ por $3 \mathrm{~h}$.

As observações acima permitem propor a ocorrência do seguinte conjunto de reações durante o hidrotratamento do dodecano em ausência de catalisador. Em primeiro lugar, tem-se o craqueamento térmico das cadeias (rompimento de uma ligação $C-C$ ), com a formação de dois radicais 1-alquil:
(i)
$\mathrm{C}_{12} \mathrm{H}_{26}$ $\left(\mathrm{C}_{12}\right.$ $\mathrm{C}_{12-\mathrm{x}} \mathrm{H}_{2}$ $2(12-\mathrm{x})+1) \cdot+\left(\mathrm{C}_{\mathrm{x}} \mathrm{H}_{2 \mathrm{x}+1}\right) \cdot$ $(\mathrm{x}=1,2, \ldots, 6)$ dodecano radicais 1 -alquil

Em seguida, os radicais formados podem se estabilizar seguindo pelo menos quatro caminhos distintos. 
a) Em primeiro lugar, eles podem captar um hidrogênio radicalar do meio para formar um n-alcano $<\mathrm{C} 12$ :

(ii) $\mathrm{RC}_{2}+\mathrm{H} \cdot \longrightarrow \mathrm{RCH}_{3} \quad \mathrm{R}=\mathrm{H}$ ou um grupo n-alquil

1-alquil alcano

b) Em segundo lugar, radicais com pelo menos dois átomos de carbono $(\geq \mathrm{C} 2)$ podem perder um hidrogênio para formar o alqueno terminal (1-alqueno):

(iii)

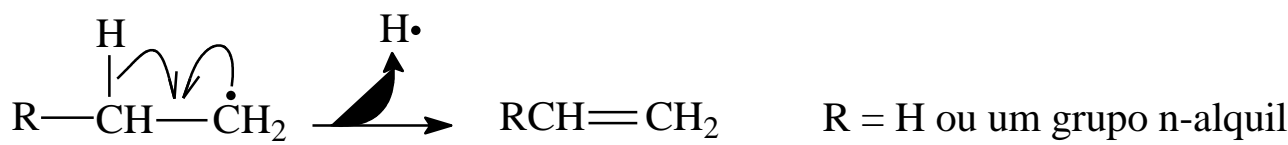

1-alquil 1-alqueno

c) Os radicais também podem reagir com um alqueno formado por meio da reação (iii), gerando um alcano ou alqueno, normais ou ramificados, conforme abaixo descrito.

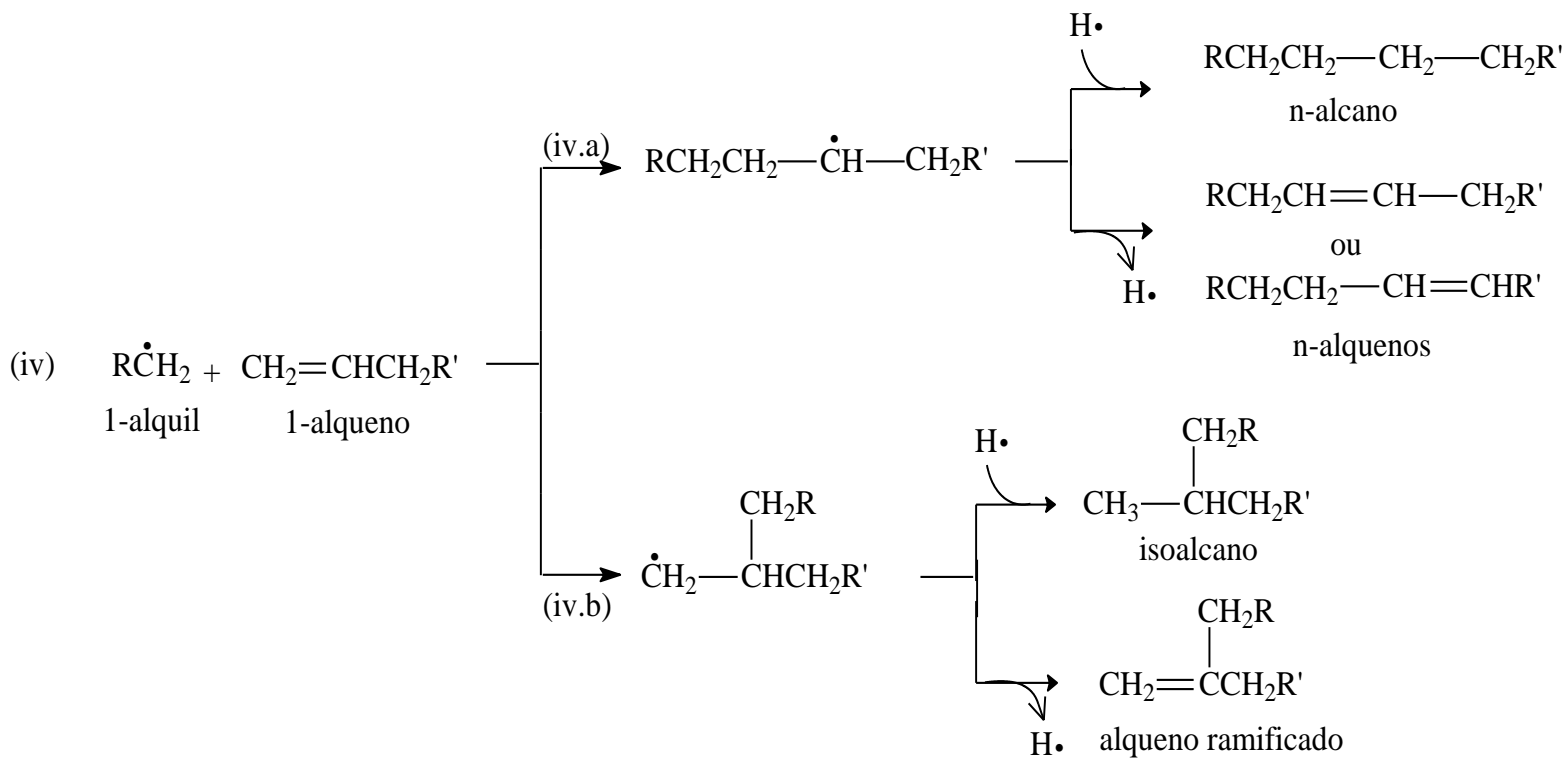

A formação dos compostos normais via reação (iv.a) envolve um radical intermediário mais estável (radical secundário) do que aquele envolvido na formação dos compostos ramificados via reação (iv.b) (radical primário), de forma que a formação dos compostos normais teria preferência sobre a dos ramificados. 
d) Finalmente, dois diferentes radicais podem acoplar-se para formar um n-alcano.

(v) $\quad \dot{\mathrm{C}}_{2}+\dot{\mathrm{C}} \mathrm{H}_{2} \mathrm{R}^{\prime} \longrightarrow \mathrm{RCH}_{2}-\mathrm{CH}_{2} \mathrm{R}^{\prime}$

radicais 1-alquil n-alcano

As reações (iv) e (v) são capazes de explicar a ocorrência das espécies >C12 cujos picos são observados no cromatograma.

A ocorrência de alquenos internos pode ser atribuída a eventuais rearranjos dos radicais 1 -alquil para formar radicais isoalquil:

(vi)
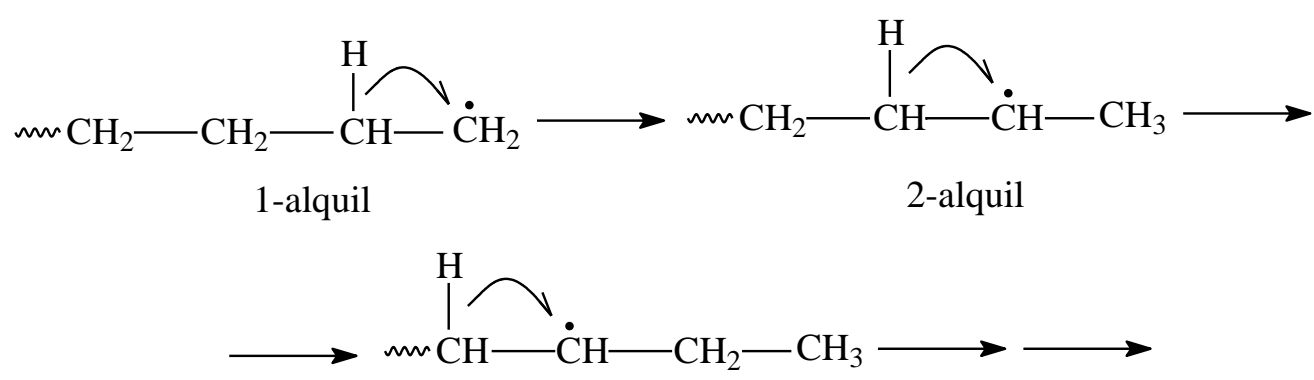

3-alquil

Embora os rearranjos possam levar o elétron desemparelhado para qualquer átomo de carbono da cadeia, substancial estabilização é verificada apenas quando se tem a migração do carbono terminal para o carbono adjacente, pois o radical deixa de ser primário para ser secundário. Assim, acredita-se que os principais radicais gerados por rearranjo sejam os radicais 2-alquil. Ao estabilizar-se pela perda de um hidrogênio, um radical 2-alquil pode gerar um alqueno terminal ou um 2-alqueno. Assim, seria possível explicar por que, entre as várias possibilidades de alquenos internos, os isômeros cis e trans dos 2-alquenos predominam.

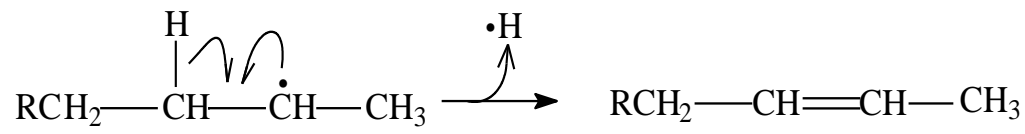

2-alquil

cis/trans-2-alqueno

$\mathrm{R}=\mathrm{H}$ ou um grupo n-alquil

(viii)

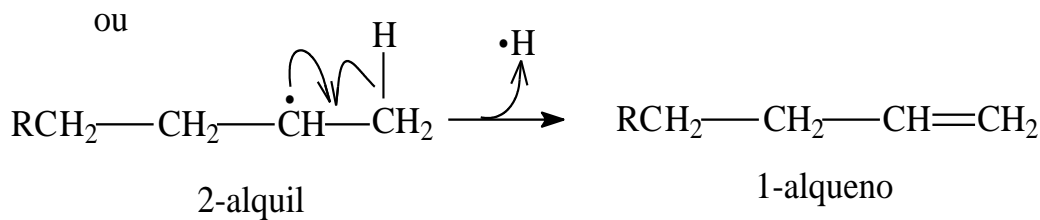


É válido ressaltar que alquenos internos podem ser formados também a partir de radicais isoalquil gerados pelo rompimento de ligações $\mathrm{C}-\mathrm{H}$, conforme descrito na reação (ix). Entretanto, nesse caso não haveria motivos para a ocorrência preferencial de 2-alquenos em detrimento aos demais alquenos internos, visto que 0 rompimento da ligação $\mathrm{C}-\mathrm{H}$ pode ocorrer com similar probabilidade em qualquer carbono secundário ao longo da cadeia. Assim, acredita-se que os radicais isoalquil envolvidos na formação de alquenos internos sejam aqueles gerados principalmente a partir do rearranjo dos radicais 1 -alquil, e não a partir do rompimento de ligações $\mathrm{C}-\mathrm{H}$.
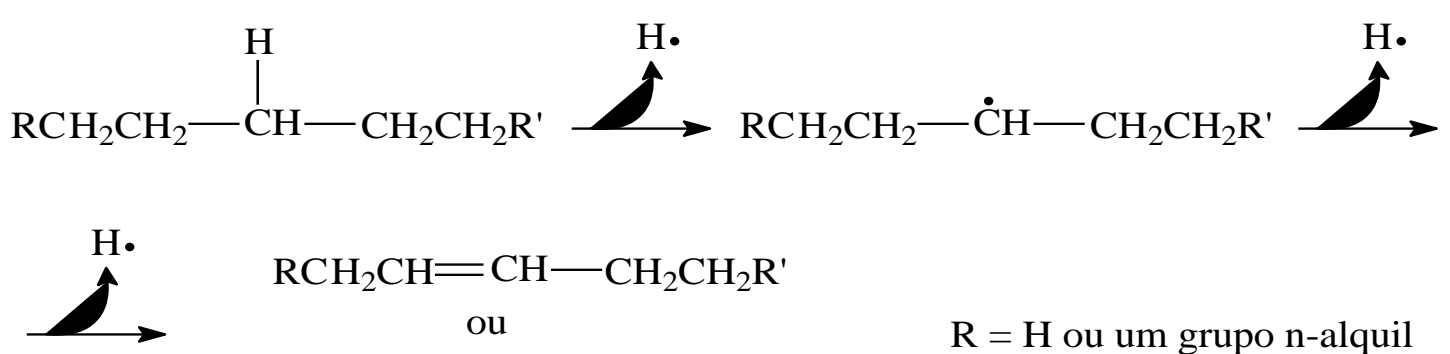

$$
\begin{aligned}
& \mathrm{RCH}_{2} \mathrm{CH}=\mathrm{CH}-\mathrm{CH}_{2} \mathrm{CH}_{2} \mathrm{R}^{\prime} \\
& \text { ou } \\
& \mathrm{RCH}_{2} \mathrm{CH}_{2}-\mathrm{CH}=\mathrm{CHCH}_{2} \mathrm{R}^{\prime}
\end{aligned}
$$

Conforme sugerido nas reações acima, a formação das duplas ligações é uma forma de estabilização dos radicais formados a partir do craqueamento térmico das cadeias, o que explica o fato de que não foi observada considerável presença de alquenos $\mathrm{C} 12$.

Finalizando, é válido destacar a presença, ainda, de uma pequena proporção de alcanos ramificados, principalmente metilalcanos. Compostos ramificados podem ser formados a partir da reação (iv.b); entretanto, conforme já discutido, essa reação não é favorecida. Outra possibilidade seria que os compostos ramificados fossem formados a partir da migração de um radical metil, conforme descrito em (x); porém, nesse mecanismo, um radical secundário dá origem a um radical primário, razão pela qual a migração não é favorecida. Assim, resta justificada a baixa ocorrência de alcanos ramificados no produto da reação em questão.

(x)

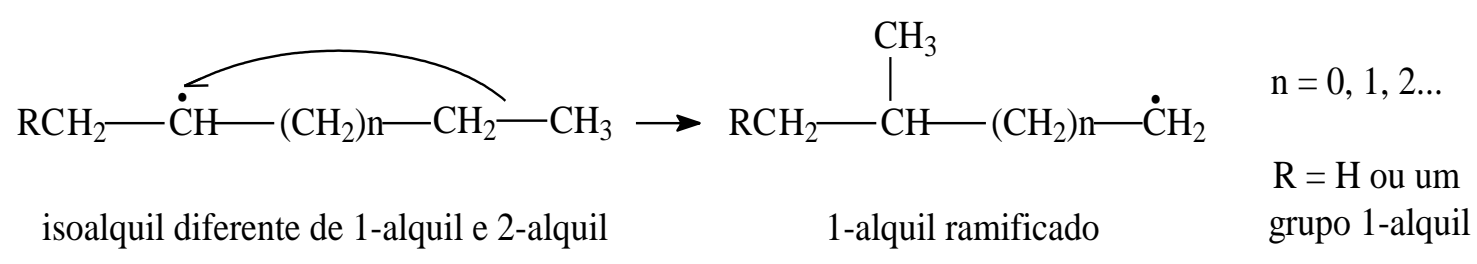




\subsubsection{Hidropirólise não catalítica do ácido láurico}

A Figura 4.5 apresenta o cromatograma do produto da reação de hidropirólise do ácido láurico, a $400{ }^{\circ} \mathrm{C}$, em ausência de catalisador. Percebe-se que, em comparação à reação do dodecano nas mesmas condições (seção anterior), houve uma conversão muito mais elevada do composto de partida, com a formação de um número muito maior de produtos de reação. Ainda assim, parte do ácido permaneceu na mistura mesmo após $3 \mathrm{~h}$ de reação, gerando um pico em 28,85 min (ver secção 4.7.2).

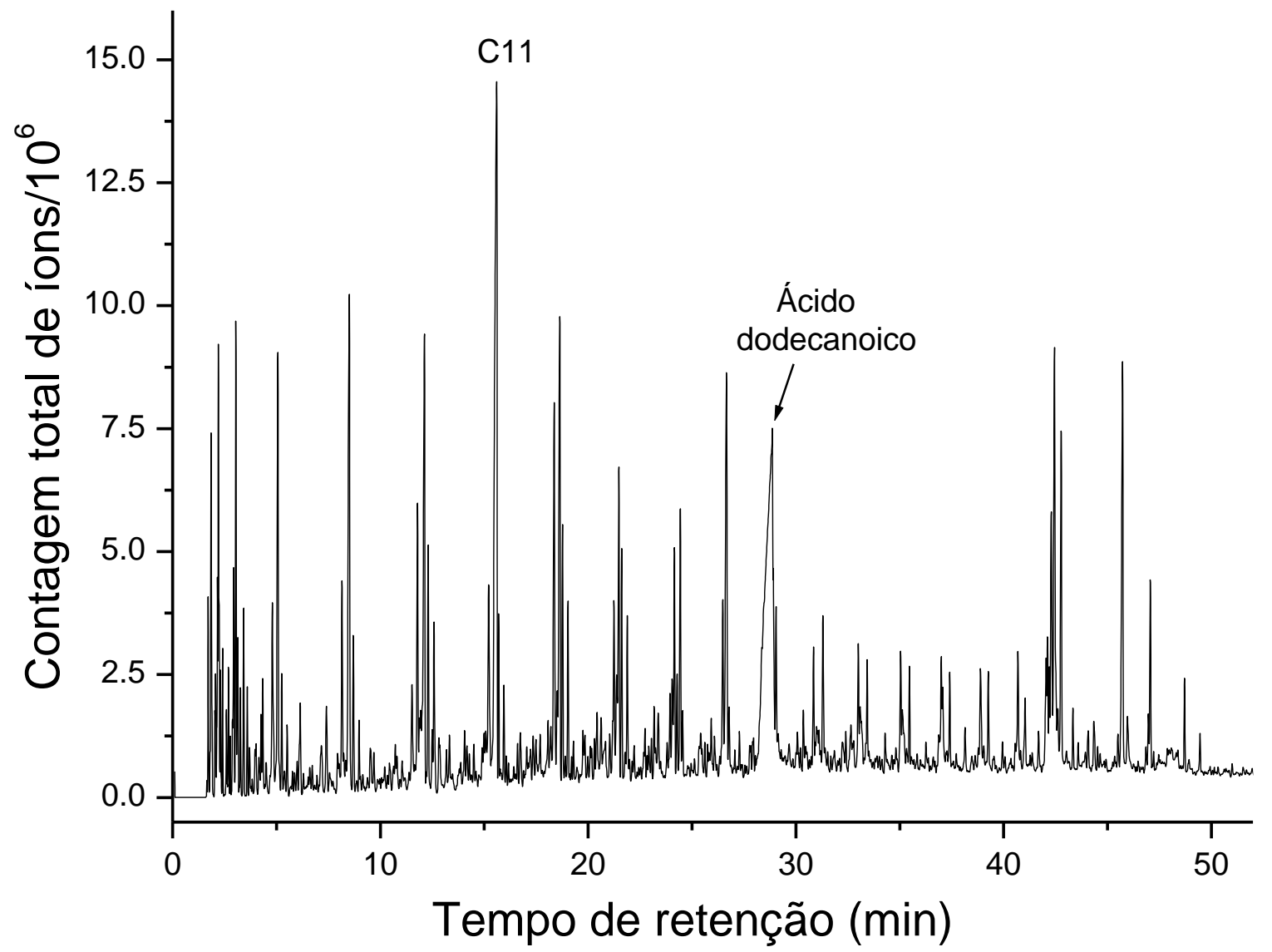

Figura 4.5 - Cromatograma (GC/MS) do produto da reação do ácido dodecanoico (láurico) em ausência de catalisador, a $400^{\circ} \mathrm{C}$, por $3 \mathrm{~h}$.

A maior susceptibilidade do ácido dodecanoico (ácido láurico) às reações de hidropirólise pode ser atribuída à facilidade com que as ligações $\mathrm{O}-\mathrm{H}$ e HO-C sofrem cisão homolítica para formar os radicais alcanoxil e alcanoil, respectivamente, de acordo com as reações (xi) e (xii). 
(xi)

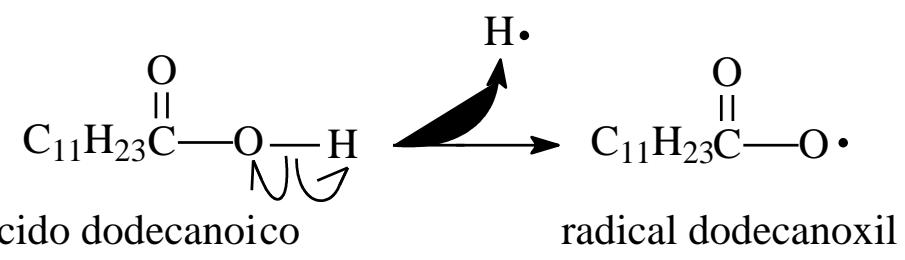

(xii)

$\mathrm{C}_{11} \mathrm{H}_{23} \stackrel{\mathrm{O}}{\mathrm{C}}-\frac{\mathrm{O}}{\mathrm{O}}-\mathrm{H}$ ácido láurico

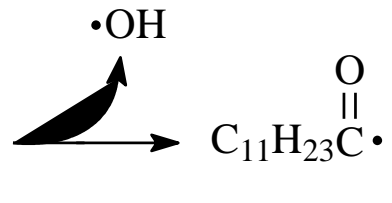

radical dodecanoil

Essa susceptibilidade pode ser explicada pela estabilização, por ressonância, dos radicais formados:

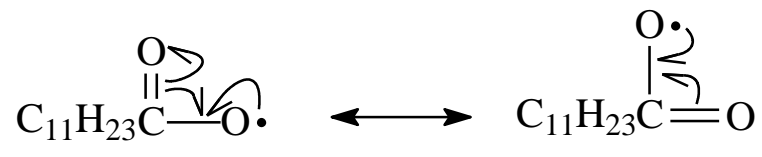

radical dodecanoxil

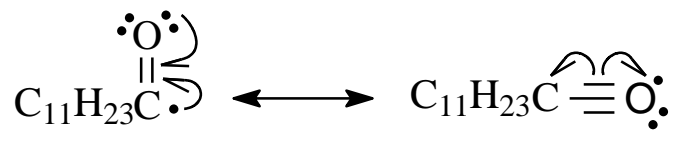

radical dodecanoil

Os radicais dodecanoxil e dodecanoil podem perder $\mathrm{CO}_{2}$ e $\mathrm{CO}$, respectivamente, para formar o radical 1-undecil:

(xiii)

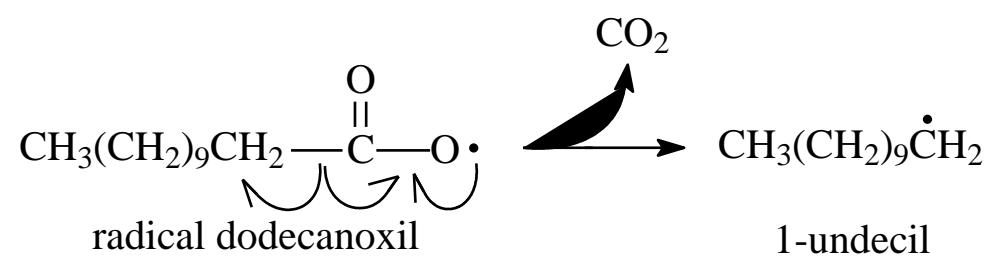

(xiv)

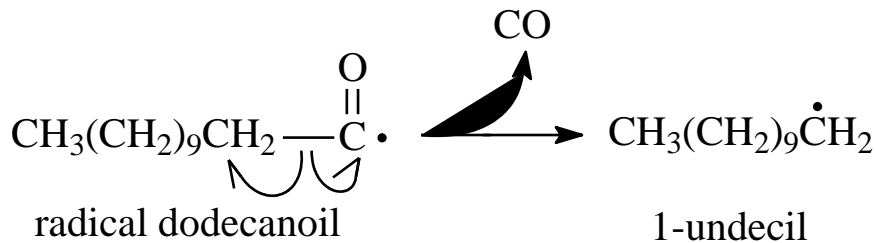


Na sequência, o radical 1-undecil pode estabilizar-se por meio das reações já descritas de (ii) a (x). O principal composto gerado é o undecano, o que ocorre de acordo reação (ii), sendo o pico desse composto localizado em 15,60 min. Além disso, foram formadas quantidades relativamente elevadas de undecenos, principalmente o 1-undeceno e os isômeros cis e trans do 2-undeceno (ver seção 4.7.1), o que está em acordo com as reações (iii), (iv), (viii) e (ix).

Com a finalidade de permitir a observação com um maior nível de detalhamento, a Figura 4.6 apresenta apenas a região do cromatograma referente a tempos de retenção mais elevados. Nela, evidencia-se a presença de um pico relativo ao dodecanal, em 24,44 min (ver seção 4.7.3), o que demonstra que, além de perder $\mathrm{CO}$, o radical dodecanoil também pode ser estabilizado pela captação de um hidrogênio radicalar conforme a reação:

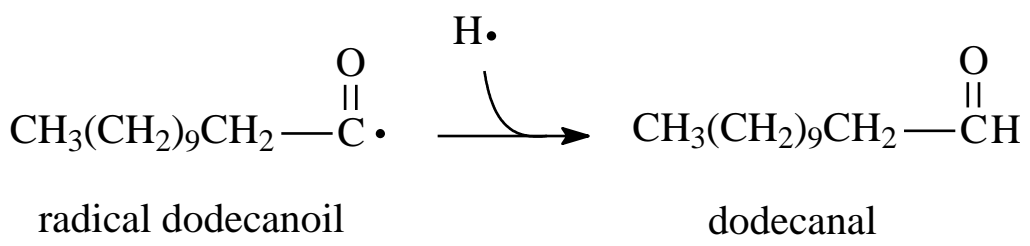

É válido destacar que, mesmo o dodecanal contendo apenas doze átomos de carbono, seu pico aparece em um tempo de retenção próximo ao do tetradecano (24,15 min), perfazendo um índice de Kovats de 1412. Isso ocorre devido a dois fatores: em primeiro lugar, à simples presença do átomo de oxigênio na molécula, o qual contribui para as Forças de London; em segundo lugar, o oxigênio confere um caráter polar à molécula, aumentando ainda mais sua capacidade de estabelecer interações de van der Waals com a fase estacionária da coluna cromatográfica. 


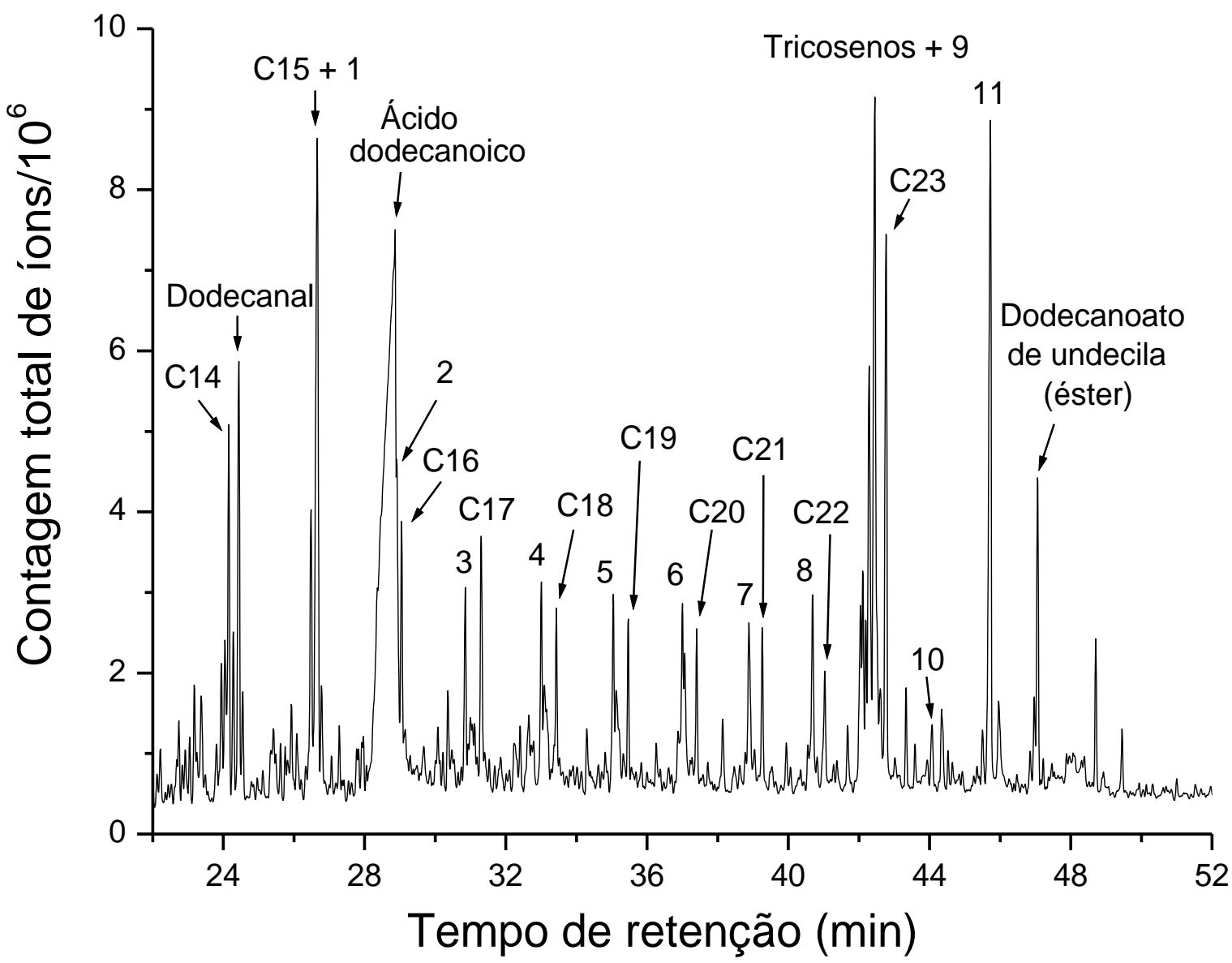

Figura 4.6 - Região relativa aos alcanos $\geq \mathrm{C} 14$ do cromatograma (GC/MS) do produto da reação do ácido dodecanoico (ácido láurico) em ausência de catalisador a $400{ }^{\circ} \mathrm{C}$ por $3 \mathrm{~h}$. Os picos relativos aos n-alcanos com $X$ átomos de carbono são identificados por $\mathrm{CX}$; as cetonas, pelo número correspondente à Tabela 4.2.

Além do pico do dodecanal, tem-se a ocorrência de uma série de picos referentes às alquilundecilcetonas (ver seção 4.7.4), os quais são listados na Tabela 4.2. É válido destacar que, assim como verificado para o dodecanal, as cetonas apresentam tempos de retenção similares aos dos alcanos com dois átomos de carbono a mais. Assim, o pico da 2-tridecanona se encontra sobreposto ao pico do pentadecano (em torno de 26,6 $\mathrm{min}$ ), o pico da 4-tetradecanona (28,91 $\mathrm{min}$ ) se encontra muito próximo ao pico do hexadecano (29,05 min), e assim por diante. 
Tabela 4.2 - Relação de alquilundecilcetonas identificadas no cromatograma (GC/MS) do produto da reação do ácido láurico em ausência de catalisador a $400 \stackrel{\circ}{C}$ por $3 \mathrm{~h}$.

\begin{tabular}{cllc}
\hline Pico & \multicolumn{1}{c}{ Nomenclatura } & \multicolumn{1}{c}{ Estrutura } & $\begin{array}{c}\text { Tempo de } \\
\text { retenção (min) }\end{array}$ \\
\hline 1 & metilundecilcetona (2-tridecanona) & $\mathrm{C}_{11} \mathrm{H}_{23} \mathrm{C}(=\mathrm{O}) \mathrm{CH}_{3}$ & 26,61 \\
2 & etilundecilcetona (3-tetradecanona) & $\mathrm{C}_{11} \mathrm{H}_{23} \mathrm{C}(=\mathrm{O}) \mathrm{C}_{2} \mathrm{H}_{5}$ & 28,91 \\
3 & propilundecilcetona (4-pentadecanona) & $\mathrm{C}_{11} \mathrm{H}_{23} \mathrm{C}(=\mathrm{O}) \mathrm{C}_{3} \mathrm{H}_{7}$ & 30,85 \\
4 & butilundecilcetona (5-hexadecanona) & $\mathrm{C}_{11} \mathrm{H}_{23} \mathrm{C}(=\mathrm{O}) \mathrm{C}_{4} \mathrm{H}_{9}$ & 33,01 \\
5 & pentilundecilcetona (6-heptadecanona) & $\mathrm{C}_{11} \mathrm{H}_{23} \mathrm{C}(=\mathrm{O}) \mathrm{C}_{5} \mathrm{H}_{11}$ & 35,04 \\
6 & hexilundecilcetona (7-octadecanona) & $\mathrm{C}_{11} \mathrm{H}_{23} \mathrm{C}(=\mathrm{O}) \mathrm{C}_{6} \mathrm{H}_{13}$ & 37,00 \\
7 & heptilundecilcetona (8-nonadecanona) & $\mathrm{C}_{11} \mathrm{H}_{23} \mathrm{C}(=\mathrm{O}) \mathrm{C}_{7} \mathrm{H}_{15}$ & 38,89 \\
8 & octilundecilcetona (9-eicosanona) & $\mathrm{C}_{11} \mathrm{H}_{23} \mathrm{C}(=\mathrm{O}) \mathrm{C}_{8} \mathrm{H}_{17}$ & 40,69 \\
9 & nonilundecilcetona (10-eneicosanona) & $\mathrm{C}_{11} \mathrm{H}_{23} \mathrm{C}(=\mathrm{O}) \mathrm{C}_{9} \mathrm{H}_{19}$ & $*$ \\
10 & decilundecilcetona (11-docosanona) & $\mathrm{C}_{11} \mathrm{H}_{23} \mathrm{C}(=\mathrm{O}) \mathrm{C}_{10} \mathrm{H}_{21}$ & 44,07 \\
11 & diundecilcetona (12-tricosanona) & $\mathrm{C}_{11} \mathrm{H}_{23} \mathrm{C}(=\mathrm{O}) \mathrm{C}_{11} \mathrm{H}_{23}$ & 45,73 \\
\hline
\end{tabular}

*Sobreposto aos picos referentes aos tricosenos.

Conforme se pode observar, as cetonas identificadas apresentam sempre o grupo dodecanoil, $\mathrm{C}_{11} \mathrm{H}_{23} \mathrm{C}(=\mathrm{O})$, o que sugere que elas resultem do acoplamento entre o radical correspondente e um radical 1 -alquil formado no meio, conforme abaixo indicado.

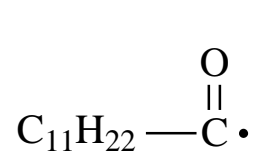<smiles>[R]C(C)C</smiles><smiles>[R]CC(=O)CCC</smiles>
$\mathrm{R}=\mathrm{H}$ ou um grupo 1-alquil radical dodecanoil alquilundecilcetona

Conforme discutido anteriormente, o principal radical alquil formado na hidropirólise do ácido láurico é o 1-undecil (reações (viii) e (ix)), o que explica por que a diundecilcetona é a cetona cujo pico apresenta, de longe, maior intensidade.

(xvii)

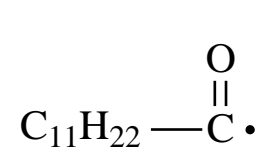

$$
\mathrm{C}_{11} \mathrm{H}_{23} \bullet
$$

radical dodecanoil

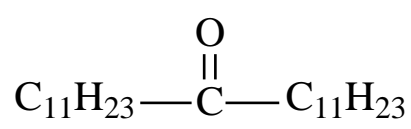

diundecilcetona 
Os radicais 1-alquil $<\mathrm{C} 11$, que dão origem às demais cetonas cujos picos apresentam intensidade bem menor, podem ser gerados a partir da cisão de ligações $C-C$ nas diversas moléculas presentes no meio, a exemplo das reações que ocorrem durante a hidropirólise do dodecano, conforme discutido na seção anterior. Além de acoplar-se a um radical dodecanoil para formar as alquilundecildetonas, esses radicais podem estabilizar-se para formar alcanos e alquenos $<\mathrm{C} 11$, de acordo com as reações (ii), (iii), (iv), (vii) e (viii). De fato, a Figura 4.7 demonstra que, entre os produtos de craqueamento, mais uma vez predominam os alcanos e os respectivos 1-alquenos e 2-alquenos (cis e trans), conforme descrito pelas citadas reações. Ainda, esses radicais poderiam sofrer reações de acoplamento com outros radicais ou alquenos presentes no meio, o que explicaria a ocorrência de grande parte dos alcanos $\geq \mathrm{C} 12$ (ver Figura 4.6).

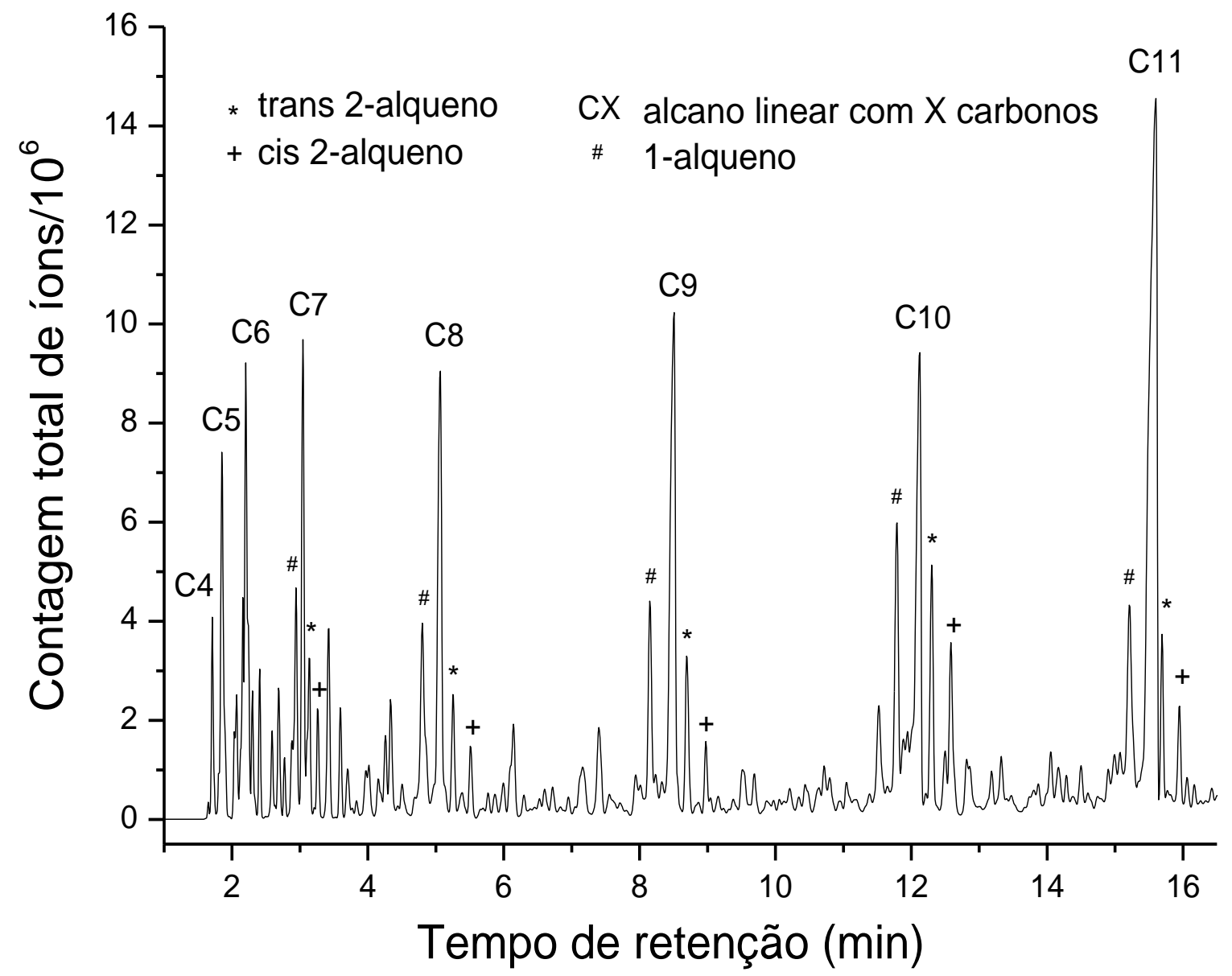

Figura 4.7 - Região relativa aos compostos $<\mathrm{C} 11$ do cromatograma (GC/MS) do produto da reação do ácido dodecanoico (láurico) em ausência de catalisador a $400 \stackrel{\circ}{\circ} \mathrm{C}$ por $3 \mathrm{~h}$. 
Além dos picos do dodecanal e da série de alquilundecilcetonas, também se destaca, no cromatograma em apreço, um pico que foi atribuído ao éster dodecanoato de undecila (ver discussão na seção 4.7.5). A formação deste éster seria explicada de maneira muito similar à da diundecilcetona; entretanto, em vez de um radical dodecanoil, seria um radical dodecanoxil, gerado conforme a reação (xi), que se acoplaria a um radical 1-undecil:

(xviii)

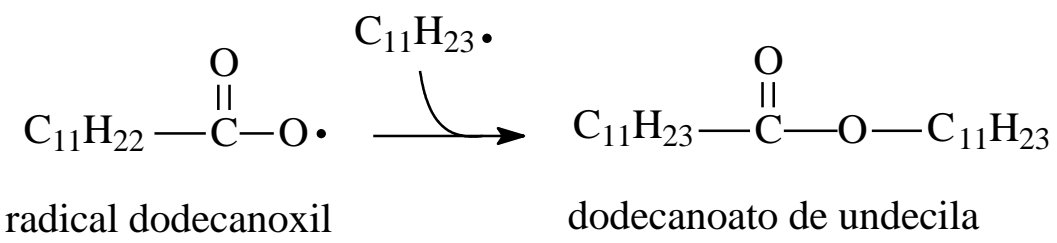

Outro aspecto que se destaca na região correspondente a tempos de retenção mais elevados é a presença de picos bastante intensos referentes a alcanos e alquenos com 23 átomos de carbono (tricosano e tricosenos). A explicação mais trivial para a formação de tricosano e tricosenos seria de que eles fossem formados a partir do acoplamento de uma espécie contendo 11 átomos de carbonos (que, conforme já visto, são formados com relativa intensidade no meio) com outra contendo 12 átomos de carbono. As possibilidades seriam:

a) um radical 1-undecil com um radical 1-dodecil, segundo modelo proposto pela reação (v);

b) um radical 1-undecil com uma molécula de 1-dodeceno ou de um radical 1-dodecil com uma molécula de 1-undeceno, segundo proposto pela reação (iv.a).

Portanto, para haver destacada formação de compostos C23, seria necessária uma proeminente geração tanto de radicais 1-undecil quanto 1-dodecil (seja para atuarem diretamente, seja para formarem 1-undeceno ou 1-dodeceno, respectivamente). Entretanto, nesse caso, seria privilegiada, também, a ocorrência de compostos C22 e C24, o que não é verificado.

Assim, a única explicação plausível para tamanho destaque na formação dos alcanos e alquenos C23 é que eles se originem a partir da redução da diundecilcetona que, conforme discutido acima, se forma em relevante proporção devido ao acoplamento dos radicais dodecanoil e 1-undecil (reação xvii)). É claro 
que também as demais alquilundecilcetonas e mesmo o dodecanal também sofreriam este tipo de reação, contribuindo para a formação dos respectivos hidrocarbonetos:

(xix)

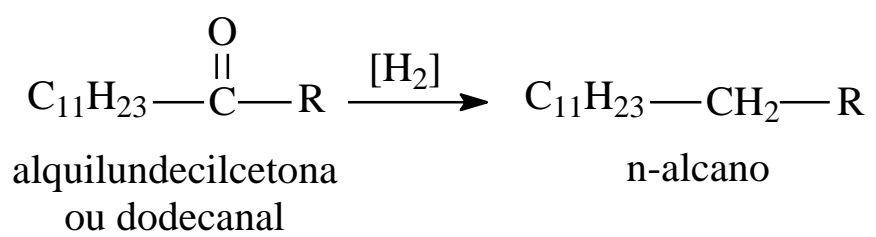

Embora a redução de cetona a alcano não seja uma reação convencional, é válido destacar que a presente reação foi realizada em temperatura elevada e sob alta pressão de $\mathrm{H}_{2}$. Além disso, utilizou-se um reator de aço inox, de forma que as próprias paredes do reator poderiam, eventualmente, atuar como catalisador. Foge ao escopo do presente trabalho, porém, uma investigação detalhada acerca de como se daria o mecanismo dessa reação. É claro que diversas outras reações se passam dentro de um sistema exposto a condições tão severas de temperatura e pressão. Entretanto, o objetivo aqui foi o de compreender as principais reações que ocorrem, de forma que essa compreensão possa contribuir para o entendimento do processo de hidrodesoxigenação, que é o alvo principal do presente trabalho.

\subsection{2 $\mathrm{HDO}$ de compostos modelo catalisada por $\mathrm{NiMoS}_{2} / \mathrm{Al}_{2} \mathrm{O}_{3}$}

Na próxima seção, é apresentada a caracterização, por espectrometria de absorção na região do infravermelho (FTIR), dos ácidos láurico (dodecanoico) e oleico (octadecanoico), o que será útil, na sequência, para o acompanhamento dos resultados das reações. Nas seções 4.2.2.2 e 4.2.2.3 são apresentados então, os resultados referentes à HDO do ácido láurico e do ácido oleico, respectivamente. 


\subsubsection{Caracterização dos ácidos láurico e oleico por FTIR}

Na Figura 4.8 são apresentados os espectros de FTIR do ácido láurico e do ácido oleico. Nos espectros, entre as absorções características de ácidos carboxílicos, destacam-se aquelas referentes à60:
a) deformação axial da ligação $\mathrm{O} \_$— $\mathrm{H}$ em torno de $3500-2500 \mathrm{~cm}^{-1}$ (banda larga);
b) deformação axial $\mathrm{C}=\mathrm{O}$ em $1706 \mathrm{~cm}^{-1}$;
C) deformação angular no plano de $\mathrm{C}-\mathrm{O}-\mathrm{H}$ entre $1440-1395 \mathrm{~cm}^{-1}$;
d) deformação axial de $\mathrm{C}=\mathrm{O}$ 1320-1180 $\mathrm{cm}^{-1}$;
e) deformação angular fora do plano de $\mathrm{O}-\mathrm{H} 930 \mathrm{~cm}^{-1}$.

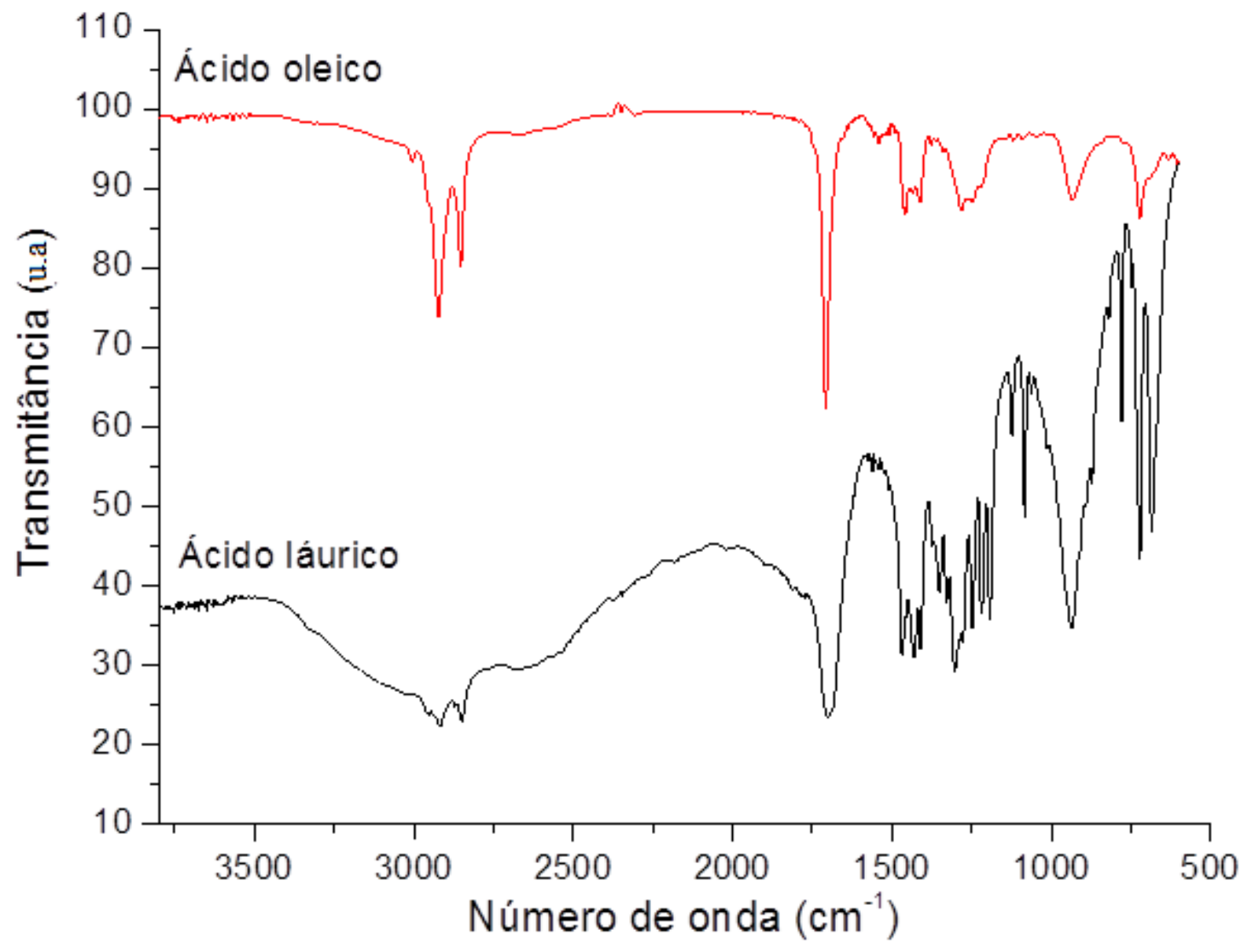

Figura 4.8 - Espectros de FTIR do ácido oleico e do ácido láurico (este último, obtido em pastilha de $\mathrm{KBr})$. 


\subsubsection{HDO do ácido láurico}

Inicialmente, a HDO do ácido láurico em presença do catalisador NiMoS $2 / \mathrm{Al}_{2} \mathrm{O}_{3}$ foi realizada a uma temperatura relativamente elevada, $400{ }^{\circ} \mathrm{C}$, de forma a propiciar uma primeira avaliação acerca da viabilidade de se realizar a desoxigenação do substrato com o sistema reacional empregado (catalisador e reator, principalmente). Os dados da Tabela 4.3 (Entrada 1) demonstram que 0 índice de acidez do produto da reação foi muito próximo de zero, de apenas 0,32 $\mathrm{mg} / \mathrm{g}$. Além disso, no espectro FTIR (Figura 4.9.a), percebe-se a inexistência de picos relativos às absorções características de ácidos carboxílicos (citadas na seção anterior), bem como de qualquer absorção característica de compostos oxigenados. Em vez disso, fazem-se presentes apenas bandas de absorção características de alcanos, a saber, aquelas relativas à ${ }^{60}$ :

a) deformação axial simétrica dos grupos $\mathrm{CH}_{3}$, e $\mathrm{CH}_{2}$ ocorrendo, respectivamente, próximos a 2872 e $2853 \mathrm{~cm}^{-1}$, e ao estiramento assimétrico desses mesmos grupos a 2962 e $2926 \mathrm{~cm}^{-1}$;

b) deformação angular simétrica e assimétrica de $\mathrm{CH}_{2}$, próximos a $1464 \mathrm{~cm}^{-1} \mathrm{e}$ $724 \mathrm{~cm}^{-1}$, respectivamente;

c) deformação angular assimétrica e simétrica de $\mathrm{CH}_{3}$, próximos a $1450 \mathrm{~cm}^{-1} \mathrm{e}$ $1379 \mathrm{~cm}^{-1}$, respectivamente.

Tabela 4.3 - Índices de acidez para as misturas obtidas a partir da HDO do ácido do ácido láurico utilizando o catalisador $\mathrm{NiMoS}_{2} / \mathrm{Al}_{2} \mathrm{O}_{3}$, a diferentes temperaturas, por diferentes períodos de tempo.

\begin{tabular}{cccc}
\hline Entrada & $\mathbf{T}\left({ }^{\circ} \mathbf{C}\right)$ & $\mathbf{t}(\mathbf{h})$ & $\mathbf{I A}^{\mathbf{1}}$ \\
\hline $\mathbf{1}$ & 400 & 1 & 0,32 \\
$\mathbf{2}$ & 340 & 1 & 17,8 \\
$\mathbf{3}$ & 340 & 3 & 0,35 \\
$\mathbf{4}$ & 280 & 3 & 19,0 \\
$\mathbf{5}$ & 280 & 6 & 0,32
\end{tabular}

\footnotetext{
1índice de acidez em miligramas de $\mathrm{KOH}$ gastos por grama de amostra titulada.
} 


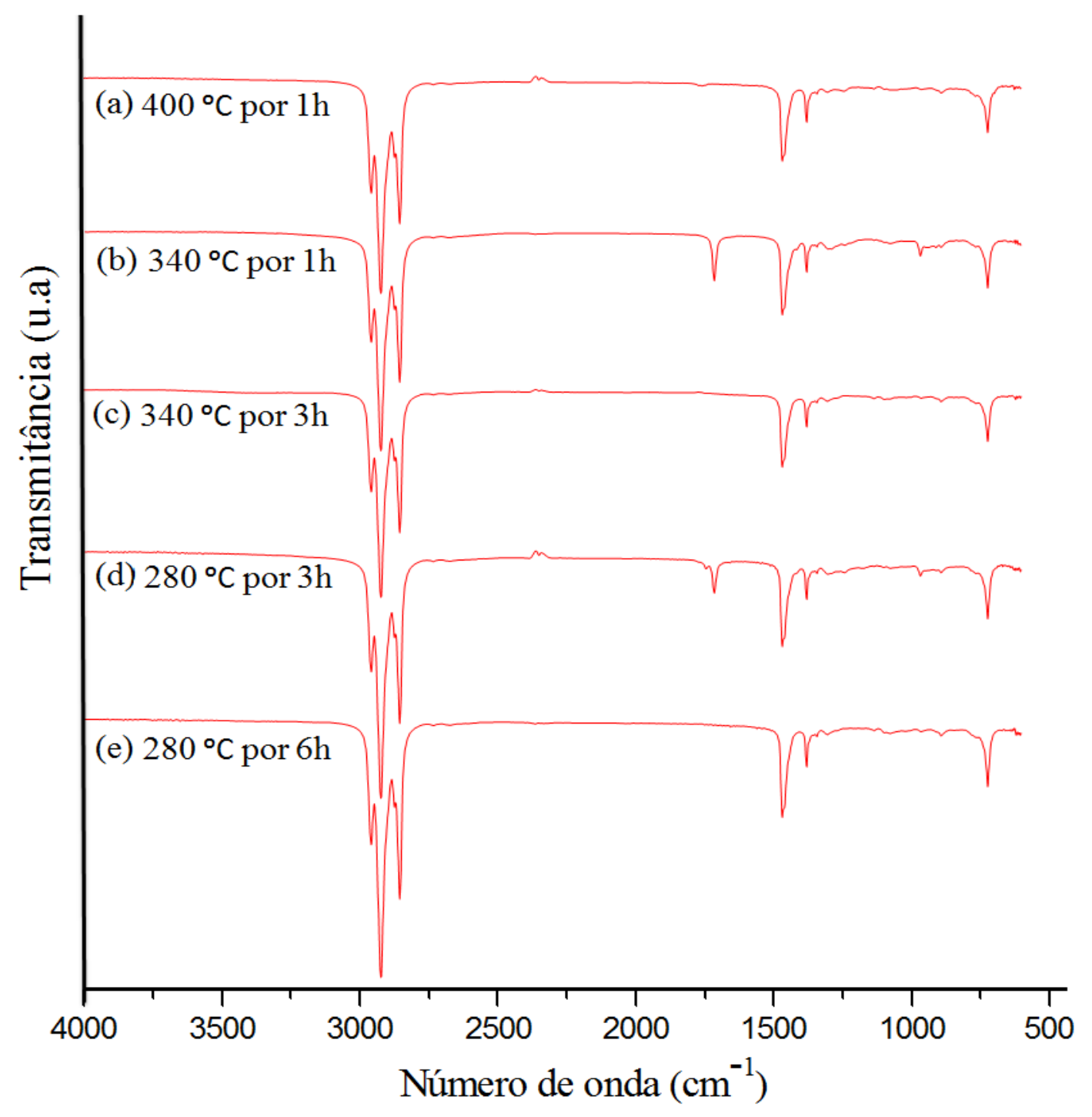

Figura 4.9 - Espectros de FTIR dos produtos da HDO do ácido láurico utilizando o catalisador NiMoS $/ 2 \mathrm{Al}_{2} \mathrm{O}_{3}$, a diferentes temperaturas, por diferentes períodos de tempo: (a) $400^{\circ} \mathrm{C}, 1 \mathrm{~h}$; (b) $340^{\circ} \mathrm{C}$, $1 \mathrm{~h}$; (c) $340^{\circ} \mathrm{C}, 3 \mathrm{~h}$; (d) $280^{\circ} \mathrm{C}, 3 \mathrm{~h}$; (e) $280^{\circ} \mathrm{C}, 6 \mathrm{~h}$.

$\mathrm{Na}$ sequência do trabalho, avaliou-se a possibilidade de realizar a desoxigenação do ácido láurico em temperaturas mais reduzidas, 340 e $280{ }^{\circ} \mathrm{C}$, e a influência disso sobre a composição do produto obtido.

As análises dos espectros FTIR demonstram que, a $340 \stackrel{\circ}{\circ} \mathrm{C}, 1 \mathrm{~h}$ não foi suficiente para propiciar uma eficiente desoxigenação do ácido, pois verifica-se a ocorrência de uma banda referente à deformação axial $\mathrm{C}=\mathrm{O}$, próxima a $1712 \mathrm{~cm}^{-1}$ (Figura 4.9.b). Além disso, o índice de acidez medido foi relativamente alto, de 17,8 $\mathrm{mgKOH} / \mathrm{g}$ (Tabela 4.3/Entrada 2). 
Visto que $1 \mathrm{~h}$ propiciou uma desoxigenação apenas parcial a $340{ }^{\circ} \mathrm{C}$, o tempo de reação foi aumentado para $3 \mathrm{~h}$, sendo que a análise do produto obtido demonstra que esse tempo foi suficiente para que 0 processo se completasse. $O$ índice de acidez medido foi de apenas $0,35 \mathrm{mgKOH} / \mathrm{g}$ (Tabela 4.3/Entrada 3) e, assim como na reação a $400{ }^{\circ} \mathrm{C}$ por $1 \mathrm{~h}$, não foi possível detectar a presença de picos relativos a absorções características de compostos oxigenados no espectro FTIR (Figura 4.9.c).

Já para a reação a $280{ }^{\circ} \mathrm{C}$, três horas não foram suficientes para propiciar a completa desoxigenação do ácido, sendo observada uma banda referente à deformação axial $\mathrm{C}=\mathrm{O}$, próxima a $1712 \mathrm{~cm}^{-1}$, no espectro $\mathrm{FTIR}$ do produto obtido (Figura 4.9.d) e o índice de acidez medido foi relativamente alto, de $19,0 \mathrm{mgKOH} / \mathrm{g}$ (Tabela 4.3/Entrada 4). Dessa forma, o tempo de reação foi aumentado para $6 \mathrm{~h}$, o que propiciou uma completa desoxigenação da amostra. Mais uma vez, o índice de acidez medido foi bastante baixo, de apenas $0,32 \mathrm{mg} / \mathrm{g}$ (Tabela 4.3/Entrada 5), e não foi possível detectar picos relativos a absorções características de compostos oxigenados no espectro FTIR (Figura 4.9.e).

\subsection{Efeito da temperatura sobre a reação de HDO do ácido láurico}

Os cromatogramas da Figura 4.10 demonstram que, para a HDO do ácido láurico em presença do catalisador $\mathrm{NiMoS}_{2} / \mathrm{Al}_{2} \mathrm{O}_{3}$ a $400 \stackrel{\circ}{\circ} \mathrm{C}, 340 \stackrel{\circ}{\circ} \mathrm{C}$ e $280 \stackrel{\circ}{\circ} \mathrm{C}$ por 1,3 e $6 \mathrm{~h}$, respectivamente, não foi possível detectar a ocorrência do pico relativo ao ácido que, conforme reportado na seção 4.2.1.2, apareceria na região próxima ao pico do hexadecano. Os cromatogramas também demonstram que os produtos principais obtidos são o undecano e o dodecano. Conforme especificado na seção 4.2.1.2, o undecano é resultado das reações de descarbonilação ou descarboxilação do ácido láurico, enquanto o dodecano resulta das reações de hidrogenação/desidratação. Nos cromatogramas, percebe-se que o pico relativo ao undecano é mais intenso do que o pico relativo ao dodecano, o que indica que as reações de descarbonilação/descarboxilação prevalecem sobre as de hidrogenação/desidratação. Entretanto, a diferença entre as intensidades dos picos diminui à medida que a temperatura diminui, com que se conclui que temperaturas 
mais elevadas favorecem a descarbonilação/descarboxilação, enquanto temperaturas mais reduzidas favorecem a hidrogenação/desidratação.

Os picos do dodecano e do undecano são acompanhados por picos de seus isômeros de cadeia, principalmente dos isômeros monorramificados (ver discussão na seção 4.7.1), sendo que estes picos são ligeiramente mais intensos para as reações realizadas em temperaturas mais elevadas. Os mecanismos das reações de desoxigenação e de isomerização serão considerados em detalhes nas seções 4.2.2.2.2 e 4.2.2.2.3, respectivamente.

A Figura 4.11 apresenta, em detalhes, a região do espectro dos alcanos $\mathrm{C} 11$ e C12 para o produto da reação realizada a $400 \stackrel{\circ}{\circ}$ por $1 \mathrm{~h}$; os picos de menor intensidade, não identificados na Figura, correspondem a alquenos, alcanos multirramificados (birramificados, principalmente) e cicloexanos e benzenos substituídos. 


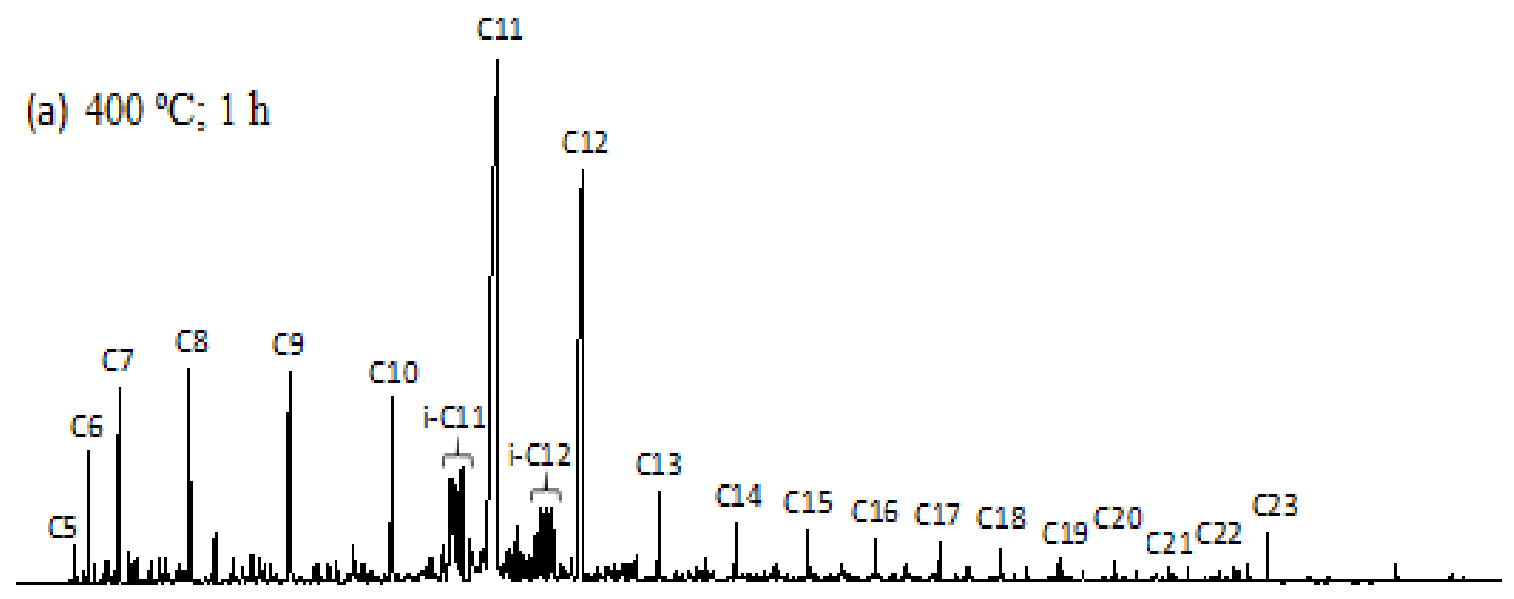

(b) $340{ }^{\circ} \mathrm{C} ; 3 \mathrm{~h}$

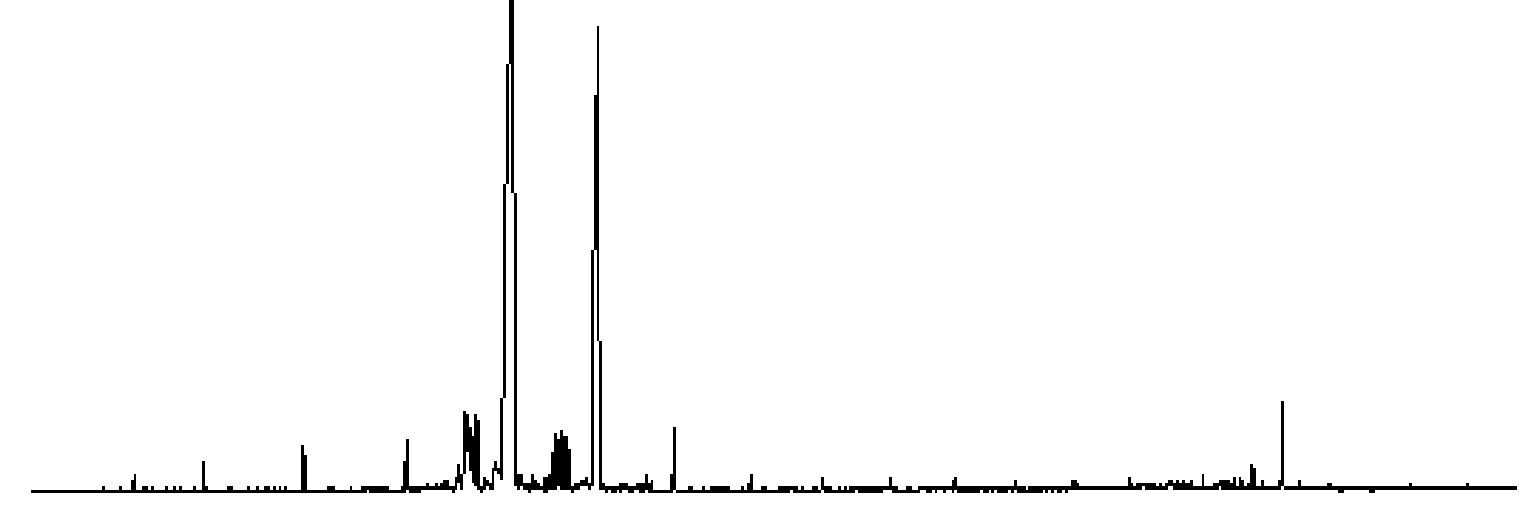

(c) $280^{\circ} \mathrm{C} ; 6 \mathrm{~h}$

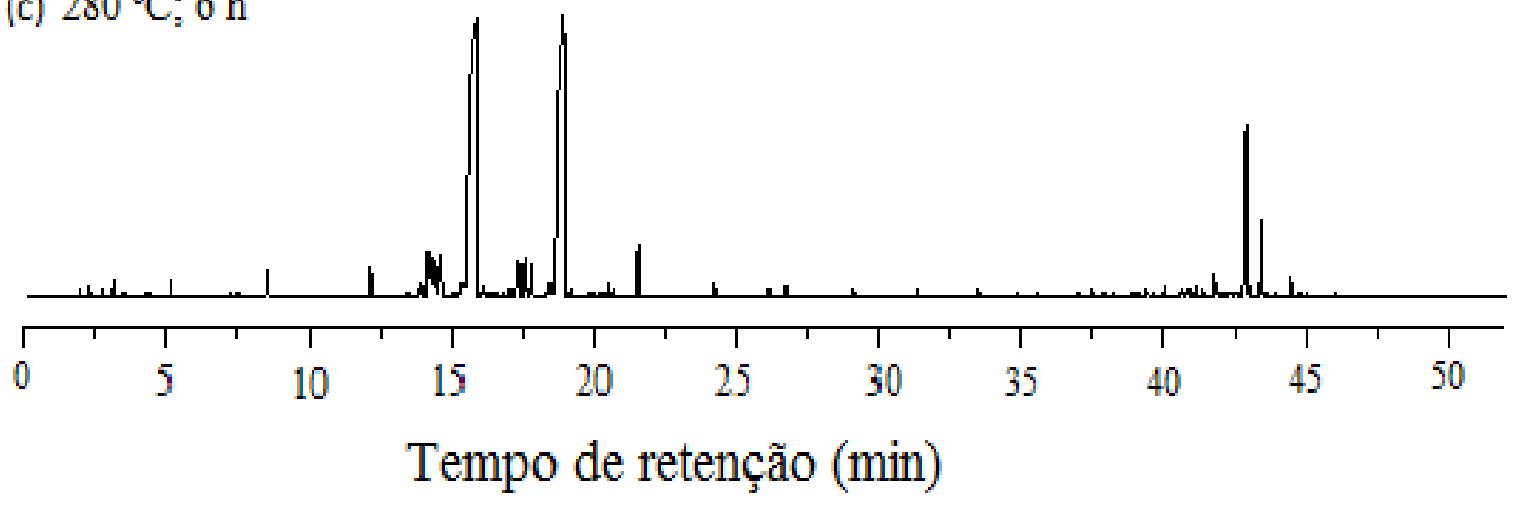

Figura 4.10 - Cromatogramas (GC/MS) dos produtos da reação de HDO do ácido láurico utilizando o catalisador $\mathrm{NiMoS}_{2} / \mathrm{Al}_{2} \mathrm{O}_{3}$, a diferentes temperaturas, por diferentes períodos de tempo: (a) $400^{\circ} \mathrm{C}, 1$ h; (b) $340^{\circ} \mathrm{C}, 3 \mathrm{~h}$; (c) $280^{\circ} \mathrm{C}, 6 \mathrm{~h}$. CX e i-CX correspondem, respectivamente, aos n-alcanos com X átomos de carbono e a seus isômeros ramificados. 


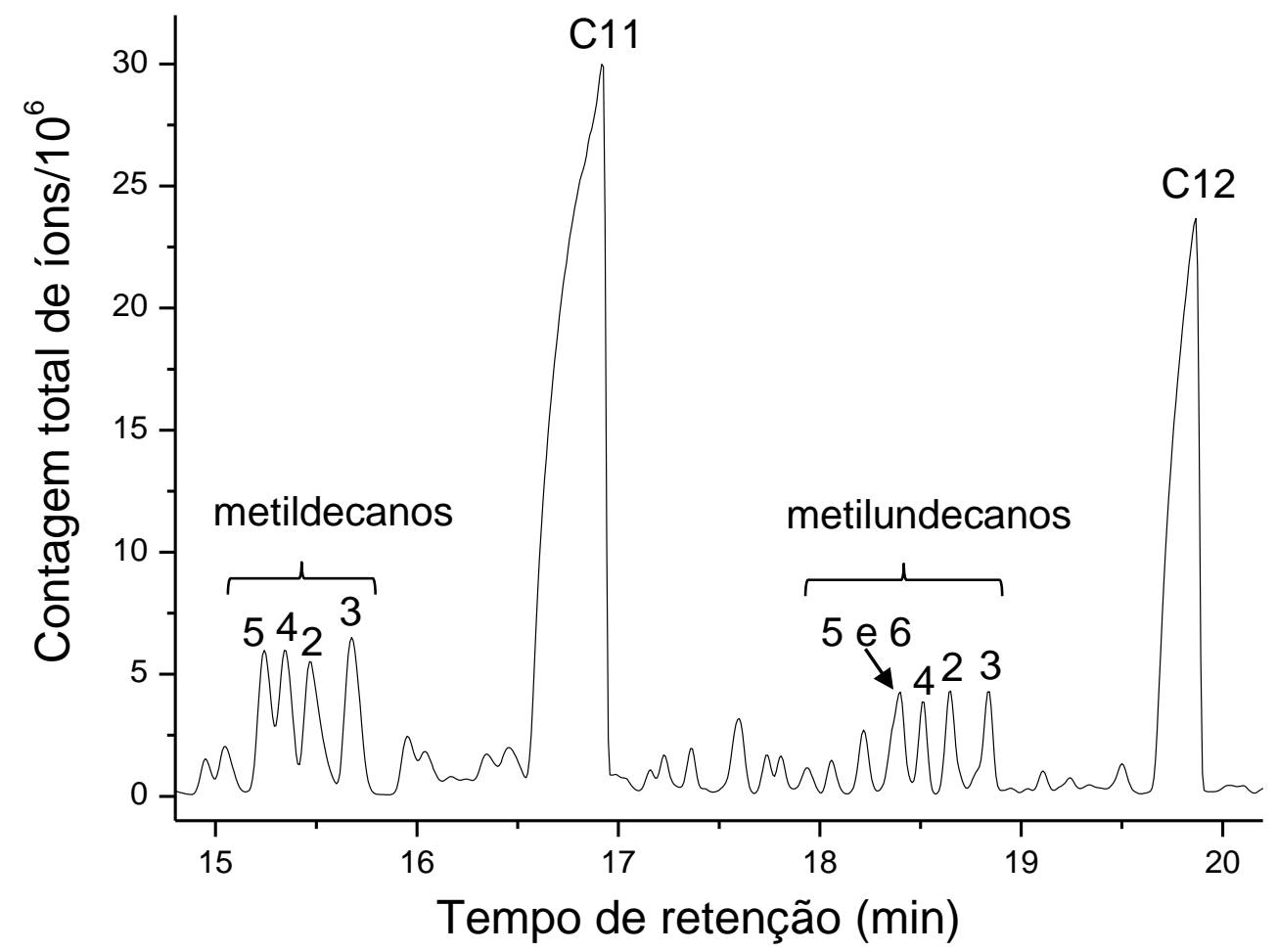

Figura 4.11 - Região correspondente à eluição dos hidrocarbonetos $\mathrm{C} 11$ e $\mathrm{C} 12$ do cromatograma (GC/MS) do produto da reação de $\mathrm{HDO}$ do ácido láurico utilizando o catalisador $\mathrm{NiMoS}_{2} / \mathrm{Al}_{2} \mathrm{O}_{3}$ a $400^{\circ} \mathrm{C}$ por $1 \mathrm{~h}$. O número identificando cada pico corresponde à posição do radical metil na cadeia carbônica.

Além dos hidrocarbonetos $\mathrm{C}_{11}$ e $\mathrm{C}_{12}$, é verificada também a ocorrência de compostos com menos de 11 átomos de carbono $(<\mathrm{C} 11)$, que são produtos de reações de craqueamento, e também compostos com mais de 12 átomos de carbono (>C12), que são produtos que envolvem, obrigatoriamente, reações de acoplamento entre duas diferentes espécies.

Comparando-se os cromatogramas da Figuras 4.10.a com o da Figura 4.5 percebe-se que, a $400{ }^{\circ} \mathrm{C}$, o produto da HDO realizada em presença de $\mathrm{NiMoS}_{2} / \mathrm{Al}_{2} \mathrm{O}_{3}$ apresenta, em relação ao produto da hidropirólise não catalítica, uma proporção muito menor tanto de compostos oriundos de reações de craqueamento quanto de reações de acoplamento. Esse comportamento pode ser atribuído ao fato de que a presença do catalisador acelera a conversão do ácido por um caminho que não aquele descrito ao longo da seção 4.2.1.

Comparando-se os cromatogramas dos produtos das reações de HDO realizadas em presença de $\mathrm{NiMoS}_{2} / \mathrm{Al}_{2} \mathrm{O}_{3}$, mas em diferentes temperaturas (Figura 4.10), percebe-se claramente que a redução da temperatura da reação proporciona 
uma redução da proporção de produtos de reações de craqueamento e, com exceção do tricosano, também dos produtos das reações de acoplamento. Em relação ao craqueamento, além das temperaturas mais elevadas favorecerem a cinética das reações, ele também é favorecido do ponto de vista termodinâmico, visto que propicia um aumento de entropia. Já com relação aos produtos de reações de acoplamento, com exceção do tricosano, estes são gerados, em grande parte, justamente a partir de espécies formadas pelas reações de craqueamento. Assim, se o craqueamento não é favorecido a temperaturas mais baixas, também não o são as reações de acoplamento.

A exceção feita ao tricosano advém do fato de que, conforme discutido na seção 4.2.1.2, sua formação se daria a partir da redução da diundecilcetona que, por sua vez, seria formada a partir do acoplamento entre o radical dodecanoil com um radical 1-undecil (reação (xvii)), ou seja, sem o envolvimento de espécies geradas a partir de reações de craqueamento. Ainda com relação ao tricosano, percebe-se que sua ocorrência se torna mais intensa em menores temperaturas. Supostamente isto se deva ao fato de que a formação do tricosano envolva, previamente, o acoplamento entre o radical dodecanoil e o radical 1-undecil para formação da diundecilcetona e, uma vez que reações de acoplamento são acompanhadas por redução de entropia, elas são termodinamicamente mais favorecidas em temperaturas reduzidas.

Em relação às reações realizadas a $280 \stackrel{\circ}{ } \mathrm{C}$, uma observação muito importante a ser feita é de que foi constatada a presença de coque no produto da reação, na forma de um pó negro muito fino disperso na mistura líquida. Esse fenômeno decorre de reações de aromatização e condensação de aromáticos que também são termodinamicamente mais favorecidas nesta faixa de temperatura devido ao fato de causarem redução de entropia.

\subsection{Efeito da pressão de $\mathrm{H}_{2}$ sobre a HDO do ácido láurico}

Com a finalidade de se avaliar o efeito da pressão de $\mathrm{H}_{2}$ sobre a $\mathrm{HDO}$ do ácido láurico catalisada por $\mathrm{NiMoS}_{2} / \mathrm{Al}_{2} \mathrm{O}_{3}$, foram realizadas reações empregando a temperatura de $340{ }^{\circ} \mathrm{C}$ com uma pressão inicial de $\mathrm{H}_{2}$ de 15 bar, ou seja, metade da pressão até então empregada. As análises dos produtos obtidos demonstram que, 
após 3 horas de reação, o índice de acidez ainda foi de $1,57 \mathrm{mg} \mathrm{KOH} / \mathrm{g}$ e, no espectro de FTIR, ainda se fez presente uma absorção muito pequena referente à carbonila, em $1709 \mathrm{~cm}^{-1}$ (destacada com um círculo na Figura 4.12.a). Aumentandose o tempo de reação para $5 \mathrm{~h}$, o índice de acidez caiu, mais ainda foi de 0,50 $\mathrm{mg} / \mathrm{KOH} / \mathrm{g}$, embora já não tenha sido possível identificar qualquer sinal relativo à carbonila no espectro FTIR do produto obtido. Esses resultados demonstram que é possível realizar a HDO do ácido empregando uma pressão de $\mathrm{H}_{2}$ mais reduzida; entretanto, o tempo necessário para que se tenha uma eficiente desoxigenação aumenta consideravelmente.

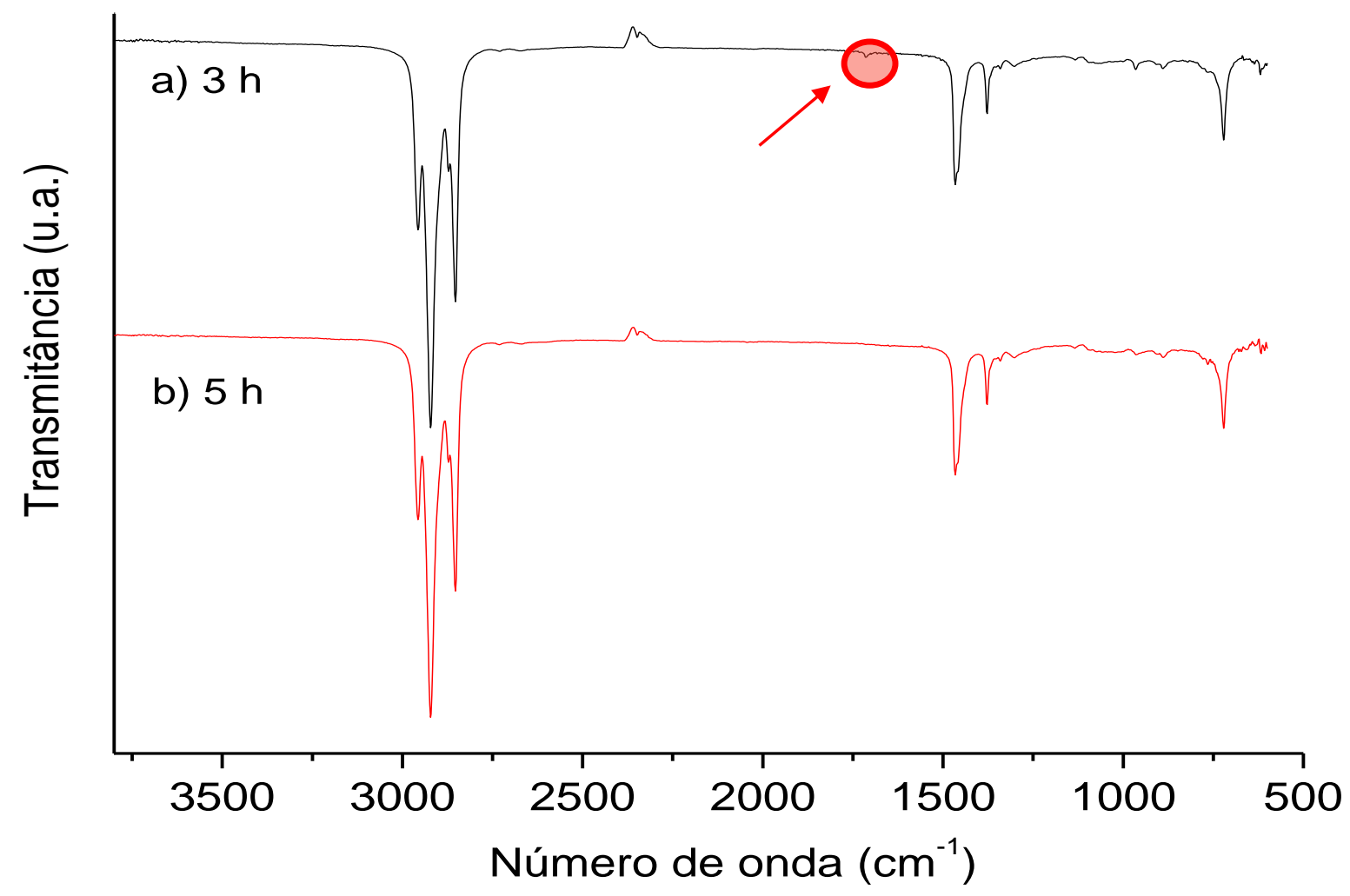

Figura 4.12 - Espectros de FTIR dos produtos da HDO do ácido láurico utilizando o catalisador NiMoS $2 / \mathrm{Al}_{2} \mathrm{O}_{3}$, a $340^{\circ} \mathrm{C}$, com uma pressão inicial de $\mathrm{H}_{2}$ de 15 bar, por (a) $3 \mathrm{~h}$ e (b) $5 \mathrm{~h}$.

\subsection{Mecanismos das reações de desoxigenação envolvidas na HDO do ácido láurico}

A observação atenta dos cromatogramas dos produtos das reações de HDO que não propiciaram uma completa desoxigenação permite identificar intermediários que revelam importantes detalhes acerca das reações e mecanismos envolvidos. 
Podem ser identificados, nos cromatogramas dos produtos da reação a $340{ }^{\circ} \mathrm{C}$ por 1 h e a $280 \stackrel{\circ}{\circ}$ por 6 h (Figura 4.13), picos correspondentes ao dodecanal em 24,41 min e ao 1-dodecanol em 26,05 min (para identificação deste, ver seção 4.7.6), além de picos referentes a dodecenos e undecenos. A identificação de todos esses compostos está em acordo com a proposta de rota reacional apresentada por Senol et a ${ }^{46}$ para a reação de $\mathrm{HDO}$ do heptanoato de metila catalisada por $\mathrm{NiMoS} 2 / \mathrm{Al}_{2} \mathrm{O}_{3}$.
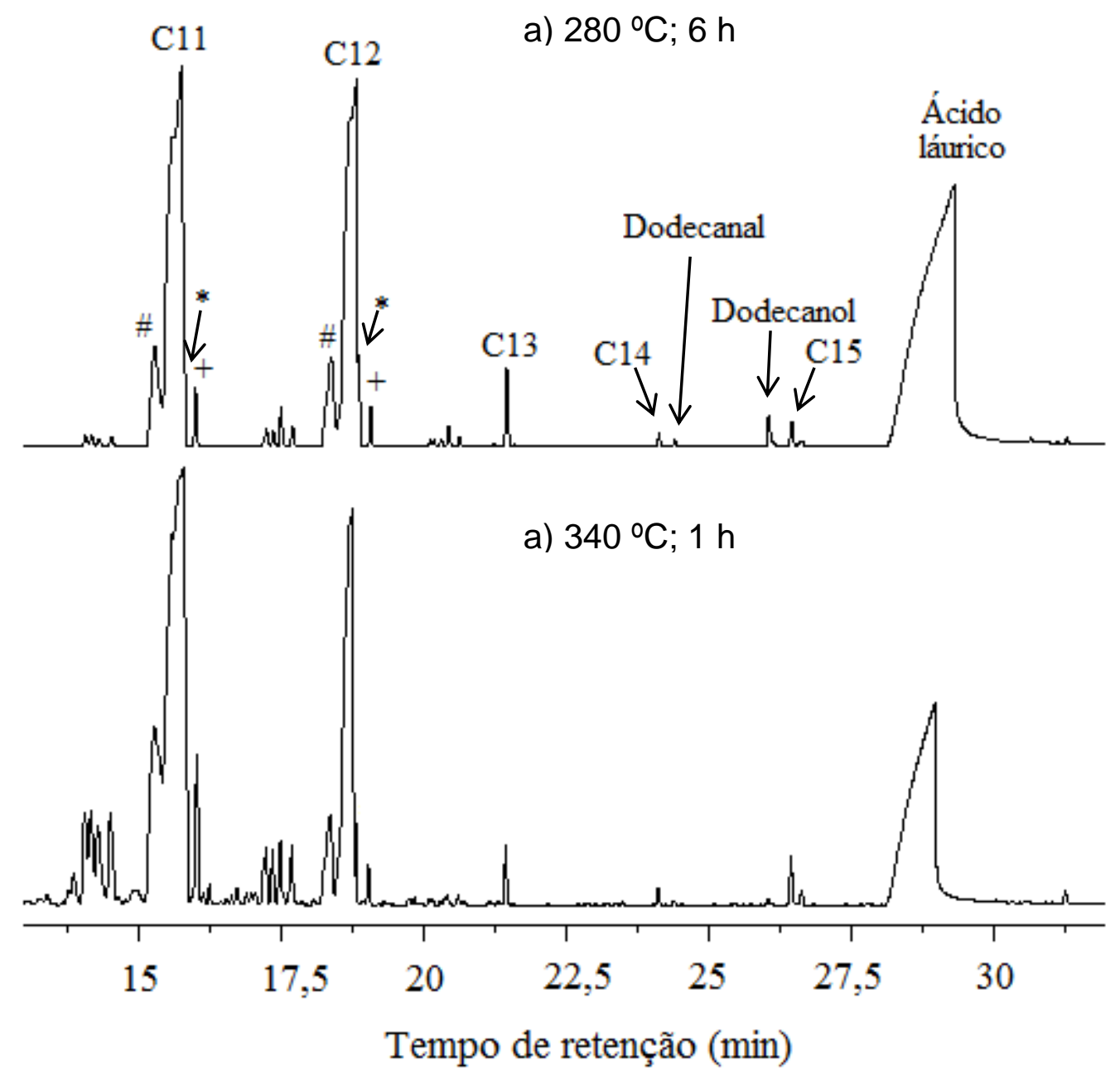

Figura 4.13 - Cromatogramas (GC/MS) dos produtos das reações de HDO do ácido láurico utilizando o catalisador $\mathrm{NiMoS}_{2} / \mathrm{Al}_{2} \mathrm{O}_{3}$ a $280 \stackrel{\circ}{\circ} \mathrm{C}$ por $6 \mathrm{~h}$ e, $340 \stackrel{\circ}{\circ} \mathrm{C}$ por $1 \mathrm{~h}$. CX: n-alcanos com $\mathrm{X}$ átomos de carbono; \#: alquenos terminais; * $\mathrm{e}+$ : isômeros cis e trans dos 2-alquenos, respectivamente.

Destaca-se o fato de que, além dos picos de alquenos terminais, são verificados em intensidades consideráveis também picos referentes aos isômeros cis e trans do 2-dodeceno e do 2-undeceno. A presença de alquenos internos leva à conclusão de que o mecanismo de desoxigenação catalisada pelo $\mathrm{NiMoS}_{2} / \mathrm{Al}_{2} \mathrm{O}_{3}$ envolva a formação de carbocátions. Inicialmente, seriam formados carbocátions primários que, entretanto, podem sofrer posterior rearranjo para formar carbocátions 
secundários. Os carbocátions primários, por desidrogenação, dão origem apenas ao alqueno terminal; entretanto, os carbocátions secundários podem formar alquenos internos.

As observações acima permitem propor um esquema mais detalhado para o mecanismo das reações de hidrodesoxigenação do ácido láurico, conforme detalhado na sequência.

Em primeiro lugar, o oxigênio da carboxila se coordenaria ao Mo do catalisador. Para isso, utilizaria uma "vacância de enxofre" existente na superfície, assim como sugerido por Chorkendorff e Niemantsverdriet ${ }^{50}$ para o processo de hidrodessulfurização de combustíveis (ver seção 2.4).

(xxvi)

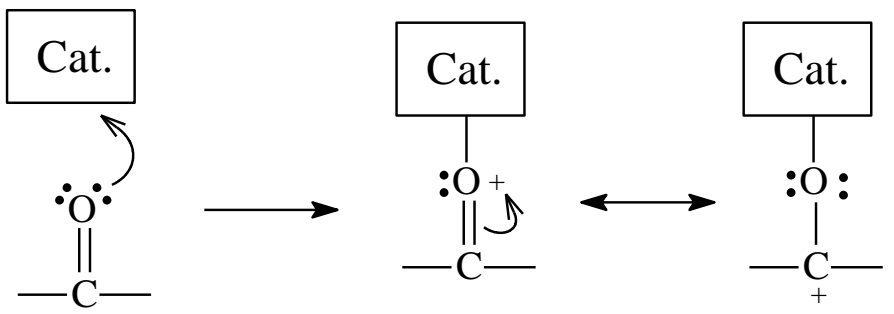

A estrutura formada poderia seguir então dois caminhos distintos. Em um deles, poderia haver a cisão heterolítica da ligação do carbono da carbonila, deficiente em elétrons, com o carbono alfa, havendo a formação de um carbocátion primário que, na sequência, poderia estabilizar-se pela formação de undecano ou 1 undeceno:

(xxvii)
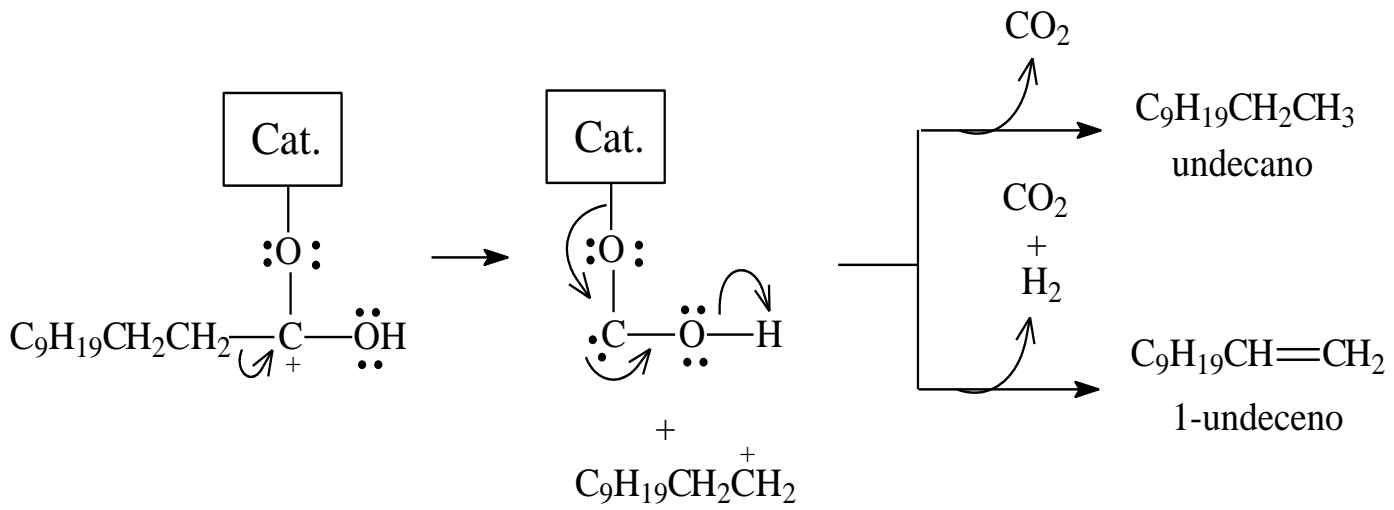

1-undeceno

Ainda, o carbocátion primário formado em (xxvii) poderia sofrer rearranjo: 
(xxviii)

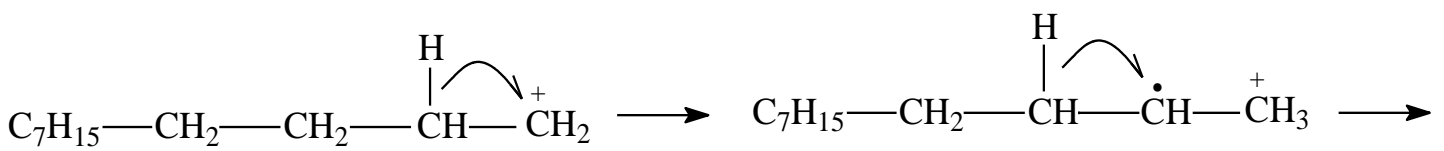
cátion 1-undecil

cátion 2-undecil

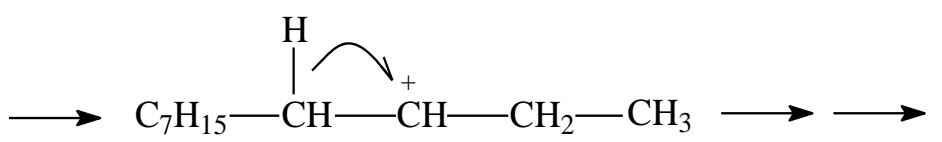

cátion 3-undecil

Os carbocátions secundários gerados a partir desse rearranjo, ao se estabilizarem, podem formar alquenos internos. Por exemplo, no caso do cátion 2undecil, podem ser formados os isômeros geométricos do 2-undeceno:

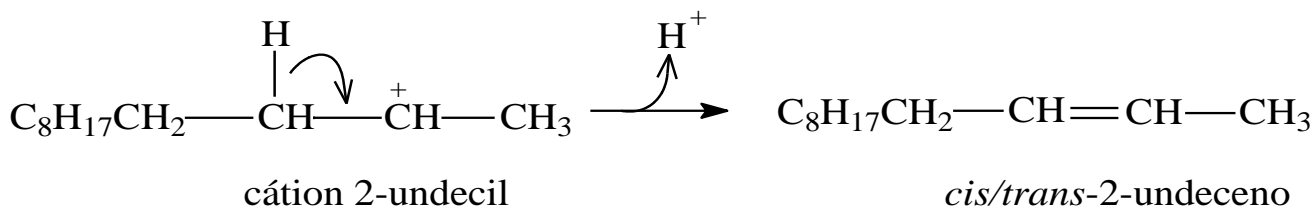

(xxix)

ou

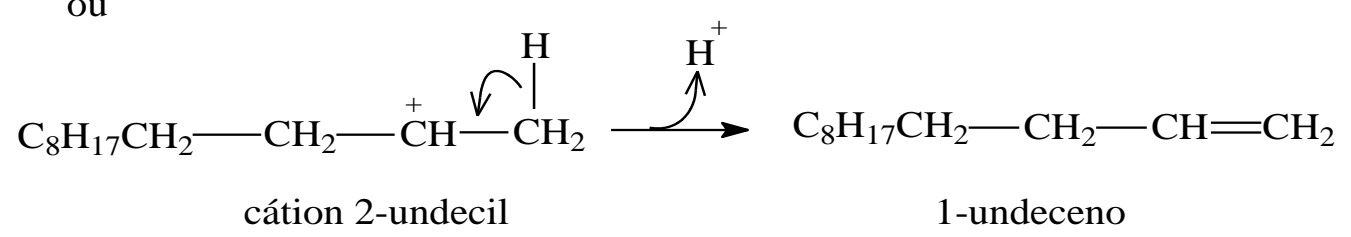

Acredita-se que, embora múltiplos rearranjos sejam possíveis, conforme indicado acima, apenas o primeiro ocorra com relativa intensidade, porque é o único em que se tem considerável ganho de estabilidade devido à transformação de um carbocátion primário em um carbocátion secundário. Isso então justificaria por que, entre os vários alquenos internos possíveis, apenas os isômeros geométricos do 2undeceno têm ocorrência relativamente pronunciada.

Em um segundo caminho, a estrutura formada pela coordenação do oxigênio da carbonila ao catalisador poderia sofrer hidrogenólise, o que seria seguido pela formação de um diol geminal que, por sua vez, sofreria desidratação para gerar o dodecanal: 


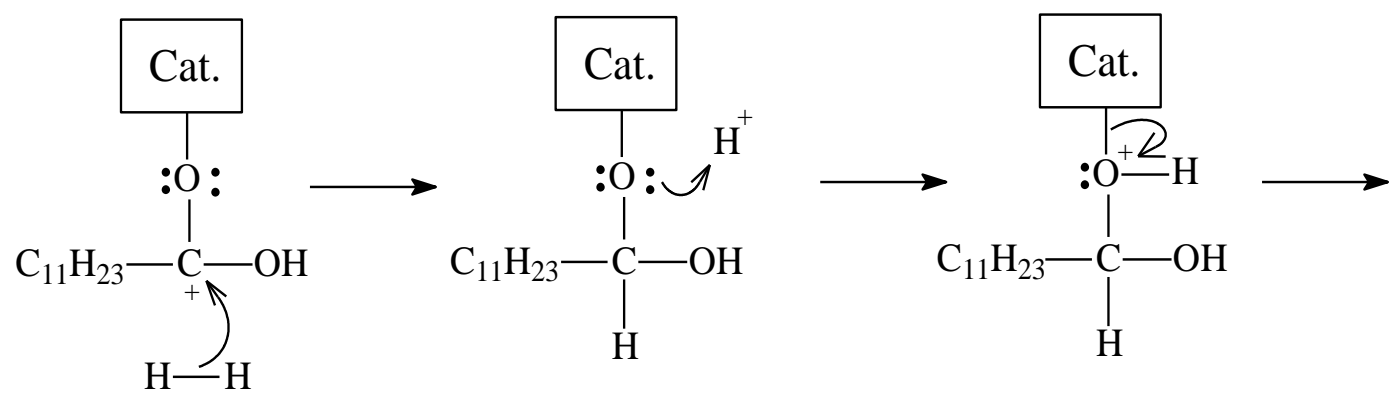

$(\mathrm{xxx})$

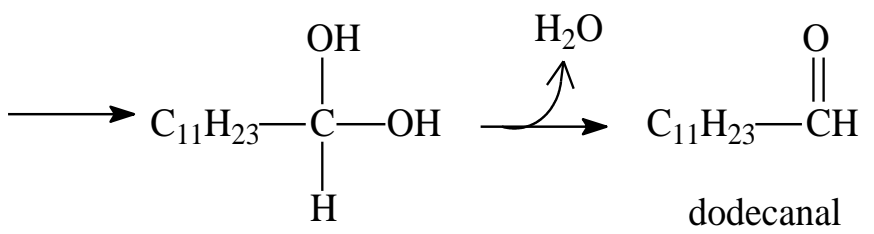

gem-diol

O dodecanal formado poderia, posteriormente, coordenar-se ao catalisador por meio do oxigênio de sua carbonila e, assim como no caso do ácido, a reação prosseguiria por dois caminhos distintos. No primeiro, haveria a cisão heterolítica da ligação do carbono da carbonila, deficiente em elétrons, com o carbono alfa, havendo a formação de um carbocátion primário que, na sequência, poderia estabilizar-se pela formação de undecano ou 1-undeceno:

(xxxi)
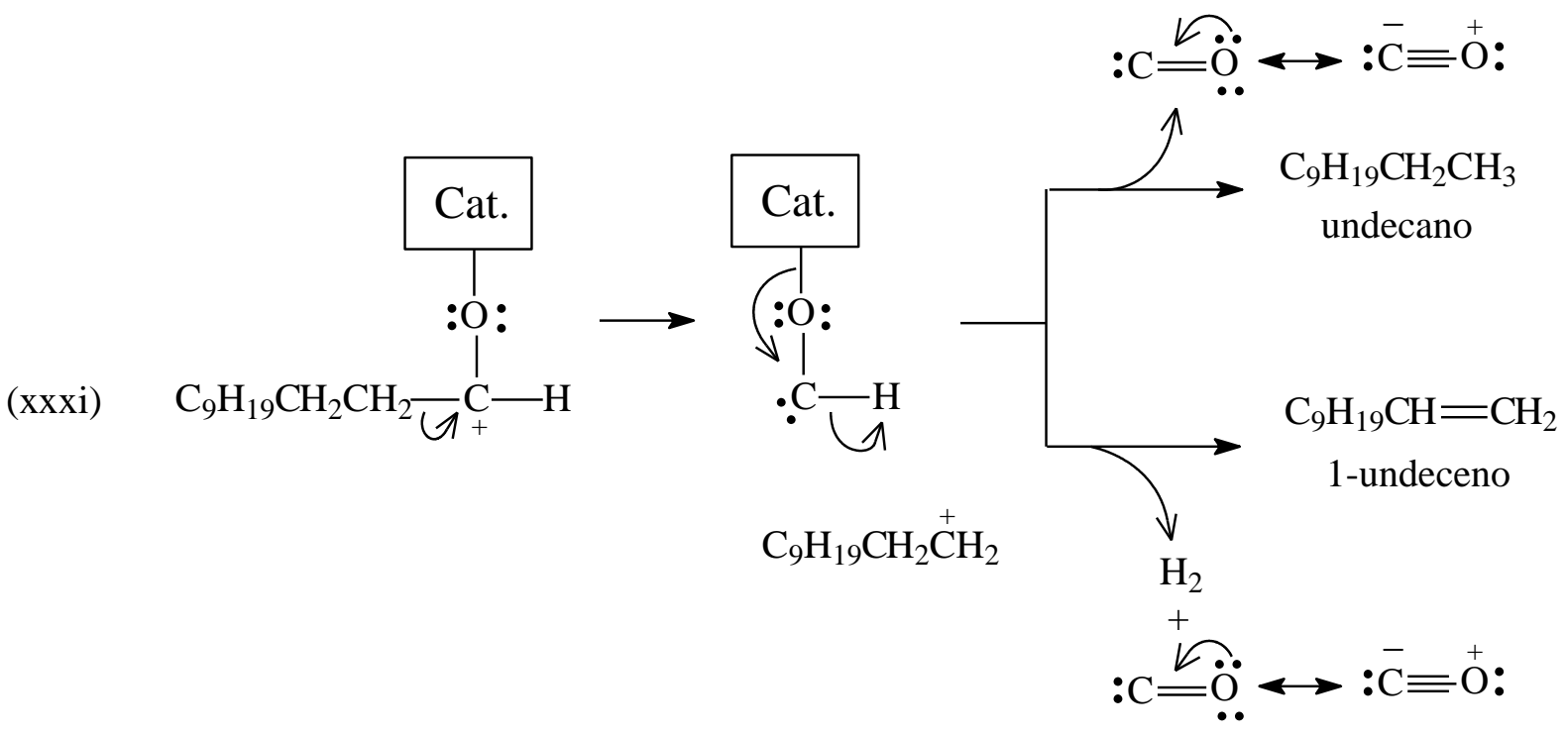

Conforme descrito em (xxviii), o carbocátion primário poderia sofrer rearranjo para gerar carbocátions secundários e, estes, ao se estabilizarem, poderiam formar alquenos internos, principalmente os isômeros geométricos do 2-undeceno - reação (xxix). 
Em um segundo caminho possível, o aldeído coordenado ao catalisador sofreria hidrogenólise para formar o 1-dodecanol:

(xxxii)

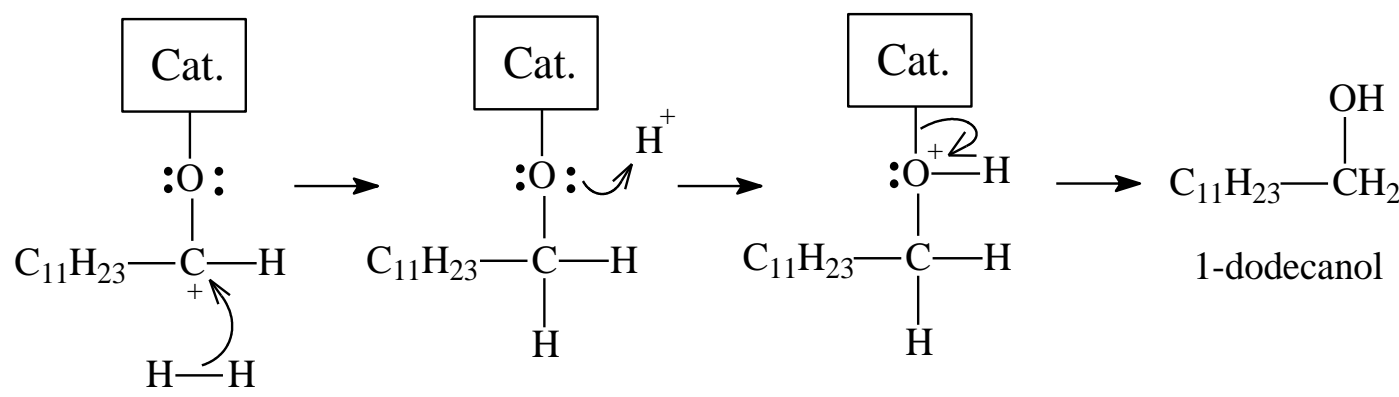

Por fim, o 1-dodecanol poderia coordenar-se ao catalisador por meio do oxigênio de sua hidroxila:

(xxxiii)

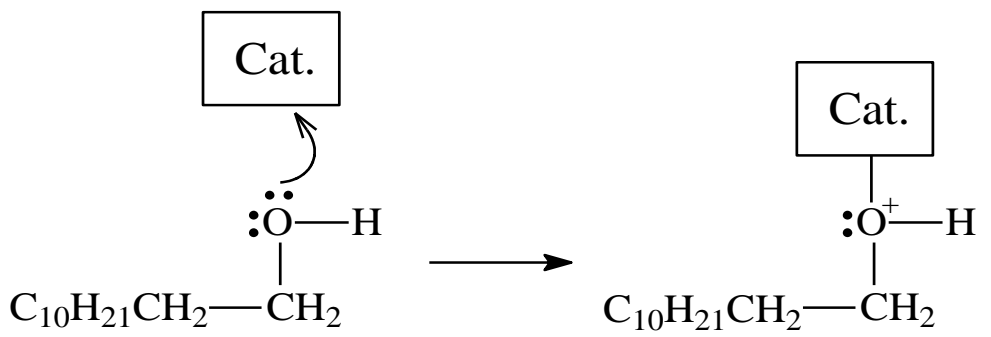

A carga positiva no átomo de oxigênio enfraqueceria a ligação deste com o carbono alfa, propiciando a cisão desta ligação e a formação de um carbocátion primário que, na sequência, poderia estabilizar-se pela formação de dodecano ou do 1-dodeceno:

(xxxiv)

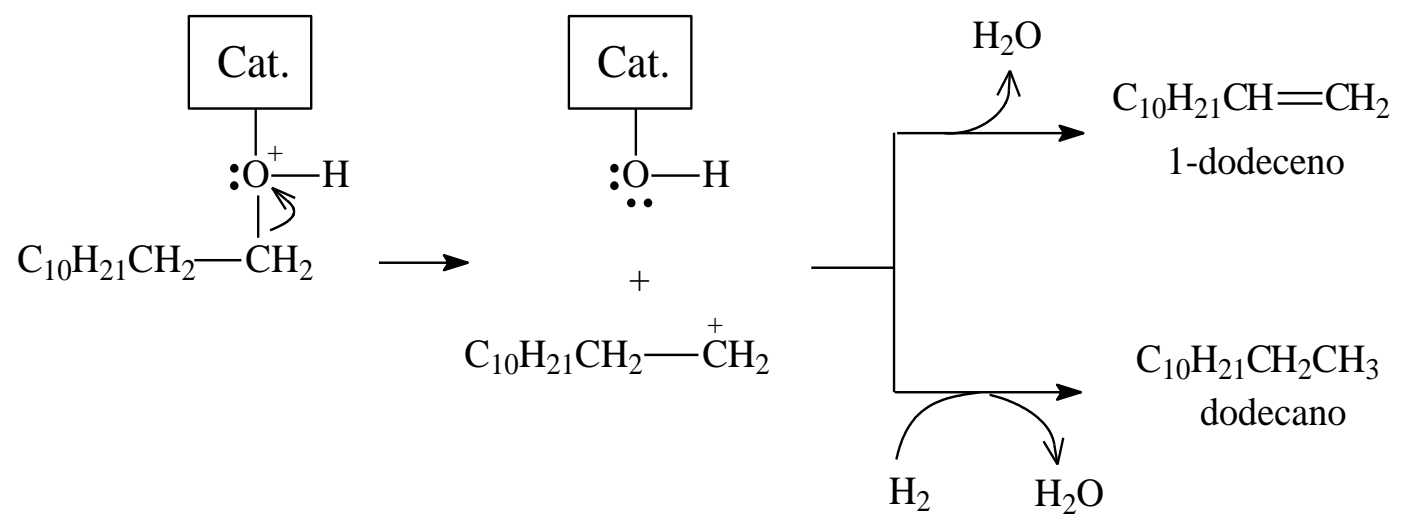

É claro que, assim como descrito nas reações (xxviii), o carbocátion primário poderia sofrer rearranjo para gerar carbocátions secundários e, estes, ao se estabilizarem, poderiam formar alquenos internos, principalmente os isômeros geométricos do 2-dodeceno, de maneira similar ao descrito na reação (xxix) para a formação de 2-undeceno. 
Nesse ponto, é válido destacar que, embora os cromatogramas das amostras em que a desoxigenação não se completou exibam picos intensos relativos a alquenos (Figura 4.13), o mesmo não ocorre para as amostras em que a desoxigenação foi completa (Figuras 4.10 e 4.11). Assim, fica claro que o $\mathrm{NiMoS}_{2} / \mathrm{Al}_{2} \mathrm{O}_{3}$ atua também de forma muito eficiente como catalisador para as reações de hidrogenação de olefinas.

\subsection{Mecanismos das reações de isomerização durante a HDO do ácido láurico}

Conforme discutido por Brandão61, a ocorrência de reações de isomerização de cadeia em alcanos encontra-se atrelada à ocorrência de carbocátions. Nesse contexto, os carbocátions gerados durante as reações de desoxigenação do ácido láurico catalisadas por $\mathrm{NiMoS}_{2} / \mathrm{Al}_{2} \mathrm{O}_{3}$ (ver seção 4.2.2.2.3) poderiam servir de substrato para as reações de isomerização. Em acordo com o mecanismo proposto por Guisnet et a ${ }^{\not 2}$, os carbocátions primários e secundários inicialmente formados se transformariam em carbocátions terciários, mais estáveis, via um intermediário ciclopropano protonado:

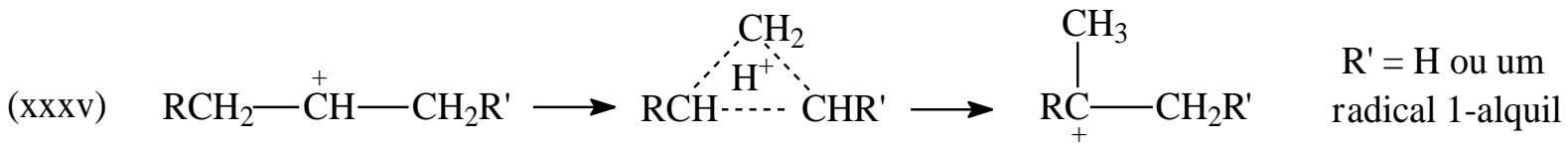

O carbocátion terciário formado perderia então um próton para formar um alqueno que seria posteriormente hidrogenado pela ação do catalisador par dar origem a um alcano ramificado:

(xxxvi)

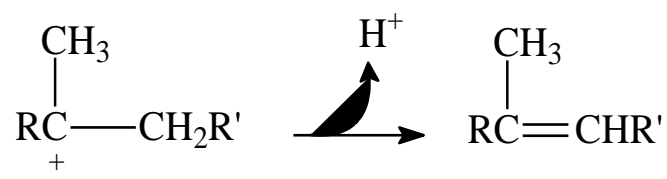

(xxxvii)<smiles>[R]C=[C]C</smiles><smiles>[R]CC(C)[R]C</smiles> 


\subsection{Considerações finais acerca da HDO do ácido láurico}

As discussões realizadas ao longo da seção 4.2.2.2 deixam claro que, ao menos para o ácido láurico, a temperatura ideal para realizar gira em torno de 340 ㄷ. Temperaturas demasiadamente baixas resultam em uma lenta desoxigenação e na formação de produtos sólidos de polimerização térmica. Em contrapartida, temperaturas muito altas intensificam o processo de craqueamento. A reação por $3 \mathrm{~h}$ a $340 \stackrel{\circ}{\circ}$ gerou uma mistura cujo componente principal foi o $n$-undecano (produto das reações de descarbonilação e descarboxilação), seguido pelo n-dodecano (produto da hidrodesoxigenação). Além disso, praticamente não houve formação de produtos sólidos e a presença de produtos de craqueamento foi bastante baixa.

\subsubsection{HDO do ácido oleico}

Tomando-se como base os resultados dos estudos realizados com o ácido láurico, a $\mathrm{HDO}$ do ácido oleico catalisada por $\mathrm{NiMoS}_{2} / \mathrm{Al}_{2} \mathrm{O}_{3}$ foi realizada a $340{ }^{\circ} \mathrm{C}$ sob pressão inicial de $\mathrm{H}_{2}$ de 30 bar. As análises do produto da reação demonstram que a desoxigenação ocorreu de maneira eficiente após $3 \mathrm{~h}$ de reação: 0 índice de acidez do produto da reação foi muito próximo de zero, de apenas $0,44 \mathrm{mgKOH} / \mathrm{g} \mathrm{e}$, no espectro FTIR (Figura 4.14), percebe-se a inexistência de picos relativos às absorções características de ácidos carboxílicos (citadas na seção 4.2.2.1), bem como de qualquer outra absorção característica de compostos oxigenados. Em vez disso, fazem-se presentes apenas bandas de absorção características de alcanos, assim como foi verificado para a reação do ácido láurico sob condições idênticas (ver seção 4.2.2.2.1). De fato, no cromatograma do produto da reação (Figura 4.15), não foi detectada a presença (ao menos em considerável intensidade) do pico relativo ao ácido oleico que, segundo os índices de Kovats encontrados na literatura (segundo a ref. ${ }^{63}$ ), o índice de Kovats do ácido oleico é de 2115), se situaria entre os picos do eneicosano e do docosano (C21 e C22, respectivamente). 


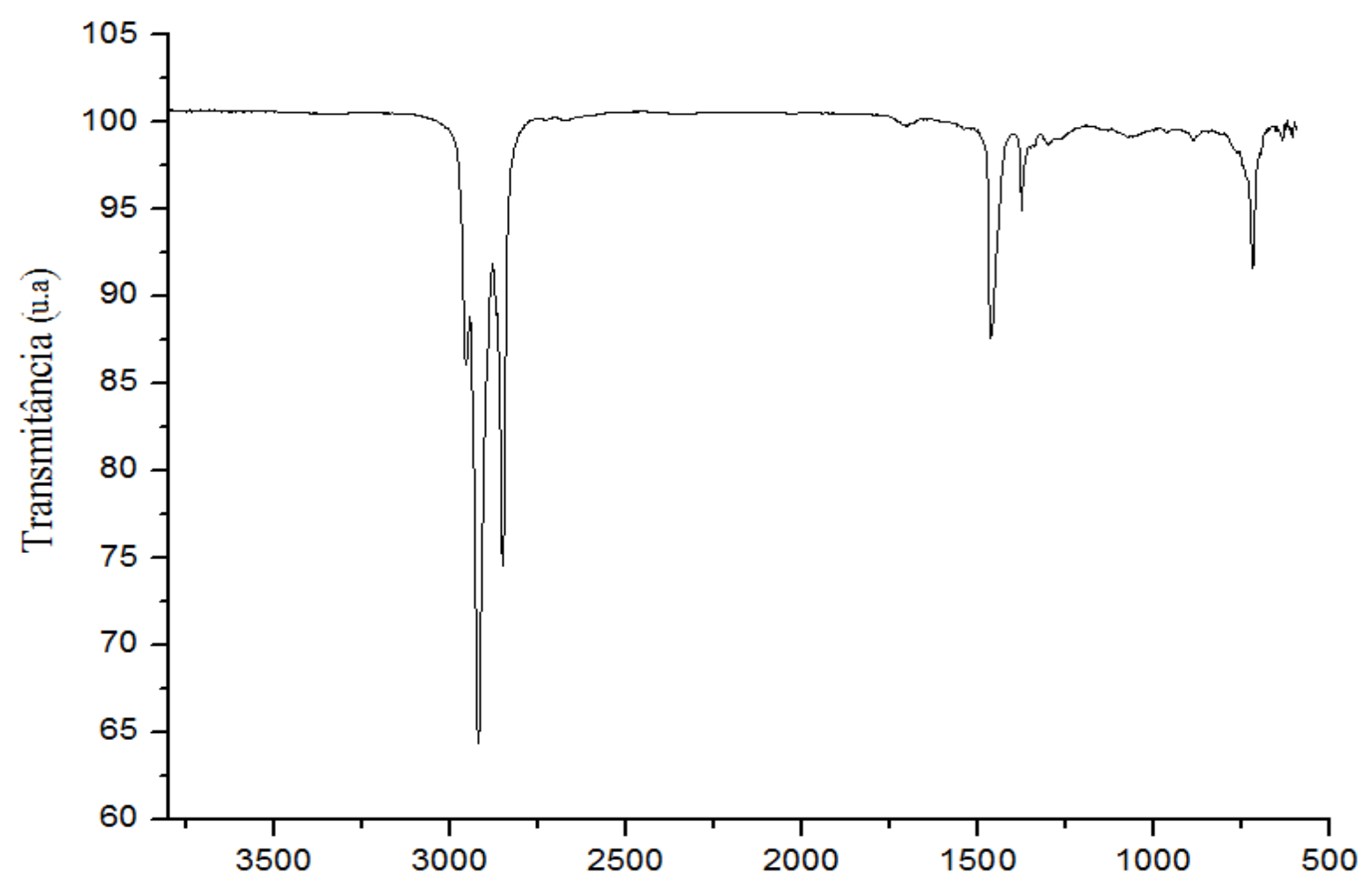

Figura 4.14 - Espectro FTIR do produto da HDO do ácido oleico utilizando o catalisador $\mathrm{NiMoS}_{2} / \mathrm{Al}_{2} \mathrm{O}_{3}$ a $340^{\circ} \mathrm{C}$ por $3 \mathrm{~h}$.

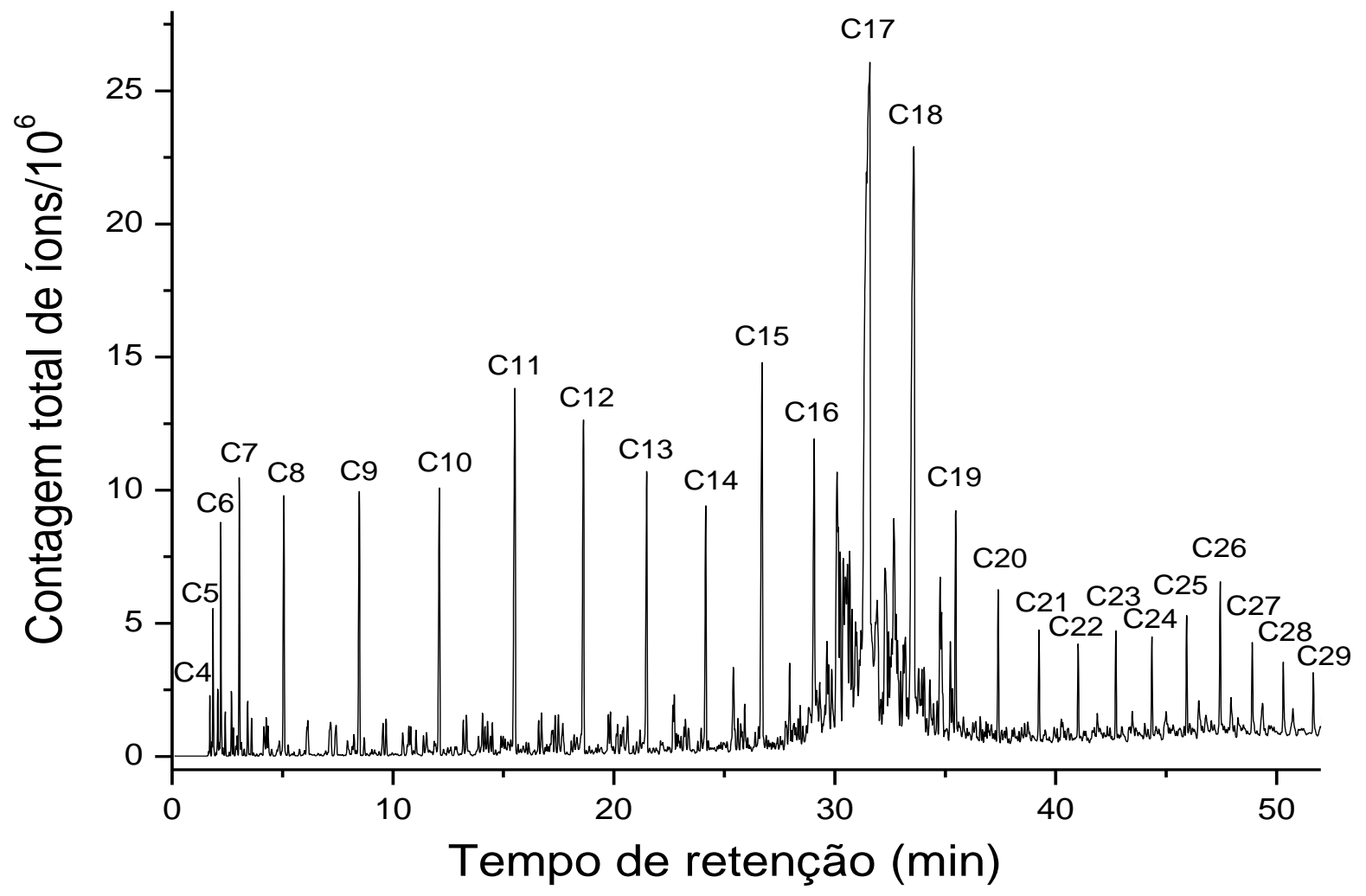

Figura 4.15 - Cromatograma (GC/MS) do produto da reação de HDO do ácido oleico utilizando o catalisador $\mathrm{NiMoS}_{2} / \mathrm{Al}_{2} \mathrm{O}_{3}$, a $340^{\circ} \mathrm{C}, 3 \mathrm{~h}$; CX corresponde aos n-alcanos com X átomos de carbono. 
Os compostos formados indicam que a reação seguiu um curso muito similar àquele verificado para a reação do ácido láurico em condições idênticas. Novamente, os principais compostos formados foram aqueles decorrentes das reações de descarbonilação/descarboxilação e hidrogenação/desidratação do ácido: desta vez, o octadecano, seguido pelo heptadecano. É válido destacar que, em consonância com a elevada atividade hidrogenante demonstrada pelo catalisador, reportada na seção 4.2.2.2.2, em paralelo às reações de desoxigenação ocorreu também a hidrogenação tanto dos produtos olefínicos formados conforme descrito nas reações (iii) e (iv), quanto da dupla ligação inicialmente presente no ácido oleico. Uma vez mais, houve também considerável formação de alcanos ramificados, principalmente monorramificados) e de produtos de reações de craqueamento e acoplamento.

Uma observação importante que surge da comparação dos cromatogramas dos produtos das reações de HDO das amostras de ácido láurico e de ácido oleico a $340^{\circ} \mathrm{C}$ por $3 \mathrm{~h}$ (Figuras 4.10.b e 4.15) é de que, no caso do ácido oleico, houve a formação de uma proporção muito superior de compostos oriundos de reações de craqueamento ( $<\mathrm{C} 17)$. Esse resultado pode ser atribuído a dois fatores. Em primeiro lugar, deve-se levar em conta o maior tamanho da cadeia do ácido oleico: moléculas maiores apresentam maior polarizabilidade, o que faz com que os radicais livres formados durante as reações de craqueamento sejam mais facilmente estabilizados por meio da dispersão do spin desemparelhado. Em segundo lugar, deve-se considerar a presença da ligação dupla da molécula do ácido oleico, a qual permite, antes de ser hidrogenada, a formação de radicais alílicos, que apresentam maior estabilidade devido à ressonância:

(xXXviii)

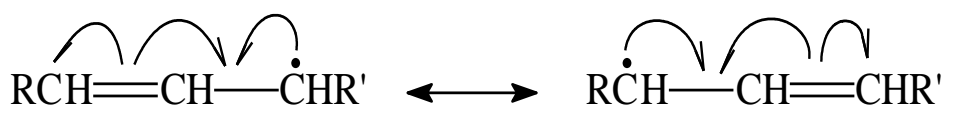

R e R' = H ou um grupo n-alquil

Radical alil

Portanto, fica claro que, especialmente na HDO de moléculas de cadeias longas e/ou insaturadas, deve-se dar preferência a temperaturas de reação moderadas, de maneira que, ao mesmo tempo em que se controle as reações de polimerização, também se evite um craqueamento além do desejável. Esse é o caso, por exemplo, das reações a serem realizadas com o óleo de soja, visto que, 
conforme descrito na seção 2.1.2, ele apresenta elevados teores de ésteres de ácido oleico, linoleico e linolênico em sua composição.

\section{3 $\mathrm{HDO}$ de óleos vegetais catalisada por $\mathrm{NiMoS}_{2} / \mathrm{Al}_{2} \mathrm{O}_{3}$}

Tomando-se como base os resultados dos estudos realizados com os compostos modelo, a HDO dos óleos vegetais (óleos de coco e de soja) catalisadas por $\mathrm{NiMoS}_{2} / \mathrm{Al}_{2} \mathrm{O}_{3}$ foram realizadas sob pressão inicial de $\mathrm{H}_{2}$ de 30 bar e empregando-se a temperatura de $340^{\circ} \mathrm{C}$. Na próxima seção, é apresentada a caracterização, por espectrometria de absorção na região do infravermelho (FTIR), dos óleos, o que será útil, na sequência, para o acompanhamento dos resultados das reações. Nas seções 4.2.3.2 e 4.2.3.3 são apresentados então, os resultados referentes à HDO do óleo de coco e do óleo de soja, respectivamente. Finalmente, na seção 4.2.3.4, é feita uma avaliação da composição dos óleos de coco e de soja desoxigenados, comparando-as com a de uma amostra comercial de querosene para aviação.

\subsubsection{Caracterização dos óleos de coco e soja por FTIR}

Na Figura 4.16 são apresentados os espectros de FTIR do óleo de coco e do óleo de soja. Nos espectros, entre as absorções características de ésteres de ácidos carboxílicos, destacam-se aquelas referentes à deformação axial $\mathrm{C}=\mathrm{O}$ em $1743 \mathrm{~cm}^{-1}$ e às chamadas "vibrações de deformação axial de C—O", que na verdade são duas vibrações assimétricas acopladas: deformação axial de $\mathrm{C}(=\mathrm{O})$ - $\mathrm{O}$ e deformação axial assimétrica de $\mathrm{O}-\mathrm{C}-\mathrm{C} .{ }^{60}$ Estas, resultaram em um conjunto de três absorções, sobrepostas, com máximos em 1226, 1152 e $1105 \mathrm{~cm}^{-1}$. 


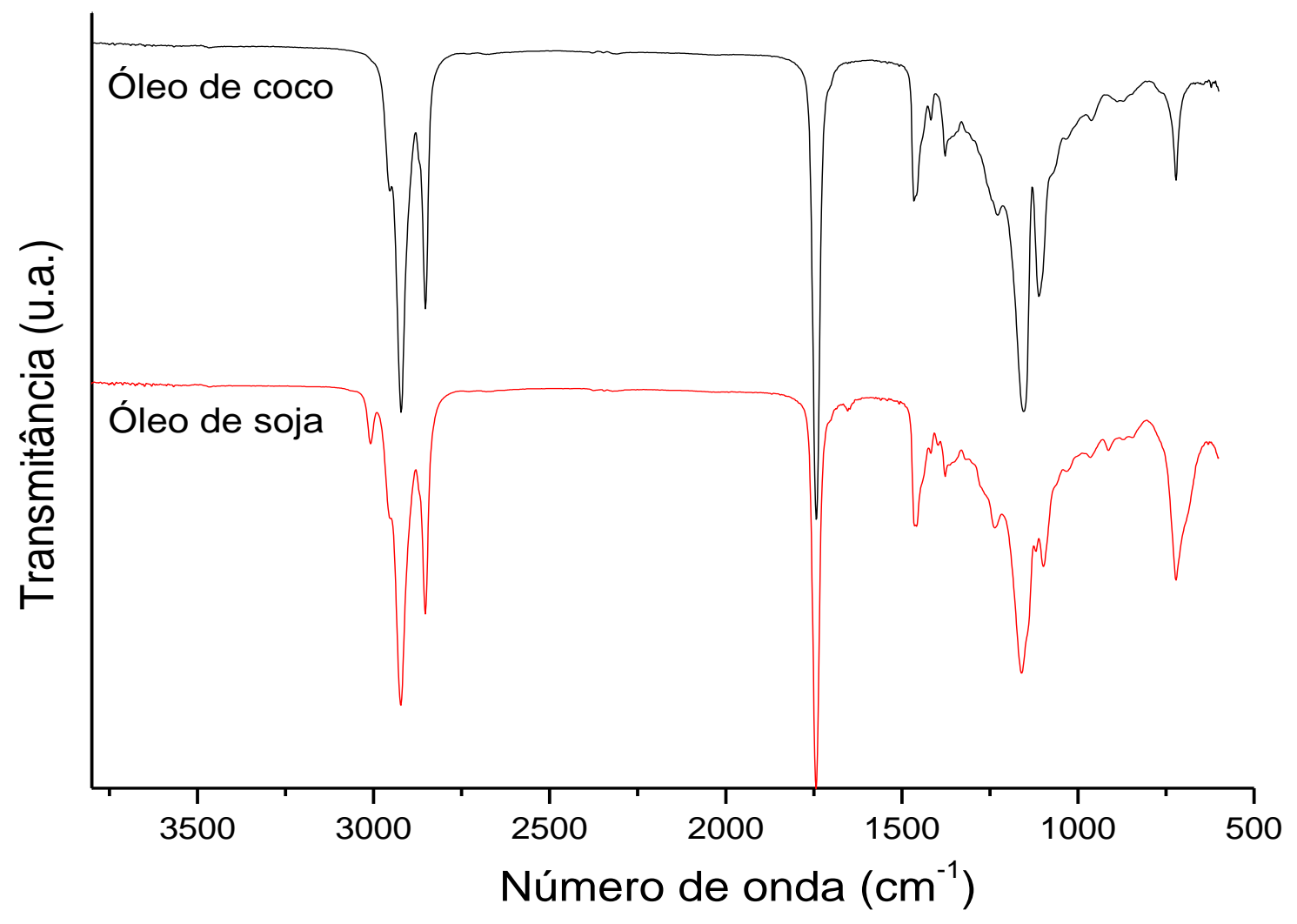

Figura 4.16 - Espectros de FTIR dos óleos de coco e de soja.

\subsubsection{HDO do óleo de coco}

Inicialmente, realizou-se a reação de HDO do óleo de coco a $340{ }^{\circ} \mathrm{C}$ por $3 \mathrm{~h}$, período este que se mostrou suficiente para assegurar uma completa desoxigenação dos ácidos láurico e oleico na referida temperatura. Entretanto, o espectro de FTIR indica claramente a presença de ácidos carboxílicos no produto obtido, com a presença de: uma banda muito tênue e larga referente à deformação axial $\mathrm{O}-\mathrm{H}$, em torno de $3500-2500 \mathrm{~cm}^{-1}$; uma banda relativamente intensa correspondente à deformação axial $\mathrm{C}=\mathrm{O}$, em $1709 \mathrm{~cm}^{-1}$ (lembre-se que, para os ésteres constituintes dos óleos, essa absorção ocorreu em $1743 \mathrm{~cm}^{-1}$ ). Além dessas, fazem-se presentes também algumas absorções fracas relativas à deformação axial de $C(=0)-O$, entre cerca de 1100 e $1300 \mathrm{~cm}^{-1}$, mas que não deixam claro se em ácidos carboxílicos ou ésteres. 


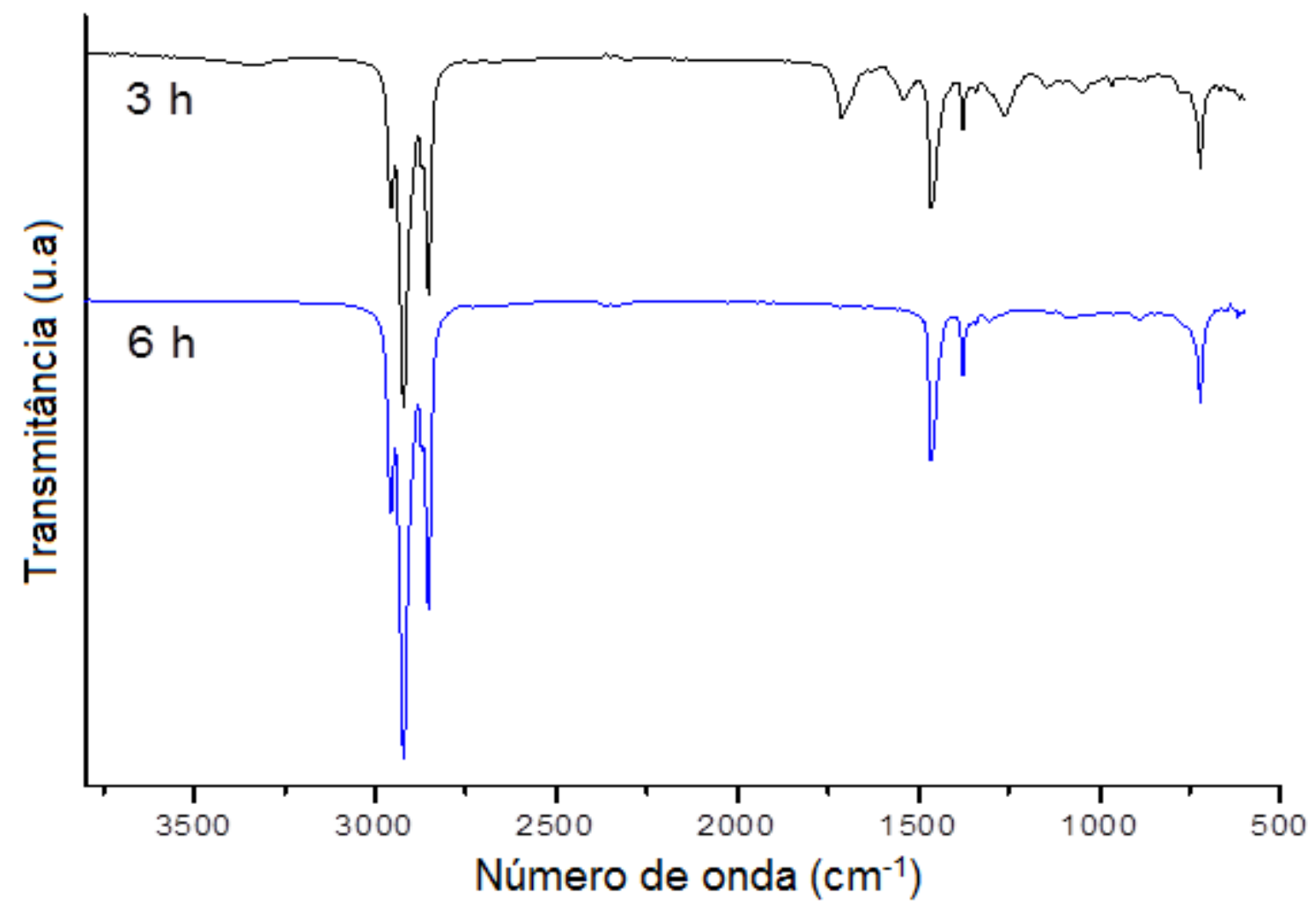

Figura 4.17- Espectros de FTIR dos produtos da HDO do óleo de coco utilizando o catalisador $\mathrm{NiMoS}_{2} / \mathrm{Al}_{2} \mathrm{O}_{3}$ a $340 \stackrel{\circ}{\mathrm{C}}$ por 3 e $6 \mathrm{~h}$.

Em concordância com as observações acima, foi verificada uma acidez de $6,33 \mathrm{mgKOH} / \mathrm{g}(3 \mathrm{~h})$ e 0,23 ( $6 \mathrm{~h}$ ) para o produto em questão. Além disso, foram detectados, no cromatograma da amostra (Figura 4.18.a), picos referentes aos ácidos láurico e mirístico (ácido tetradecanoico) - ver seção 4.7.2, que correspondem justamente aos dois ácidos com maior contribuição na constituição dos triacilglicerídeos do óleo de coco, conforme reportado na seção 2.2.2. Essa observação demonstra que, durante a HDO do óleo de coco, os triésteres são inicialmente hidrolisados para formar os respectivos ácidos carboxílicos:

(xxxix)<smiles>CCC(=O)OCC(COC(=O)CC)OC(=O)CC</smiles>

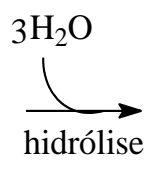<smiles>CCC(=O)O</smiles> 

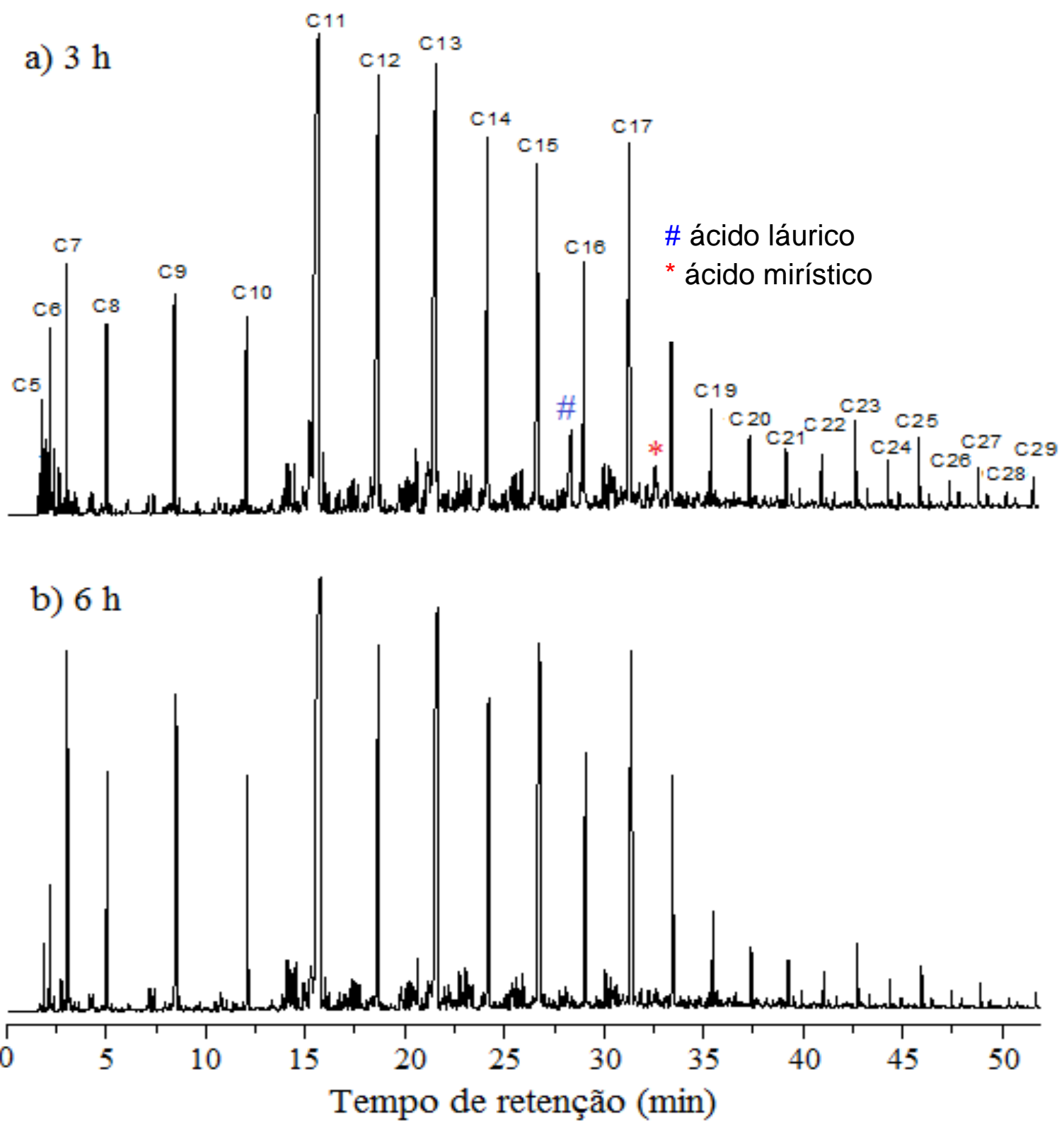

Figura 4.18 - Cromatogramas (GC/MS) dos produtos da HDO do óleo de coco utilizando o catalisador $\mathrm{NiMoS} 2 / \mathrm{Al}_{2} \mathrm{O}_{3}$, a $340^{\circ} \mathrm{C}$ por (a) e $3 \mathrm{~h}$ (b) $6 \mathrm{~h}$. CX corresponde aos $\mathrm{n}$-alcanos com $\mathrm{X}$ átomos de carbono.

Nesse ponto, é válido destacar que os óleos empregados no presente trabalho não passaram por uma etapa prévia de secagem. Assim, a umidade presente no óleo pode ser a responsável por iniciar o processo de hidrólise dos triacilglicerídeos; posteriormente, a própria água formada durante as reações de conversão dos ácidos carboxílicos a aldeídos e de hidrogenação/desidratação de álcoois (reações (xxx) e (xxxiv), respectivamente) poderia atuar na hidrólise dos triacilglicerídeos restantes. Alternativamente, os ésteres das moléculas de triacilglicerídeos poderiam sofrer hidrogenólise para formar álcoois graxos, conforme 
descrito na reação $(x x x x)$. Os álcoois formados poderiam então sofrer hidrogenação/desidratação, liberando a água necessária para iniciar o processo de hidrólise.

$(\mathrm{xxxx})$<smiles>CCCCCCCCCCCCCCC(=O)OCC(COC(=O)CC)C(O)COC(=O)CC</smiles>

De fato, aumentando-se o tempo de reação para $6 \mathrm{~h}$, houve uma desoxigenação bastante satisfatória, conforme demonstrado por meio da análise do produto obtido: o índice de acidez medido foi de apenas 0,23 $\mathrm{mg} \mathrm{KOH} / \mathrm{g}$; no espectro de FTIR (Figura 4.17), fizeram-se presentes apenas as absorções correspondentes a alcanos (ver seção 4.2.2.2); não foram identificados, no cromatograma (Figura 4.18.b), os picos referentes aos ácidos láurico e mirístico, bem como a outros compostos oxigenados.

No cromatograma do produto da reação de HDO do óleo de coco, observa-se a presença, em intensidade mais elevada, dos picos relativos aos alcanos lineares de $\mathrm{C7}$ a C18. A formação dos n-alcanos com número par de átomos de carbonos (Cn) se dá a partir da reação de hidrogenação/desidratação dos principais ácidos carboxílicos presentes na composição do óleo (Tabela 2.1); já a formação dos nalcanos com número ímpar de átomos de carbonos $(\mathrm{Cn}-1)$ se dá a partir das reações de descarbonilação ou descarboxilação. Em consonância com o que foi verificado nas reações dos compostos modelo a $340{ }^{\circ} \mathrm{C}$ (seção 4.2.2), a intensidade dos picos relativos aos $n$-alcanos $\mathrm{Cn}$ é sempre menor do que ao correspondente $\mathrm{Cn}$ 1, ou seja, as reações de descarbonilação e descarboxilação prevalecem sobre as de hidrogenação/desidratação. Finalmente, é válido destacar que as intensidades dos picos cromatográficos estão em acordo com a proporção com que os respectivos ácidos contribuem para a constituição do óleo: ácido C12 (láurico) >> ácido C14 (mirístico) > ácido C16 (palmítico e palmitoleico) > ácidos C18 (esteárico, oleico e linoleico $) \approx(\mathrm{C} 10)$ cáprico $\approx(\mathrm{C} 8)$ caprílico. Assim, para as intensidades dos picos dos n-alcanos, tem-se: $\mathrm{C} 12>>\mathrm{C} 14>\mathrm{C} 16>\mathrm{C} 18 \approx \mathrm{C} 10 \approx \mathrm{C} 8 ; \mathrm{C} 11>>\mathrm{C} 13>$ $\mathrm{C} 15>\mathrm{C} 17 \approx \mathrm{C} 9 \approx \mathrm{C} 7$. Assim como foi o caso nas reações dos compostos modelo, os picos dos n-alcanos são acompanhados por picos dos respectivos isômeros de cadeia, principalmente dos isômeros monorramificados. 


\subsubsection{HDO do óleo de soja}

Tomando-se como base a reação realizada previamente com o óleo de coco, a $\mathrm{HDO}$ do óleo de soja catalisada pelo $\mathrm{NiMoS}_{2} / \mathrm{Al}_{2} \mathrm{O}_{3}$ foi realizada a $340{ }^{\circ} \mathrm{C}$ por $6 \mathrm{~h}$. A análise do produto obtido indica que a desoxigenação ocorreu de maneira bastante satisfatória: o índice de acidez medido foi de apenas $0,35 \mathrm{mg} \mathrm{KOH} / \mathrm{g} \mathrm{e}$, no espectro de FTIR (Figura 4.19), fizeram-se presentes apenas as absorções correspondentes a alcanos (ver seção 4.2.2.2). Ainda, não foram verificados, no cromatograma do produto (Figura 4.20), picos referentes a ácidos carboxílicos.

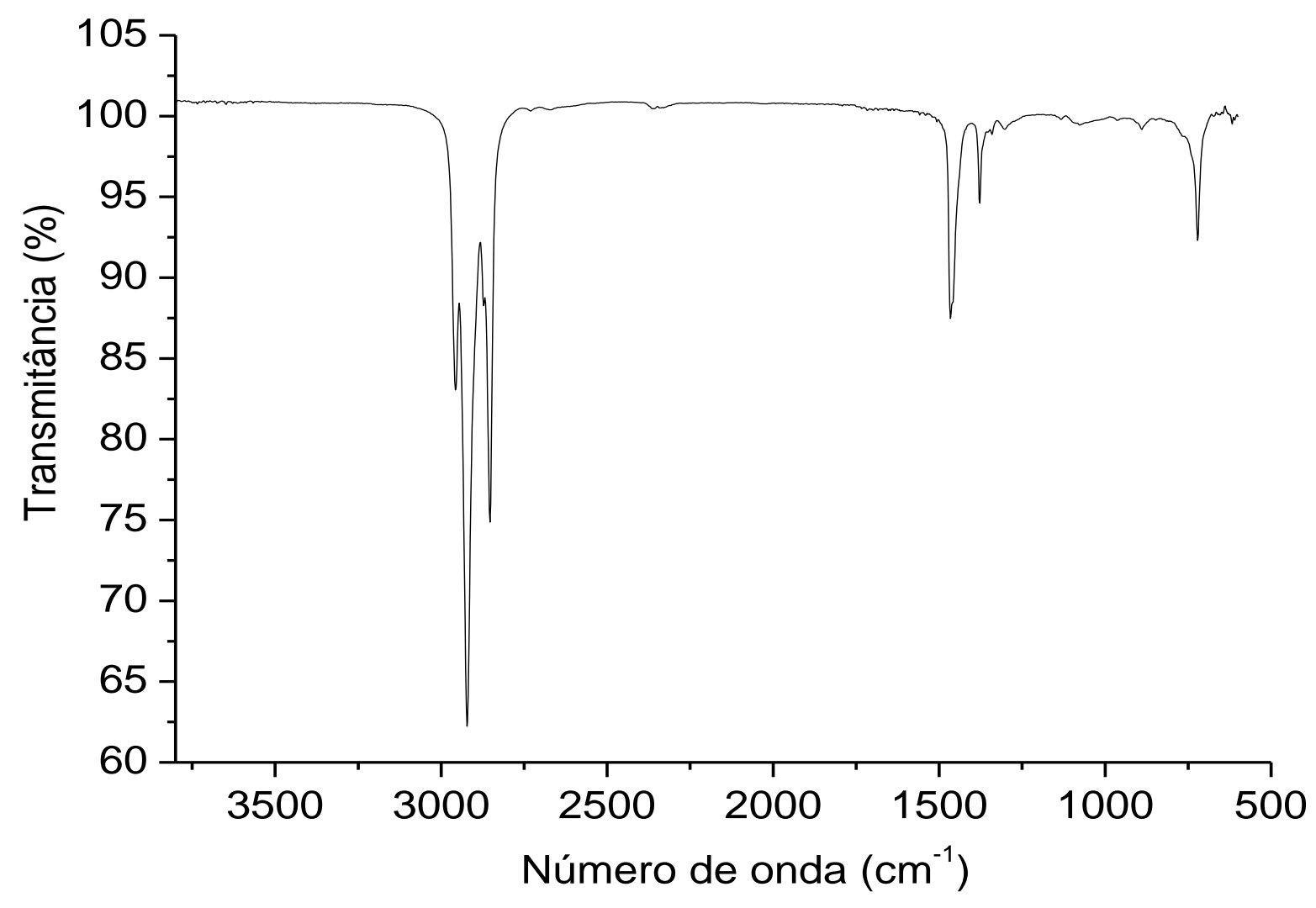

Figura 4.19 - Espectro de FTIR do produto da HDO do óleo de soja utilizando o catalisador $\mathrm{NiMoS} / 2 / \mathrm{Al}_{2} \mathrm{O}_{3}$ a $340 \stackrel{\circ}{\circ} \mathrm{C}$ por $6 \mathrm{~h}$. 


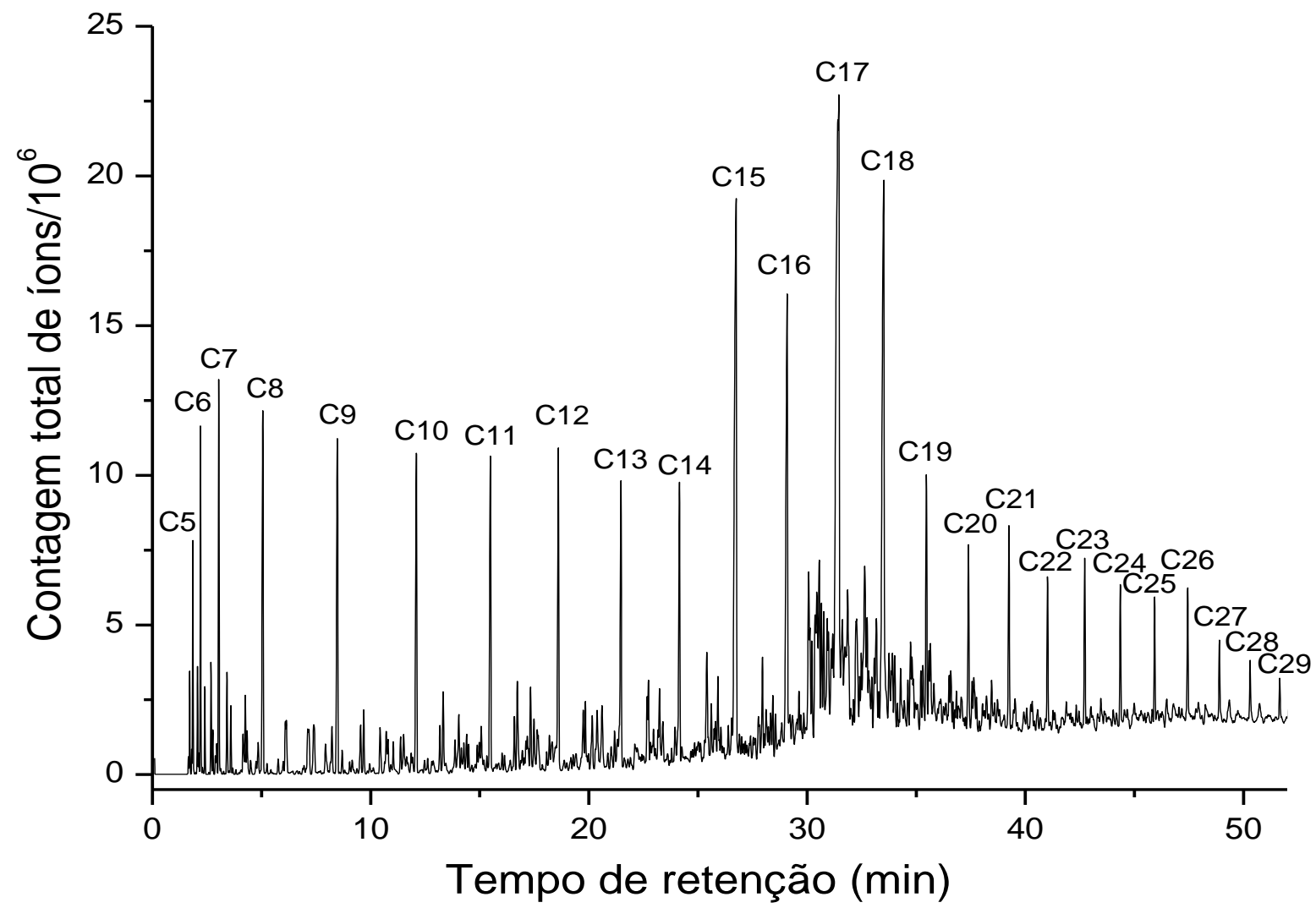

Figura 4.20 - Cromatogramas (GC/MS) do produtos da HDO do óleo de soja utilizando o catalisador $\mathrm{NiMoS} / \mathrm{Al}_{2} \mathrm{O}_{3}$, a $340^{\circ} \mathrm{C}$ por $6 \mathrm{~h}$. $\mathrm{CX}$ corresponde aos $\mathrm{n}$-alcanos com $\mathrm{X}$ átomos de carbono.

O perfil de reações seguido pelo óleo de soja foi muito similar àquele seguido pelo óleo de coco. Porém, é claro, os produtos formados foram diferentes devido ao fato de que o óleo de soja é formado basicamente por ácidos carboxílicos C16 e C18 (Tabela 2.1). Assim, os principais picos observados, em ordem crescente de intensidade, são para os n-alcanos $\mathrm{C} 17>\mathrm{C} 15 \approx \mathrm{C} 18>\mathrm{C} 16$.

Fica clara, também, a presença relativamente pronunciada de produtos de craqueamento ( $\mathrm{e}$, consecutivamente, de reações de acoplamento). Conforme discutido na seção 4.2.2.3, referente à HDO do ácido oleico, o craqueamento seria favorecido pelo tamanho avantajado das cadeias constituintes do óleo de soja e pela pronunciada presença de cadeias insaturadas (seção 2.1.2).

Por fim, assim como ocorreu nas demais reações de HDO, os picos dos nalcanos são acompanhados por picos dos respectivos isômeros de cadeia, principalmente dos isômeros monorramificados. 


\subsection{Considerações finais acerca das reações de HDO de óleos vegetais}

Os resultados apresentados ao longo da seção 4.2 e as discussões realizadas permitem elaborar um esquema sistematizando as principais reações que ocorrem durante a hidrodesoxigenação de óleos e gorduras vegetais e animais catalisada por $\mathrm{NiMoS}_{2} / \mathrm{Al}_{2} \mathrm{O}_{3}$, conforme apresentado na Figura 4.21. É preciso destacar que esse esquema se assemelha ao proposto por Senol et al. ${ }^{46}$ para as reações de hidrodesoxigenação do heptanoato de metila. Diversas outras reações de menor importância podem ocorrer no interior do sistema. Por exemplo, pode-se citar todas as reações envolvidas no craqueamento térmico, conforme discutido na seção 4.2.1.

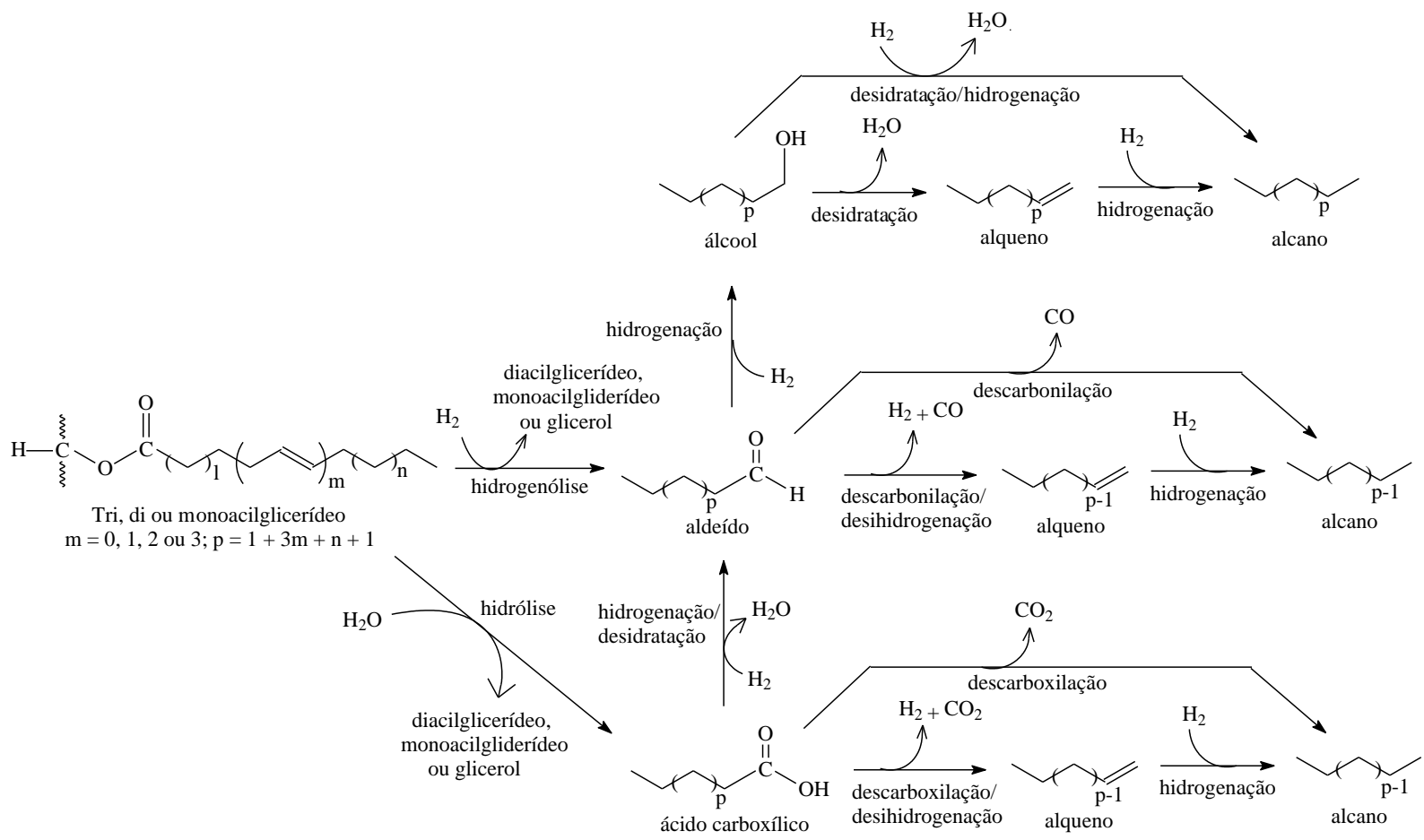

Figura 4.21 - Esquema proposto para as principais reações que ocorrem durante a hidrodesoxigenação de óleos e gorduras vegetais e animais catalisada por $\mathrm{NiMoS}_{2} / \mathrm{Al}_{2} \mathrm{O}_{3}$. 


\subsection{Avaliação da composição dos óleos de coco e de soja desoxigenados}

A Figura 4.22 mostra os cromatogramas das amostras de óleo de soja e de coco desoxigenados e de uma amostra de querosene de aviação comercial. A comparação dos cromatogramas demonstra que, em termos do tamanho de cadeia, a composição da amostra de óleo de coco desoxigenado se encontra muito próxima da composição da querosene comercial. As diferenças, fundamentalmente, se encontram na proporção de compostos ramificados, que é muito maior na amostra de querosene comercial. Esse resultado demonstra que o óleo de coco possui grande potencial para ser utilizado como precursor de bioquerosene para aviação. Entretanto, é necessário um tratamento, posterior ao de $\mathrm{HDO}$ com $\mathrm{NiMoS}_{2} / \mathrm{Al}_{2} \mathrm{O}_{3}$, que permita a isomerização das cadeias. Conforme discutido na seção 4.6 , a presença de considerável proporção de compostos ramificados é importante para propiciar propriedades a frio adequada à querosene de aviação.

Por sua vez, a amostra de óleo de soja desoxigenado apresenta, em relação à querosene de aviação comercial, um perfil cromatográfico deslocado para maiores tempos de retenção, ou seja, sua composição química apresenta-se centrada em torno de compostos com maior tamanho de cadeia. Esse resultado sugere que o óleo de soja desoxigenado apresente maior potencial para ser empregado como biodiesel parafínico, embora exista a possibilidade de que, por meio de hidrocraqueamento, sua composição possa ser ajustada à faixa de tamanhos de cadeias requeridas para a bioquerosene de aviação. Por fim, a baixa proporção de compostos ramificados presente na amostra indica que, tanto para o emprego como óleo diesel quanto como bioquerosene, o óleo de soja desoxigenado deve ser submetido a um processo de isomerização das cadeias: no primeiro caso, especificamente para melhorar as propriedades a frio do combustível; no segundo, também para aumentar a octanagem. 

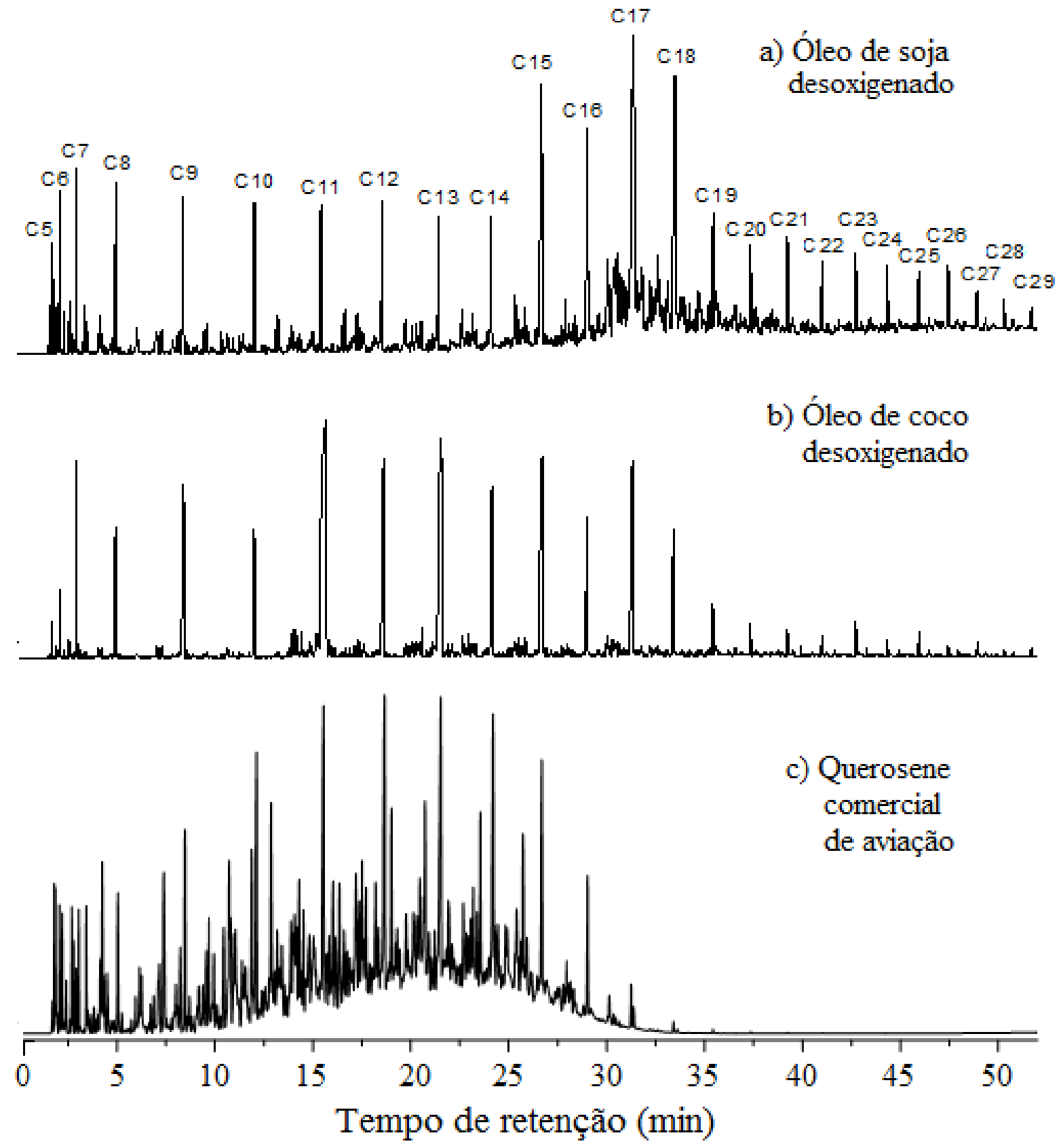

Figura 4.22 - Cromatogramas (GC/MS) dos produtos da HDO do (a) óleo de coco e do (b) óleo de soja utilizando o catalisador $\mathrm{NiMoS}_{2} / \mathrm{Al}_{2} \mathrm{O}_{3}$, a $340^{\circ} \mathrm{C}$ por $6 \mathrm{~h}$, e (c) de uma amostra comercial de querosene para aviação. CX corresponde aos n-alcanos com X átomos de carbono.

\subsection{Hidroisomerização dos óleos de coco e de soja desoxigenados}

Em um trabalho paralelo realizado por outro integrante de nosso grupo de pesquisa, os óleos de coco e de soja desoxigenados via HDO foram submetidos a uma etapa posterior de hidroisomerização em presença de um catalisador de 
Pt/SAPO-11. ${ }^{61}$ Com isso, foi possível aumentar consideravelmente o grau de isomerização das misturas, conforme pode ser observado por meio da comparação dos cromatogramas do óleo de coco desoxigenado antes e após o referido tratamento (Figura 4.23). As porcentagens de compostos ramificados com número de átomos de carbono na faixa de $\mathrm{C} 11$ a $\mathrm{C} 18$ foi de $42,4 \%$ e $39,9 \%$ para os produtos da hidroisomerização dos óleos de coco e de soja, respectivamente (Tabela 4.4).
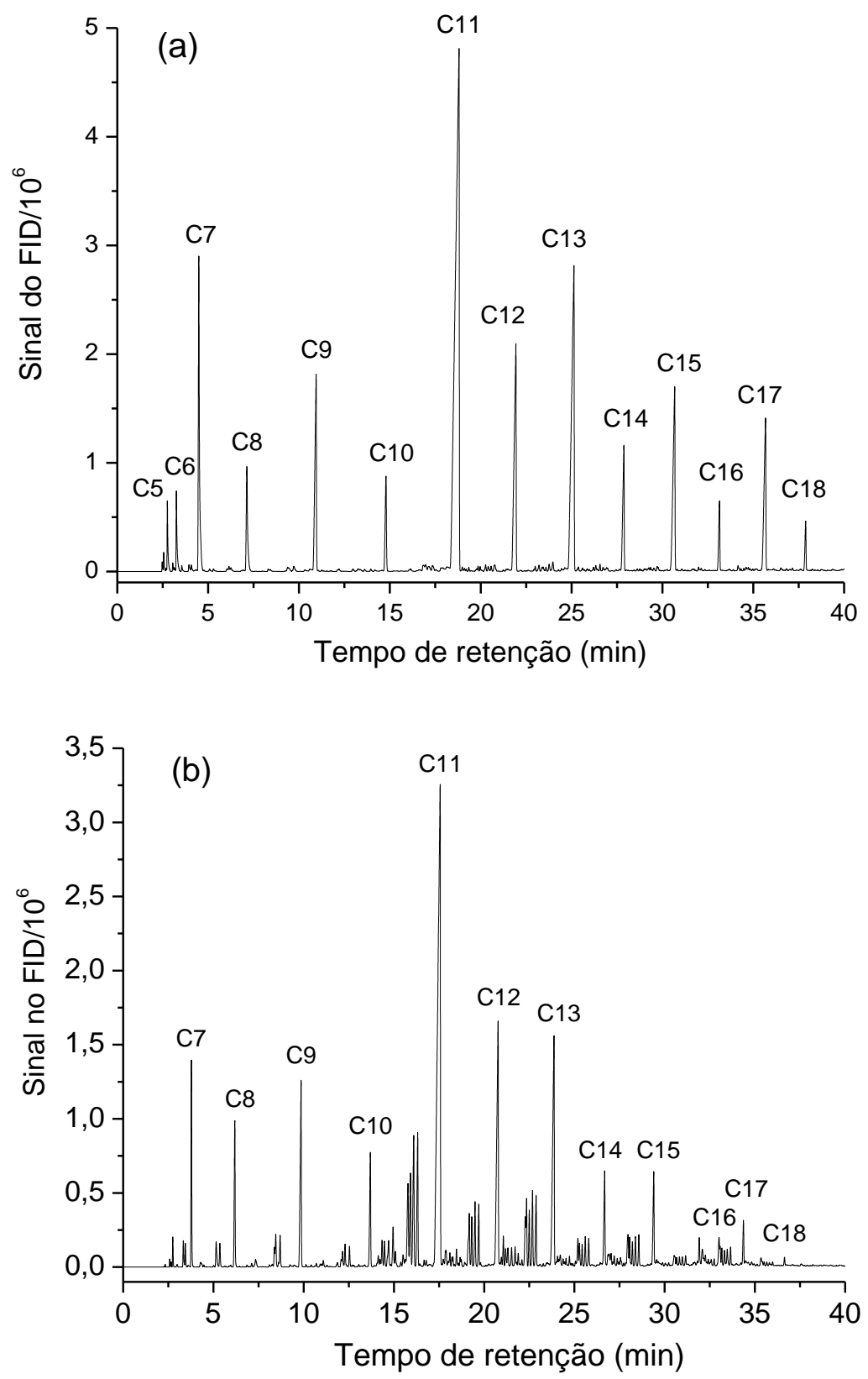

Figura 4.23 - Cromatogramas GC-FID do: (a) produto da HDO do óleo de coco, catalisada por $\mathrm{NiMoS}_{2} / \mathrm{Al}_{2} \mathrm{O}_{3}\left(340^{\circ} \mathrm{C}, 6 \mathrm{~h}\right)$; (b) produto da reação de isomerização do óleo de coco desoxigenado catalisada por Pt/SAPO- $11\left(350^{\circ} \mathrm{C}, 8 \mathrm{~h}\right) .{ }^{61}$ 
Tabela 4.4 - Composição, a partir dos cromatogramas GC/FID, dos produtos obtidos a partir da hidroisomerização, catalisada por Pt/SAPO-11, dos óleos de coco e de soja desoxigenados por meio do processo de $\mathrm{HDO}\left(\mathrm{NiMoS}_{2} / \mathrm{Al}_{2} \mathrm{O}_{3}, 340^{\circ} \mathrm{C}, 6 \mathrm{~h}\right)$.

\begin{tabular}{lccc}
\hline Precursor & iso-C11:C18 & n-C11:C18 & $\leq$ C10 \\
\hline Óleo de coco & 42,4 & 41,0 & 16,6 \\
Óleo de soja & 39,9 & 41,0 & 19,2 \\
\hline
\end{tabular}

Os resultados apresentados demonstram o potencial apresentado por óleos e gorduras vegetais para serem empregados na síntese de biocombustíveis parafínicos por meio do processo de hidrotratamento (hidrodesoxigenação/hidroisomerização). Entretanto, é válido salientar que muitos estudos ainda precisam ser realizados. Fundamentalmente, é necessário desenvolver um sistema que permita trabalhar em maior escala, possivelmente um sistema contínuo. Assim, será possível realizar uma caracterização mais completa dos produtos obtidos e, então, fazer-se uma melhor avaliação das condições que devem ser empregadas na preparação de combustíveis com aplicações específicas.

\subsection{Identificação dos componentes dos produtos de reação por GC/MS}

Na presente seção, é explicado, de maneira sucinta, como foram identificados os picos referentes aos compostos mais importantes presentes nos produtos das reações realizadas. No que se refere aos índices de Kovats, buscou-se, na literatura, valores obtidos em colunas o mais próximas possível das utilizadas no presente trabalho.

\subsubsection{Alcanos e alquenos}

A identificação de alcanos e alquenos de baixa massa molar nos cromatogramas GC/MS é feita de maneira muito fácil a partir da biblioteca de espectros de massas. Por exemplo, a Figura 4.24 mostra o espectro obtido para o hexano e o fornecido pela biblioteca, sendo verificada uma similaridade de $97 \%$. 


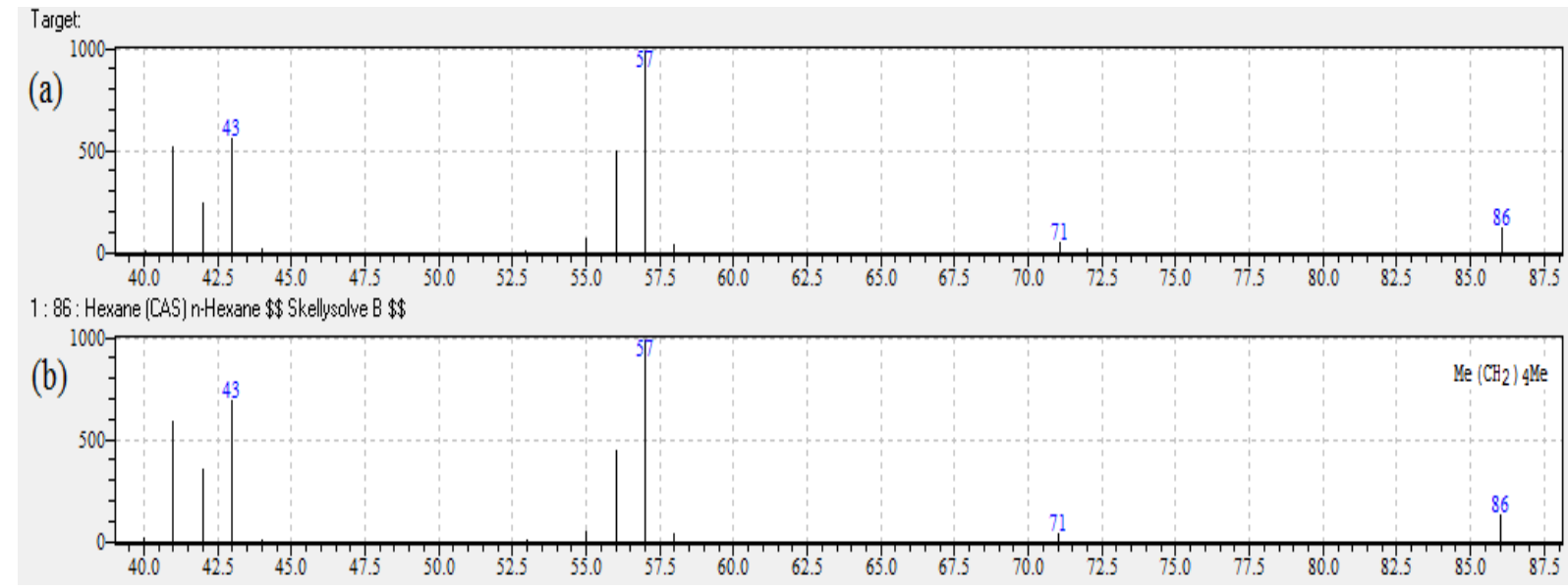

Figura 4.24 - Espectros de massas correspondentes (a) ao pico em 2,20 min no cromatograma das Figuras 4.5 e 4.7 e (b) ao hexano na biblioteca digital.

Nos espectros de massas de alcanos, tem-se os picos correspondentes a $\mathrm{m} / \mathrm{z}$ 15, 29, 43, 57 e assim por diante; ou seja, em $\mathrm{m} / \mathrm{z}(15+\mathrm{n} \cdot 14)$, onde $\mathrm{n}=0,1,2,3 \ldots$ O primeiro, em $\mathrm{m} / \mathrm{z} 15$, corresponde ao carbocátion metil $\left(\mathrm{CH}_{3}{ }^{+}\right)$; os demais, correspondem a aumentos de 14 unidades de massa devido ao acréscimo de um grupo $\mathrm{CH}_{2}\left(\mathrm{CH}_{3}{ }^{+}, \mathrm{CH}_{3} \mathrm{CH}_{2}{ }^{+}, \mathrm{CH}_{3} \mathrm{CH}_{2} \mathrm{CH}_{2}{ }^{+}, \ldots\right)$. Normalmente, os picos mais intensos são os correspondentes a m/z 43 e 57 e, na sequência, as intensidades decrescem continuamente. Todos esses aspectos podem ser facilmente observados no espectro de massas do dodecano, na Figura 4.25.a.
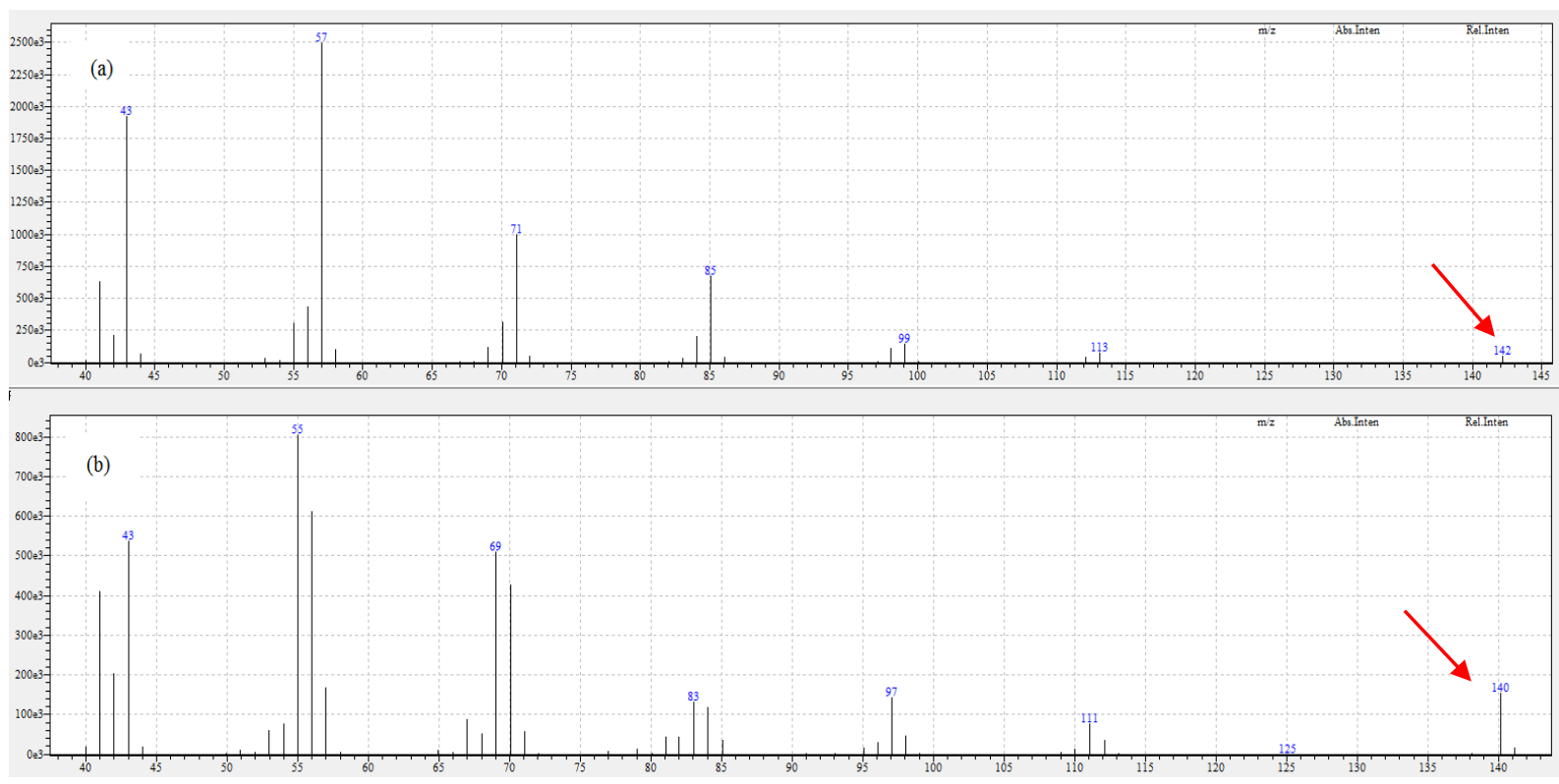

Figura 4.25 - Espectros de massas correspondentes aos picos em (a) 12,12 min (decano) e (b) 12,30 min (trans-2-deceno) no cromatograma das Figuras 4.5 e 4.7. Obs. Os respectivos picos $M+$ são destacados com setas. 
É válido destacar que, quanto maior a massa molar do alcano, menos estável é seu íon molecular e, dessa forma, menos intenso o pico correspondente $\left(M_{+}\right)$, conforme se pode observar na comparação dos espectros do hexano e do decano apresentados nas Figuras 4.24 e 4.25.a, respectivamente.

Os alquenos apresentam espectros de certa forma semelhantes aos alcanos. Entretanto, dois aspectos permitem muito facilmente diferenciá-los: 1) Além dos picos em $\mathrm{m} / \mathrm{z}(15+\mathrm{n} \cdot 14)$, também se fazem presentes, em intensidades relativamente elevadas e, às vezes até superiores, picos em m/z $(15+n \cdot 12)$ e $(15+$ $\mathrm{n}$.13); 2) nos alquenos, os picos $M+$ são mais intensos porque o íon molecular deriva da perda de um elétron $\pi$ da dupla ligação. Essas diferenças podem ser verificadas por meio da comparação dos espectros do decano e do 2-deceno nas Figuras 4.25.a e 4.25.b, respectivamente.

Ainda com relação aos alquenos, muitas vezes é difícil diferenciar precisamente a posição da dupla. Entretanto, é válido destacar que, no presente trabalho, esse não era objetivo de grande interesse. Ainda assim, na maior parte das vezes, principalmente para os produtos de craqueamento da reação de hidropirólise não catalítica, foi possível identificar um padrão regular de picos relativamente intensos referentes aos alquenos terminais e aos isômeros cis e trans dos 2alquenos. Para isso, ajudaram em muito os índices de Kovats dos compostos, sendo que, em relação ao alcano correspondente, os índices foram sempre levemente inferiores para o alqueno terminal, levemente superior para o isômero cis do 2alqueno e, um pouco maior para o isômero trans (ver Figura 4.7).

Para os alcanos de maior massa molar, a tarefa de identificar seus picos não é tão simples, porque os espectros se tornam muito similares e os picos do íon molecular $(\mathrm{M}+)$ podem não ser detectados, conforme demonstrado na Figura 4.26 para o eicosano e o eneicosano (alcanos $\mathrm{C} 20$ e C21, respectivamente). Entretanto, na maioria das vezes o problema pode ser solucionado de uma das seguintes formas: 

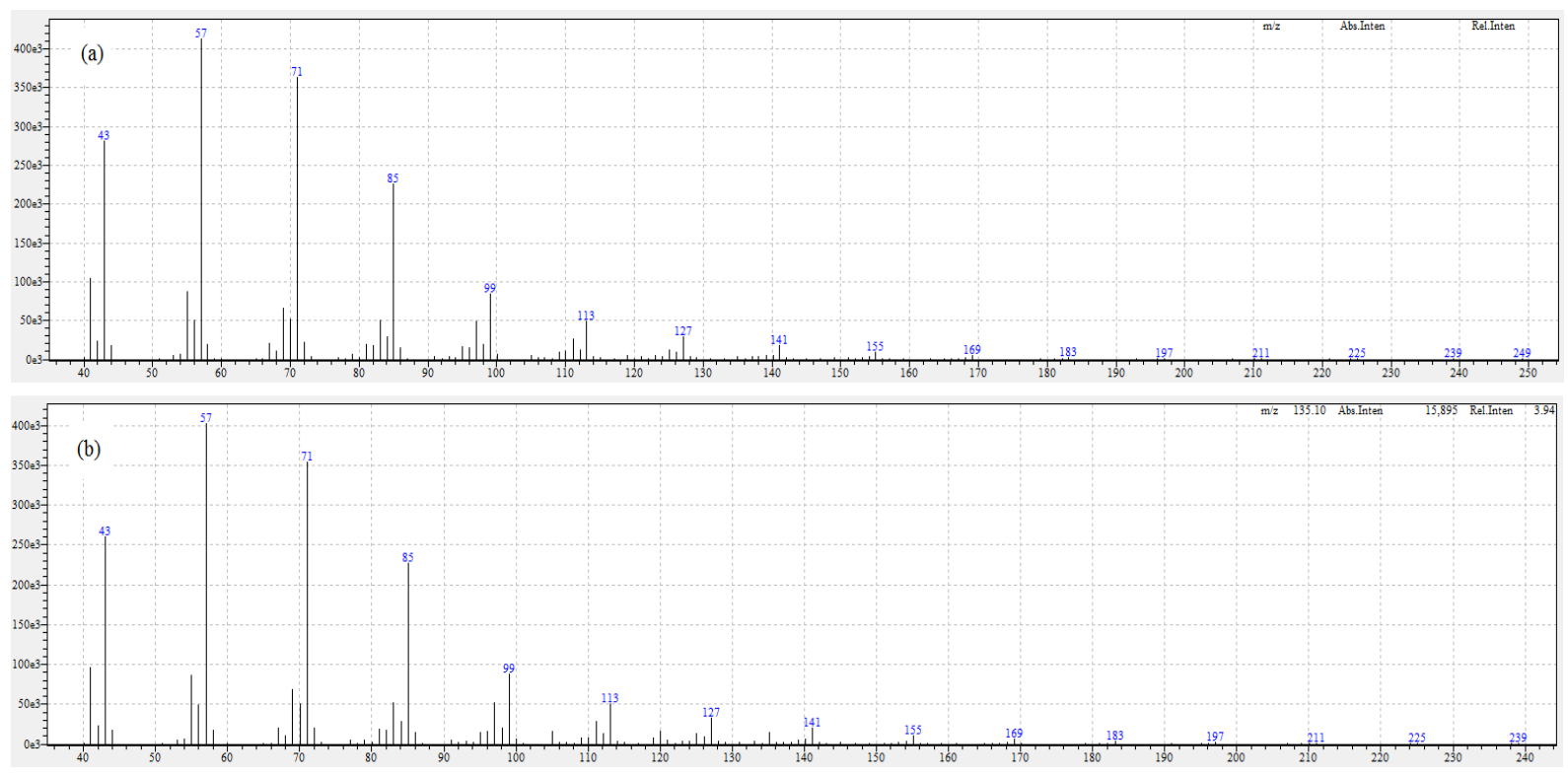

Figura 4.26 - Espectros de massas correspondentes aos picos em (a) 37,41 min (eicosano) e (b) 39,26 min (eneicosano) no cromatograma das Figuras 4.5 e 4.6.

1) Em primeiro lugar, os produtos obtidos a partir das reações de pirólise e HDO apresentam, em suas composições, a série completa de alcanos (até um certo número de átomos de carbono, evidentemente). Uma vez que os alcanos correspondem aos picos de maior intensidade no cromatograma e o espaçamento entre eles é aproximadamente constante, pode-se então, a partir dos alcanos de baixa massa molar, fazer a atribuição dos demais de acordo com a ordem crescente do número de carbonos (conforme pode ser visto na Figura 4.3, por exemplo).

2) Em segundo lugar, muitas vezes os picos dos alcanos são acompanhados, em tempos de retenção muito próximos, dos picos dos respectivos alquenos. Assim, por meio da massa molar do alqueno, verificada por meio de seu pico $\mathrm{M}^{+}$de relativa intensidade, o alcano pode ser identificado.

Finalmente, é válido destacar que os isômeros ramificados sempre apresentam tempos de retenção inferiores aos respectivos alcanos lineares. De maneira geral, conforme pode ser observado na Figura 4.11, tem-se um perfil cromatográfico em que se destacam os isômeros monorramificados. Para estes, especialmente para compostos de cadeias mais curtas, é possível fazer a identificação de cada pico, seja por meio dos índices de Kovats, seja por meio da biblioteca de espectros. Entretanto, para os isômeros bi e multirramificados, especialmente de compostos de maior massa molar, essa identificação torna-se bastante difícil porque o número de possíveis isômeros se torna elevado. Entretanto, 
mais uma vez, salienta-se que o importante, neste trabalho, foi identificar, de maneira geral, a ocorrência de isômeros ramificados.

Por fim, cabe destacar que os picos de alcanos ramificados $\mathrm{Cn}$ muitas vezes se encontram na mesma região de picos relativos a outros compostos, especialmente compostos cíclicos $\mathrm{Cn}-1$ (aromáticos e não aromáticos). Entretanto, os picos referentes aos alcanos ramificados podem ser facilmente diferenciados com base em seus espectros de massas típicos de alcanos, conforme discutido no início desta seção.

\subsection{2 Ácidos carboxílicos}

A identificação dos ácidos carboxílicos foi realizada de maneira bastante simples. Em primeiro lugar, eles resultaram em picos que se destacam dos demais pela largura, o que resulta das ligações de hidrogênio que esta classe de compostos estabelece (ver Figura 4.5). Além disso, a biblioteca costuma identificar facilmente tratar-se de um ácido carboxílico devido aos picos bem característicos presentes em seus espectros de massas e que não se fazem presentes em outras classes de compostos. Como exemplo, pode-se citar os picos intensos em m/z 60 e 70, conforme demonstrado na Figura 4.27, devido ao "Rearranjo de McLafferty" e à cisão da ligação entre os carbonos $\beta$ e $\gamma$ (fragmentações I e II, respectivamente):

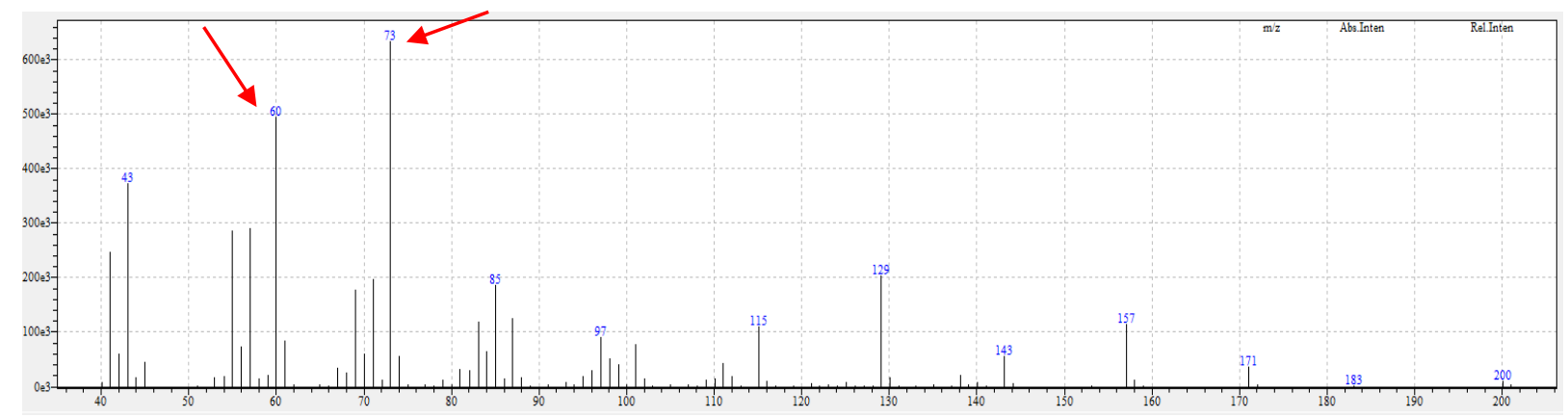

Figura 4.27 - Espectro de massas correspondente ao pico entre 28,3 e 29,0 min (ácido láurico) no cromatograma das Figuras 4.5 e 4.6 . 
(I)

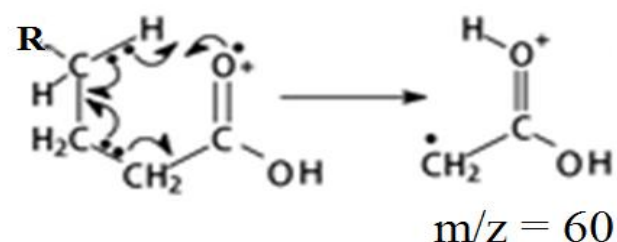

(II)

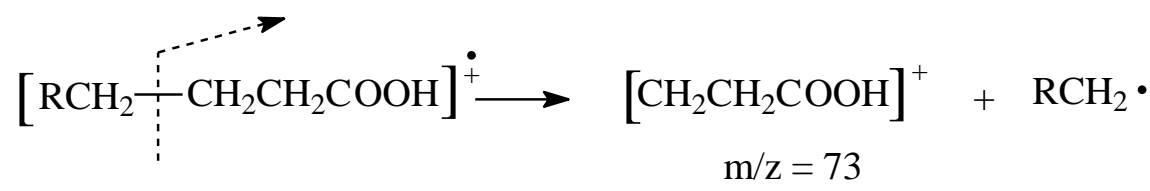

Ainda com relação aos picos dos ácidos carboxílicos, é válido destacar que, ao menos para a faixa de tamanho de cadeia com que se trabalhou no presente trabalho (C12 a C18), eles apresentam tempos de retenção pouco inferiores ao do pico referente ao alcano com quatro átomos de carbono a mais. Assim, os índices de retenção de Kovats podem ser facilmente empregados para confirmar o ácido a que se refere o pico. Por exemplo, o ácido láurico, com doze átomos de carbono, apresenta um tempo de retenção em torno de $1567^{64}$ (é válido lembrar, ao hexadecano, é atribuído, por convenção, o valor 1600); para o ácido tetradecanoico, com 14 átomos de carbono, o índice de retenção é $1770^{65}$.

\subsubsection{Aldeídos}

Os aldeídos apresentam espectros de massas bem característicos, de forma que a identificação do dodecanal (Figura 4.28) foi realizada de maneira muito precisa pela biblioteca digital de espectros, com $97 \%$ de similaridade. Além disso, ao menos para a faixa de tamanho de cadeia com que se trabalhou no presente trabalho $(\mathrm{C} 12 \mathrm{a}$ C18), os aldeídos apresentam tempos de retenção ligeiramente superiores ao do pico referente ao alcano com dois átomos de carbono a mais. Assim, o índice de retenção de Kovats do aldeído, 1409, pôde ser empregado para confirmação de seu pico. ${ }^{66}$ 

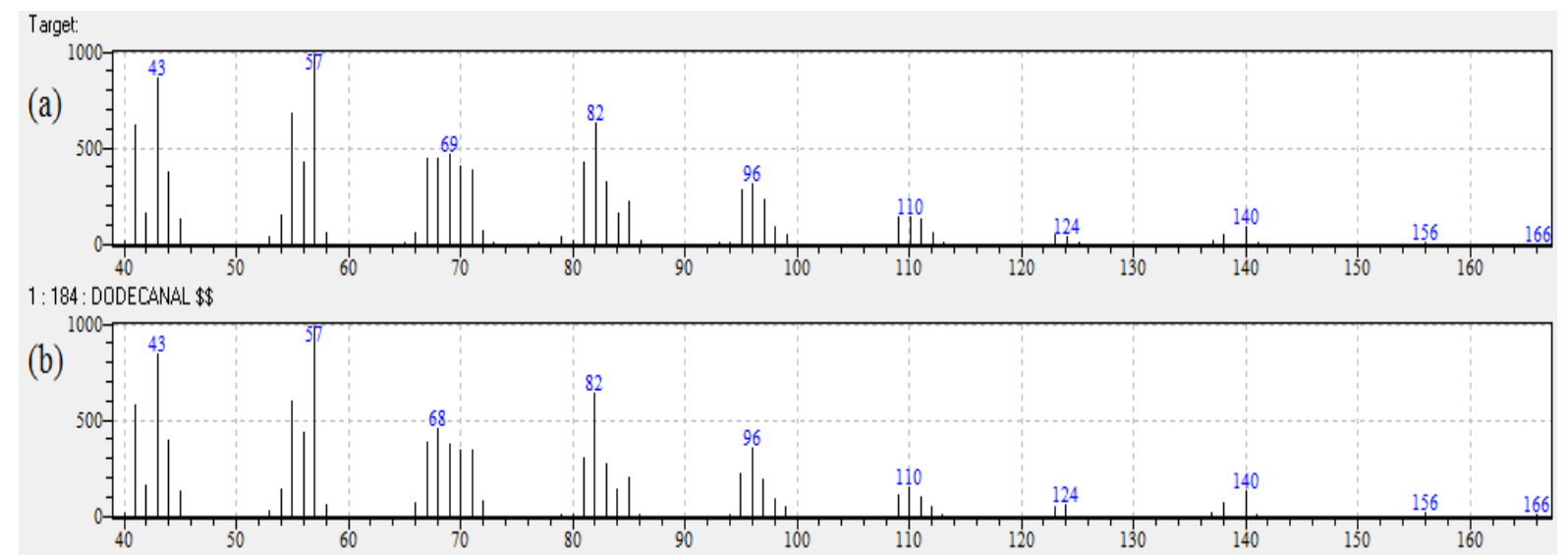

Figura 4.28 - Espectros de massas correspondente (a) ao pico em 24,43 min no cromatograma das Figuras 4.5 e 4.6 e (b) ao dodecanal na biblioteca digital.

\subsubsection{Cetonas}

Com relação à identificação de cetonas, primeiramente é válido destacar que, no cromatograma do produto da hidropirólise não catalítica do ácido láurico, de maneira geral fez-se presente, em tempos de retenção muito próximos a cada pico referente aos alcanos $\geq 15$, outro pico, de intensidade similar (ver cromatograma da Figura 4.6), que a biblioteca digital sugeriu serem de cetonas; porém, sem conseguir precisar qual.

A análise dos espectros de massas correspondentes evidenciou a presença, em todos eles, a partir do C16, de um pico em $\mathrm{m} / \mathrm{z}$ 183, conforme exemplificado, na Figura 4.29, para alguns dos compostos. Essa massa corresponde à massa do cátion dodecanoil, $\left[\mathrm{CH}_{3}\left(\mathrm{CH}_{2}\right){ }_{10} \mathrm{C}(=\mathrm{O})\right]^{+}$, o que serviu como forte indício de que realmente a série de picos em questão refere-se a cetonas e que elas resultariam do acoplamento entre o radical dodecanoil, formado de acordo com a reação (xiv), apresentada na seção 4.2.1.2, com um radical $n$-alquil, conforme mostra a reação (xvi). Assim, o pico em m/z 183 resultaria da fragmentação devido à cisão de uma ligação $\alpha$ à carbonila para formar o íon acílio estabilizado por ressonância:

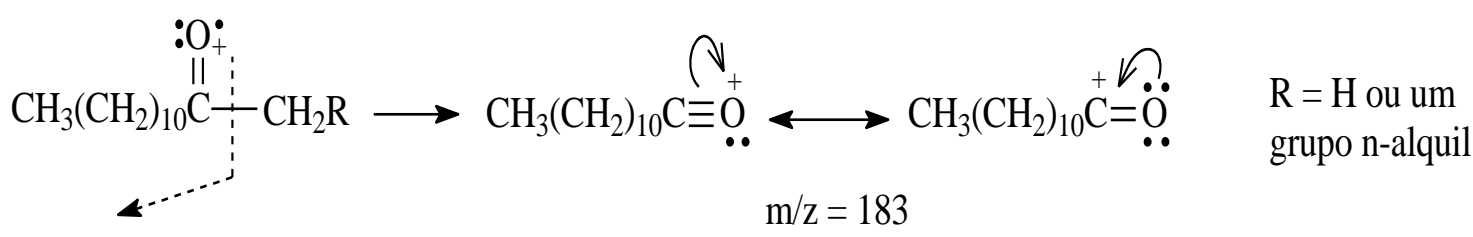




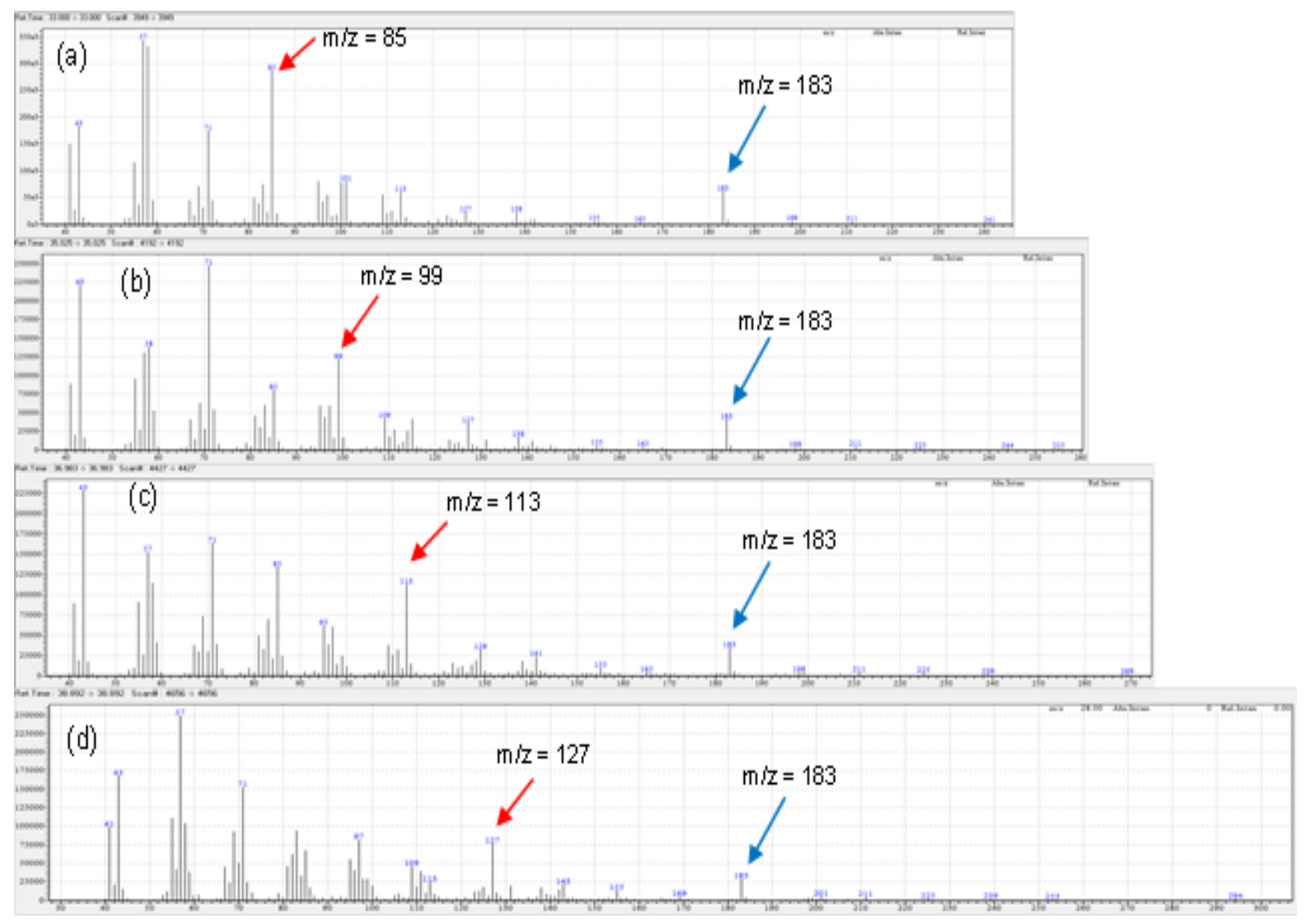

Figura 4.29 - Espectros de massas correspondentes aos picos em (a) 33,01 min (5-hexadecanona), (b) 35,04 min (6-heptadecanona), (c) 37,00 $\mathrm{min}$ (7-octadecanona) e (d) 38,89 min (8-nonadecanona) no cromatograma das Figuras 4.5 e 4.6 .

A literatura demonstra que as cetonas apresentam tempos de retenção muito próximos ao do pico referente ao alcano com dois átomos de carbono a mais. Assim, para a cetona mais simples formada a partir do radical dodecanoil, a 2-tridecanona, o índice de retenção de Kovats é de 1498 67; para a 3-tetradecanona, 1597 68; e assim por diante. Os índices verificados na literatura correspondem muito bem aos valores calculados para os picos presentes no cromatograma das Figuras 4.5 e 4.6.

Por fim, uma análise cuidadosa dos espectros de massas permitiram identificar o outro pico acílio referentes às possíveis cisões da ligações $\alpha$ à carbonila.

Para a 5-hexadecanona, por exemplo, esse pico ocorre em $\mathrm{m} / \mathrm{z} 85$ (Figura 4.29.a) e se refere à fragmentação:

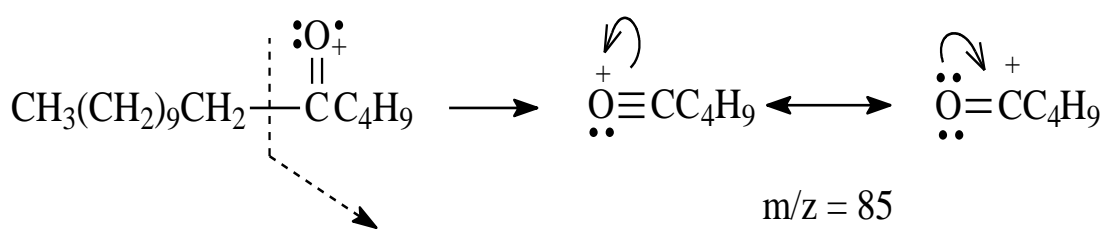


A fragmentação descrita em (IV) depende da cadeia que se ligou ao radical dodecanoil e varia de 14 em 14 unidades de massa, conforme explicitado na Figura 4.29 para a sequência 5-hexadecanona, 6-heptadecanona, 7-octadecanona e 8nonadecanona, para as quais os valores do pico correspondem a $\mathrm{m} / \mathrm{z}=85,99,113$ e 127, respectivamente.

Por tudo o que foi exposto nessa seção, não restaram dúvidas quanto à presença dos picos referentes à série de alquilundecilcetonas, desce a 2tridecanona até a 12-tricosanona.

\subsection{5 Ésteres}

O pico localizado no tempo de retenção de 47,07 min nos cromatogramas das Figuras 4.5 e 4.6 foi o de mais difícil identificação. Em primeiro lugar, é preciso destacar que ele apresenta um pico bastante intenso em m/z 201 e outro, menos intenso, em 183 (Figura 4.30), o que é típico de ésteres contendo o grupo dodecanoato, conforme mostra a Figura 4.31. Com base em todas as discussões realizadas na seção 4.2.1.2, acredita-se fortemente tratar-se do dodecanoato de undecila, resultado da reação (xviii); entretanto, não foi possível encontrar o espectro de massas desse composto na literatura e tampouco na biblioteca digital.

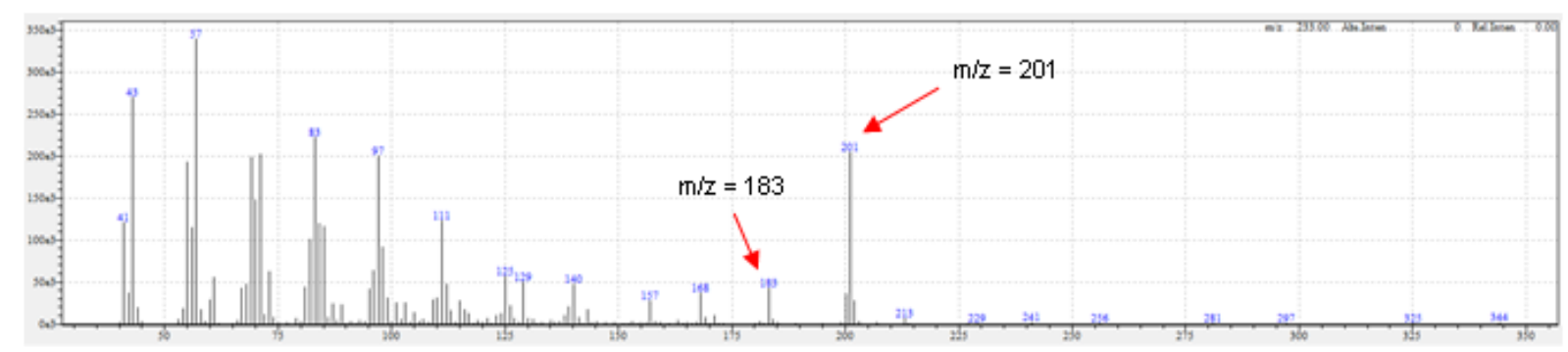

Figura 4.30 - Espectros de massas correspondente (a) ao pico em 47,07 min no cromatograma das Figuras 4.5 e 4.6 .

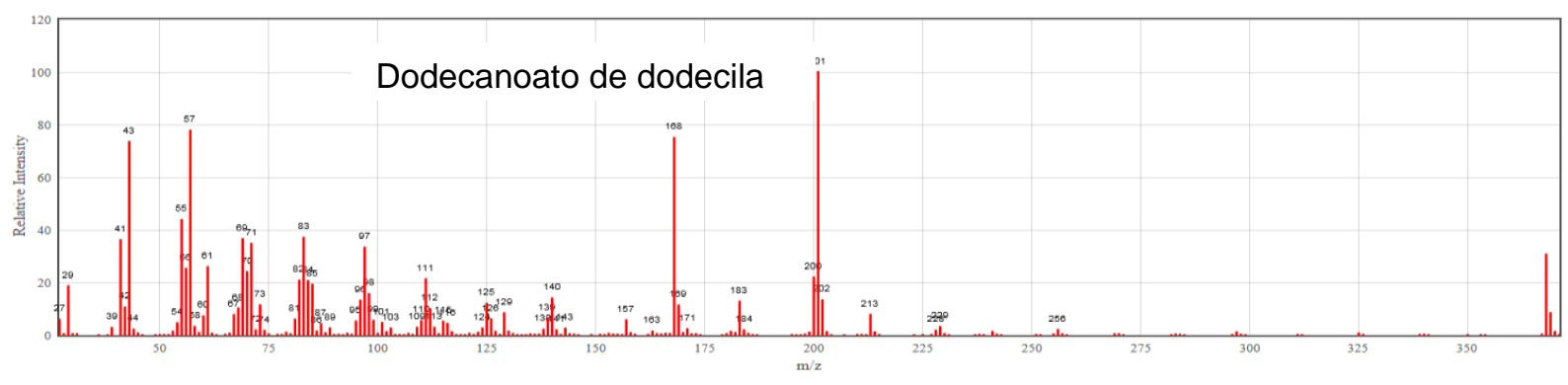

Figura 4.31 - Espectros de massas da literatura para o dodecanoato de dodecila. Fonte: ref. ${ }^{69}$. 


\subsection{6 Álcoois}

O pico correspondente ao 1-dodecanol, na Figura 4.13, foi identificado com base nos espectros da biblioteca digital (Figura 4.32), que resultou numa similaridade de $94 \%$, e no índice de Kovats do composto, $1472^{70}$.

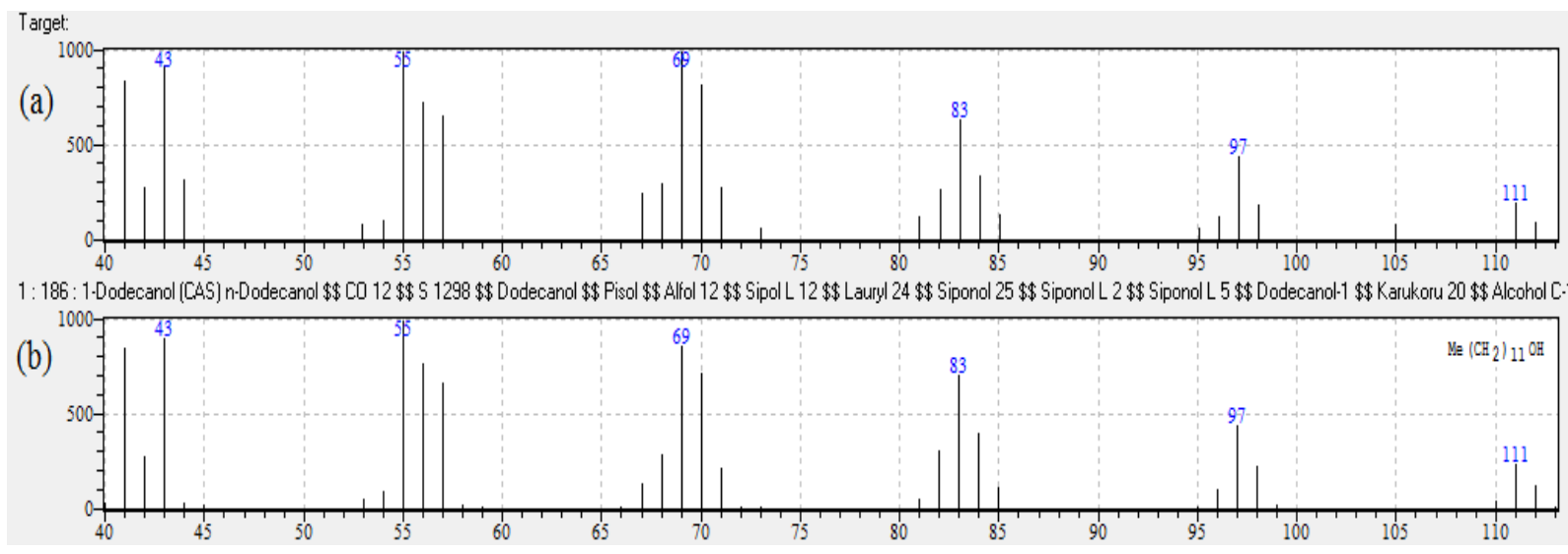

Figura 4.32 - Espectros de massas correspondente (a) ao pico em 26,05 min no cromatograma das Figuras 4.5 e 4.6 e (b) ao dodecanol na biblioteca digital. 


\section{CAPÍTULO 5 - CONCLUSÕES E PERSPECTIVAS}

No presente trabalho, foi realizado um estudo acerca da hidrodesoxigenação (HDO), em presença do catalisador $\mathrm{NiMoS}_{2} / \mathrm{Al}_{2} \mathrm{O}_{3}$, de compostos modelo (ácidos láurico e oleico) e dos óleos de coco e de soja. Em primeiro lugar, esse estudo propiciou importantes constatações acerca das reações e mecanismos envolvidos nos processos de hidropirólise não catalítica e de HDO de triacilglicerídeos. Além disso, foi possível verificar quais condições reacionais, durante a HDO, são mais adequadas para a obtenção de biocombustíveis com as propriedades desejadas.

Em relação às rotas reacionais e mecanismos envolvidos, verificou-se que, durante a hidropirólise não catalítica de triacilglicerídeos e ácidos graxos, as reações envolvem a liberação de $\mathrm{CO}_{2}$ ou $\mathrm{CO}$ e $\mathrm{H}_{2} \mathrm{O}$, com a formação dos radicais 1-alquil referentes ao grupo ligado à carbonila, ou seja, com "n-1" átomos de carbono em relação ao ácido graxo correspondente $\left(\mathrm{C}_{n} \mathrm{H}_{2 n} \mathrm{O}_{2}\right)$. Estes radicais são então estabilizados na forma dos respectivos alcanos ou alquenos terminais ou, ainda, de alquenos internos (principalmente 2-alquenos) após rearranjo dos radicais 1-alquil.

Quando do emprego do catalisador $\mathrm{NiMoS}_{2} / \mathrm{Al}_{2} \mathrm{O}_{3}$, surgem outros caminhos reacionais, de menor energia de ativação, envolvendo a formação de carbocátions. Parte desses novos caminhos também envolve reações de descarboxilação e descarbonilação, resultando nos mesmos produtos das reações da hidropirólise não catalítica, ou seja, alcanos e alquenos $\mathrm{C}_{\mathrm{n}-1}$. Entretanto, um novo caminho reacional que surge envolve a perda dos átomos de oxigênio não na forma de $\mathrm{CO}$ ou $\mathrm{CO}_{2}$, mas de $\mathrm{H}_{2} \mathrm{O}$ (hidrogenação/desidratação), levando a alcanos e alquenos $\mathrm{C}_{n}$. Por fim, o catalisador acaba por hidrogenar os alquenos a alcanos, de forma que os produtos principais da $\mathrm{HDO}$ catalisada por $\mathrm{NiMoS}_{2} / \mathrm{Al}_{2} \mathrm{O}_{3}$ são os alcanos $\mathrm{C}_{n-1}$ e $\mathrm{C}_{n}$.

Como resultado das reações de HDO dos compostos modelo, verificou-se que o emprego de uma temperatura de $340^{\circ} \mathrm{C}$ e uma pressão inicial de $\mathrm{H}_{2}$ de 30 bar propicia uma eficiente e adequada desoxigenação das moléculas. Em temperaturas mais elevadas, acentua-se o indesejado craqueamento térmico das cadeias; em temperaturas mais baixas, além das reações tornarem-se mais lentas, ocorre pronunciada polimerização térmica do material. Por sua vez, o emprego de menores pressões de $\mathrm{H}_{2}$ faz com que a velocidade das reações de desoxigenação diminua consideravelmente. Por fim, constatou-se que as cadeias de maior comprimento são mais susceptíveis ao craqueamento térmico, de forma que é necessário aumentar os 
cuidados relativos à severidade das condições reacionais empregadas, de forma a controlar o craqueamento térmico.

Análises cromatográficas mostram que os produtos obtidos a partir da HDO dos óleos de coco e de soja apresentam distribuições de tamanho de cadeias carbônicas na mesma faixa do bioquerosene de aviação e do óleo diesel, respectivamente, mas com menor teor de alcanos ramificados. Entretanto, foi possível aumentar consideravelmente o teor de isômeros nas misturas por meio de um tratamento posterior de hidroisomerização catalisada por Pt/SAPO-11.

Assim, de maneira geral, o trabalho realizado demonstrou a viabilidade técnica de se preparar bioquerosene e biodiesel parafínicos a partir de óleos e gorduras vegetais e animais por meio do processo de hidrotratamento (hidrodesoxigenação/hidroisomerização). Entretanto, é válido salientar que muitos estudos ainda precisam ser realizados. Fundamentalmente, é necessário desenvolver um sistema que permita trabalhar em maior escala, possivelmente um sistema contínuo. Assim, será possível realizar uma caracterização mais completa dos produtos obtidos e, então, fazer-se uma melhor avaliação das condições que devem ser empregadas na preparação de combustíveis com aplicações específicas, bem como ter-se uma ideia da viabilidade econômica do processo. 


\section{REFERÊNCIAS BIBLIOGRÁFICAS}

1. Pereira Netto, A. D.; Moreira, J. C.; Dias, A. E. X. O.; Arbilla, G.; Ferreira, L. F. V.; Oliveira, A. S.; Barek, J. Avaliação da Contaminação Humana por Hidrocarbonetos Policiclicos Aromáticos (HPAS) e seus Derivados Nitrados (NHPAS): Uma Revisão Metodológica. Química Nova. 2000. 23: 765-773.

2. Graça, I.; Lopes, J. M.; Cerqueira, H. S.; Ribeiro, M. F. Bio-oils upgrading for second generation biofuels. Industrial \& Engineering Chemistry Research. 2013. 52: 275-287.

3. Ma, F.; Hanna, M. A. Biodiesel Production: A Review. Bioresource Technology. 1999. 70: $1-15$.

4. Mohammad, M.; Hari, T. K.; Yaakob, Z.; Sharma, Y. C.; Sopian, K. Overview on the production of paraffin based-biofuels via catalytic hydrodeoxygenation. Renewable Sustainable Energy Reviews. 2013. 22: 121-132.

5. Zhang, X.; Wang, T.; Zhang, Q.; Jiang, T.; Ma, L. Hydrotreatment of bio-oil over Ni-based catalyst. Bioresource Technology. 2013. 127: 306-311.

6. Confederação Nacional da Agricultura e Pecuária. Relatório de Inteligência: Do Bagaço ao Posto. Disponível em: <http://www.icna.org.br/>. Acessado em 08de abril de 2015.

7. Resolução ANP № 23, DE 13.8.2012 - DOU 14.8.2012 - Retificada DOU 15.8.2012 e DOU 15.4.2014. Disponível em: <http://nxt.anp.gov.br/.> Acessado em 20 de maio de 2015.

8. Plano Nacional de Energia 2030. Ministério das Minas e Energia. Disponível em: <www.epe.gov.br/PNE/20080111_1.pdf> Acessado em 23 de maio de 2015.

9. Yu, Y.; Lou, X; Wu, H. Some Recent Advances in Hydrolysis of Biomass in HotCompressed Water and Its Comparisons with Other Hydrolysis Methods. Energy Fuels. 2008. 22: $46-60$.

10. Murphy, J. D.; McCarthy, K. Ethanol production from energy crops and wastes for use as a transport fuel in Ireland. Applied Energy. 2005. 82: 148-166.

11. Dominguez, J.M.O. Efecto de los productos de degradación originados en la explosión por vapor de biomasa de chopo sobre kluyveromyces marxianus. Tese de doutorado. Universidad Complutense de Madrid, 2003.

12. Aguiar, A.; Ferraz, A. Mecanismos envolvidos na biodegradação de materiais lignocelulósicos e aplicações tecnológicas correlatas. Química Nova. 2011. 34: 17291738.

13. Polizeli, M. L. T. M.; Rizzati, A. C.; Monti, R.; Terenzi, H. F.; Jorge, J. A.; Amorim, D. S. Xylanases from fungi: properties and industrial applications. Appl. Microbiol Biotechnology. 2005. 67: 577-591.

14. Morais, S.A.L.; Nascimento, E. A.; Melo, D. C. Chemical analysis of Pinus oocarpa wood PARTE I - quantification of macromolecular components and volatile extractives. Revista Árvore. 2005. 29: 461-470.

15. Lange, J-P.; Lignocellulose conversion: An introduction to chemistry, process and economics. Biofuels Bioprod. Biorefing. 2007. 1: 39-48. 
16. Graboski, M. S.; McCormick, R. L. Combustion of fat and vegetable oil derived fuels in diesel engines. Prog Energy Combust Sci. 1998. 24: 124-164.

17. Garcia, C. M. Transesterificação de óleos vegetais. Dissertação de mestrado. Universidade Estadual de Campinas, 2006.

18. Iha, O. K. Produção e análises de bio-óleo e biodiesel utilizando oleaginosas que possam contribuir para o aumento da matriz energética renovável brasileira. Dissertação de mestrado. Universidade de Brasília, 2010.

19. Gong, S.; Shinozaki, A.; Qian, E. W. Role of Support in Hydrotreatment of Jatropha Oil Over Sulfided NiMo catalysts. Ind Eng Chem Res. 2012. 51: 13953-13960.

20. Kubicka, D.; Simacek, P.; Zilkova, N. Transformation of vegetable oils into hydrocarbons over mesoporous-alumina-supported CoMo catalysts. Top. Catal. 2009. 52: 161-168.

21. Crabbe, E.; Nolasco-Hipolito, C.; Kobayashi, G.; Sonomoto, K.; Ishizaki, A. Biodiesel production from crude palm oil and evaluation of butanol extraction and fuel properties. Process Biochem. 2001. 37: 65-71.

22. Moretto, E.; Fett, R. Tecnologia de óleos e gorduras vegetais na indústria de alimentos. (Varela, 1998).

23. Romero, D. M. Obtención de Combustibles Renovables Mediante Hidrotratamiento Catalítico de Aceites Vegetales y Gasóleo. Dissertação de mestrado. Instituto Politécnico Nacional, Cidade do México, 2011.

24. Suarez, P. A. Z.; Meneghetti, S. M. P.; Meneghetti, M. R.; Wolf, C. R.; Transformação de triglicerídeos em combustíveis, materiais poliméricos e insumos químicos: algumas aplicações da catálise na oleoquímica. Química Nova. 2007. 30: 667-676.

25. Shay; E. G. Diesel fuel from vegetable-oils - Status and opportunities. Biomass Bioenergy. 1993. 4: 227-242.

26. Tashtoush; G.; Al-Widyan; M. I.; Al-Shyoukh; A. O.; Combustion performance and emissions of ethyl ester of a waste vegetable oil in a water-cooled furnace. Appl Therm Eng. 2003. 23: 285-293.

27. Suarez, P. A. Z.; Santos, A. L. F.; Rodrigues, J. P.; Alves, M. B.; Biocombustíveis a partir de óleos e gorduras: desafios tecnológicos para viabilizá-los. Química Nova. 2009. 32: 768- 775 .

28. Lang, X.; Dalai, A. K.; Bakhshi, N. N.; Reaney, M. J.; Hertz, P. B.; Preparation and characterization of bio-diesels from various bio-oils. Bioresource Technology. 2001. 80: $58-62$.

29. Tóth, C.; Baladinez, P.; Kovács, S.; Hancsók, J. Producing clean diesel fuel by cohydrogenation of vegetable oil with gas oil. Clean Techn Env. Policy. 2011. 13: 581-585.

30. Hancsók, J.; Kasza, T.; Kovács, S.; Solymosi, P.; Holló, A.; Production of bioparaffins by the catalytic hydrogenation of natural triglycerides. Journal. Clean. Prod. 2012. 34: 7681.

31. Czernik, S.; Bridgwater, A. V. Overview of Applications of Biomass Fast Pyrolysis Oil. Energy Fuels. 2004. 54: 590-598. 
32. Wang, Y.; Fang, Y.; Hu, H.; Wu, J.; Hydrodeoxygenation of dibenzofuran over noble metal supported on mesoporous zeolite. Bioresource Technology. 2011. 12: 1201-1205.

33. Jacobson, K.; Maheria, K. C.; Dalai, A. K.; Bio-oil valorization: A review. Energy Rev. 2013. 23: 91-106.

34. Oasmaa, A.; Czernik, S. Fuel Oil Quality of Biomass Pyrolysis Oils State of the art for the end-users. Energy Fuels. 1999 .13: 914-921.

35. Mortensen, P. M.; Grunwaldt, J. D.; Jensen, P. A.; Knudsen, A. D.; Jensen, A. D. A review of catalytic upgrading of bio-oil to engine fuels. Appl. Catal. Gen. 2011. 407: 119.

36. Chiaramonti, D.; Oasmaa, A.; Solantausta, Y. Power generation using fast pyrolysis liquids from biomass. Renew. Sustain. Energy Rev. 2007. 11: 1056-1086 .

37. Bridgwater, T. Review Biomass for energy. J. Sci. Food Agric. 2006. 86: 1755-1768.

38. Kubicka, D.; Kaluza, L. Deoxygenation of vegetable oils over sulfided Ni, Mo and NiMo catalysts. Appl. Catal. Gen. 2010. 372: 199-208.

39. Furimsky, E. Catalytic hydrodeoxygenation. Appl. Catal. Gen. 2000. 199: 147-190.

40. Veransyah, B.; Han, J. Y.; Kim, S. K.; Hong, S-A.; Kim, Y. J.; Lim, J. S.; Shu, Y-W.; Oh, S-G.; Kim, J. Production of renewable diesel by hidroprocessing of soybean oil: Effect of catalysts. Fuel. 2012. 9: 578-585.

41. Wang, W-C.; Thapaliya, N.; Campos, A.; Stikeleather, L.F.; Roberts, W. L.; Hydrocarbon fuels from vegetable oils via hydrolysis and thermo-catalytic decarboxylation. Fuel. 2012. 95: 622-629.

42. Liu, Q.; Zuo, H.; Wang, T.; Ma, L.; \& Zhang, Q. One-step hydrodeoxygenation of palm oil to isomerized hydrocarbon fuels over Ni supported on nano-sized SAPO-11 catalysts. Appl. Catal. Gen. 2013. 468: 68-74.

43. Snare, M.; Kubickova, I.; Makl-Arvela, P.; Eranen, K.; Murzin, D. Y.; Overview on heterogeneous catalytic deoxygenation of stearic acid for production of biodiesel. Ind Eng .Chem .Res. 2006. 45: 5708-5715.

44. Solymosi, P.; Varga, Z.; Hancsók, J. Motorfuel purpose hydrogenation of waste triglycerides. 2013. 46th International Conference on Petroleum Processing.

45. Mikulec, J.; Cvengros, J.; Kova, L. J.; Banic, M.; Kleinova, A. Second generation diesel fuel from renewable sources. J. Clean. Prod. 2010. 18: 917-926.

46. Senol, O. I.; Ryymin, E. M.; Viljava, T. R.; Krause, A. O. I. Reactions of methyl heptanoate hydrodeoxygenation on sulphided catalysts. J. Mol. Catal. Chem. 2007. 268: $1-8$.

47. Mikkonen, S. Second-generation renewable diesel offers advantages. Hydro-Carbon Process. 2008. 87: 63-66.

48. Gomes, J. R.; H-Bio. (2005).

49. Marsh, G. Biofuels: aviation alternative. Renewable Energy Focus. 2008. 9: 48-51. 
50. Chorkendorff, I.; Niemantsverdriet, J. W.; Concepts of Modern Catalysis and Kinetics. (Wiley, 2003).

51. Haber, J.; Block, H.; Delmon, B.; Manual of methods and procedures for catalyst characterization. Pure Appl. Chem. 1995. 67: 1257-1306.

52. Topsøe, H. The role of Co-Mo-S type structures in hydrotreating catalysts. Appl. Catal. Gen. 2007. 322: 3-8.

53. Tuxen, A.; Gøbel, H.; Hinnemann, B.; Li, Z.; Kim, G. K.; Topsøe, H.; Lauritsen, J. V.; .; Besenbacher, F. Journal of Catalysis. 2011. 281: 345-351.

54. Lauritsen, J. P.; Kibsgaard, J.; Olesen, G. H.; Moses, P. G.; Hinnemann, B.; Helveg, S.; Nørskovb, J. K.; Clausenc, B. S.; Topsøe; H.; Lægsgaard , E.; Besenbacher , F. Location and coordination of promoter atoms in Co-and Ni-promoted MoS2-based hydrotreating catalysts. Journal of Catalysis. 2007. 249: 220-233.

55. Egorova, M.; Prins, R. The role of $\mathrm{Ni}$ and Co promoters in the simultaneous HDS of dibenzothiophene and HDN of amines over Mo/ $/ \mathrm{Y}-\mathrm{Al} 2 \mathrm{O} 3$ catalysts. Journal of Catalysis. 2006. 241: 162-172.

56. Romero, Y.; Richard, F.; Brunet, S. Hydrodeoxygenation of 2- ethylphenol as a model compound of bio-crude over sulfided Mo-based catalysts: Promoting effect and reaction mechanism. Appl. Catal. B Environ. 2010. 98: 213-223.

57. Laurent, E.; Delmon, B. Study of the hydrodeoxygenation of carbonyl, carboxylic and guaiacyl groups over sulfide CoMo/y-Al203 and NiMo/ y-Al203 catalysts. I.Catalytic reaction schemes. Appl. Catal. Gen. 1994. 109: 77-96.

58. Bonato, P. S.; Collins, C. H.; Braga, G. L. Fundamentos de Cromatografia. (Unicamp, 2006).

59. Wang, Y.; Lin, H. \& Zheng, Y. Hydrotreatment of lignocellulosic biomass derived oil using a sulfided NiMo/y-Al2O3 catalyst. Catal. Sci. Technol. 2014. 4: 109-119.

60. Silverstein, R. M.; Bassler, C. G.; \& Morrill, T. C. Spectrometric Identification of Organic Compounds. (Jonh Wiley, 2005).

61. Brandão, R. D. Hidroisomerização de n-Parafinas de Cadeia Longa Catalisada por Metais Platínicos Depositados em Silicoaluminofostatos para Produção de Biocombustíveis. Dissertação de mestrado. Universidade de Brasília, 2015.

62. Ribeiro, F. R.; Guisnet, M.; Zeólitos - Um nanomundo ao Serviço da Catálise. (Fundação Calouste Gulbenkian, 2004).

63. Senatore, F.; Landolfi, S.; Celik, S.; Bruno, M.; Volatile components of Centaurea calcitrapa L. and Centaurea sphaerocephala L. ssp. sphaerocephala, two Asteraceae growing wild in Sicily. Flavour Fragr. J. 2006. 21: 282-285.

64. Adams, R.P.; Morris, J.A.; Pandey, R.N.; \& Schwarzbach, A.E. Cryptic speciation between Juniperus deltoides and Juniperus oxycedrus (Cupressaceae) in the Mediterranean. Biochem .Syst. Ecol. 2005. 33: 771-787.

65. Wu, S.; Krings, U.; Berger, R. G. Volatiles from submerged and surface-cultured beefsteak fungus, Fistulina hepatica. Flavour Fragr. J. 2007. 22: 53-60. 
66. da Silva, M. H. L.; Zoghbi, M. G. B.; Andrade, E. H. A.; Maia, J. G. S. The essential oils of Peperomia pellucida Kunth and P. circinnata link var. circinnata. Flavour Fragrance J. 1999. 14: 312-314.

67. Xu, L-L.; Han, T.; Wu, J. Z.; Zhang, H.; Huang, B. K.; Rahman, K.; Qin, L. P. Comparative research of chemical constituents, antifungal and antitumor properties of ether extracts of Panax ginseng and its endophytic fungus. Phytomedicine. 2009. 16 (67): 609-616.

68. Rostad, C. E.; Pereira, W. E. Kovats and Lee retention indices determined by gas chromatography/mass spectrometry for organic compounds of environmental interest. $\mathrm{J}$ High Resolution Chromatogr. Comm. 1986. 9: 328-334.

69 .http://webbook.nist.gov/cgi/cbook.cgi?ID=C13945761\&Mask=200\#Mass-Spec. Acessado em 02 de junho de 2015.

70. Hanai, T.; Hong, C. Structure-retention correlation in CGC. Journal High Resolution Chromatogr. 1989. 12: 327-332. 